

\title{
DISCLAIMER
}

This report was prepared as an account of work sponsored by an agency of the United States Government. Neither the United States Government nor any agency thereof, nor Battelle Memorial Institute, nor any of their employees, makes any warranty, expressed or implied, or assumes any legal liability or responsibility for the accuracy, completeness, or usefulness of any information; apparatus, product, or process disclosed, or represents that its use would not iniringe privately owned rights. Reference herein to any specific commercial product, process, or service by trade name, trademark, manufacturer, or otherwise does not necessarily constitute or imply its endorsement, recommendation, or favoring by the United States Government or any agency thereof, or Battelle Memorial Institute. The views and opinions of authors expressed herein do not necessarily state or reflect those of the United States Government or any agency thereof.

\author{
PACIFIC NORTHWEST LABORATORY \\ operated by \\ BATTELLE MEMORIAL INSTITUTE \\ for the \\ UNITED STATES DEPARTMENT OF ENERGY \\ under Contract DE-AC06-76RLO 1830
}

Printed in the United States of America

Available to DOE and DOE contractors from the

Dffice of Scientific and Technical Information, P.O. Box 62, Oak Ridge, TN 37831; prices available from (615) 576-8401. FTS 626-8401.

Available to the public from the National Technical Information Service, U.S. Department of Commerce, 5285 Port Royal Rd., Springfield, VA 22161. 


\section{ATMOSPHERIC DISPERSION IN MOUNTAIN VALLEYS AND BASINS}

K. J. Aliwine

January 1992

Prepared for the U.S. Department of Energy under Contract DE-AC06-76RLO 1830

Pacific Northwest Laboratory Richland, Washington 99354

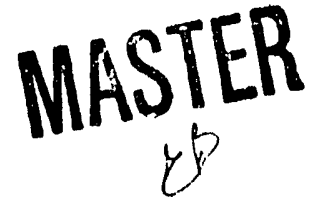




\section{PREFACE}

This report is K. J. Allwine's dissertation submitted to the College of Engineering of Washington State University in partial fulfillment of the requirement for the degree of Doctor of Philosophy in Engineering Science (Fluid Dynamics and Mathematics). This report is in the format required by the Graduate School of Washington State University with the exception of the cover page, title page, this preface, and the distribution list at the end of the report. These added report components follow PNL's report format. 


\section{ACKNOWLEDGEMENTS}

I would like to thank Pacific Northwest Laboratory (PNL) in Richland, Washington for allowing me to take educational leave during August 1987 through July 1990. Drs. Chris Doran, Jake Hales and Bill Pennell, managers in the Atmospheric Sciences Department of PNL, supporteci me in this effort. The U.S. Department of Energy (DOE) contributed financially in two ways, first, through a Graduate Fellowship stipend, and second, through direct support of a portion of this research. My research was also supported in part by the U.S. Forest Service, through a related services agreement with DOE, and by the U.S. Environmental Protection Agency through a research grant with WSU (my Graduate Research assistantship). I would also like to thank the Air and Waste Management Association for a scholarship award during the 1989 school year.

I would like to thank my committee, Drs. Lamb, Whiteman, Stock and Crowe, for their interest and guidance in this research. I would especially like to thank Dr. Brian Lamb, my committee chairman, who kept me pressing toward the mark, and Dr. Dave Whiteman, my colleague at Battelle, who was a solid source of information. Dr. Hal Westberg, head of the Laboratory for Atmospheric Research, was a considerable help in facilitating my return to graduate school.

My family, Cherie, Eric and John, supported me completely in this effort. For this I am especially grateful. 


\title{
ATMOSPHERIC DISPERSION IN MOUNTAIN VALLEYS AND BASINS
}

\author{
Abstract \\ by K. Jerry Allwine, Ph.D. \\ Washington State University \\ December 1991
}

Chair: Brian K. Lamb

The primary goal of this research is to further characterize and understand dispersion in valley and basin atmospheres. A secondary, and related goal, is to identify and understand the dominant physical processes governing this dispersion. This has been accomplished through a review of the current literature, and analyses of recently collected data from two field experiments. This work should contribute to an improved understanding of material transport in the atmospheric boundary layer. It was found that dispersion in a freely draining valley (Brush Creek valley, $\mathrm{CO}$ ) atmosphere is much greater than in an enclosed basin (Roanoke, VA) atmosphere primarily because of the greater wind speeds moving past the release point and the greater turbulence levels. The development of a cold air pool in the Roanoke basin is the dominant process governing nighttime dispersion in the basin, while the nighttime dispersion in the Brush Creek valley is dominated by turbulent diffusion and plume confinement between the valley sidewalls. The interaction between valley flows and above ridgetops flows is investigated. A "ventilation rate" of material transport between the valley and above ridgetop flows is determined. This is important in regional air pollution modeling and global climate modeling. A simple model of dispersion in valleys, applicable through a diurnal cycle, is proposed. 


\section{TABLE OF CONTENTS}

PREFACE

iii

ACKNOWLEDGEMENTS.

ABSTRACT.

vii

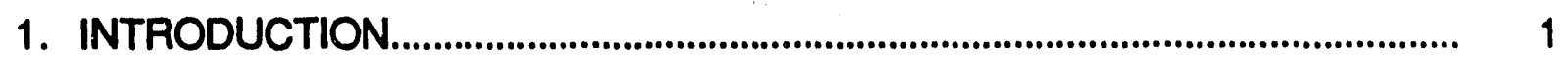

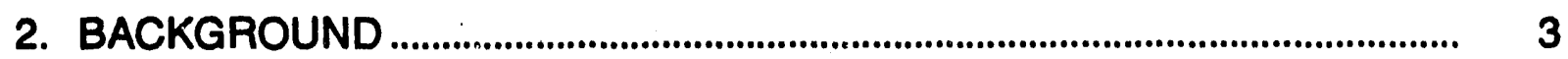

Dispersion in Valleys............................................................................... 9

Dispersion in Basins................................................................................... 18

3. ATMOSPHERIC DISPERSION AND TRACER VENTILATION IN A DEEP MOUNTAIN VALLEY .................................................................................. 23

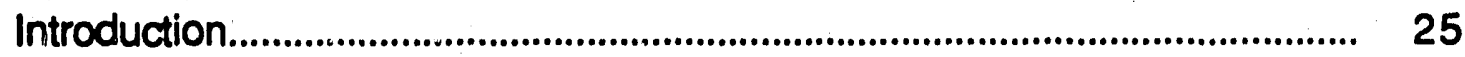

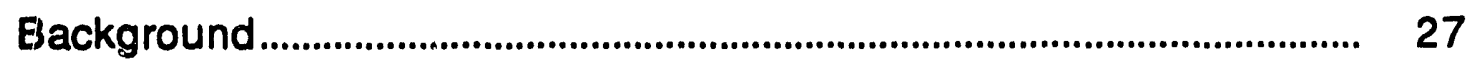

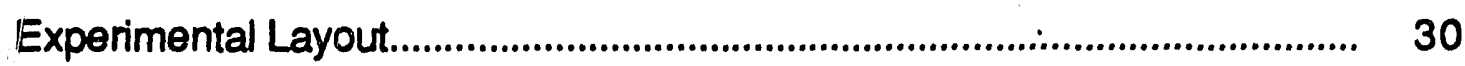

Results and Discussion............................................................................ 41

Summary and Conclusions...................................................................... 80

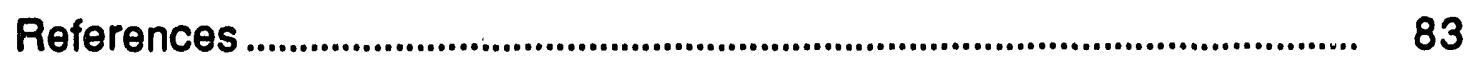

4. WINTER-TIME DISPERSION IN A MOUNTAINOUS BASIN AT ROANOKE, VIRGINIA: TRACER STUDY .................................................. 87

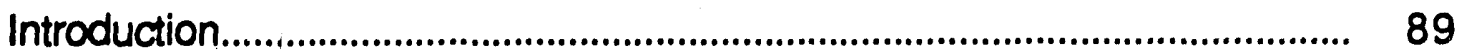

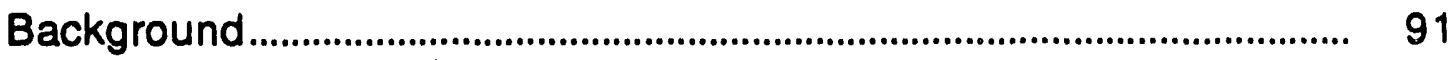

Experimental Design...................................................................................... 93

Results and Discussion....................................................................... 107

Summary and Conclusions.................................................................. 133

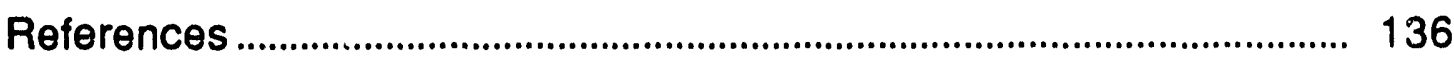


5. DISPERSION MODELING IN VALLEYS AND BASINS ............................. 139

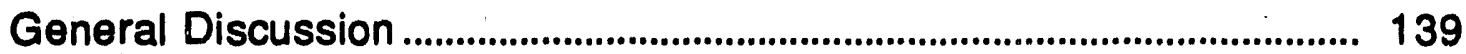

Formulation of a Valley Dispersion Model ...................................................... 142

Thoughts on a Basin Dispersion Model........................................................ 148

6. SUMMARY AND RECOMMENDATIONS ................................................... 151

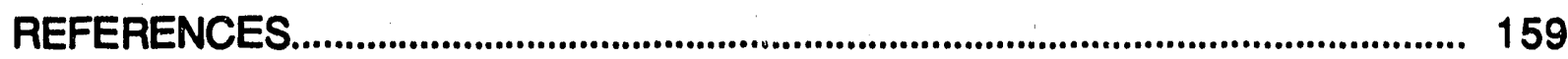

APPENDIX. VALLEY DISPERSION MODEL ..................................................... 165

General Description.............................................................................................. 165

Domain and Coordinate System................................................................ 166

Computational Grid - Flowtubes.......................................................... 168

Conservation of Air Mass..................................................................................... 172

Conservation of Species .................................................................................. 176

Treatment of Various Meteorological Regimes ......................................... 185

Improvements and Additions .................................................................. 188 


\section{LIST OF TABLES}

Chapter 2

1. Meteorological Phenomena of Importance to Air Flow and Dispersion in Complex Terrain................................................................... 5

2. Summary of Significant Situations and Governing Processes Identified as Important to Air Quality in Complex Terrain

Chapter 3

1. Release Information for the Tracer PMCP ............................................. 33

2. Release information for the Tracer PMCH........................................... 33

3. Release Information for the Tracer PDCH............................................ 33

4. Ground-Level Samplers Identification and Sampling Times............... 38

5. Elevated Samplers Ideritification and Sampling Times....................... 39

6. Elevations and UTM Coordinates of Key Locations.............................. 39

7. Sunrise and Sunset Times on 9/30/84 from the BREB Stations......... 43

8. Average (0200-0700 MST) Turbulence Quantities and Fluxes on $9 / 26 / 84$ from the Towers.

9. Average (0200-0700 MST) Valley Air Mass Flow Rates 011 9/26/84 from the Lidar, Sodars and Tethersondes.

10. Average (0200-0700 MST) Valley Tracer Mass Flow Rates on 9/26/84 Using the Tethersonde and Lidar Down-valley Winds......

11. Variation of Nighttime Turbulence Levels with Distance from the Valley Release.

12. PMCH Mass Budget for the Brush Creek Valley Atmosphere Control Volume on $9 / 26 / 84$ 
xii

Chapter 4

1. $S_{6}$ Release Information ........................................................................ 98

2. Operation of Integrated Tracer Samplers ............................................... 100

3. Operation of Mobile Tracer Vans .............................................................. 102

4. Horizontal Plume Spread............................................................................ 126 


\section{LIST OF FIGURES}

Chapter 2

1. A Classification of the Effects of Terrain on Atmospheric Motions....... 7

2. Ventilation of Pollutants from a Valley during the Morning Transition Period.

3. Illustration of the Hypothesis of Inversion Destruction

\section{Chapter 3}

1. Brush Creek Valley Terrain Contours and Locations of Ground-level and Vertical Tracer Samplers in the Vicinity of the Four Sampling Arcs.

2. Tracer Sampler Identification Numbers on the Four Sampling Arcs in Brush Creek Valley

3. Identification Numbers of Tracer Samplers Located in the Carr, Brush, Clear and Roan Creek Valleys and Located on the Ridgetops.

4. Tracer Saripler Locations Versus Along-valley Distance and Ele'vation

5. Locations of the Meteorological System Used in this Analysis

6. Thirty Minute Average Observations of Sensible Heat Flux at the Surface, and Air Temperature, Wind Speed and Wind Direction at $\sim 1 \mathrm{~m} \mathrm{AGL}$

7. Nighttime Average (0100-0530) Profiles of Potential Temperature, Wind Speed and Wind Direction from 4 Tethersondes Located in Brush Creek Valley

8. Nighttime Average (0100-0530) Dimensionless Wind Profile on 9/26/84 in the Center of Brush Creek Valley at Four Along-Valley Locations.

9. Nighttime Average (0100-0530) Down-valley Air Volume Flow Rate in Brush Creek Valley Below $2200 \mathrm{~m} \mathrm{MSL}$ on 9/26/84 
10. Down-valley Winds at the Release Location on 9/26/84 Estimated from Nearby Wind Measurements from a Sodar and Tethersonde.....

11. Hour Average Down-valley Winds on 9/26/84 Determined from the LANL Sodar Observations.

12. Tethersonde Observations of Potential Temperature, Wind Speed and Wind Direction on the Morning (0530-1000) of 9/26/84

13. Time Variation of the Down-valley Air Volume Flow Rates in Brush Creek Valley Determined for Each Sounding from Four Tethersondes.

14. Time Variations in the 9/26/84 Hour-average Nighttime PMCH and PDCH Concentrations Measured by Certain Ground-level Samplers in the Brush Creek Valley.

15. Cross-valley Isopleths of the Nighttime Average (0200-0700) PMCP, PMCH and PDCH Concentrations for 9/26/84 in the Brush Creek Valley

16. Along-valley Isopleths of the Nighttime Average (0200-0700) PMCP. PMCH and PDCH Concentrations for 9/26/84 in the Brush Creek Valley

17. Time Variations in the Hour-Average PMCP, $\mathrm{PMCH}$ and $\mathrm{PDCH}$ Concentrations Measured at the Ridgetop Samplers on $9 / 26 / 84$

18. Maximum Nighttime Average (0200-0700) PMCH Concentrations Measured Along the Brush Creek Valley Floor on 9/26/84, Compared with the Gaussian Plume Equation

19. The Time Variation in Skinner Ridge PMCH Concentrations and the PMCH Ventilation rate on 9/26/84

20. Hour-average Cross-Valley Isopleths of PMCH Concentrations at Four Times (midpoint) Through the Morning Transition Period for $9 / 26 / 84$ in the Brush Creek Valley

21. Hour-average Along-Valley Isopleths of PMCH Concentrations at Four Times (midpoint) Through the Morning Transition Period for 9/26/84 in the Brush Creek Valley.

22. Estimate of the Time Variation of PMCH Mass in the Control Volume on $9 / 26 / 84$. 
23. Dimersionless Ventilation Rate from the Brush Creek Valley

Beginning at Sunrise and Continuing Until the Valley

Temperature Inversion is Destroyed on $9 / 26 / 84$

Chapter 4

1. Terrain Elevations of the Roanoke, Virginia, Area................................. 94

2. Fò ancke, Virginia, Vicinity Map and Measurement Site Locations.... 96

3. Northwest-Southeast Cross Section Through the

Roanoke Basin Shoving Certain K'ey Measurement Sites and

Topographic Features.

4. Southwest-Northeast Cross Section Along Hershberger Road.......... 97

5. Locations of Integrated Tracer Samplers in Roanoke........................... 99

6. Temperature, Not Radiation, Wind Direction, Wind Speed, and Felative Humidity for the Entire Study Period Measured at the Tower Site.

7. Hourly Average Winds at $10 \mathrm{~m} \mathrm{AGL}$ at the WP Site

8. Five Minute Average Winds at $2.1 \mathrm{~m} \mathrm{AGL}$ at the Release Site and at $34 \mathrm{~m} \mathrm{AGL}$ at the Tower Site

9. Five Minute Average Temperatures at the Tower and Hour Average Temperatures at the WP Site.

10. Estimated "Plume" Centerline Locations at 6 Times Computed Using Measured Winds.

11. Potential Temperature Profiles at the Tower and Tethersonde During Exp 4

12. Wind Speed Profiles from the Tethersonde During Exp 4

13. Wind Direction Profiles from the Tethersonde During Exp 4 . 119

14. Tracer and Temperature Profiles at 0340-0400 LST from the Tethersonde During Exp 4 .

15. One Hour Average Ground-Level Tracer Concentrations Measured Over the Study Domain at 6 Selected Times. 
xvi

16. Maximum 1 Hour Average Ground-Level Tracer Concentration Measured ori: Eech Sampling Arc Versus Distance from the Release Site.

17. Sampling Path Showing Instantaneous Ground-Level Tracer Concentrations on Arcs 01 and $\mathrm{O} 2$ Measured at Various Times with the Mobile Van

18. Sampling Path Showing Instantangous Ground-Level Tracer Concentrations around the 'study Dornain Measured at Various Times with the Mobile Van

Chapter 5

1. Example of the Flowtube Approach Used in the Valley Dispersion Model.

2. Illustration of the Computational Domain on a Valley Cross Section at Time t After Sunrise

Appendix

1. Conforming of the Center Flowtube to the Shape of the Valley

2. Simplified Valley Cross-Section Showing Required Parameters 171

3. Sources/Sinks, Flow and Flux of Species Mass Through a Flowtube Volume Element

4. Index Notation Associated with the Flowtubes on a Valley Cross Section 


\section{Chapter 1}

\section{INTRODUCTION}

The primary goal of this research is to further characterize and understand dispersion in valley and basin atmospheres. A valley is generally considered to be "a depression between ranges of hills or mountains" (Merriam-Webster dictionary), and a basin is considered to be a blocked valley; that is, the flow of air along the valley axis is restricted by terrain barriers or special flow characteristics. A secondary, and related goal of this research is to identify and understand the dominant physical processes governing dispersion in valley and basin atmospheres. From this added understanding, a phenomenological modeling approach, applicable to dispersion in valleys, is proposed. These research goals are accomplished through a review of the literature, and through analyses of recently collected data from two atmospheric tracer experiments. This work should contribute to an improved understancing of material transport in the atmospheric boundary layer.

One tracer experiment was conducted in the deep Brush Creek valley located in the Rocky Mountains of western Colorado during the fall of 1984, as

part of the Department of Energy's (DOE's) Atmospheric Studies in Complex Terrain (ASCOT) program. This valley has a semiarid, continental climate with low precipitation ( $40 \mathrm{~cm}$ annually), low relative humidity, large temperature 
variations; and high evaporation. Strong down-valley winds developed in the valley during the night when the weather was relatively undisturbed and cloudfree.

The other tracer experiment was conducted, as part of the Environmental Protection Agency's (EPA's) Integrated Air Cancer Project (IACP), in the broad Roanoke basin located in Virginia's Blue Ridge Mountains. ihe tracer study was conducted during the winter of 1989 . This basin has a moist, continental climate with moderate precipitation (109 $\mathrm{cm}$ annually), high relative humidity, moderate temperature variations, and low evaporation. During relatively undisturbed and cloud-free nights, calm to very light winds developed in the basin.

The dispersion characteristics of the Brush Creek valley atmosphere were quite different from those of the Roanoke basin atmosphere. This contrast provided an opportunity for a more generally applicable dispersion modeling approach to be investigated than would have been possible from studying just one landform.

Chapter 2 gives a review of the current literature and describes the basic characteristics of dispersion in valley and basin atmospheres. Chapters 3 and 4 describe dispersion in the Brush Creek valley and Roanoke basin atmospheres. These two chapters will be submitted for publication in the Journal of Applied Meteorology and are in the format required by the journal. Chapter 5 synthesizes the understanding of dispersion from Chapters 3 and 4 and the current literature and proposes an initial phenomenological dispersion modeling approach for use in valleys. Chapter 6 provides a summary and recommendations. 
Chapter 2

\section{BACKGROUND}

Dispersion in the atmospheric boundary layer has been the focus of a significant amount of research for many years. The need for the industrialized countries to address problems associated with air pollution has accelerated this research effort during the past three decades. These problems include the effects of air pollution on man's health, and un the earth's ecosystems and climate. Understanding dispersion is also important when estimating budgets of global trace gases and when formulating plans for responding to emergency situations at, for example, chemical or nuclear facilities.

Literally thousands of repoits, papers in conference proceedings, and published articles are available concerning various aspects of dispersion in the atmospheric boundary layer. Many books are dedicated to, or contain chapters dealing with various aspects of atmospherc dispersion. These include Slade (1968), Csanady (1973), Pasquill and Smith (1983), Randerson (1984), Seinfeld (1986), and Venkatram and Wyngaard (1988). Several reference texts are also available describing the character and behavior of the atmospheric boundary layer. These include Haugen (1973), Pielke (1984), Dutton (1986), Stull (1988), Arya (1988), Cotton and Anthes (1989), and Sorbjan (1089). The American Meteorological Society (AMS), and the Air and Waste Management Association (AWMA, formerly APCA) have sponsored conferences and workshops dealing 
with dispersion and air pollution modeling. Many international conferences have been held on these topics.

The body of literature dealing with dispersion in complex terrain has grown considerably over the past two decades. This growth is a result of the need to assess air pollution impacts from sources located in complex terrain. A factor contributing to growth in complex terrain dispersion research was the realization that existing dispersion models and corresponding assumptions for flat terrain situations were not adequate, or in many cases, not appropriate for complex terrain. Hundreds of articles exist on dispersion and air pollution modeling in complex terrain, and even more exist on identifying, characterizing and investigating the processes governing the behavior of the boundary layer over complex terrain. This literature on complex terrain covers results from field experiments, physical, mathematical and computer modeling, and theoretical investigations.

Two recent volumes of the Journal of Applied Meteorology (Vol. 28, No 6 and 7,1989$)$ were dedicated to current research in complex terrain meteorology and dispersion. The results were primarily from research in DOE's ASCOT program. Over the past decade, research from the ASCOT program has contributed significantly toward the understanding of the atmospheric boundary layer over complex terrain. Orgill (1981) provided a comprehensive review of the current understanding of terrain-induced airflow phenomena and dispersion in complex land forms. This document was used in the planning of the ASCOT research program.

Orgill (1981) identified and discussed meteorological phenomena of importance to air flow and dispersion in and around complex landforms. His 
general classes of phenomena are listed in Table 1, and examples of specific phenomena in each class are also given. Orgill also identified six conditions of specific concern relative to air quality in complex terrain. They are channeling of plumes, impact of elevated plumes on terrain surfaces, stagnation of air pollutants in basins and valleys, effects of thermal winds (e.g., mountain-valley) on dispersion, fumigation of elevated plumes or pollutant layers, and effects of deformation, turbulence and terrain-induced eddies on plumes and dispersion.

Table 1. Meteorological Phenomena of Importance to Air Flow and Dispersion in Complex Terrain.

GENERAL PHENOMENA

Airflow Deformation

Separation and Wakes

Gravity Waves

Local Winds

Stagnation and Ventilation

Eddies and Vorticies

Momentum and Thermal Boundary Layer

Turbulence

Forest Canopy Flow and Exchange Processes
EXAMPLES OF SPECIFIC PHENOMENA

Streamline distortion, speed-up, channeling and other venturi effects

Around escarpments or cliffs, ridges, valleys, canyons, isolated hills and mountains

Laminar airflow, lee waves, rotors, hydraulic jumps, blocking

Land-sea breezes, slope winds, mountainvalley winds, interaction of wind systems

Within valleys and basins

Transverse and separation eddies, longitudinal vorticies

Internal boundary layers, low-level jets, nocturnal destabilization

Common to all phenomena

Uniform stand, clearing, edges 
The phenomena listed in Table 1 operate over a wide spectrum of time and space scales. Large mountain ranges, for example, can produce waves several hundred kilometers in extent, whereas a small hill could produce waves measured in tens to hundreds of meters. The scales of many phenomena are tied directly to the diurnal cycle. Examples are mountain-valley and land-sea wind systems which are driven by diurnal heating and cooling effects.

Fig. 1 illustrates the wide spectrum of length and time scales associated with air motion over terrain. This figure, developed by Orgill, casts the flow phenomena resulting from terrain effects into the classification scheme of atmospheric motion developed by Orlanski (1975). Orgill points out that this figure is for illustrative purposes and is by no means comprehensive, nor does it impiy dynamic or kinematic similarity. The flow phenomena associated with basins and valleys fall in Orlanski's mesoscale $\beta$ and mesoscale $\gamma$ classifications with time scales of hours to days, and length scales of kilometers to tens of kilometers.

The AMS held a workshop on dispersion in complex terrain during May 1983. Egan and Schiermeier's (1986) summary of the workshop identified four specific situations that are of special importance to the problem of estimating the air quality impacts of sources located in or near complex terrain. They are plume interaction with the windward-facing terrain features, plume interaction with lee sides of terrain features, dispersion of pollutants in valley situations, and convective circulations in complex terrain. 


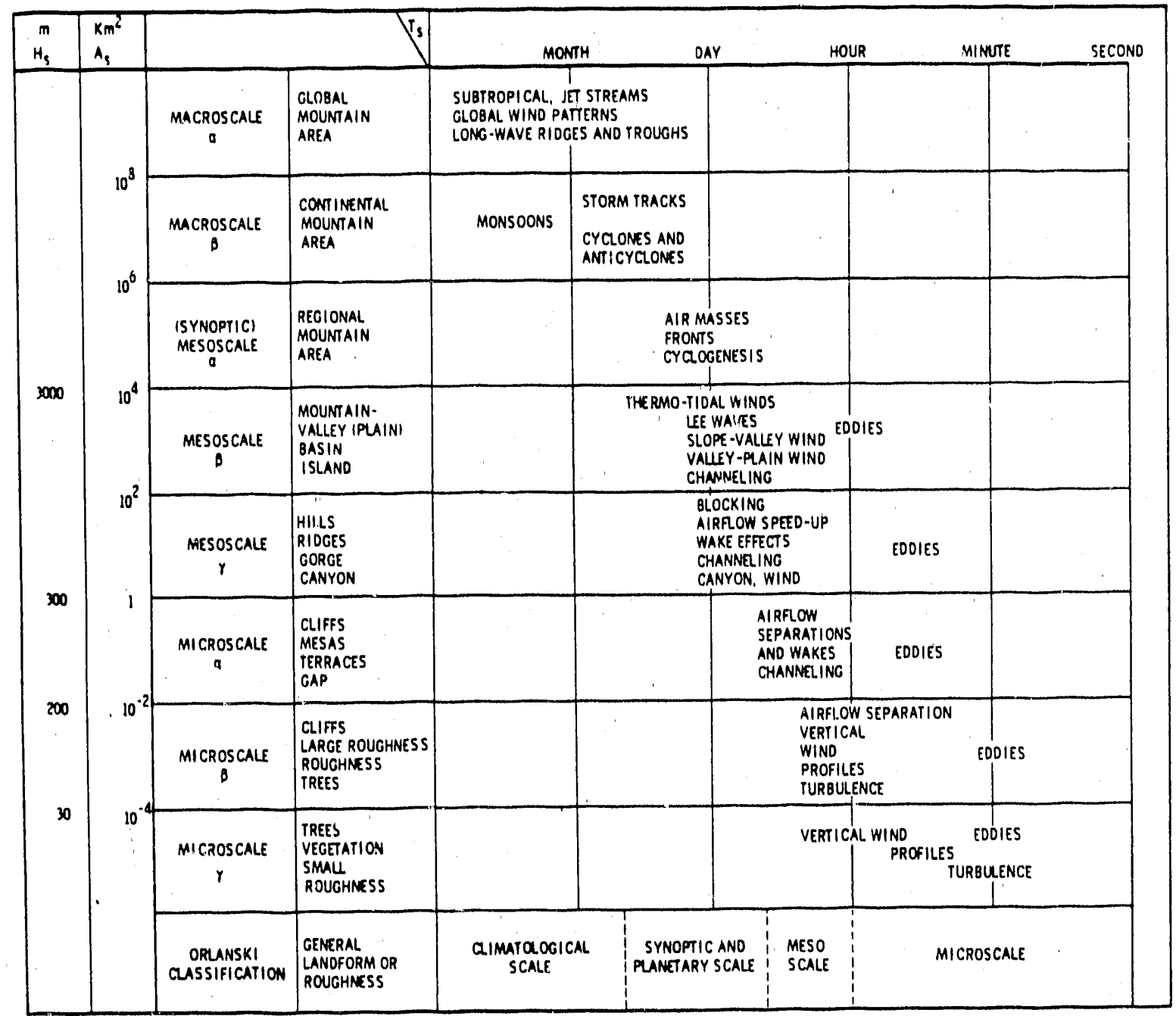

Figure 1. A classification of the effects of terrain on atmospheric motions, where $A_{s}$ is the area scale, $T_{s}$ is the time scale, and $H_{s}$ is the height scale. (Orgill, 1981).

More recently the AMS published a monograph (Blumen, 1990) on atmospheric processes over complex terrain. It gives discussions on wind systems in mountainous terrain (including thermal winds, waves, downslope winds, flow over hills), terrain effects on dispersion, remote sensing over complex terrain, the role of mountains in making clouds, and the predictability of flows over 
complex terrain. Plume impingement on high terrain, pooling in valleys, drainage flows toward populatisri centers, and persistence due to channeling were identified as key air pollution situations in complex terrain. The phenomena of gravity waves, multivalley circulations, sea breezes, pooling, and influences of external metcorology (e.g., subsidence) were identified as areas needing further research.

Whiteman et al. (1991) recently completed a study characterizing the wintertime meteorology of the Grand Canyion region of Arizona. They identified several key phenomena that are important from an air quality viewpoint. The region was dominated by persistent cold air pools in basins. The vertical structure of the boundary layer was very complicated and appeared to be governed by the influence of thermally driven circulations (e.g., up- and downslope flows) from various sizes of landforms. Stagnation and recirculation episodes lasting from hours to days dominated the lowest third of the Lake Powell basin. They also found that the flow through the Grand Canyon was not driven by thermal winds, but rather by the synoptic pressure field overlying the region.

Table 2 gives a summary of the situations identified as of specific concern relative to dispersion and air quality in complex terrain. All of these situations can be encountered within valleys and basins or as a result of the presence of valleys and basins. The remainder of this section will focus on valley and basin dispersion. First, the current understanding of dispersion in valleys is summarized along with the dominant atmospheric processes governing this dispersion. This is followed by a similar discussion on basins. 
Table 2. Summary of Significant Situations and Governing Processes Identified as Important to Air Quality in Compley. Terrain.

PLUME SITUATION GOVERNING ATMOSPHERIC PROCESSES

Channeling

Longitudinal thermal winds, katabatic winds, large-scale forcing

impaction

Windward side stable flows, lee side edciles, crossvalley flows

Stagnation

Cold air pooling, trapping inversions

Recirculation

Thermal circulations (diurnal), eddies

Fumigation

CBL growth, vakes

Deflection

Mountain waves, streamline deformation

Layering

Process divisions (e.g., katabatic flow over cold-air pool)

Ventilation

CBL growth, wave sweeping, large-scale forcing

Diffusion

Enhanced turbulence, intermittent turbulence

\section{DISPERSION IN VALLEYS}

Many population centers around the world are located in valleys. Air quality problems routinely occur in mountain valleys from pollutant sources located within or near the valleys (Hewson and Gill, 1944; Tyson, 1969; and, Wanirer and Hertig, 1984). With the increased use of wood burning for residential heating, many small communities in mountain valleys are experiencing significant air pollution episodes during the winter months (Cooper, 1980; and Sexton et al., 1984). Addressing these air quality problems and determining mitigation strategies requires the use of atmospheric dispersion models. Also, cities with 
10

chemical or nuclear facilities may require the use atmospheric dispersion models as part of their emergency plan for responding to accidental releases of toxic materials. A considerable amount of research has been conducted in response to these needs for valley dispersion estimates.

Numerous meteorological and tracer experiments have been conducted to investigate the dispersive characteristics of valley atmospheres (Start et al., 1975; Willson et al., 1983: Gudiksen et al., 1984; Gryning and Lyck, 1983; Clements et al., 1989; Whiteman, 1989; and Doran et al., 1990). Also, the dynamic and dispersive behavior of valley atmospheres has been investigated theoretically and with numerical models (McNider, 1981; Bader and McKee, 1985; Vergeiner et al., 1987; Segal et al., 1988; and, Bader and Whiteman, 1939). A more complete understanding of dispersion and the processes governing dispersion in valleys is emerging as a result of this research. However, much more work is required, especially on the applicability of the findings to other valleys, and the interactions of the various processes.

Egan and Schiermeier (1986) summarized, from the AMS workshop, that nocturnal drainage flows, persistent low wind speed stable flows, fumigation, and flow channeling by valley sidewalls are processes important to valley dispersion situations. They identified three valley configurations, shallow valleys, deep, draining valleys, and closed valleys (basins - discussed in the next section). The shallow valley is characterized by the effluent plume of interest being significantly higher than the valley sidewalls. During stable atmospheric conditions the plume does not interact with the valley atmosphere, except that the plume trajectory may be steered by the valley orientation. Dispersion in deep, draining valleys has been the focus of considerable research lately, especially in the ASCOT program 
(Clements et al., 1989). Here the effluent release is within the vallay, and the dispersion is dependent on the behavior of the valley atmosphere.

The behavior of pollutants in the valley atmosphere from the perspective of regional dispersion (hundreds of kilometers transport) is discussed by Allwine and Whiteman (1988). Material trapped in down-valley flows through the night can be carried out of the valley into the regional flows during the morning transition period. The valley processes governing pollutant "venting" (Fig. 2) are not typically resolved in regional scale dispersion models. This valley venting process must then be parameterized in regional scale models or, more typically, is not treated. Segal et al. (1988) demonstrate valley venting in one of their valley case studies with a primitive equation meteorological model and a Lagrangian dispersion model. Venting from a deep Colorado valley has also been observed and discussed by Orgill (1989).

Allwine and Whiteman (1988) hypothesize that, during times of weak synoptic influences, the dynamical behavior of the valley atmosphere governs the amount and timing of pollutants vented into the regional flows. They demonstrate the effects of the valley venting process on regional concentration levels, using a regional-scale puff trajectory model (Allwine and Whiteman, 1985) containing a parameterizetion of the venting process. The release from a hypothetical continuous point source located in a deep Colorado valley was simulated. They found a considerable difference in the pattern of ground-level concentrations when comparing model results with and without the parameterization. 

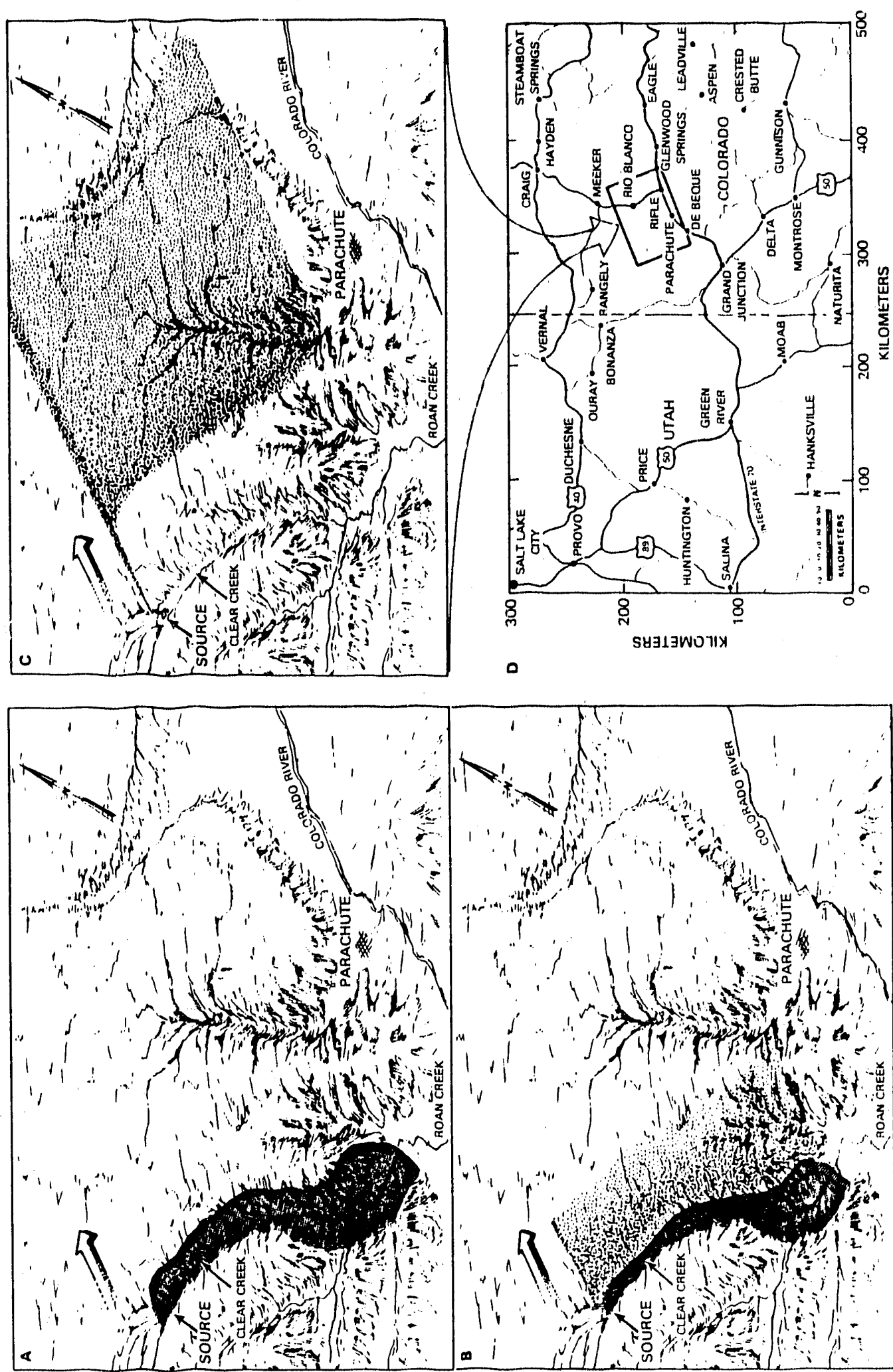

ذ)

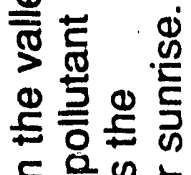

드웧

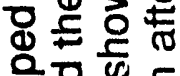

응유 둥

แ ส

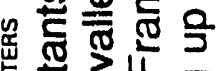

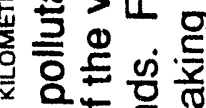

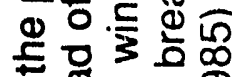

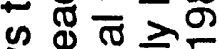

응 응 웧

क 5 엉증

ธ

o

ह 톤도

진

1 为은

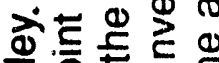

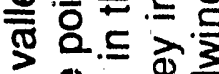

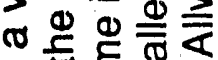

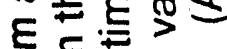
은 통등동 옹 응융 듀 हᄃㄴㄴㅇㄴ 声 으웓ㄴ동 ธั口ㄷㄷㄷ

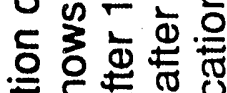
吾的劣上 至㖉亦 \品

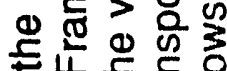

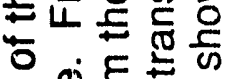
응. 온 은

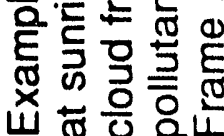
N 옥 
The foundation of the valley venting parameterization used in Allwine and Whiteman's regioral scale dispersion model is Whiteman and McKee's (1982) bulk thermodynamis model which predicts the breakup of the nocturnal stable valley atmosphere during the morning transition period. This thermodynamic model is also the basis of a valley-scale air pollution computer code (Whiteman and Allwine, 1985), which predicts ground-level concentrations from the fumigation of elevated plumes to the surface during the morning transition period.

Whiteman and McKee's bulk thermodynamic model is illustrated conceptually in Fig. 3. The stable core of the valley atmosphere (stippled region) is entrained into a growing convective boundary layer (CBL) and upslope flows. The top of the inversion descends (from air mass conservation) as indicated by the potential temperature profiles on the left side of the figure. The plots of alongvalley winds show down-valley flow in the stable core and up-valley flow in the growing CBL. The inversion destruction takes place nominally during three to five hours beginning at local sunrise. The entrainment of the descending stable core into a growing CBL and upslope flows is hypothesized as the dominant mechanism by which venting of pollution takes place.

The timing and duration of the morning transition period is dependent on the geometry of the valley, characteristics of the nocturnal inversion, surface cover, moisture content, weather, solar input, and time of year. In winter, temperature inversions may not be destroyed diurnally, and may persist for extended periods. The inversion breakup may also occlir in other patterns than the one illustrated in Fig. 3. For example, breakup could occur solely due to CBL growth, or solely due to inversion top descent (Whiteman, 1982). 

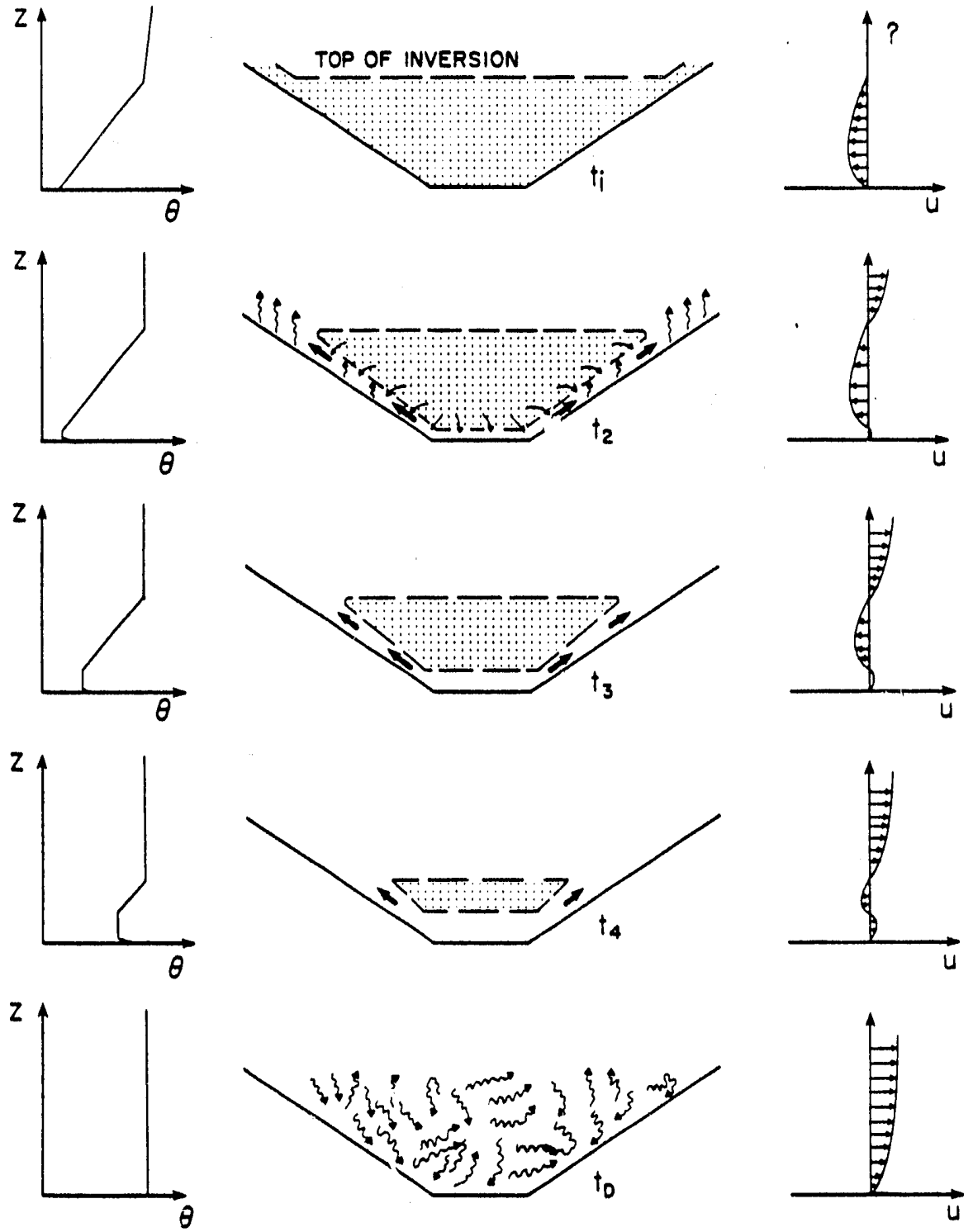

Figure 3. Illustration of the hypothesis of inversion destruction. The stable core region of the valley atmosphere is darkened. Potential temperature profiles at the center of the valley are given on the left side of the figure, and on the right are corresponding profiles of the upvalley wind component. At sunrise, $t_{i}$, an inversion is present in the valley. At $t_{2}$, sunlight has illuminated the valley floor and slopes, and a growing CBL is present over the valley surfaces. Mass and heat (deficit) from the stable core are entrained into the CBLs and carried up the sidewalls in the upslope flows. This results in a sinking of the stable core. The CBLs continue to grow and the stable core sink ( $t_{3}$ and $t_{4}$ ) until the inversion is broken (tD), giving a well-mixed neutral atmosphere through the valley depth. Winds continue downvalley in the stable core during the inversion breakup period, whereas, winds in the CBL below, and the region above often are upvalley during this same period. (Whiteman and Allwine, 1985) 
Bader and McKee (1985) have investigated numerically the effects of valley width, surface heating rate, wind shear above the valley, valley orientation, sidewall slope, initial stability, and surface albedo on the evolution of the daytime valley boundary layer. They found that the effects of the sidewall slopes decrease with increasing valley width, lower surface heating rates influence the rate but not the structure of the boundary layer development, moderate wind shear and valley orientation have very little effect, steeper sidewall slopes and stronger initial stabilities inhibit slope flow development and produce less inversion descent, and lower surface albedos along the valley sidewalls can dramatically increase the magnitude of the inversion descent.

The breakup depicted in Fig. 3 is for an idealized situation in which the sidewalls and valley floor are uniformly heated. This idealized situation rarely occurs in actual valleys because of their varying orientations relative to the sun, and their nonhomogeneous surface characteristics which effect the flux of heat between the surface and the atmosphere. This differential heating can lead to cross-valley flows (Hennemuth, 1986) which can have a significant effect on concentrations seen at the surface. Cross-valley flows were observed by Whiteman (1989) in a deep Colorado valley, and investigated by Bader and Whiteman (1989) using a dynamic mesoscale model. They found from the numerical simulations that the cross-valley effects on the plume are strongly dependent on the initial plume elevation and the surface heating distribution (season). In the summer case, a plume in the lower third of the valley migrated to the more strongly heated sidewall after sunrise and was entrained in the CBL and upslope winds; whereas, a plume near the top of the valley remained near the valley center. During the winter case, neither plume's migration was significant. 
The daily behavior of the valley atmosphere from thermal effects can be divided into four time regimes, morning transition, daytime, evening transition, and nighttime (Whiteman, 1990). The morning transition period has already been described and illustrated in Fig. 3. The daytime period is characterized by fully developed CBLs over all valley surfaces - floor, sidewalls, and ridgetops, and the presence of upslope winds. Up-valley flows are present throughout the depth of the valley and significant interaction occurs with the above ridgetop winds. The evening transition period begins at sunset, and is probably the least investigated and understood of the flow regimes. Down-slope flows on the valley sidewalls and floor develop after sunset, and a temperature inversion begins to form. The colder stable air gathering in the lower portions of the valley can lead to horizontal pressure gradients, resulting in down-valley winds. The temperature inversion may eventually fill the valley. The nighttime is characterized by downvalley near-steady flows throughout the valley depth.

Thermally forced flows have been the focus of the discussion thus far. These flows are caused by buoyancy forces and horizontal pressure gradient forces that develop due to temperature differences. Egger (1990) discusses these thermally forced flows from a theoretical standpoint. He states that conceptual modeling of valley wincis has reached a stage where the basic features of thermally induced flows in valleys can now be reproduced and understood. Reaching this stage, according to Egger, was accomplished with the development of an approach (Brehm, 1986) for describing the interaction of the slope wind layers with the core of the valley atmosphere.

External forcing due to, for example, lee waves, synoptic pressure gradients, large-scale thermal winds, and weather systems also dictate the behavior of the 
valley atmosphere (Barr and Orgill, 1989; Bell and Thompson, 1980; and Kimura and Manins, 1988). Barr and Orgill discuss in some detail the effects of external forcing on the Brush Creek valley atmosphere during the 1984 ASCOT experiments. Even though the focus of the experiments was on undisturbed clear nights, external effects were observed during all experiments. They identified the influence of external wind and radiative effects on the collection of cold air within the valley, and on the erosion of established drainage flows by turbulent entrainment. These, in turn, affected the depth of the drainage flow, and the along-valley volume flux of air. Barr and Orgill also found that the Brush Creek valley atmosphere exhibited a shear-induced helix imposed upon the downvalley drainage. They concluded from the meteorological and tracer data that this induced helix can significantly influence pollution distributions.

Kimura and Manins (1988) investigated numerically the effects of stably stratified flows over the tops of periodic valleys (several valley-ridge configurations giving a sinusoidal cross-section) on the cross-valley flows within the valleys. They found that at small Froude number $(U / N h<0.5$, where $U$ is ambient wind speed, $\mathrm{N}$ is the ambient buoyancy frequency, and $\mathrm{h}$ is the height of the ridges) the valleys' atmospheres were stagnant. For Froude numbers near one, stagnation was a wave phenomenon, resulting from wave steepening and overturning or turbulent mixing. Under these conditions a finite thickness of the valley atmosphere was brought to rest or carried in a rotor. Complete sweeping of the valleys' atmospheres occurred at Froude numbers above about 2.8 .

Chapter 3 addresses plume channeling and venting in a deep draining valley. The periods of focus are the nighttime and morning transition periods, 
and the dominant processes investigated are along-vailey flows, upslope flows, and interaction with ridgetop flows.

\section{DISPERSION IN BASINS}

Closed valleys (termed basins here) were identified in an AMS workshop on dispersion in complex terrain (Egan and Schiermeier, 1986) as a valley configuration of importance to adverse dispersion situations and air pollution problems. Basins often exhibit weak outflow during typical drainage (primarily nighttirne, weak synoptic influence) conditions trcause of flow blockage. Relatively littie research has been conducted on understanding the dynamical behavior of, and dispersion in, basin atmospheres. The bulk of basin research that has been conducted has been within the last decade (e.g., Petkovsek, 1978; Banta and Cotton, 1981; Wanner and Hertig, 1984; Gassmann and Burki, 1987; Beniston, 1987; Maki arid Harimaya, 1988; Neff and King, 1989; Kondo and Okusa, 1990; Toritani, 1990; and Eskridge et al., 1990).

Basin air pollution problems have been observed for many years. The principal problem is air stagnation that may persist from several hours to several days. The mechanisms for the development of these stagnation periods may vary from basin to basin and with time. The Los Angeles basin is well known for its air pollution episodes. This basin is open on one side toward the Pacific Ocean and ringed by mountains. A marine boundary layer penetrating onshore, limited in extent by the mountains, and bounded by a warm layer aloft (below the mountain levels), is a common condition of limited dispersion and high pollutant concentrations in the Los Angeles basin (Stephens, 1975). Liu and Goodin 
(1976) applied a two-dimensional model based on the shallow convection equations to the dispersion of carbon monoxide, primarily from automobiles, in the Los Angeles basin. They concluded that the assumption of a well-mixed marine boundary layer was reasonable, and that the ground-level distribution of CO was primarily dictated by advection and not horizontal diffusion.

Tapp (1985) discusses dispersion in an open basin in Australia. The basin, which contains Melbourne (pop. 2.8 million), is open to the ocean on one side and surrounded by mountains on the others. Melbourne can experience air stagnations during the winter under the influence of strong, slow moving anticyclones centered near the region. During a particularly severe stagnation period (June 1978), Tapp's analysis of meteorological data revealed a pattern of eddies across the city in the lee of upstream topography. He concluded that this phenomena aided in the persistence of high pollutant concentrations by adding to the considerable recycling of air in the Melbourne basin.

Western Oregon has one of the highest meteorological potentials for air pollution in the United States (Holzworth, 1971). Stagnation periods occur in the basins (restricted valleys) along the Columbia and Willamette rivers during the northward movement of the Pacific anticyclone in summer and early fall, and with advection of warm air aloft from the south during late fall and winter (Olsson et al., 1974). They frequently found a direct relationship between the height of an elevated stable layer aloft and a well defined top of the haze layer. When the base of the stable layer was below the top of the surrounding mountains, the natural ventilation of the region was greatly restricted.

Wind speed oscillations with a period of about 15 minutes were observed by Eskridge et al. (1990) in the Boise, Idaho, basin during winter nights. The flows 
observed were light with an almost complete lack of turbulent energy. They observed an instantaneous tracer plume at ground-level to be quite narrow and the hourly average plume width to be relatively large (larger than unstable urban dispersion rates). They concluded that the hourly average plume dispersion was dominated by plume meander from the 15 minute velocity oscillations with very little contribution from smaller scales of motion. They also observed tributary flow from a side canyon penetrating into the basin atmosphere.

Toritani (1990) summarized results from several studles concerning the periodic nature of wind speed and temperature oscillations in cold air drainages. The observed periodicities ranged from 25 to 90 minutes, with the average being roughly 60 minutes. The effects of this periodic motion on dispersion are not well understood.

Gudiksen et al. (1984) discuss results of tracer experiments conducted in a complex terrain region of northern California, designed to investigate dispersion in nocturnal drainage flows. Tracers were released within slope drainage flows, immediately above the drainage flows, and at elevated heights within the Anderson Creek valley. This valley has the characteristics of a basin with pooling occurring in the lower reaches of the basin. They found that the drainage flows from about mid-slope elevations and below were generally not influenced by the regional scale flows. This was based on the observation that the surface tracer concentration patterns, for tracer released within the slope flow, did not vary appreciably over a wide range of regional flow conditions.

Tracers released just above the drainage flows near the ridgetop did reveal considerable mixing between the drainage flows and the winds above the drainage flows as the drainage flows proceeded downslope. The dispersion 
rates of the tracer released just above the drainage flows were appreciably higher than those reported over flat terrain. The dispersion of tracer released at elevated heights above the slopes, but still within the basin, was extremely dependent on the regional scale flows.

Nappo et al. (1989) investigated the dispersion of tracers in the slope flows in the Anderson Creek valley using a two-dimensional dynamic meteorological model with a species-conservation equation and first-order closure. They confirm the observations that tracers released just above the drainage layer can be entrained into the layer and diffused to the ground. Tracer released within the drainage layer can spread through the entire depth of the layer, and the dispersion characteristics are quite different from those for stable flows over flat terrain. The differences result from increases of boundary-layer depth, wind speed, and turbulence as the katabatic flow develops downslope. Nappo et al. (1989) underpredicted the observed concentrations and depth of the drainage layer in the lower region of the slope because the model could not simulate the pooling of air in the basin.

Several research programs concerned with climate and air pollution in cities of Switzerland have been conducted in the past decade (Wanner and Hertig, 1984; Gassmann and Burki, 1987; Beniston, 1987; Wanner et al., 1986; and Filliger and Wanner, 1986). These cities are located in prealpine basins north of the Swiss Alps and south of the Jura mountains, stretching roughly $300 \mathrm{~km}$ from the Lake of Geneva (southwest) to the Lake of Constance (northeast). According to Wanner and Hertig, the interactions of three important processes must be studied to understand dispersion in these Swiss cities. These processes are 
heat islands and city-induced air flows, synoptic flows, and terrain-induced local flows.

Numerous air pollution episodes have been observed in Swiss cities under predominantly anticyclonic weather situations. During the summer anticyclonic situations, high photochemical smog episodes are experienced, and during the winter the Swiss prealpine basins suffer from the effects of strong inversions, fog and relatively high amounts of air pollution. Thick cold air pools spread out over the prealpine basins, and urban heat islands produce stable convection cells (Wanner and Hertig, 1984).

Some of the physical processes identified as important in governing dispersion in basins are external forcing (geostrophic winds, mountain waves, rotors) down-slope (katabatic) flows, up-slope flows, flow oscillations (gravity waves, surges from competing llows), local cold air pooling, flow blocking and channeling, thermal winds (longitudinal pressure gradients), surface roughness (buildings and trees), urban heat island effect, external bursts (intermittent penetrations from aloft), wakes, atmospheric stability (Richardson number considerations), temperature inversions, wind shears, convective boundary layer growth, weather events (fronts) and turbulence characteristics.

Chapter 4 addresses plume layering, diffusion and stagnation in a basin. The main period of focus is the nighttime with some results given for the evening and morning transition periods. The dominant processes investigated are slope flows, oscillations, penetrations from aloft, and cold air pooling. 
Chapter 3

\section{ATMOSPHERIC DISPERSION AND TRACER VENTILATION IN A DEEP MOUNTAIN VALLEY}

Allwine, K. J.

to be submitted to J. Appl. Meteor. 


\title{
Atmospheric Dispersion and Tracer Ventilation in A Deep Mountain Valley
}

\author{
K. Jerry Allwine \\ Pacific Northwest Laboratory, Richland, Washington
}

\begin{abstract}
During September and October 1984 a major meteorological and tracer study was conducted in Colorado's Brush Creek valley. The characteristics of atmospheric dispersion during the nighttime and morning transition periods are discussed in this paper. Tracer released in the lower. portions of the valley did not reach the ridgetops (escape from the valley) during the nighttime, but was confined to the valley, being carried in down-valley flows. After sunrise, with the onset of convective boundary layer growth and initiation of upslope flows, the tracer within the valley was carried into the upper reaches of the valley atmosphere and ventilated from the valley. This was confirmed by the ridgetop tracer samplers and by a tracer mass budget applied to a valley atmosphere control volume. The ventilation rate of tracer from the valley atmosphere to the above ridgetop flows was calculated from the tracer mass budget. The nighttime valley centerline groundlevel concentrations from a continuous release at the valley floor were well represented (within $20 \%$ ) out to $8 \mathrm{~km}$ by a Gaussian plume equation solved in a segmented fashion. This agreement was attained by accounting for plume reflections from the valley sidewalls, initial plume dispersion due to wake effects from a forest stand, and along-valley variations in turbulence characteristics.
\end{abstract}

\section{Introduction}

The exchange of heat, moisture, gases and other matter between the earth's surface and the atmosphere is governed by the interaction of various scales of motion present in the atmosphere. One important interaction is that between valley atmospheres and flows above the valley ridgetops. Throughout the world, population centers and human activities occur in valleys. Understanding the behavior of valley atmospheres and the interaction of valley atmospheres with 
above-ridgetop flows is essential for understanding and estimating the effects of man's activities on his environment. The interaction of valley flows with aboveridgetop flows can be important in estimating the consequences of the regional transport of air pollutants, and in estimating the surface fluxes of heat, moisture and trace gases in global climate models. This scale of interaction is not generally accounted for in regional-scale air pollution models or global climate models. This paper gives an initial look at quantifying the interaction between a valley atmosphere and the above-ridgetop flows.

In September and October of 1984, a large meteorological and tracer field study was conducted in Colorado's Brush Creek valley by the U.S. Department of Energy's Atmospheric Studies in Complex Terrain (ASCOT) program. The Brush Creek valley has a semiarid, continental climate with low precipitation, low relative humidity, large temperature variations, and high evaporation. Strong down-valley winds develop in this valley during the night.

The overall design of the 1984 ASCOT field study, including objectives, equipment and layout, is described by Clements et al. (1989). The major objectives of the tracer experiments were to evaluate the behavior of inert gases entrained in nocturnal valley flows and the subsequent ventilation of the gases into above-ridgetop flows during the morning transition period. Tracer and meteorological data were collected in and around the Brush Creek valley during five experimental periods (typically midnight to noon). A number of papers have been previously published on results from the 1984 ASCOT study, including several papers in the special ASCOT issues of the Journal of Applied Meteorology (Vol. 28, No. 6 and 7). 
The 1984 ASCOT tracer experiments were a significant accomplishment in light of the very difficult logistics, three types of tracers released, and the extent of the ground-based (more than 90 samplers) and vertical sampling (11 profiling systems). Several thousand individual samples were collected and chemically analyzed for the three perfluorocarbon tracers. The samplers were deployed over a more than $25 \mathrm{~km}$ by $25 \mathrm{~km}$ area of very complicated terrain with very few and poor roads. The samplers were deployed by truck, foot and by helicopter. The U.S. Department of Energy's Environmental Measurements Laboratory (EML) and the U.S. National Oceanographic and Atmospheric Administration's Air Resources Laboratory (ARL) were principally responsible for the successful outcome of the tracer experiments.

The primary objective of this paper is to assess the dispersive characteristics of the Brush Creek valley atmosphere and to estimate the valley ventilation rate by analyzing the tracer data and certain of the meteorological measurements. The Background section gives the current status of research on dispersion in mountain valleys. The Experimental Layout section gives a description of the site, equipment, and tracer release and sampling network. The Results and Discussion section gives the meteorological observations, the nighttime tracer concentrations and diffusion rates, the morning transition period tracer concentrations and ventilation rates, and the tracer mass budget calculations. This is followed by the Summary and Conclusions.

\section{Background}

Numerous meteorological and tracer experiments have been conducted to determine the dispersive characteristics and the behavior of valley atmospheres 
(Start et al., 1975; Willson et al., 1983; Gudiksen et ai., 1984; Gryning and Lyck, 1983; Clements et al., 1989; Whiteman, 1989; and Doran et al., 1990). Additionally, several numerical and theoretical inyestigations have investigated both the dynamic and dispersive behavior of valley atmospheres (McNider, 1981; Bader and McKee, 1985; Vergeiner et al., 1987; Segal et al., 1988; and Bader and Whiteman, 1989). A more complete understanding of dispersion and the processes governing dispersion in valleys is emerging as a result of this research. However, much more work is required; especially on the applicability of the fincir $s$ to other vaileys, and on the interactions of the various processes.

Egan and Schiermeier (1986) concluded that nocturnal drainage flows, persistent low wind speed stable flows, fumigation, and flow channeling by valley sidewalls are processes important to dispersion in valleys. They identified three valley configurations, shallow valleys, deep, draining valleys, and clused valleys (basins). In shallow valleys the effluent plume is significantly higher than the valley sidewalls. During stable atmospheric conditions the plume does not interact with the valley topography, except that the plume trajectory may be channeled along the valley axis. Dispersion in deep, draining valleys has been the focus of considerable recent research, especially in the ASCOT program (Clements et al., 1989). Here the effluent release is within the valley, and the dispersion is dependent on the behavior of the valley atmosphere and its interaction with the underlying valley topography.

The behavior of pollutants in deep draining valleys from the perspective of regional dispersion (hundreds of kilometers transport) is discussed by Allwine and Whiteman (1988). Material trapped in down-valley flows during the night can be carried out of the valley into the regional flows during the morning transition 
period. The valley processes governing pollutant "venting" are not typically resolved in regional-scale dispersion models, so that parameterizations of the valley venting process must be included in regional-scale models. Segal et al. (1988) demonstrate valley venting in one of their valley case studies with a primitive equation meteorological model and a Lagrangian dispersion model. Venting from a deep Colorado valley has also been observed and discussed by Orgill (1989).

Allwine and Whiteman (1988) hypothesize that, during times of weak synoptic influence, the dynamical behavior of the valley atmosphere governs the amount and timing of pollutants vented into the regional flows. They demonstrate the effects of the valley venting process on regional concentration levels, using a regional-scale puff trajectory model (Allwine and Whiteman, 1985) containing a parameterization of the venting process. The release from a hypothetical continuous point source located in a deep Colorado valley was simulated. They found a considerable difference in the pattern of ground-level concentrations when comparing model results with and without the parameterization.

Thermally forced flows have been the focus of the discussion thus far. These flows are caused by buoyancy forces, and horizontal pressure gradient forces that develop due to temperature differences. The forcing of valley atmospheres is not limited to these thermally developed forces. External forcing due to, for example, lee waves, synoptic pressure gradients, large-scale thermal winds, and weather systems also dictate the behavior of the valley atmosphere (Barr and Orgill, 1989; Bell and Thompson, 1980; and Kimura and Manins, 1988). Barr and Orgill discuss in some detail the effects of external forcing on the Brush Creek valley atmosphere during the 1984 ASCOT experiments. Even though the 
focus of the experiments was on undisturbed clear nights, external effects were observed during all experiments. They identified the influence of external wind and radiative effects on the collection of cold air within the valley, and on the erosion of established drainage flows by turbulent entrainment. These, in turn, affected the depth of the drainage flow, and the down-valley volume flux of air. Barr and Orgill also found that the Brush Creek valley atmosphere exhibited a shear-induced helix imposed upon the down-valley drainage. They concluded from the meteorological and tracer data that this induced helix can significantly influence pollution distributions.

Kimura and Manins (1988) investigated numerically the effects of stably stratified flows over the tops of periodic valleys (several valley-ridge configurations giving a sinusoidal cross section) on the cross-valley flows within the valleys. They found that at small Froude number $(U / N h<0.5$, where $U$ is ambient wind speed, $\mathrm{N}$ is the ambient buoyancy frequency, and $\mathrm{h}$ is the height of the ridges) the valleys' atmospheres were stagnant. For Froude numbers near one, stagnation was a wave phenomenon, resulting from wave steepening and overturning or turbulent mixing. Under these conditions a finite thickness of the valley atmosphere was brought to rest or carriec in a rotor. Complete sweeping of the valleys' atmospheres occurred at Froude numbers above about 2.8.

\section{Experimental layout}

\section{a. The Brush Creek valley}

The Brush Creek valley is an uninhabited valley in the Rocky Mountains located $55 \mathrm{~km}$ north-northeast of Grand Junction, Colorado. It has a semiarid, continental climate with low precipitation ( $40 \mathrm{~cm}$ annually at the valley floor), low 
relative humidity, large diurnal temperature variations, and high evaporation. Brush Creek is a 25-km-long tributary of Roan Creek. The lowest $10 \mathrm{~km}$ of Brush Creek are shown in Fig. 1. The valley runs from northwest to southeast, and has a valley floor that falls gradually at 0.8 degrees $(14 \mathrm{~m}$ per $\mathrm{km}$ ). It is $650 \mathrm{~m}$ deep at its lower end and has sidewalls with slopes of 30 to 40 degrees. The Brush Creek valley is a near-linear valley having no major tributaries (principally short box canyons), uniform sidewall angles, a simple well-defined drainage area, and relatively flat or rolling mesa-type ridgetops. The spatial variation of vegetation in the Brush Creek valley (e.g. sagebrush, mountain shrubs, pines, juniper and barren slopes) reflects the increase of precipitation with elevation and the existence of different radiation microclimates on surfaces of different aspect and inclination (Whiteman et al., 1987).

b. Tracer release

Three non-reactive, gaseous perfluorocarbon (PFC) tracers, perfluoromethylcyclopentane (PMCP), perfluoromethylcyclohexane (PMCH), and perfluorodimethylcyclohexane $(\mathrm{PDCH})$, were released simultaneously during 5 experimental periods at the two locations shown in Fig. 1. Releases were generally begun at midnight and continued for about nine hours (until the nighttime down-valley flows reversed). These tracers have very low levels of ambient background concentrations: $\mathrm{PDCH}-0.05$ parts per trillion (ppt), PMCP and $\mathrm{PMCH}-0.005 \mathrm{ppt}$. For further information on these tracers see, for example, Dabbert and Dietz (1986).

The PMCP tracer was released at approximately $1.5 \mathrm{~m}$ above ground level (AGL) at a site on top of Skinner ridge along the northeastern edge of the Brush Creek valley. This site was located near the head of Pack Canyon in a shallow 
draw which extended from the ridge line to the head of Pack Canyon. The release was about $550 \mathrm{~m}$ above the floor of the Brush Creek valley.

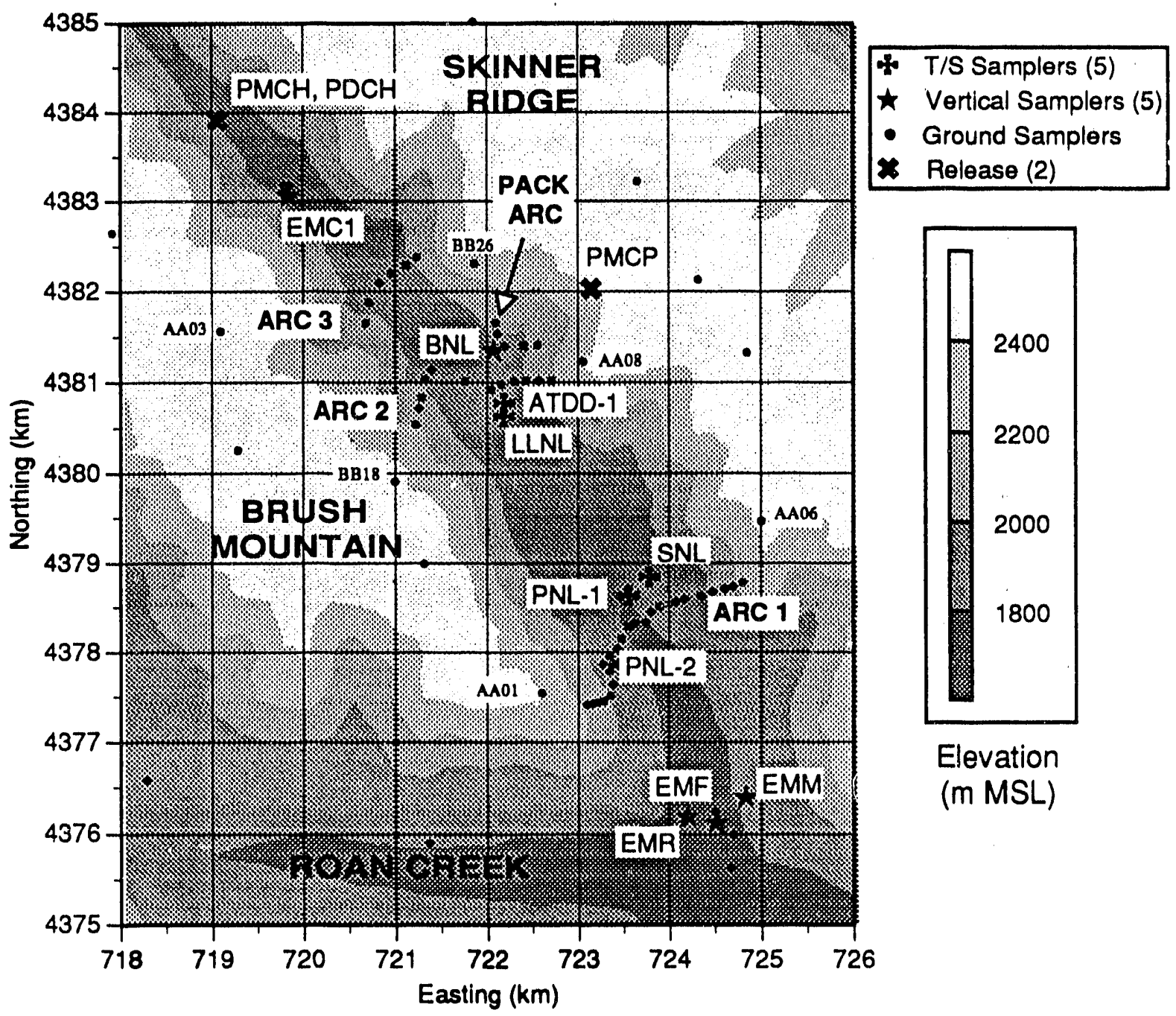

Figure 1. Brush Creek valley terrain contours and locations of ground-level and vertical tracer samplers in the vicinity of the four sampling arcs. The coordinate system is UTM grid zone 12.

$\mathrm{PMCH}$ and $\mathrm{PDCH}$ were released from a site on the Brush Creek valley floor approximately $10 \mathrm{~km}$ up-valley from its mouth. The $\mathrm{PMCH}$ was released at nominally $5 \mathrm{~m} \mathrm{AGL}$, and the PDCH at $180 \mathrm{~m} \mathrm{AGL}$. At times considerable difficulty was experienced in flying the balloons that carried the release lines aloft because of the strong winds and turbulence associated with the nocturnal jet. 
Consequently, the release height and, at times, the release rates varied. Detailed information concerning the PMCP, PMCH and PDCH releases are given in Tables 1,2 and 3, respectively.

TABLE 1. Release Information for the Tracer PMCP (Skinner Ridge location).

\begin{tabular}{cccccccc}
\hline $\begin{array}{c}\text { EXP } \\
\#\end{array}$ & $\begin{array}{c}\text { DATE } \\
(84)\end{array}$ & $\begin{array}{c}\text { START } \\
(\text { MST) }\end{array}$ & $\begin{array}{c}\text { STOP } \\
(\text { MST) }\end{array}$ & $\begin{array}{c}\text { TOTAL } \\
(\mathrm{g})\end{array}$ & $\begin{array}{c}\text { RATE } \\
(\mathrm{g} / \mathrm{s})\end{array}$ & $\begin{array}{c}\text { RANGE } \\
(\mathrm{g} / \mathrm{s})\end{array}$ & $\begin{array}{c}\text { HEIGHT } \\
(\mathrm{m} \text { AGL })\end{array}$ \\
\hline 1 & $9 / 20$ & 0100 & 0900 & 3273 & 0.11 & $0.11-0.13$ & 1.5 \\
2 & $9 / 26$ & 0000 & 0900 & 10092 & 0.31 & $0.31-0.32$ & 1.5 \\
3 & $9 / 28$ & 0130 & 0900 & 4568 & 0.17 & $0.14-0.19$ & 1.5 \\
4 & $9 / 30$ & 0000 & 0800 & 5055 & 0.18 & $0.16-0.19$ & 1.5 \\
5 & $10 / 6$ & 0300 & 0800 & 3397 & 0.19 & $0.15-0.20$ & 1.5 \\
\hline
\end{tabular}

TABLE 2. Release Information for the Tracer PMCH (Brush Creek valley location).

\begin{tabular}{ccccccccc}
\hline $\begin{array}{c}\text { EXP } \\
\#\end{array}$ & $\begin{array}{c}\text { DATE } \\
(84)\end{array}$ & $\begin{array}{c}\text { START } \\
(M S T)\end{array}$ & $\begin{array}{c}\text { STOP } \\
(M S T)\end{array}$ & $\begin{array}{c}\text { TOTAL } \\
(\mathrm{g})\end{array}$ & $\begin{array}{c}\text { RATE } \\
(\mathrm{g} / \mathrm{s})\end{array}$ & $\begin{array}{c}\text { RANGE } \\
(\mathrm{g} / \mathrm{s})\end{array}$ & $\begin{array}{c}\text { HEIGHT } \\
(\mathrm{m} \text { AGL) }\end{array}$ & COMMENTS \\
\hline 1 & $9 / 20$ & 0000 & 0900 & 7065 & 0.22 & $0.21-0.22$ & 5 & \\
2 & $9 / 26$ & 0000 & 0900 & 7293 & 0.23 & $0.21-0.23$ & 5 & $75 \mathrm{~m} 0000-0050$ \\
3 & $9 / 28$ & 0130 & 0900 & 6726 & 0.25 & $0.22-0.28$ & $190 \pm 20$ & 2 to $213 \mathrm{~m}$ before 0240 \\
4 & $9 / 30$ & 0030 & 0800 & 6308 & 0.23 & $0.22-0.24$ & 5 & \\
5 & $10 / 6$ & 0000 & 0800 & 8152 & 0.28 & $0.27-0.31$ & 5 & \\
\hline
\end{tabular}

TABLE 3. Release Information for the Tracer PDCH (Brush Creek valley location).

\begin{tabular}{|c|c|c|c|c|c|c|c|c|}
\hline $\begin{array}{c}\text { EXP } \\
\#\end{array}$ & $\begin{array}{l}\text { DATE } \\
(84)\end{array}$ & $\begin{array}{l}\text { START, } \\
\text { (MST) }\end{array}$ & $\begin{array}{l}\text { STOP } \\
\text { (MST) }\end{array}$ & $\begin{array}{l}\text { TOTAL } \\
\text { (g) }\end{array}$ & $\begin{array}{l}\text { RATE } \\
(\mathrm{g} / \mathrm{s})\end{array}$ & $\begin{array}{c}\text { RANGE } \\
(\mathrm{g} / \mathrm{s})\end{array}$ & $\begin{array}{l}\text { HEIGHT } \\
\text { (m AGL) }\end{array}$ & COMMENTS \\
\hline $\begin{array}{l}1 \\
2 \\
3 \\
4\end{array}$ & $\begin{array}{l}9 / 20 \\
9 / 26 \\
9 / 28 \\
9 / 30\end{array}$ & $\begin{array}{l}0000 \\
0000 \\
0215 \\
0000\end{array}$ & $\begin{array}{l}0720 \\
0900 \\
0900 \\
0800\end{array}$ & $\begin{array}{l}3991 \\
7830 \\
6292 \\
5454\end{array}$ & $\begin{array}{l}0.15 \\
0.24 \\
0.26 \\
0.22\end{array}$ & $\begin{array}{l}0.13-0.23 \\
0.24-0.25 \\
0.25-0.26 \\
0.02-0.27\end{array}$ & $\begin{array}{r}160 \\
183 \\
2 \\
119\end{array}$ & $\begin{array}{l}145 \mathrm{~m} 0100-0200 \\
168-183 \mathrm{~m} 0200-0600 \\
200 \mathrm{~m} \text { to } 0230 \\
205 \mathrm{~m} \text { before } 0045 \text { and } \\
\text { after } 0500 ; 0.02 \mathrm{~g} / \mathrm{s} \text { at } 0 \\
\mathrm{~m} 0400-0500\end{array}$ \\
\hline 5 & $10 / 6$ & 0010 & 0800 & 5897 & 0.21 & $0.20-0.22$ & 205 & 198 to $213 \mathrm{~m}$ \\
\hline
\end{tabular}

c. Ground-level tracer sampling

Time integrated samples of the three PFC tracers were collected at groundlevel using 64 Brookhaven Atmospheric Tracer samplers (BATS) and 30 NOAA Air Resources Laboratory (ARL) samplers. The BATS samplers typically held 10 or 20 adsorption tubes (depending on the number of samples to be collected), and the ARL samplers held 12 tubes. The sampling was conducted from midnight to 1300 Mountain Standard Time (MST) with different samplers 
covering different periods of time. The integration times of individual samples were 15 min., 30 min., or $1 \mathrm{~h}$. Sample chemical analysis was performed by Brookhaven National Laboratory (BNL) and DOE's Environmental Measurements Laboratory (EML) after the study using electron capture gas chromatography.

The sampler locations are shown in Figs. 1 through 4 along with the location identification codes (the first letter " $B$ " indicates BATS samplers and the " $A$ " denotes ARL samplers). Sixty-one samplers were located within the Brush Creek valley (25 on Arc 1, 13 on Arc 2, 6 on Arc 3, 5 on Pack Arc, and 12 on the valley floor), and the remaining 33 were spread along the ridgetops and surrounding valleys (12 on Skinner Ridge, 9 on Brush Mountain, 6 in the Roan Creek valley, 3 in the Clear Creek valley, 2 in the Carr Creek valley, and 1 on Kimball Mountain). The locations of the four Brush Creek valley sampling arcs are shown in Fig. 1, and the individual samplers on each of the four arcs are labeled in Fig. 2. The locations of the 12 samplers along the Brush Creek valley floor are shown in Fig. 3 as three clusters (one just down-valley from the release, one on Arc 1, and one at the mouth) of three samplers each, one cluster (on Arc 2) of two samplers, and a single sampler (BB59) up-valley from the release. The locations of 32 of the 33 samplers located outside the Brush Creek valley are given in Fig. 3. The location of the sampler at De Beque (BB01), $25 \mathrm{~km}$ down the Roan Creek valley from the mouth of the Brush Creek valley, is not shown. Fig. 4 shows the along-valley and cross-valley locations of the ground-level samplers with respect to elevation. The spatial coverage of the samplers relative to the valley floor, ridgetops, and sidewalls is shown in this figure. The sampling duration and integration period for each sampler are given in Table 4. 

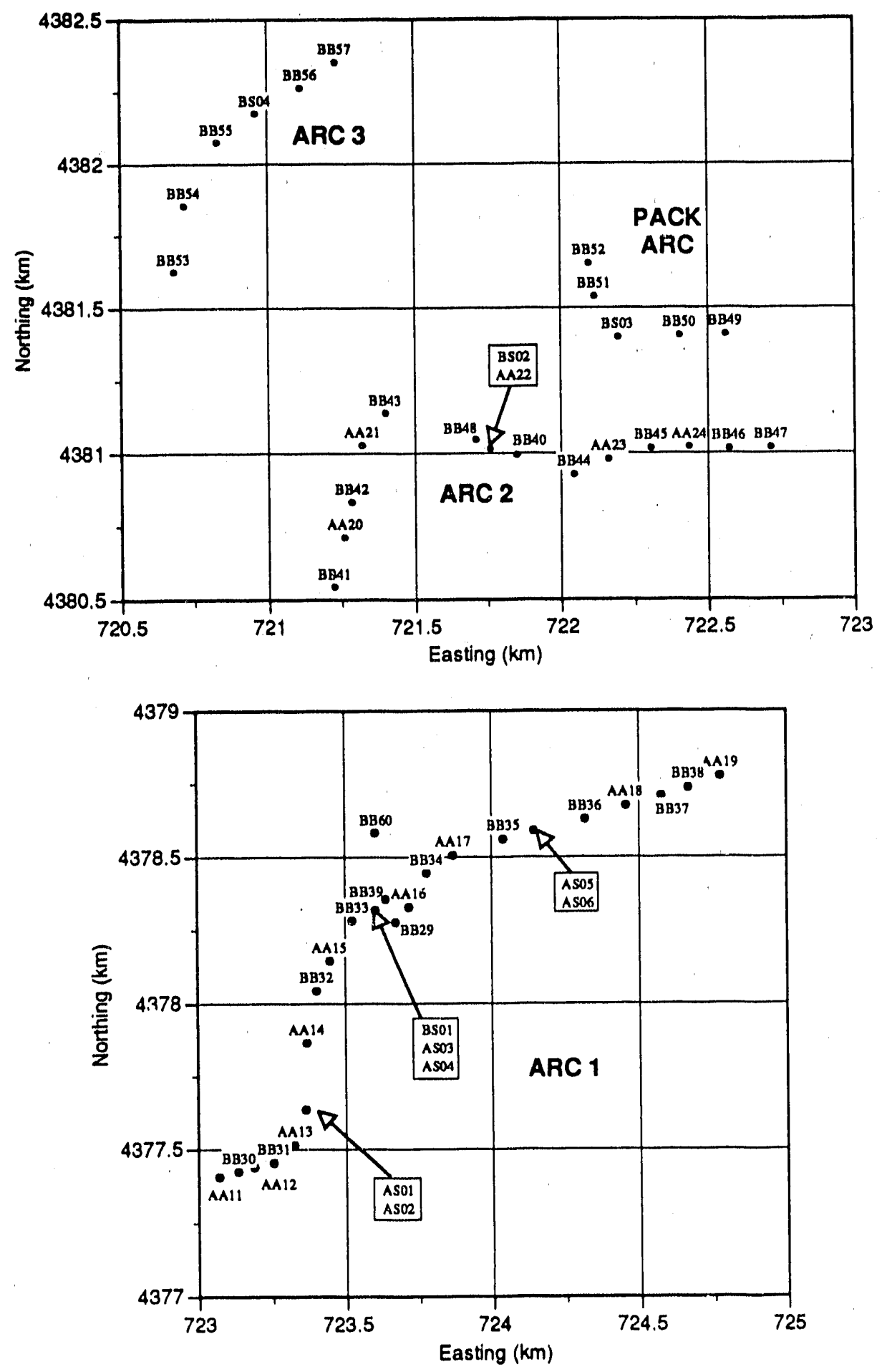

Figure 2. Tracer sampler identification numbers on the four sampling arcs in the Brush Creek valley. Multiple samplers were co-located at some locations. The identification numbers of the co-located samplers are given in the boxes. 


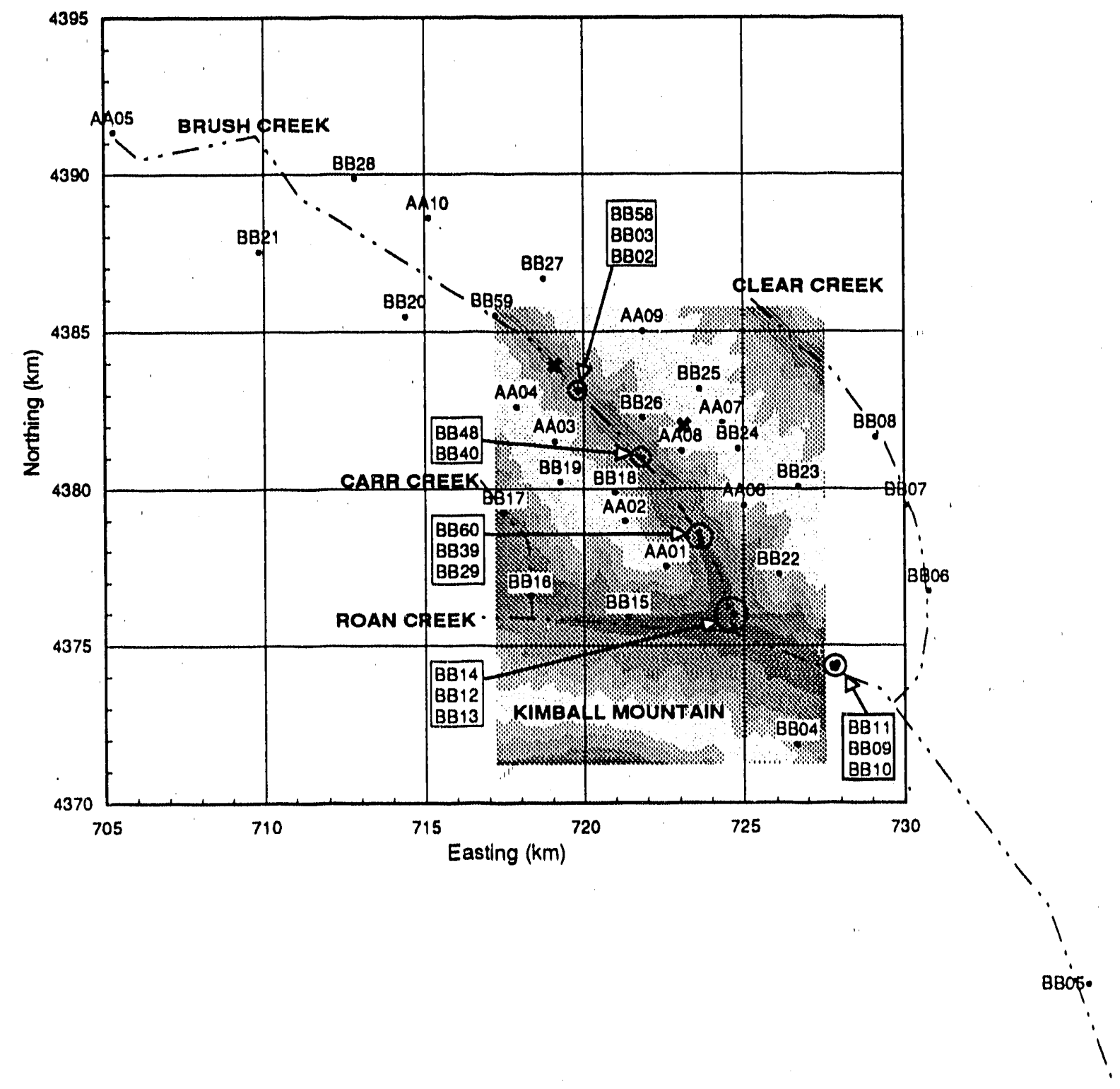

Figure 3. Identification numbers of tracer samplers located in the Carr, Brush (excluding samplers identified in Fig. 2), Clear and Roan Creek valleys and located on the ridgetops. The ' $X$ ' represents the tracer release locations. 

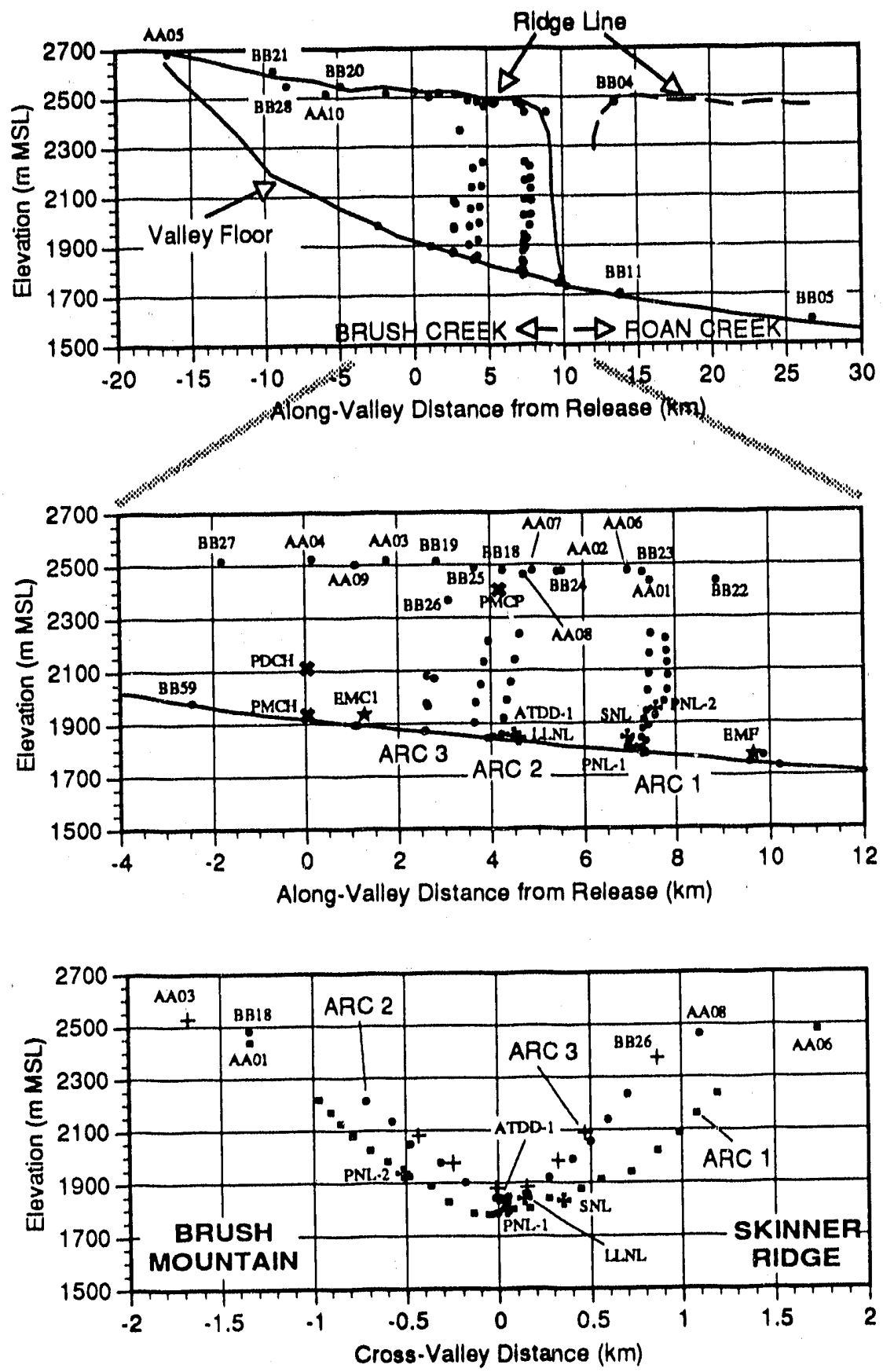

Figure 4. Tracer sampler locations versus along-valley distance and elevation. The first panel (A) shows the along-valley profile of the elevation of the valley floor and the ridgelines from the head of Brush Creek valley to its mouth, then following $\sim 20 \mathrm{~km}$ down Roan Creek valley. Also shown are the locations of the ground-level tracer samplers within Brush and Roan Creek valleys and along the ridgetops. Panel $B$ shows a section of Brush Creek valley with the locations of the release $(\mathbf{X})$, fixed-height tracer profiler $(\star)$, variable-height tracer profiler $(\boldsymbol{\Psi})$, and ground-level samplers $(\bullet)$ identified. Panel $C$ gives the cross-valley locations of the ground-level samplers on Arc 1 (घ), Arc 2 (•) and Arc $3(+)$. 
TABLE 4. Ground-Level Samplers Identification and Sampling Times.

\begin{tabular}{lcc}
\hline Identification Code & $\begin{array}{c}\text { Integration Time } \\
(\mathrm{min})\end{array}$ & $\begin{array}{c}\text { Sampling Duration } \\
\text { (MST) }\end{array}$ \\
\hline BS 01-04 01500 \\
AS 01, 03, 05 & 15 & 0000 to 0500 \\
AS 02, 04, 06 & 15 & 0500 to 0800 \\
BB 01-17, 29-60 & 15 & 0800 to 1100 \\
BB 18-28 & 60 & 0000 to 1000 \\
AA 02, 05, 07 & 60 & 0100 to 1100 \\
AA 01, 03, 04, 06, 08-10 & 60 & 0100 to 1300 \\
AA 11-24 & 60 & 0000 to 1200 \\
\hline
\end{tabular}

d. Elevated tracer sampling

Elevated PFC samples were collected using 10 balloon-borne profiling systems within the Brush Creek valley. The locations of these 10 systems are given in Fig. 1. Five of the systems (EMM, EMF, EMR, EMC1, and BNL) operated by fixing the balloons at a maximum height above ground (500 m AGL) with the samplers at fixed locations along the tetherline (Table 5). At each height, integrated samples (e.g. $60 \mathrm{~min}$.) were collected through the experimental period. The other 5 tracer profiling systems (ATDD-1, LLNL, SNL, PNL-1, PNL-2) were operated as part of a meteorological tethersonde system. A tracer sampling package was connected in the tetherline near thie meteorological package. As the balloon ascended at a nearly constant rate $(\sim 15 \mathrm{~m}$ per minute), the six samplers in the tracer sampling package were sequenced using a radio transmitter. The heights sampled are given in Table 5. The sampling durations listed in Table 5 for the variable-height samplers are approximate, based on the approximate balloon ascent rate of $15 \mathrm{~m}$ per minute.

e. Meteorological observations

Clements et al. (198\%) describe the meteorological observing systems used during the 1984 ASCOT study. Certain data from a subset of these systems are 
used for the analyses described in this paper. These data are: winds, temperature, and sensible heat flux from four Bowen ratio energy budget (BREB) stations (WST, PNL, EST and WPL); winds and temperature from five tethered balloon systems (WPL, LANL, LLNL, PNL-1 and ATDD-2); winds from two Doppler sodars (LANL and PNL); turbulence quantities from four instrumented towers (LANL-3, WPL-1, WPL-2 and ATDD-1); and winds from a dual Doppler lidar (WPL). The locations of these systems are given in Figs. 1 and 5. Table 6 gives the UTM coordinates (grid zone 12) and elevations for the meteorological observing systems, the tracer reloase locations, and the tracer profilers.

TABLE 5. Elevated Samplers Identification and Sampling Times.

\begin{tabular}{|c|c|c|c|}
\hline Identification Code & $\begin{array}{l}\text { Sampling Start Time } \\
\text { (MST) }\end{array}$ & $\begin{array}{c}\text { Sampling Heights } \\
\text { (m AGL) }\end{array}$ & $\begin{array}{l}\text { Sample Duration } \\
\text { (min) }\end{array}$ \\
\hline $\begin{array}{l}\text { ATDD-1, LLNL, } \\
\text { SNL, PNL-1, PNL-2 }\end{array}$ & $\begin{array}{c}0100,0230,0400 \\
0530,0700,0830,1000\end{array}$ & $\begin{array}{c}0-75,75-150,150-250 \\
250-350,350-500,500 \\
700\end{array}$ & $5,5,7,7,10,13$ \\
\hline $\begin{array}{l}\text { EMM, EMF, EMR, } \\
\text { EMC1 }\end{array}$ & $\begin{array}{c}0200,0400,0600 \\
0800,1000\end{array}$ & $\begin{array}{c}100,150,200,250,300 \\
400,500\end{array}$ & 60 \\
\hline BNL & $0000,0330,0630,0930$ & $\begin{array}{c}0,10,20,40,60,90,120, \\
160,200,250,300,350, \\
400,450,500\end{array}$ & 135 and 90 \\
\hline
\end{tabular}

TABLE 6. UTM Coordinates and Elevations of Key Locations

\begin{tabular}{|c|c|c|c|c|c|c|c|}
\hline D & $\begin{array}{c}\text { UTM - E } \\
(\mathrm{km})\end{array}$ & $\underset{(\mathrm{km})}{\mathrm{UTM}-\mathrm{N}}$ & $\begin{array}{c}\text { ELEV } \\
(\mathrm{m} M S L)\end{array}$ & $\mathrm{ID}$ & $\begin{array}{c}\text { UTM }-E \\
(\mathrm{~km})\end{array}$ & $\begin{array}{l}\text { UTM - N } \\
(\mathrm{km})\end{array}$ & $\begin{array}{c}\text { ELEV } \\
\text { (m MSL) }\end{array}$ \\
\hline Tracer Releases & & & & \multicolumn{4}{|c|}{ Additional Tethersondes } \\
\hline $\begin{array}{l}\text { PMCP } \\
\text { PMCH, PDCH } \\
\text { Tracer Profilers }\end{array}$ & $\begin{array}{l}723.14 \\
719.06\end{array}$ & $\begin{array}{l}4382.03 \\
4383.92\end{array}$ & $\begin{array}{l}2399 \\
1926\end{array}$ & $\begin{array}{l}\text { ATDD-2 } \\
\text { LANL } \\
\text { WPL }\end{array}$ & $\begin{array}{l}724.24 \\
719.84 \\
718.93\end{array}$ & $\begin{array}{l}4375.94 \\
4383.12 \\
4384.05\end{array}$ & $\begin{array}{l}1734 \\
1897 \\
1930\end{array}$ \\
\hline EMM & 724.83 & 4376.38 & 1792 & \multicolumn{4}{|l|}{ Towers } \\
\hline $\begin{array}{l}\text { EMF } \\
\text { EMR } \\
\text { BNL } \\
\text { EMC1 } \\
\text { Profilers/Tetherso }\end{array}$ & $\begin{array}{l}724.51 \\
724.20 \\
722.07 \\
719.85 \\
\text { ndes }\end{array}$ & $\begin{array}{l}4376.10 \\
4376.16 \\
4381.33 \\
4383.05\end{array}$ & $\begin{array}{l}1743 \\
1740 \\
1902 \\
1896\end{array}$ & $\begin{array}{l}\text { LANL-3 } \\
\text { WPL-1 } \\
\text { WPL-2 } \\
\text { ATDD-1 } \\
\text { Doppler Lidar }\end{array}$ & $\begin{array}{l}719.68 \\
721.08 \\
720.95 \\
724.18\end{array}$ & $\begin{array}{l}4333.22 \\
4381.94 \\
4382.01 \\
4377.50\end{array}$ & $\begin{array}{l}1890 \\
1859 \\
1865 \\
1768\end{array}$ \\
\hline $\begin{array}{l}\text { PNL-2 } \\
\text { PNL-1 }\end{array}$ & $\begin{array}{l}723.34 \\
723.55\end{array}$ & $\begin{array}{l}4377.84 \\
4378.61\end{array}$ & $\begin{array}{l}1939 \\
1798\end{array}$ & $\begin{array}{l}\text { WPL } \\
\text { BREB Stations }\end{array}$ & 723.18 & 4379.43 & 1821 \\
\hline $\begin{array}{l}\text { SNL } \\
\text { LLNL } \\
\text { ATDD-1 } \\
\text { Sodars }\end{array}$ & $\begin{array}{l}723.78 \\
722.18 \\
722.19\end{array}$ & $\begin{array}{l}4378.82 \\
4380.60 \\
4380.75\end{array}$ & $\begin{array}{l}1835 \\
1829 \\
1843\end{array}$ & \multirow[t]{2}{*}{$\begin{array}{l}\text { WPL } \\
\text { WST } \\
\text { PNL } \\
\text { EST }\end{array}$} & \multirow[t]{2}{*}{$\begin{array}{l}721.11 \\
723.32 \\
723.55 \\
723.88\end{array}$} & \multirow[t]{2}{*}{$\begin{array}{l}4381.94 \\
4377.83 \\
4378.51 \\
4379.19\end{array}$} & \multirow[t]{2}{*}{$\begin{array}{l}1857 \\
1942 \\
1795 \\
1935\end{array}$} \\
\hline $\begin{array}{l}\text { LANL } \\
\text { PNL }\end{array}$ & $\begin{array}{l}719.70 \\
723.54\end{array}$ & $\begin{array}{l}4383.22 \\
4378.64\end{array}$ & $\begin{array}{l}1897 \\
1798\end{array}$ & & & & \\
\hline
\end{tabular}


The coverage of the lidar system is indicated by the dashed line in Fig. 5 . The up-valley horizontal coverage extended from $312.1^{\circ}$ to $332.5^{\circ}$ in $0.4^{\circ}$ increments (52 elements), and the up-valley vertical coverage extended from $0.5^{\circ}$ to $10.9^{\circ}$ elevation angle in $0.4^{\circ}$ increments (27 elements). The down-valley horizontal coverage extended from $133.5^{\circ}$ to $184.5^{\circ}$ in $1.0^{\circ}$ increments (52 elements), and the down-valley vertical coverage extended from $-0.5^{\circ}$ to $12.5^{\circ}$ in $0.5^{\circ}$ increments (27 elements). The lidar measured the radial component of the winds averaged along $300 \mathrm{~m}$ long paths at 22 up-valley and 16 down-valley range gates.

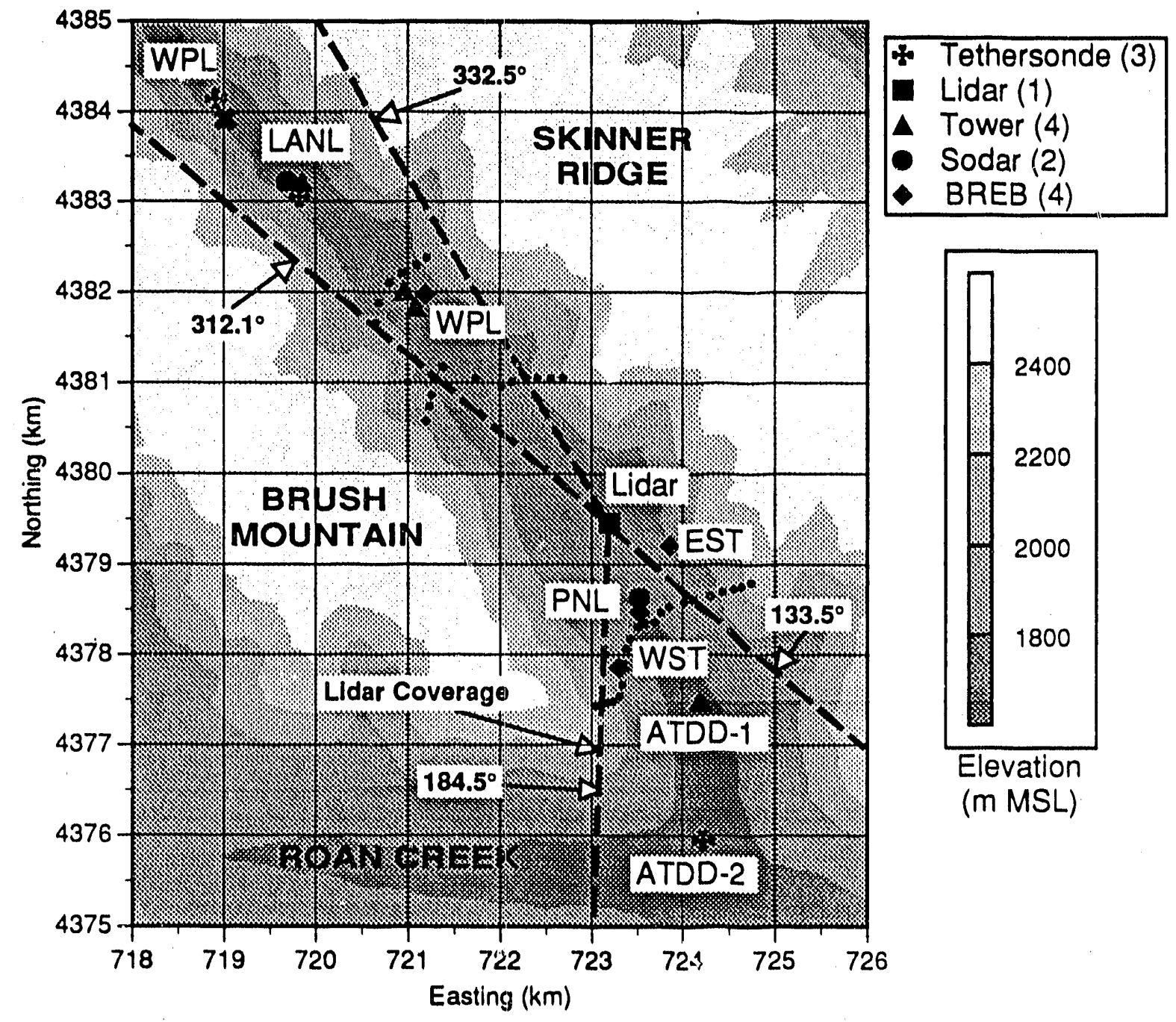

Figure 5. Locations of the meteorological system used in this analysis. 


\section{Results and discussion}

Detailed results from the 9/26/84 experiment are given. This experiment demonstrates the dominant processes governing the dispersion in this valley during fall clear-sky conditions. The release conditions for the three tracers were reasonably reliable on this date.

\section{a. General meteorology}

The general characteristics of the meteorology in the Brush Creek valley during the 1984 experiments are shown in Fig. 6, which gives the diurnal variations in the surface sensible heat flux, temperature, and winds measured at about $2 \mathrm{~m} \mathrm{AGL}$ at the four BREB station sites shown in Fig. 5. Clouds were present during the early morning and daytime of $9 / 26 / 84$, as evidenced by lower values of sensible heat flux. In order to more fully appreciate the "typical" diurnal variations during clear-sky conditions, the diurnal cycle for the 9/30/84 experiment is given. The timing of certain key events can be more easily identified from this experiment. For example, the times of local sunrise and sunset are given in Table 7. These times are determined primarily from the net radiation data (when the net radiation changes sign) collected by the BREB stations. The average duration of direct sunlight at any location in the valley is roughly $8.2 \mathrm{~h}$, which is about $70 \%$ of the total daylight period. Direct sunlight reaches the majority of the valley surfaces about $3 \mathrm{~h}$ after astronomical sunrise. Local sunrise occurs first on the west sidewall and progresses across the entire valley. From Fig. 6, the average surface ( 2 $\mathrm{m} \mathrm{AGL}$ ) nighttime cooling rate is roughly $0.6^{\circ} \mathrm{C} / \mathrm{h}$ on $9 / 30 / 84$ and $0.4^{\circ} \mathrm{C} / \mathrm{h}$ on $9 / 26 / 84$. The corresponding nighttime average surface sensible heat fluxes throughout the valley are about $25 \mathrm{~W} / \mathrm{m}^{2}$ and $15 \mathrm{~W} / \mathrm{m}^{2}$, respectively. 
$($ (2) w/M 46

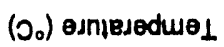

(s/u) poeds puin

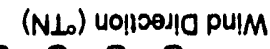

88

888


g

के

을 ఝ

角

ไู้ ำ

응명

过

สิ

응

完

ষ⿻ำ 옹

穹

㟧

สั

뜨은

$\stackrel{2}{E}$

$\Phi$

은

음 뜸

里

능을

(⿻)

옳

20

号

ㄷ

क्षه

ฆ

包?

苞茴

E

를

F.

ט. 은

혹은 
TABLE 7. Sunrise and Sunset Times on 9/30/84 from the BREB Stations.

\begin{tabular}{cccc}
\hline Location & $\begin{array}{c}\text { Local Sunrise } \\
\text { (MST) }\end{array}$ & $\begin{array}{c}\text { Local Sunset } \\
\text { (MST) }\end{array}$ & $\begin{array}{c}\text { Daylight Period } \\
(\mathrm{h}, \text { min.) }\end{array}$ \\
\hline Ridgetops & 0620 & 1800 & 11,40 \\
WST & 0705 & 1435 & 7,30 \\
PNL & 0730 & 1610 & 8,40 \\
WPL & 0740 & 1610 & 8,30 \\
EST & 0840 & 1650 & 8,10 \\
\hline
\end{tabular}

Inspection of the timing of the wind direction changes shows the winds in the valley to fully reverse from down-valley $\left(\sim 320^{\circ}\right)$ to up-valley $\left(\sim 140^{\circ}\right)$ at about 0830-0900 MST. On the west sidewall (WST in Fig. 6) the slope flows change from downslope $\left(\sim 230^{\circ}\right)$ to nearly upslope $\left(\sim 60^{\circ}\right)$ rapidly at about 0700 , whereas the downslope winds on the east sidewall reverse more gradually after 0700 tending towards upslope with a considerable up-valley component. The slope and valley winds often interact closely (Hennemuth and Schmidt, 1985) and cannot be independently resolved. These interactions of slope and valley winds in the Brush Creek valley are discussed by Whiteman et al. (1989).

b. Nighttime meteorology

The nighttime meteorology of the Brush Creek valley during the 1984 ASCOT study has been extensively analyzed (e.g., Journal of Applied Meteorology, Vol. 28, No. 6 and 7). The meteorological characteristics important for understanding and describing nighttime dispersion will be emphasized here. Some additional analyses of the data will be presented to give further clarity to meteorological characteristics important to dispersion.

The nighttime (0100-0530 MST) mean profiles of potential temperature, wind speea and wind direction as measured by tethersondes at various alongvalley locations are given in Fig. 7 for 9/26/84. The characteristics in Fig. 7 


\section{4}

important to dispersion are 1) the strength and height of the nocturnal jet, 2) the height of the wind speed minimum, 3) the predominant down-valley orientation of the winds, and 4) the strength of the surface temperature inversion.
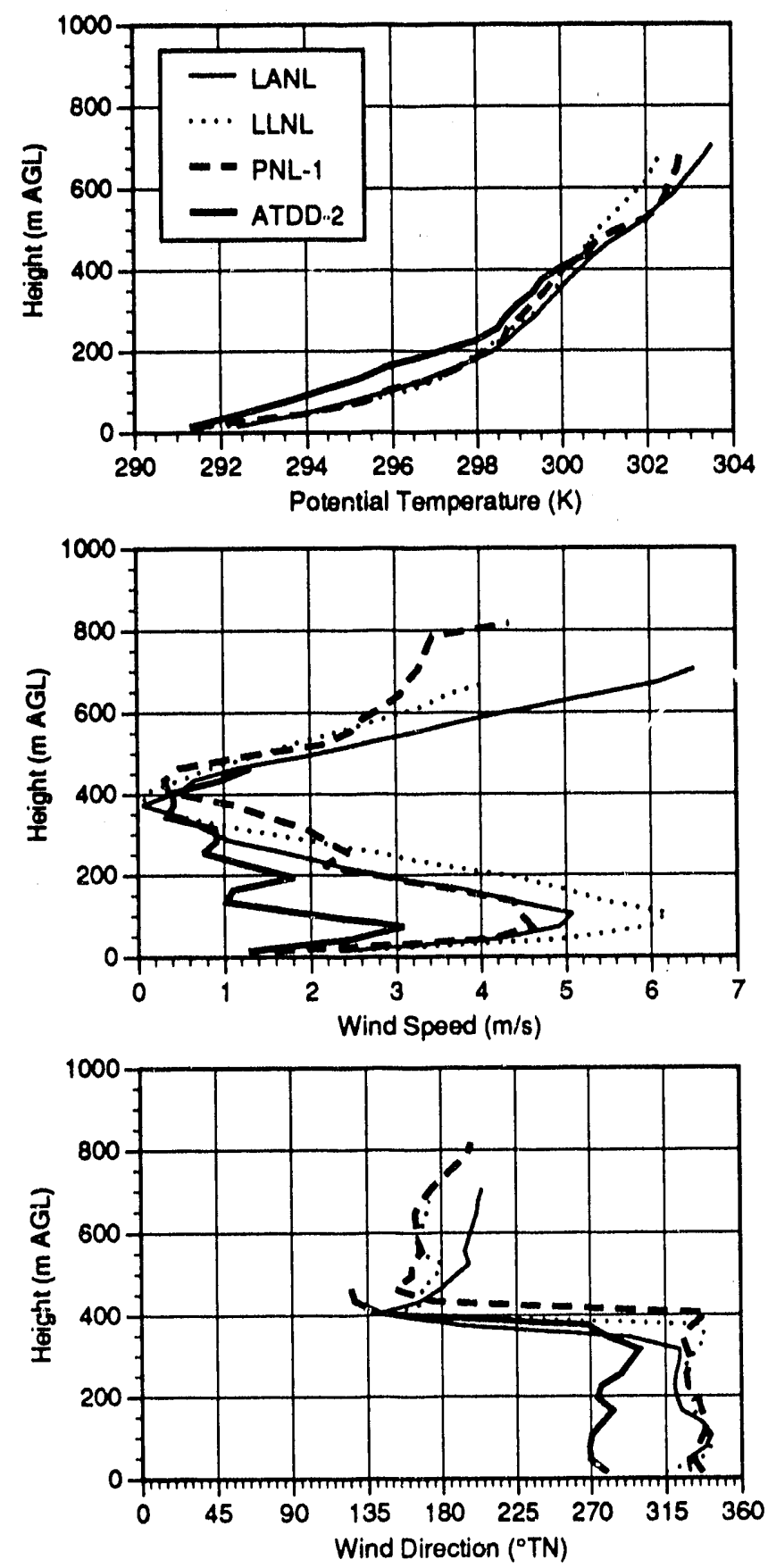

Figure 7. Nighttime average (0100-0530) profiles of potential temperature, wind speed and wind direction from 4 tethersondes located in the Brush Creek valley. The observations are on 9/26/84. 
The nighttime down-valley flows in the Brush Creek valley were observed to reach a maximum of around 5-6 m/s in a jet with its center about $80-100 \mathrm{~m}$ above the valley floor. The down-valley component of the winds decreased to zero at about $375 \mathrm{~m} \mathrm{AGL}$, switching to up-valley at this point due to the influence of the above ridgetop winds (Fig. 6). This shape of the vertical down-valley wind profile was observed on all experimental nights and was investigated and characterized by Clements et al. (1989). They were able to adequately describe the vertical profile of the down-valley winds by a non-dimensional function similar to a Prandtl profile

$$
\frac{U(z)}{u_{m}}=3.2 e^{-3.3 \frac{z}{D}} \sin \left(\pi \frac{z}{D}\right)
$$

where $u_{m}$ is the maximum down-valley wind speed in the profile and $D$ is the height above ground where the down-valley winds go to zero. The constants 3.2 and 3.3 are a result of the empirical fit to the data. Clements et al. used data from one measurement site in the Brush Creek valley (LANL site in Fig. 5) in deriving Eqn (1). The utility of Eqn (1) at other locations in the valley is investigated in Fig. 8, where the average (0100-0530) down-valley winds measured at other tethersonde sites on $9 / 26 / 84$ are compared with Eqn (1). The values of $u_{m}$ and $D$ are $5.5,4.6,5.8$ and $4.6 \mathrm{~m} / \mathrm{s}$, and $330,375,395$ and $420 \mathrm{~m} \mathrm{AGL}$, for WPL, LANL, LLNL and PNL-1, respectively. Eqn (1) adequately represents the nighttime average down-valley winds throughout the valley given $u_{m}$ and $D$ as a function of along-valley location.

Using a dynamic meteorological model, Doran (1991) investigated the effects of above-ridgetop wind speed and direction on the behavior of drainage winds in an idealized Brush Creek valley. He varied the ambient ridgetop wind 
speeds from 0.5 to $6 \mathrm{~m} / \mathrm{s}$, and the ridgetop wind directions from $0^{\circ}$ (directly upvalley) to $90^{\circ}$ (directly cross-valley) relative to the valley axis. He found that the depth and strength of the down-valley winds decreased with increasing ambient wind speeds but showed relatively little sensitivity to wind directions in the range of $10^{\circ}$ to $60^{\circ}$ to the valley axis. Doran determined that the depth of the drainage, $D$, varied roughly with the ambient ridgetop wind speed, $U_{a}$, as

$$
\frac{D}{H}=1-0.11 U_{a}
$$

where $\mathrm{H}$ is the depth of the valley. This relationship did not hold near the valley mouth.

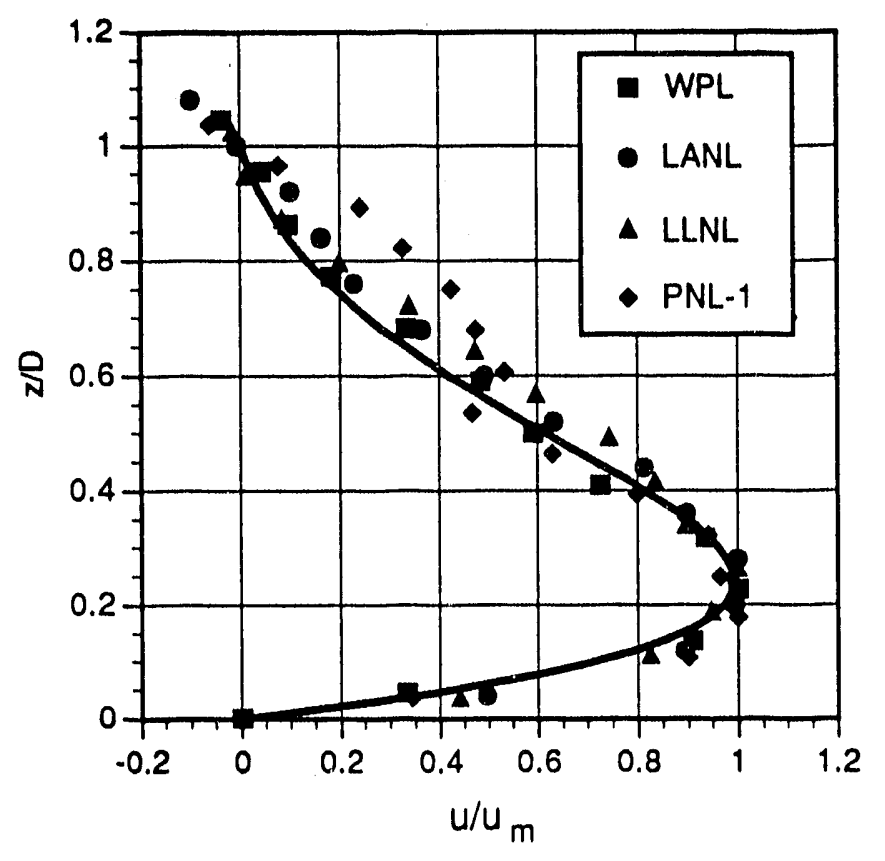

Figure 8. Nighttime average (0100-0530) dimensionless wind profile on 9/26/84 in the center of the Brush Creek valley at four along-valley locations. The curve is a plot of Eqn (1).

The nocturnal cross-valley structure of the down-valley winds was described empirically by Clements et al. (1989) using the down-valley winds measured throughout the Brush Creek valley with the Doppler lidar. This resulted in their 
extension of Eqn (1) to the "Prandtl-parabolic wind field" (PPWF) representing the down-valley winds in a valley cross section as

$$
\frac{u(y, z)}{u_{m}}=3.2 e^{-3.3 \frac{z}{D}} \sin \left(\pi \frac{z}{D}\right)\left[0.95-0.85\left(\frac{y}{W(z) / 2}\right)^{2}\right]
$$

where $W$ is the width of the valley as a function of $z$, and the constants 0.95 and 0.85 are fitting parameters. This PPWF is in a very appealing dimensionless form which may lend itself to more universal application to valleys. However, determining the general applicability of Eqn (3) will require much additional investigation. Eqn (3) forms the basis of the description of the winds used in the nighttime dispersion analysis that follows.

The character of the nighttime turbulence responsible for the diffusion of the tracer is identified using two approaches, directly measured lateral and vertical turbulence levels, and estimates of the near surface vertical diffusivity of heat and momentum. Table 8 gives the nighttime average (0200-0700) of the half-hourly turbulence statistics for the early morning of $9 / 26 / 84$ measured on four towers (Fig. 5). These values of the lateral $\left(\sigma_{v}\right)$ and vertical $\left(\sigma_{w}\right)$ turbulence statistics are used in the nighttime dispersion analysis that follows.

The vertical fluxes of heat and momentum measured in the surface layer in the Brush Creek valley are discussed by Doran et al. (1989). The averages (0200-0700) of the half-hour vertical surface momentum flux, $u_{*}{ }^{2}$, and vertical surface heat flux, $Q_{h}$, for the early morning of 9/26/84 measured on four towers are given in Table 8. Considering the flux to be proportional to the gradient ( $K$ theory) gives the turbulent diffusivities of heat $\left(K_{h}\right)$ and momentum $\left(K_{m}\right)$ as

$$
K_{h}=\frac{Q_{h}}{\rho C_{p} \partial \theta / \partial z} ; \quad K_{m}=\frac{u_{s}^{2}}{\partial u / \partial z}
$$


where

$\rho$ is the air density $\left[1 \mathrm{~kg} / \mathrm{m}^{3}\right]$,

$C_{p}$ is the specific heat of dry air at constant pressure [1005 $\left.\mathrm{m}^{2} / \mathrm{s}^{2}-\mathrm{K}\right]$,

$\partial \theta / \partial z$ is the gradient of the surface potential temperature $[\mathrm{K} / \mathrm{m}]$, and

$\partial u / \partial z$ is the gradient of the surface down-valley winds $[\mathrm{m} / \mathrm{s}-\mathrm{m}]$.

The average gradients of potential temperature and wind speed determined from the near surface profiles (least-squares fit to LANL, LLNL, and PNL-1 tethersonde data in Fig. 7) are $0.056 \mathrm{~K} / \mathrm{m}\left(r^{2}=0.9\right)$ and $0.056 \mathrm{~m} / \mathrm{s}-\mathrm{m}\left(r^{2}=0.7\right)$, respectively. The turbulent diffusivities of heat and momentum determined using Eqn (4) and the average values of $Q_{n}$ and $u_{*}^{2}$ in Table 8 , are 0.37 and $0.29 \mathrm{~m}^{2} / \mathrm{s}$, respectively. These values can be considered to represent the approximate vertical diffusivity of tracer, $K_{z}$, for this ground-level release. A $K_{z}$ value of $0.33 \mathrm{~m}^{2} / \mathrm{s}$ will be used in the diffusion analysis.

TABLE 8. Ave. (0200-0700 MST) Turbulence Quantities and Fluxes on 9/26/84 from the Towers.

\begin{tabular}{cccccc}
\hline Tower ID & $\begin{array}{c}\text { Height } \\
\text { (m AGL) }\end{array}$ & $\begin{array}{c}\sigma_{v} \\
(\mathrm{~m} / \mathrm{s})\end{array}$ & $\begin{array}{c}\sigma_{w} \\
(\mathrm{~m} / \mathrm{s})\end{array}$ & $\begin{array}{c}\mathrm{u}^{2} \\
\left(\mathrm{~m}^{2} / \mathrm{s}^{2}\right)\end{array}$ & $\begin{array}{c}Q_{h} \\
\left(\mathrm{~W} / \mathrm{m}^{2}\right)\end{array}$ \\
\hline LANL-3 & 12 & 0.29 & 0.13 & 0.011 & - \\
WPL-1\&2 & 3 & 0.42 & 0.22 & 0.020 & 18 \\
ATDD-1 & 8 & 0.15 & 0.02 & 0.017 & 23 \\
\hline Average & - & 0.29 & 0.12 & 0.016 & 21 \\
\hline
\end{tabular}

The tracer mass budget within the Brush Creek valley will be used to estimate the ventilation rate of tracer from the valley to above ridgetop flows during the morning transition period. The tracer mass budget is estimated from measured tracer concentrations and winds. The tracer budget, however, can be no more reliable than the air mass budget. Estimating the budget of air mass in the Brush Creek valley from measurements of winds is fairly straightforward, primarily because the valley winds blow in one dominant direction. The Doppler 
lidar contributed immensely to refining mass budget calculations by allowing the complete cross-sectional profile of the down-valley winds to be viewed. This was the basis of Clements et al. (1989) PPWF representation of the winds, as described previously. The nighttime average down-valley air mass flow rate in the Brush Creek valley during the 1984 ASCOT experiments has been previously described (Clements et al., 1989; Dobosy et al., 1989; and Neff, 1990) from the measurement of winds.

Complete closure of the air mass budget in the Brush Creek valley by measurements was not possible because of the difficulty in diræctly measuring the inflow of air from above and from the tributaries of the Brush Creek valley. The average (0000-0400 MST) divergence of the down-valley air mass in the Brush Creek valley on 9/26/84 was estimated to be about $20 \mathrm{~kg} / \mathrm{s}-\mathrm{m}$ from the lidar measurements (Dobosy et al., 1989). Based on other analyses of the mass flow in the Brush Creek valley (Whiteman and Barr, 1986, and Coulter et al., 1989), Dobosy et al. (1989) speculate that the source of this air is primarily by direct subsidence with a small percentage from tributary flows. However, they state that further analyses are necessary to better determine the sources of air mass in valley drainage flows, in light of Porch et al.'s (1989) results that $5-15 \%$ of the down-valley mass flow in the Brush Creek valley may be due to flow from one tributary (Pack Canyon).

The down-valley air volume flow rate (air volume flow rate and air mass flow rate are equal assuming an air density of $1 \mathrm{~kg} / \mathrm{m}^{3}$ ) at a valley cross section was calculated by two methods, numerical integration of the lidar data, and integration of the sodar (LANL and PNL) and tethersonde (WPL, LANL, LLNL and PNL-1) data using a parabolic [term in square brackets in Eqn (3)] cross-valley wind 
profile. Table 9 gives the down-valley air volume flow rates at 4 cross sections in the valley, WPL tethersonde site, LANL tethersonde site, Arc 2 and Arc 1. The valley average air volume flow rates (average of the values at the four cross sections), from the lidar and tethersondes, given in Table 9 compare to within $8 \%$ of the valley average reported by Dobosy et al. (1989). The air volume flow divergence (change in air volume flow with down-valley distance) determined from a linear regression of the values in Table 9 (Fig. 9) is $65 \mathrm{~m}^{3} / \mathrm{s}-\mathrm{m}$ from the tethersonde data, and $33 \mathrm{~m}^{3} / \mathrm{s}-\mathrm{m}$ from the lidar data. These divergence values are roughly $30 \%$ and $50 \%$ greater than those determined by Dobosy et al. The best measures of the air volume flow rate and divergence are discussed in a later section.

TABLE 9. Average (0200-0700 MST) Valley Air Mass Flow Rates on 9/26/84 from the Lidar, Sodars and Tethersondes.

\begin{tabular}{cccccc}
\hline $\begin{array}{c}\text { Cross } \\
\text { Section }\end{array}$ & $\begin{array}{c}\text { Depth } \\
\text { (m MSL) }\end{array}$ & $\begin{array}{c}\text { Area } \\
(\mathrm{sq} . \mathrm{km})\end{array}$ & $\begin{array}{c}\text { Lidar } \\
\left(105 \mathrm{~m}^{3} / \mathrm{s}\right)\end{array}$ & $\begin{array}{c}\text { Sodar } \\
\left(105 \mathrm{~m}^{3} / \mathrm{s}\right)\end{array}$ & $\begin{array}{c}\text { Tethersonde } \\
(105 \mathrm{~m} / \mathrm{s})\end{array}$ \\
\hline WPL & 224.0 & .21 & 3.0 & - & 3.4 \\
LANL & 2230 & .23 & 3.3 & 3.7 & 3.4 \\
Arc 2 & 2170 & .27 & 4.2 & - & 6.3 \\
Arc 1 & 2160 & .45 & 5.6 & 6.5 & 7.7 \\
\hline Average & 2200 & .29 & 4.1 & - & 5.2 \\
\hline
\end{tabular}

The down-valley winds at the valley release location were measured using a tethersonde (WPL) flown every $11 / 2 \mathrm{~h}$. The winds measured by the WPL tethersonde are compared with the LANL sodar (15 min. average) winds in Fig. 10. The comparison is made at the height of the maximum observed winds ( 100 $m$ AGL). The agreement is within $5 \%$ on the average, and gives confidence that the time variation in the winds measured at the LANL sodar site can be used to represent the winds at the valley release location. Since the winds at the tracer release height were not measured, Eqn (1) was used to estimate the winds at the release height. The time variation of the winds at $10 \mathrm{~m} \mathrm{AGL}$ at the valley release 
site determined using Eqn (1) [D = $330 \mathrm{~m} \mathrm{AGL}, z=10 \mathrm{~m} \mathrm{AGL}$, and $\mathrm{um}_{\mathrm{m}}$ from LANL $105 \mathrm{~m}$ AGL sodar winds] is given in Fig. 10.

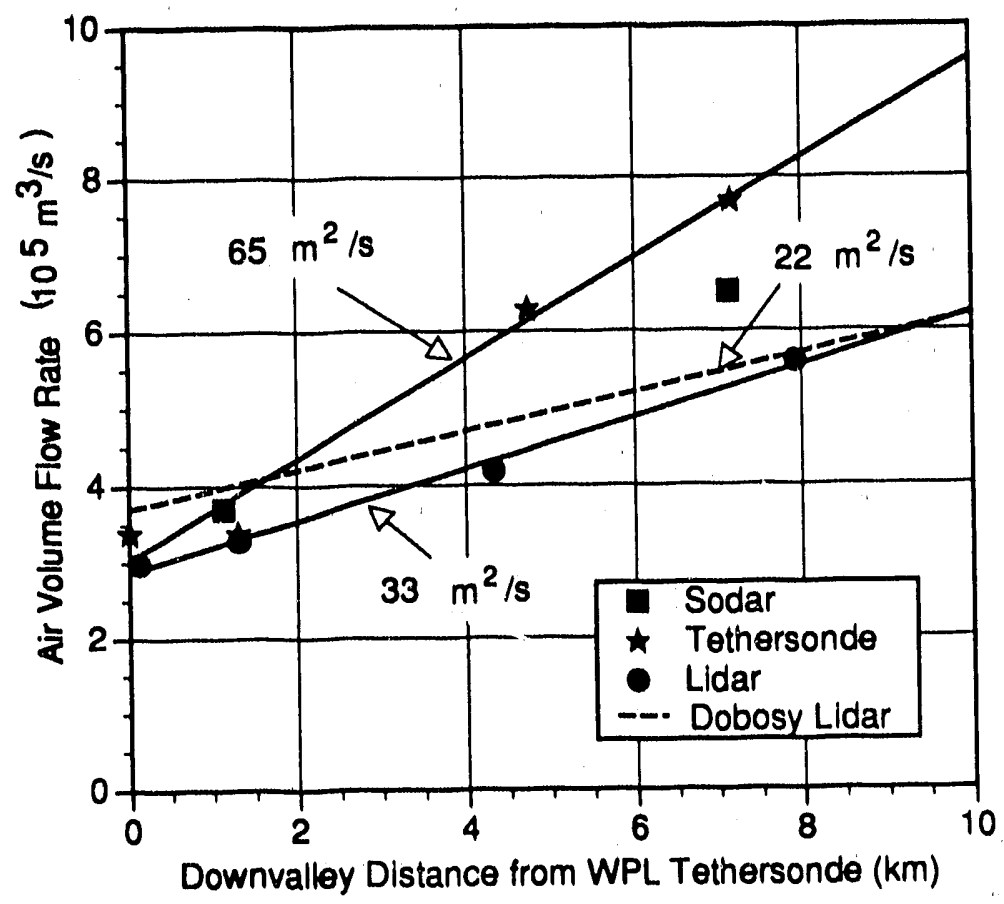

Figure 9. Nighttime average (0100-0530) down-valley air volume flow rate in the Brush Creek valley below $\sim 2200 \mathrm{~m}$ MSL on 9/26/84. Flow rates determined from tethersonde $(\star)$ and lidar $(\bullet)$ observations are given at 4 along-valley locations, and flow rates determined from sodars ( $匚$ ) are given at two locations (see Table 9). The two solid lines represent the results of least-sqaures regressions to the tethersonde and lidar data. Given for reference are the lidar results of Dobosy et al. (1989).

The time variation in the 15-min.-average down-valley winds at the LANL sodar site is reasonably steady through the period 0200-0700 MST $\left(\sigma_{u} / U=\right.$ $0.21 / 1.5=14 \%$, at $10 \mathrm{~m} \mathrm{AGL}$ ). This is significant from the aspect of dispersion because this proccss will not cause the hourly average concentrations to vary significantly with time through the night. Consequently, a steady solution to the "averaged" dispersion process can be assumed; as is discussed later. The 02000700 MST average down-valley wind speed at the valley release location at 10 
$\mathrm{m}$ AGL is $1.5 \mathrm{~m} / \mathrm{s}$. This average wind speed will be used later for computing the nighttime ground-level tracer concentration.

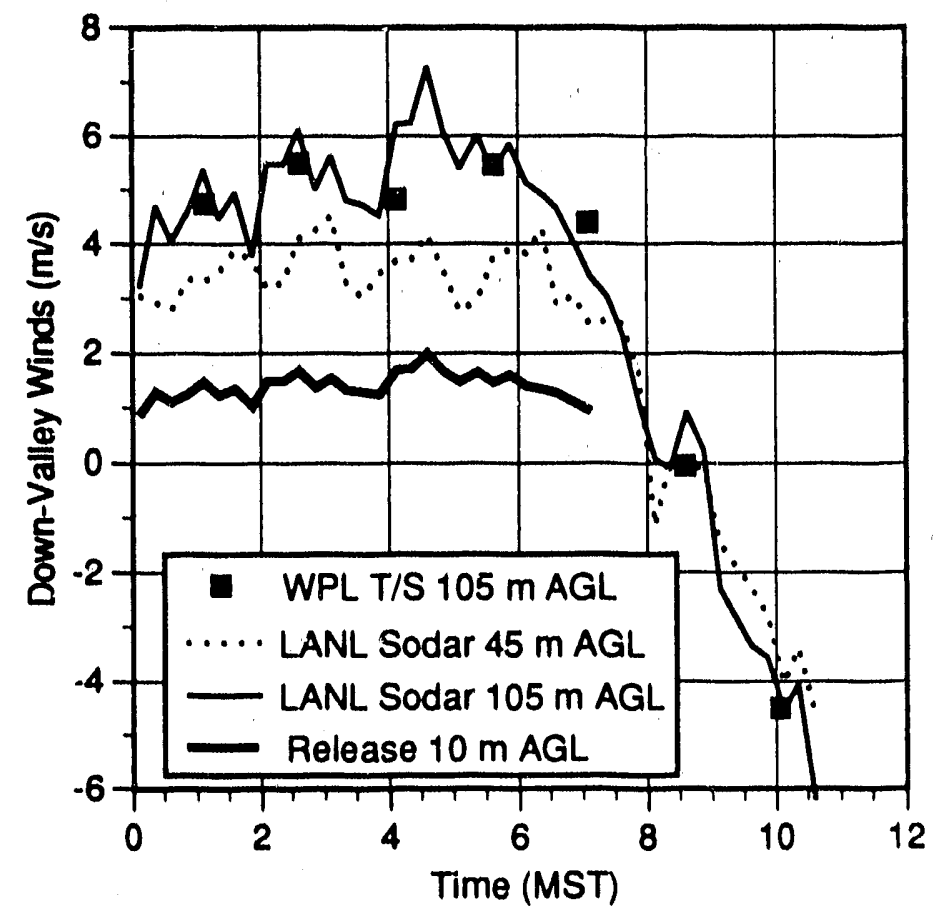

Figure 10. Down-valley winds at the release location on 9/26/84 estimated from nearby wind measurements from a sodar (LANL) and tethersonde (WPL).

c. Daytime meteorology

Figure 10 shows the 15 -min.-average down-valley winds measured by the LANL sodar through the morning hours of $9 / 26 / 84$ at 45 and $105 \mathrm{~m} \mathrm{AGL}$. Beginning at about astronomical sunrise ( 0615 MST), the maximum downvalley winds in the valley begin to decrease, cross through zero (switch to upvalley), and then increase in the up-valley direction at a nearly constant rate ( 2.5 $\mathrm{m} / \mathrm{s}-\mathrm{h})$. The winds switch from generally down-valley to up-valley throughout the valley at about $0845 \mathrm{MST}$. This time behavior of the maximum winds in the valley can be approximated by

$$
\frac{u_{m}(t)}{u_{m}\left(t_{s r}\right)}=\frac{t_{r e v}-t}{t_{r e v}-t_{s r}} ; \quad t_{s r} \leq t \leq t^{\prime}
$$


where $t_{s r}$ is the time of astronomical sunrise, $t_{r e v}$ is the time of wind reversal in the valley, and $t^{\prime}$ is some time after trev but before the time of maximum up-valley winds.

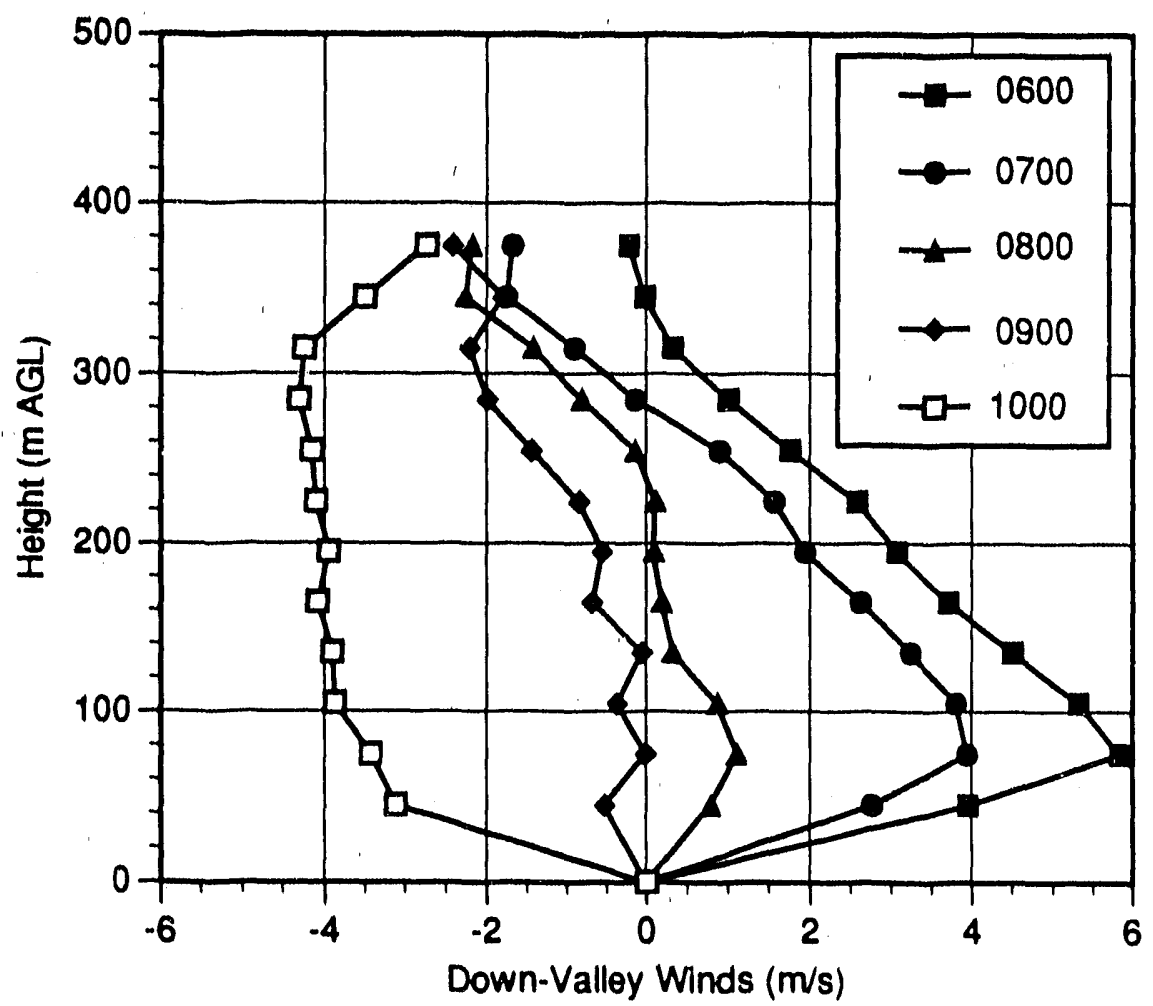

Figure 11. Hour average down-valley winds on 9/26/84 determined from the LANL sodar observations.

Vertical profiles of hourly average down-valley winds measured by the LANL sodar are shown in Fig. 11 for 0600 through 1000 MST. The daytime upvalley winds have a much "flatter" profile than the nighttime down-valley winds. This is indicative of the greater vertical momentum transport during the daytime due to convective mixing. Vertical profiles of potential temperature, wind speed and wind direction measured by the WPL, LANL, LLNL and PNL-1 tethersondes are given in Fig. 12 for the morning hours. All the locations exhibit a similar behavior with complete flow reversal from down-valley to up-valley by the 1000 MST sounding. The surface-based temperature inversion is destroyed 
throughout the morning with the growth of a CBL. The winds above the ridgetops switch from southwesterly to westerly and maintain speeds from 2 to $4 \mathrm{~m} / \mathrm{s}$.

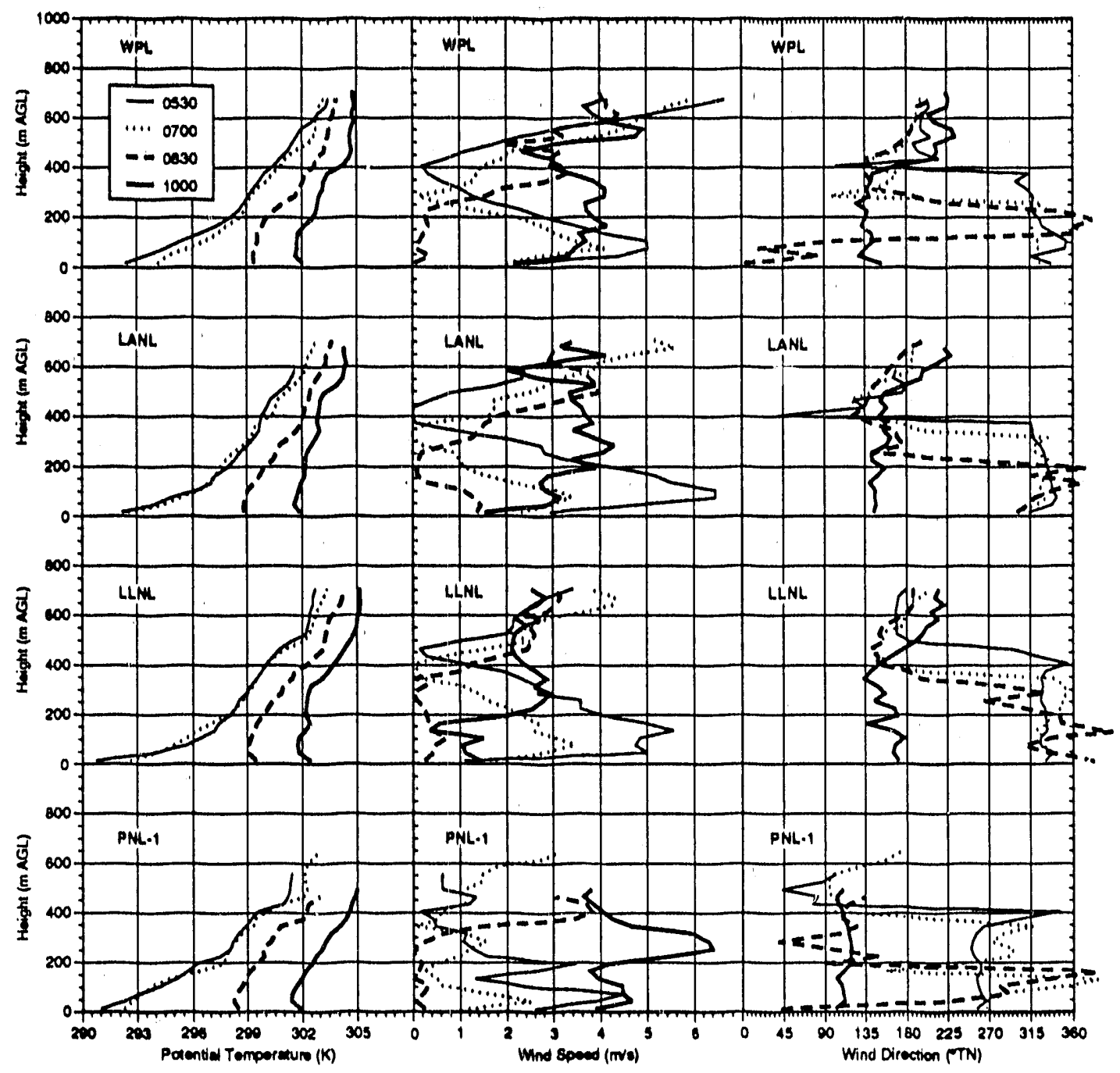

Figure 12. Tethersonde (WPL, LANL, LLNL and PNL-1) observations of potential temperature, wind speed and wind direction on the morning (05301000 ) of $9 / 26 / 84$.

The tracer experiment was designed to allow the calculation of the ventilation rate as a residual in a tracer mass budget. The wind fields used in the tracer mass budget calculations are a combination of the lidar and tethersonde profiles of winds. The cross-valley structure of the winds when using tethersonde data is that of Clements et al. (1989) described earlier. A comparison of the 
down-valley air volume flow rates at four valley cross sections is given in Fig. 13. The air volume flow divergence at $1000 \mathrm{MST}$ is $-2.4 \mathrm{~m}^{2} / \mathrm{s}$ (negative sign indicates flow out the top of the valley atmosphere) which is roughly one-third of the nighttime divergence of $65 \mathrm{~m}^{2} / \mathrm{s}$ (positive sign indlcates flow into the valley).

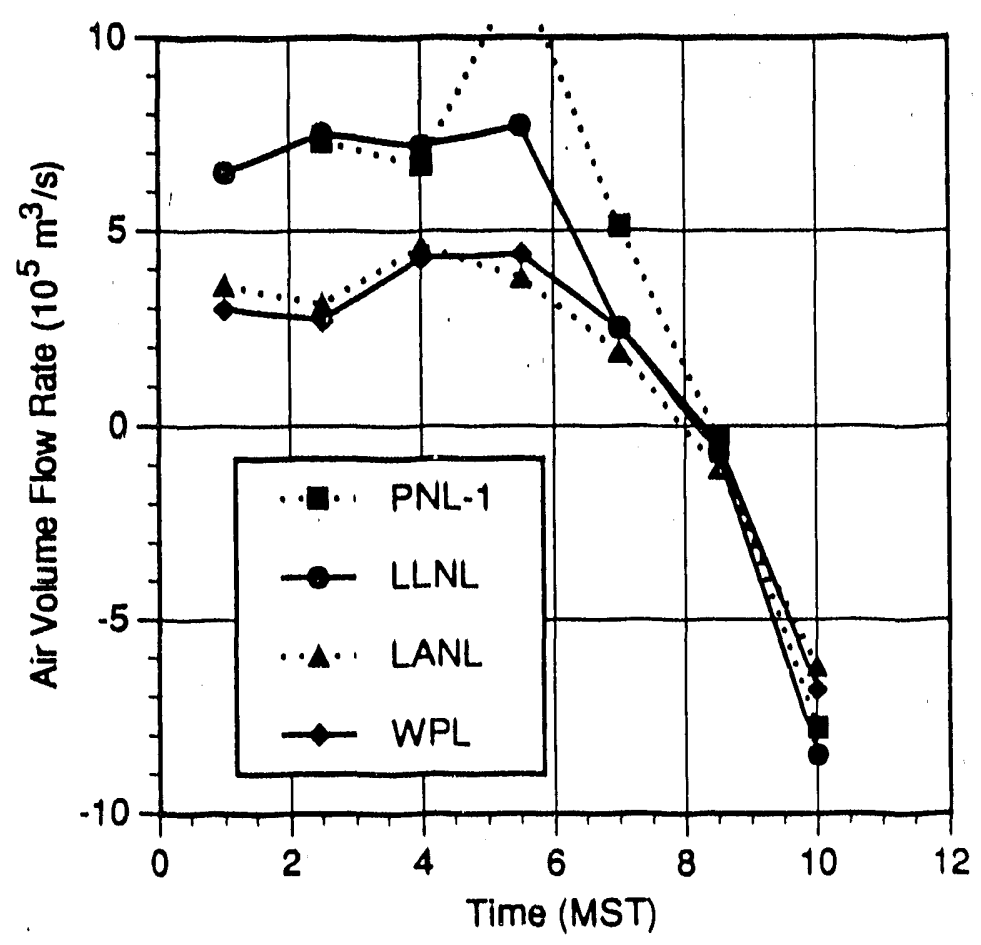

Figure 13. Time variation of the down-valley air volume flow rates in the Brush Creek valley determined for each sounding from four tethersondes.

Hourly average tracer mass budgets are calculated later. The hourly average wind fields at Arc 1 and Arc 2 used in these calculations are determined from interpolation/extrapolation of the 0530, 0700, 0830 and 1000 MST tethersonde soundings to the hour midpoint times of $0730,0830,0930$ and 1030 MST.

d. Nighttime concentrations and dispersion rates

Fig. 14 gives the nocturnal ground-level concentrations at select locations within the Brush creek valley and adjacent valleys. This figure shows the 
56

concentrations to be fairly steady after about 0200 MST. Looking at the crossvalley structure of the three tracers averaged from 0200-0700 at Arc 1 and Arc 2 (Fig. 15) shows the effects of release location and down-valley distance on tracer concentrations. These effects are also revealed in Fig. 16 in terms of the alongvalley concentration isopleths. It can be noted in Figs 15 and 16 that the vertical profiling of tracer added considerably to defining the spatial distribution of tracer concentration.

Investigating the PMCP concentrations (Fig. 15, we see that the tracer plume moves down the Pack Canyon drainage. However, the plume centerline does not follow along the Pack Canyon floor to the floor of the Brush Creek valley, but rather it remains elevated is it enters the Brush Creek valley and hugs the east sidewall of the Brush Creek valley. A portinr. of the PMCP plume also heads over Skinner Ridge in the westerly winds above the ridgetops (see, for example, locations AA09, BB25 and BB26 in Fig. 17). Another interesting observation is that the PMCP plume extends up-valley from Pack canyon. The mechanism for this appears to be the up-valley winds in the canyon above $2300 \mathrm{~m} \mathrm{MSL} \mathrm{(Fig.} \mathrm{7).}$ A portion of the plume is carried up-valley above $2300 \mathrm{~m} \mathrm{MSL}$ and is subsequently mixed downward into the down-valley flows below $2300 \mathrm{~m} \mathrm{MSL}$ giving the up-valley "nose" in the top frame of Fig. 16.

A numerical solution of the advection-diffusion equation would probably be necessary to simulate the concentration field resulting from the Pack Canyon release. An analytical solution to the advection-diffusion equation would not be possible because of the complexity of the flow. 


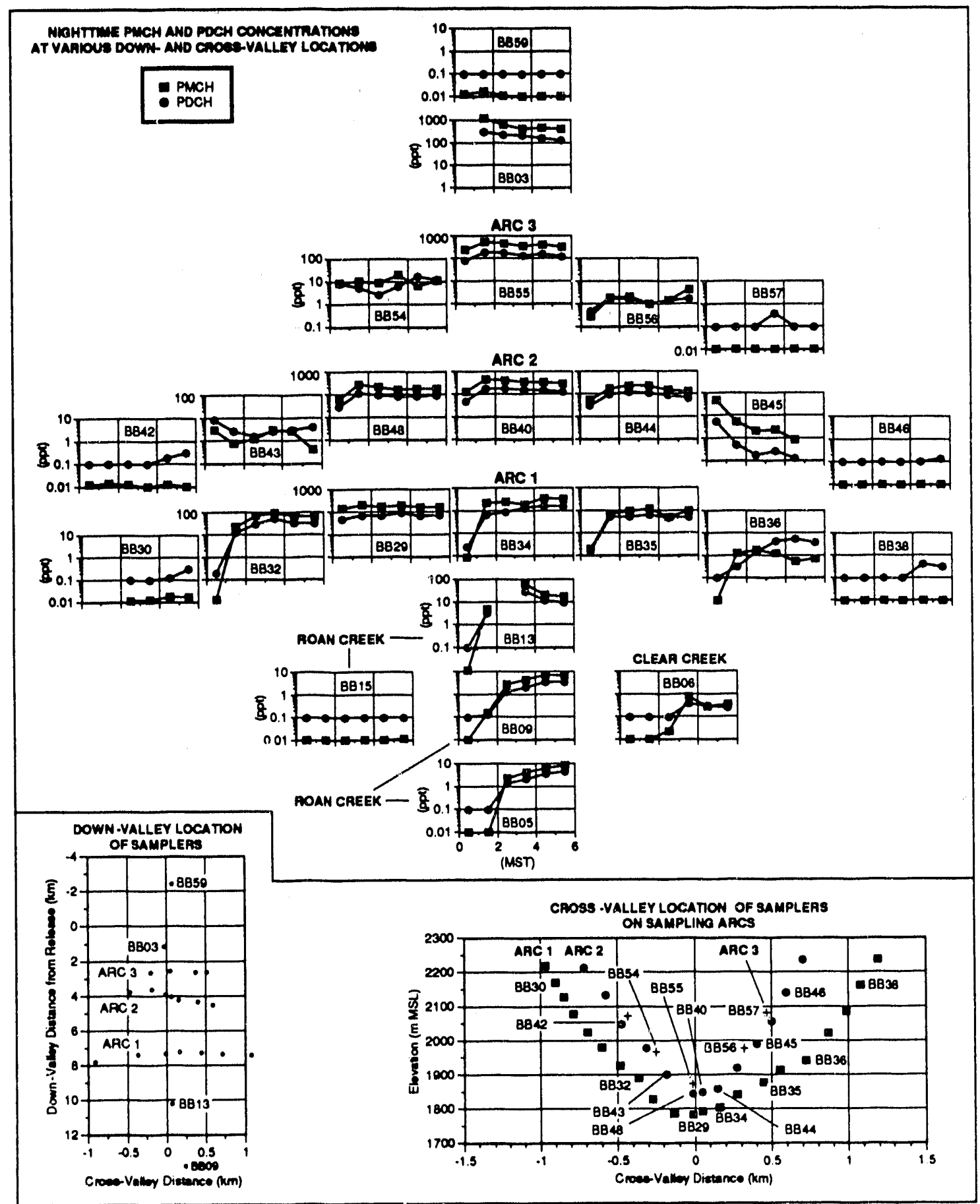

Figure 14. Time variations in the 9/26/84 hour-average nighttime $\mathrm{PMCH}$ and PDCH concentrations measured by certain ground-level samplers in the Brush Creek valley. The lower section of the figure gives the downvalley and cross-valley locations of the samplers. 

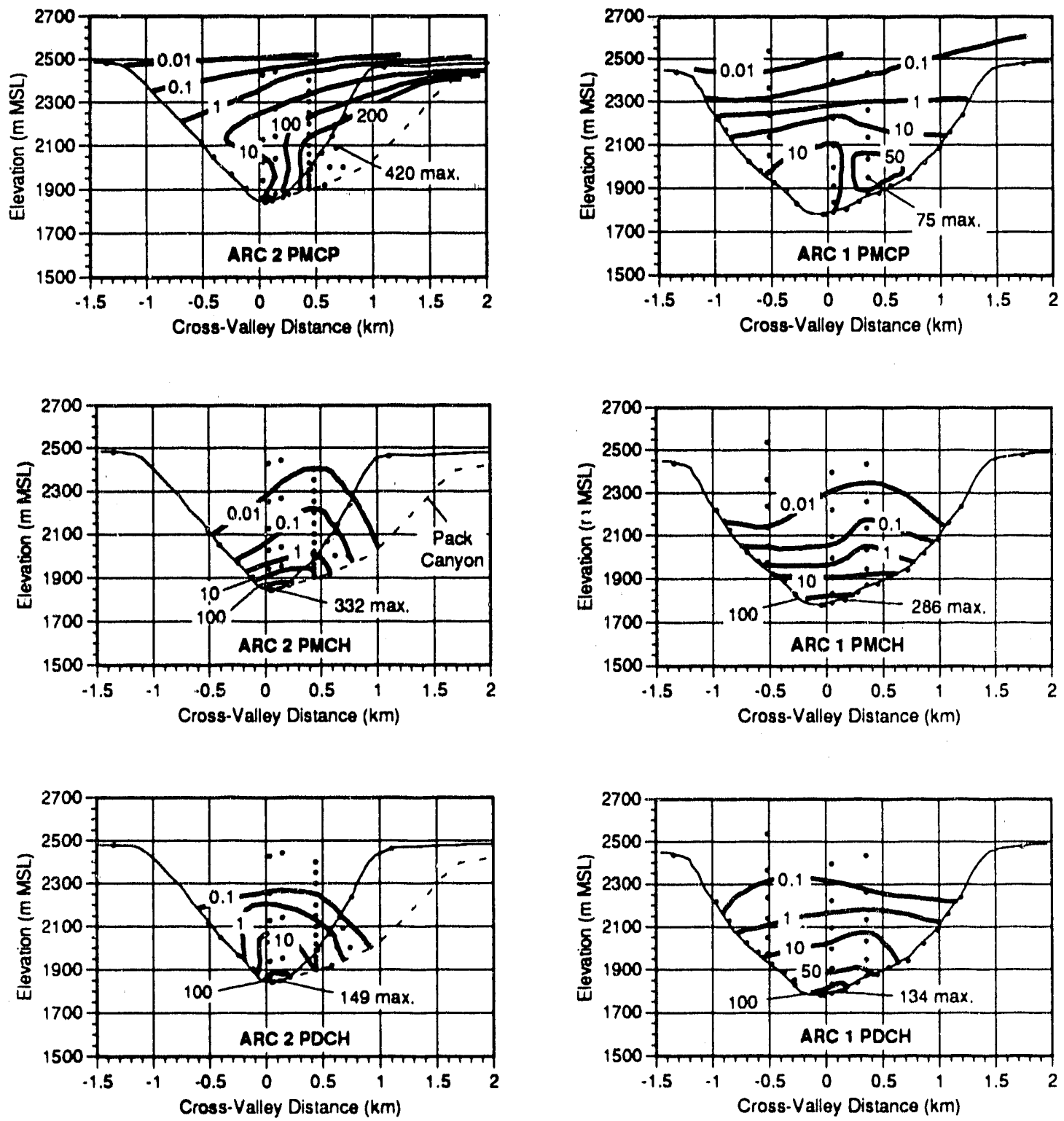

Figure 15. Cross-valley isopleths of the nighttime average (0200-0700) PMCP, $\mathrm{PMCH}$ and $\mathrm{PDCH}$ concentrations for 9/26/84 in the Brush Creek valley. The locations of all of the samplers $(\bullet)$ used to contour the concentrations are shown along with the ground profile (fine solid line). The dashed line in the Arc 2 plots shows the 'fall' line of the lowest elevations of Pack canyon from near ridgetop (Skinner ridge) to the floor of the Brush Creek valley. 

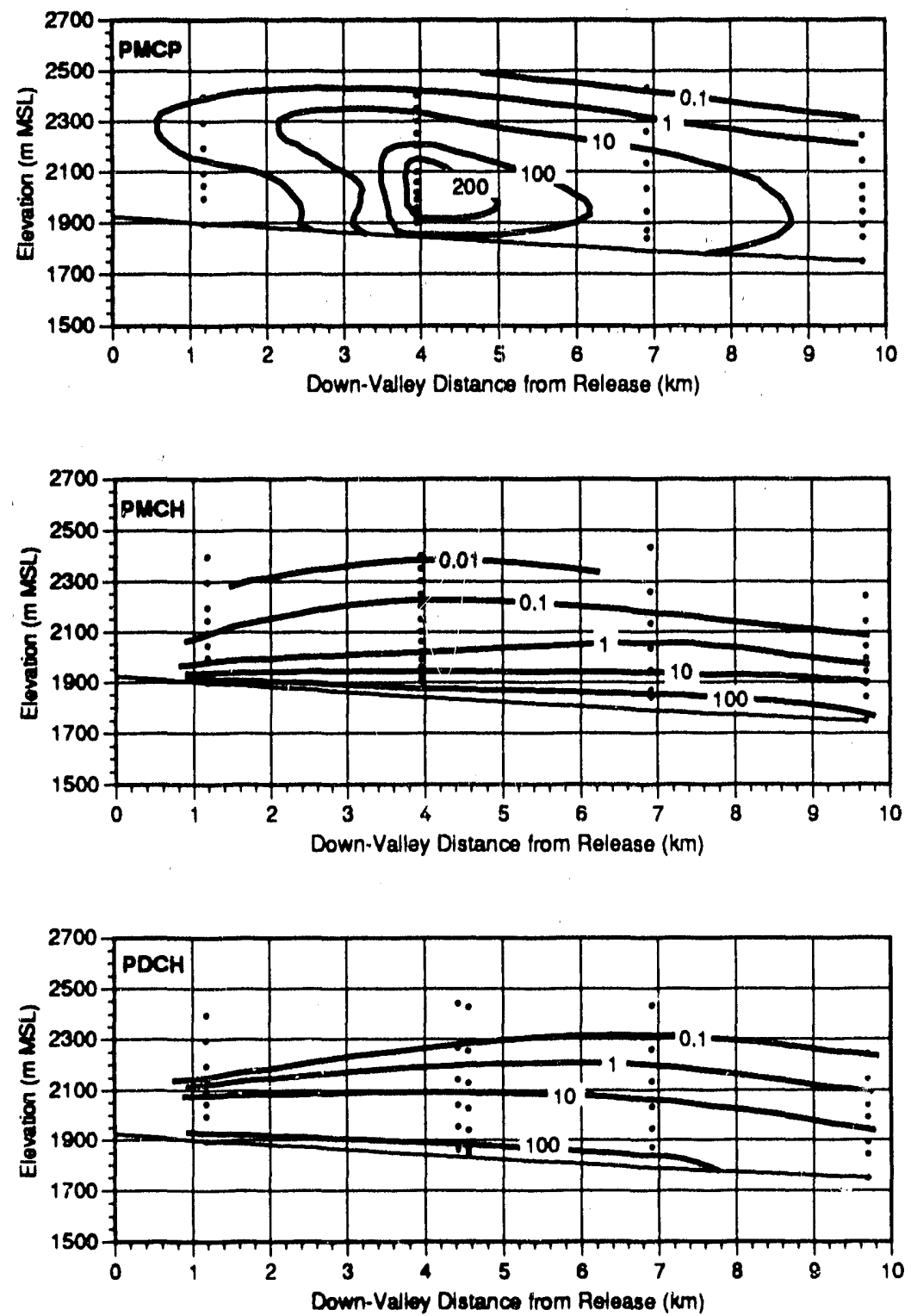

Figure 16. Down-valley isopleths of the nighttime average (0200-0700) PMCP, PMCH and PDCH concentrations for $9 / 26 / 84$ in the Brush Creek valley. The locations of all of the vertical samplers $(\bullet)$ used to contour the concentrations are shown along with the profile of the Brush Creek valley floor (fine solid line). 

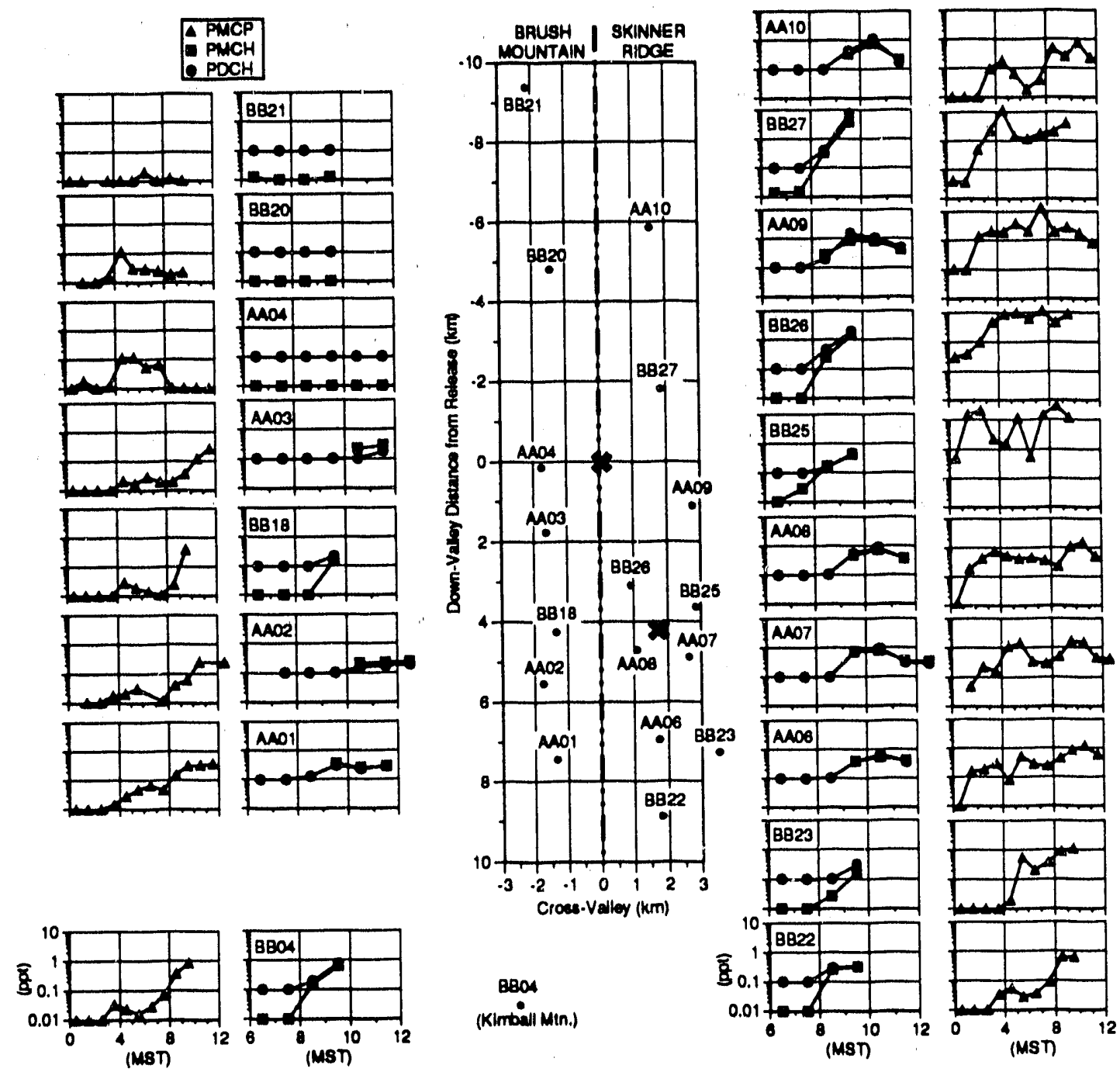

Figure 17. Time variations in the hour-average PMCP, $\mathrm{PMCH}$ and $\mathrm{PDCH}$ concentrations measured at the ridgetop samplers on $9 / 26 / 84$. The $\mathrm{PMCH}$ and $\mathrm{PDCH}$ concentrations are given from 0600 instead of from 0000 as for PMCP, because the PMCH and PDCH concentrations were at background throughout the night (0000-0600). The down-valley locations of the samplers $(\bullet)$ relative to the release locations $(\boldsymbol{H})$ are given in the middle plot.

The $\mathrm{PMCH}$ and $\mathrm{PDCH}$ concentration patterns are more easily described using available formulations for dispersion in steady conditions. Both the $\mathrm{PMCH}$ and PDCH releases behaved as ground-level releases. However, the PDCH release was supposed to be at about $180 \mathrm{~m}$ AGL (Table 3 ). This is clearly not 
indicated by the concentration patterns in the bottom panels in Figs. 16 and 17. It appears that the PDCH release was partly elevated (as indicated by the deeper concentration isopleths than the PMCH release) with a majority of the release at ground-level. A possible explanation is an undetected leak in the tubing at ground level. Tracer mass budget calculations, presented later, yeild a release rate of PDCH equal to that reported in Table 3. Consequently, the leak was probably after the tracer metering controls. Describing mathematically the concentration patterns of the PDCH release will not be pursued because of the uncertainty in the release geometry. However, because the release rate was constant, analysis of the PDCH results is useful in the ventilation rate discussions. Neither PMCH or PDCH were observed at ridgetops during the night. The tracer plumes were fully contained within the valley.

The average (0200 to $0700 \mathrm{MST}$ ) mass budget of tracer was computed on a control volume (CV) of the Brush Creek valley atmosphere bounded by the Arc 2 cross section on the up-valley side, the Arc 1 cross section on the down-valley side, the $2200 \mathrm{~m} \mathrm{MSL}$ height surface on the top, and the valley floor and sidewalls. The tracer mass budget is used to determine the correct measure of the air volume flow rate reported in Table 9, and to determine the tracer ventilation rate during the morning transition period. The budget was calculated using the PMCH and PDCH tracer results given in Fig. 15 and the down-valley winds discussed previously. The time-average tracer mass budget equation applying to the control volume is

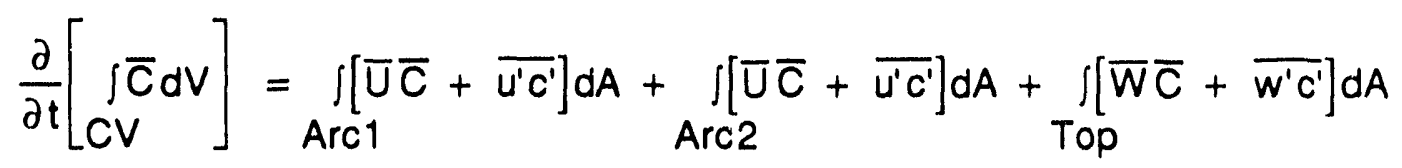


62

The sign convention for the RHS (right-hand-side) terms is " + " into the CV and "-" out of the CV. The LHS (left-hand-side) term is the "storage" of tracer within the control volume. This term is negligible during the near-steady nighttime. The last term on the RHS of Eqn (6) is the flow of tracer through the top of the control volume at $2200 \mathrm{~m} \mathrm{MSL}$, and is negligible at night as indicated by the near background levels of PMCH ( 0.01 ppt) and PDCH ( 0.1 ppt) at the $2200 \mathrm{~m} \mathrm{MSL}$ height (Fig. 15). The first and second terms on the RHS of Eqn (6) are the flow of tracer through the valley cross sections at Arc 1 and Arc 2, respectively. The along-valley diffusion of tracer $\left(\overline{u^{\prime} c^{\prime}}\right)$ is assumed small (and neglected) compared to the along-valley advection ( $\bar{U} \bar{C})$. Consequently, during the nighttime, Eqn (6) reduces to

$$
\left.0=\underset{A \operatorname{Arc} 1}{\int[\overline{\mathrm{C}}]}\right] \mathrm{dA}+\underset{\operatorname{Arc2}}{\int[\bar{U} \bar{C}] d A}
$$

The two terms in Eqn (7) are evaluated from the measured tracer concentrations and the down-valley winds measured by the tethersondes and the lidar. The results are given in Table 10. First, the worst-case difference between the two terms in Eqn (7) for the results presented in Table 10, is approximately $10 \%$. This can be considered as the "precision" in the tracer mass budget method used here. Since the release rates of the $\mathrm{PMCH}$ and $\mathrm{PDCH}$ tracer are nearly identical ( 0.23 vs $0.24 \mathrm{~g} / \mathrm{s}$ - Tables 2 and 3 ), and the tracer fluxes through Arc 1 and Arc 2 are similar, the results in Table 10 are combined for comparing the tethersonde and lidar results. The average tracer flow calculated using the tethersonde winds is $0.226 \mathrm{~g} / \mathrm{s}$, and using the lidar winds is $0.173 \mathrm{~g} / \mathrm{s}$. The average reported tracer (PMCH and $\mathrm{PDCH}$ ) release rate is $0.235 \mathrm{~g} / \mathrm{s}$. 
The tracer mass flow rate calculated using the tethersonde winds agrees to within $5 \%$ of the reported release rate, and the tracer mass flow rates calculated using the lidar winds agree to within $30 \%$. The conclusion from this is that the better measure of the air volume flow rate in the Brush Creek valley is determined by using vertical profiles of winds measured by tethersondes with the cross-valley structure of the winds inferred from the lidar data, rather than the lidar data exclusively. In the strictest sense, however, since $95 \%$ of the tracer mass flow occurred in $60 \%$ of the air volume flow (lowest half of the valley flow - 1800 to $2000 \mathrm{~m} \mathrm{MSL}$ ), the more definitive conclusion is that the tethersonde winds better represent the air volume flow rate in the lowest $200 \mathrm{~m}$ of the Brush Creek valley than the lidar winds.

Based on the results given in Table 10, the lidar is underpredicting the air volume flow rate in the Brush Creek valley by roughly $30 \%$. This suggests that Dobosy et al.'s (1989) statement that "For estimating budgets, a Doppler lidar or an equivalent remote sensor is necessary" needs to be revised to reflect that a lidar is a valuable tool for determining the cross-valley structure of the winds, but at least currently, more accurate measures of the absolute magnitude of the winds are also required.

TABLE 10. Average (0200-0700 MST) Valley Tracer Mass Flow Rates on 9/26/84 Using the Tethersonde and Lidar Down-valley Winds.

\begin{tabular}{l|c|c|c|c}
\hline \multirow{3}{*}{ Tracer } & \multicolumn{2}{|c|}{ Tethersonde } & \multicolumn{2}{c}{ Doppler Lidar } \\
\cline { 2 - 5 } & Arc 2 & Arc 1 & Arc 2 & Arc 1 \\
& $(\mathrm{g} / \mathrm{s})$ & $(\mathrm{g} / \mathrm{s})$ & $(\mathrm{g} / \mathrm{s})$ & 0.168 \\
\hline $\mathrm{PMCH}$ & 0.239 & 0.218 & 0.164 & 0.182 \\
\hline $\mathrm{PDCH}$ & 0.210 & 0.238 & 0.177 & 0.182 \\
\hline
\end{tabular}

The PMCH tracer plume followed along the floor of the valley dispersing both laterally and vertically. The progression from Arc 2 to Arc 1, in Panel B of Fig. 15, shows the plume becoming nearly uniformly mixed across the valley by 
64

the time it reached Arc 1. Given the nearly steady meteorological and release conditions throughout the night, it seemed appropriate to compare the measurements with estimates from a Gaussian plume equation. The plume centerline concentrations at ground-level were computed as

$$
\chi=C_{u} \frac{Q_{s}}{\pi U_{s}} \frac{F_{y}}{\sigma_{y}} \frac{F_{z}}{\sigma_{z}}
$$

where

$\chi$ is the ground-level centerline concentration [ppt],

$Q_{s}$ is the tracer release rate $[\mathrm{g} / \mathrm{s}]$,

$U_{s}$ is the wind speed at the release point $[\mathrm{m} / \mathrm{s}]$,

$\sigma_{y}$ is the measure of the lateral plume spread [m],

$\sigma_{\mathbf{Z}}$ is the measure of the vertical plume spread [m],

$F_{y}$ is the term accounting for multiple reflections from the valley sidewalls,

$F_{Z}$ is the term accounting for multiple reflections from the valley floor and an elevated layer, and

$\mathrm{C}_{\mathrm{u}}$ is a units conversion factor [from $\mathrm{g} / \mathrm{m}^{3}$ to $\mathrm{ppt}$ ].

$$
C_{u}=\frac{22.696+0.083 \mathrm{~T}}{P M} \times 10^{12}\left[\frac{\mathrm{ppt}}{\mathrm{g} / \mathrm{m}^{3}}\right]
$$

where

$\mathrm{T}$ is the air temperature $\left[{ }^{\circ} \mathrm{C}\right]$,

$P$ is the atmospheric pressure [mb], and

$M$ is the molecular weight of the tracer [g/mole]; (PMCP-300; PMCH-350; PDCH-400).

The multiple reflection terms are evaluated as infinite series where

$$
F_{y}=\sum_{n=-\infty}^{\infty}\left[F_{y_{0}}{ }^{(1+2 n)^{2}}+F_{y_{0}}(2 n)^{2}\right]
$$




$$
\begin{aligned}
& F_{z}=\sum_{n=-\infty}^{\infty}\left[F_{z_{0}}(2 n)^{2}\right] \\
& F_{y_{0}}=e^{-A_{y}^{2} / 2} ; A_{y}=\frac{W}{\sigma_{y}} \\
& F_{z_{0}}=e^{-A_{z}^{2} / 2} ; A_{z}=\frac{H_{L}}{\sigma_{z}}
\end{aligned}
$$

where

$W$ is width of the valley floor [m], and

$H_{L}$ is the elevated lid height [m, AGL].

The lateral reflection term is restricted to the calculation of plume centerline concentrations for a plume midway between the two valley sidewalls, assuming the sidewalls are vertical at a distance $W$ apart. The vertical reflection term is restricted to the calculation of plume centerline concentrations for a ground-level release. For other release configurations the reflection terms need to be determined from the basic infinite series [e.g., Turner, 1970; Turner's Eqn (5.8) can also be applied to lateral reflections between parallel walls]. Investigating the functional behavior of the infinite series [Eqns (10) and (11)] leads to the following approximations (within 1\%)

$$
\begin{aligned}
& \frac{F_{y}}{\sigma_{y}}=\frac{1}{\sigma_{y}} ; A_{y} \geq 3.6 \\
& \frac{F_{y}}{\sigma_{y}}=\frac{\sqrt{2 \pi}}{W}+\frac{0.21}{W}\left(A_{y}-1.5\right)^{2.25} ; 1.5<A_{y}<3.6 \\
& \frac{F_{y}}{\sigma_{y}}=\frac{\sqrt{2 \pi}}{W} ; A_{y} \leq 1.5
\end{aligned}
$$


66

$$
\begin{aligned}
& \frac{F_{z}}{\sigma_{z}}=\frac{1}{\sigma_{z}} ; A_{z} \geq 1.6 \\
& \frac{F_{z}}{\sigma_{z}}=\frac{\sqrt{\pi / 2}}{H_{L}}+\frac{0.60}{H_{L}}\left(A_{z}-0.9\right)^{1.57} ; 0.9<A_{z}<1.6 \\
& \frac{F_{z}}{\sigma_{z}}=\frac{\sqrt{\pi / 2}}{H_{L}} ; A_{z} \leq 0.9
\end{aligned}
$$

Note that when the plume is well mixed $\left(A_{y} \leq 1.5\right.$ and $\left.A_{z} \leq 0.9\right)$, Eqn (8) reduces to the "box model"

$$
\chi=C_{u} \frac{Q_{s}}{U_{s} W H_{L}}
$$

The lateral plume spread due to turbulence is assumed to be of the form recommended by Hanna et al. (1977)

$$
\sigma_{y}=\sigma_{v} t f_{y}
$$

where

$\sigma_{V}$ is the standard deviation of the cross-plume winds [m/s],

$t$ is the travel time [s], and

$f_{y}$ is a nondimensional function of travel time.

The function fy used is that recommended by Irwin (1983)

$$
y=[1+0.9 \sqrt{t / 1000}]^{-1}
$$

and the travel time $t$ can be estimated by $t=S / U_{T}$, where $U_{T}$ is the average transport wind speed and $S$ is the down-valley distance from the release.

The vertical plume spread due to turbulence $\sigma_{z}$ is determined as

$$
\sigma_{z}=\sigma_{w}+t_{z}
$$


where

$\sigma_{W}$ is the standard deviation of the vertical wind speed $[\mathrm{m} / \mathrm{s}]$,

$f_{z}$ is a nondimensional function of travel time.

The function $f_{z}$ used is that recommended by Irwin (1983) for stable conditions

$$
f_{z}=[1+0.9 \sqrt{t / 50}]^{-1}
$$

Eqn (8) was solved in a "segmented" fashion because of the need to account for the variation of the turbulence quantities with down-valley distance. The concentration as a function of down-valley distance was calculated by "marching" down-valley from the release using the concept of a "virtual travel time." Eqn (8) can be written as

$$
\chi(S)=C_{u} \frac{Q_{s}}{\pi U_{s}} \frac{F_{y}}{\sigma_{y}}\left(t_{y}\right) \frac{F_{z}}{\sigma_{z}}\left(t_{z}\right)
$$

where $t_{y}$ and $t_{z}$ are virtual travel times determined as

$$
\begin{aligned}
& t_{y}=t_{y 0}+t_{y}{ }^{\prime}+\frac{\Delta S}{U_{T}} \\
& t_{z}=t_{z 0}+t_{z}{ }^{\prime}+\frac{\Delta S}{U_{T}}
\end{aligned}
$$

and ty' and t $z^{\prime}$ are determined by solving the next two equations iteratively

$$
\begin{aligned}
& \sigma_{y}(S-\Delta S)=\sigma_{v}(S) t_{y}{ }^{\prime} t_{y}\left(t_{y}{ }^{\prime}\right) \\
& \sigma_{z}(S-\Delta S)=\sigma_{w}(S) t_{z}{ }^{\prime} t_{z}\left(t_{z}{ }^{\prime}\right)
\end{aligned}
$$

The virtual start times, tyo and $t_{z 0}$, in Eqns (26) and (27) are determined from Eqns (28) and (29) knowing the lateral and vertical plume spread at the release location. 
The average nighttime ground-level PMCH concentration was estimated from Eqn (25) using the inputs $\sigma_{y}(0)=150 \mathrm{~m}, \sigma_{z}(0)=10 \mathrm{~m}, U_{\mathrm{s}}=1.5 \mathrm{~m} / \mathrm{s}, U_{T}=1.5$ $\mathrm{m} / \mathrm{s}, Q_{\mathrm{s}}=0.23 \mathrm{~g} / \mathrm{s}, P=815 \mathrm{mb}, T=0^{\circ} \mathrm{C}, \mathrm{W}=500 \mathrm{~m}, H_{L}=300 \mathrm{~m}$, and $\sigma_{v}$ and $\sigma_{W}$ from Table 8. The resulting concentrations agreed to within $\pm 20 \%$ of the measurements out to $8 \mathrm{~km}$ from the release (Fig. 18). This reasonable agreement was attained by accounting for the following processes 1) initial plume spread; 2) plume reflections from the valley sidewalls (plume confinement); and 3) variation in turbulence levels with down-valley distance. The importance of the effects of plume confinement is demonstrated in Fig. 18 with a plot of Eqn (25) with no lateral reflection term. Without reflections, the predicted concentrations are as much as $65 \%$ lower than those observed.

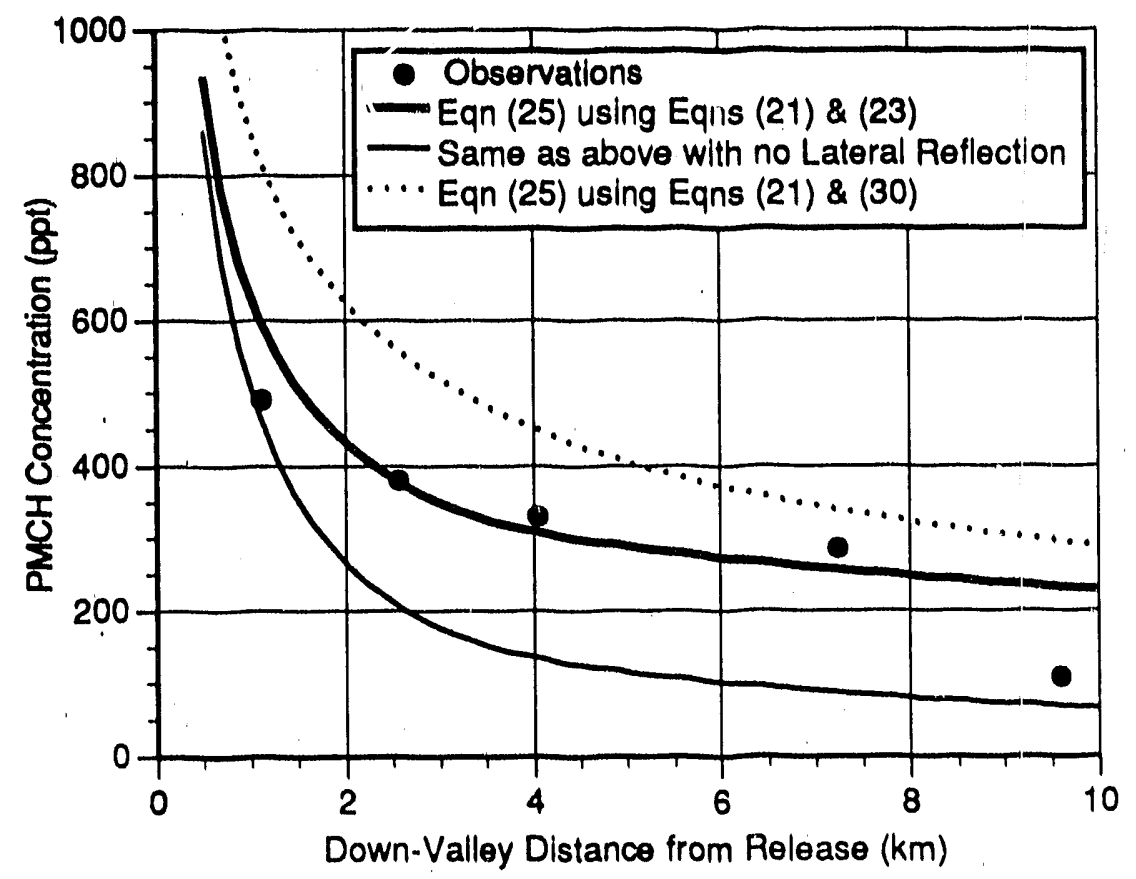

Figure 18. Maximum nighttime average (0200-0700) PMCH concentrations measured along the Brush Creek valley floor on 9/26/84, compared with the Gaussian plume equation. 
The large initial plume spread of $150 \mathrm{~m}$ in the lateral and $10 \mathrm{~m}$ in the vertical was an attempt to account for the enhanced dispersion caused by the wake effects of the trees in the bottom of the valley, both up-valley and down-valley from the release. The trees were about $10 \mathrm{~m}$ high and extended about $150 \mathrm{~m}$ across the valley. The down-valley wind speed of $1.5 \mathrm{~m} / \mathrm{s}$ was the $0200-0700$ average speed at $10 \mathrm{~m} \mathrm{AGL}$ at the valley release site which is commensurate with the tree canopy height rather than the actual release height of $5 \mathrm{~m} \mathrm{AGL}$. The turbulence levels used in Eqn (25) are given in Table 11. The average of the measurements (Table 8 ) from the LANL-3 and WPL-1\&2 towers is assumed to represent the turbulence levels in the upper portion of the valley, and the average of the WPL-1\&2 and ATDD-1 towers is assumed to represent the lower portion of the valley.

TABLE 11. Variation of Nighttime Turbulence Levels with Distance from the Valley Release.

\begin{tabular}{ccc}
\hline $\begin{array}{c}\text { Distance } \\
(\mathrm{km})\end{array}$ & $\sigma_{\mathrm{v}}$ & $\sigma_{\mathrm{W}}$ \\
\hline 0.0 & 0.36 & $(\mathrm{~m} / \mathrm{s})$ \\
3.0 & 0.36 & 0.18 \\
4.5 & 0.29 & 0.18 \\
10.0 & 0.29 & 0.12 \\
\hline
\end{tabular}

The results from Eqn (25) using the values of $\sigma_{y}$ from Eqn (21), and values of $\sigma_{z}$ from the steady solution to the advection-diffusion equation

$$
\sigma_{z}=\sqrt{2 K_{z} t}
$$

are given in Fig. 18 for comparison. The predicted concentrations are roughly $65 \%$ higher than the observed concentrations at $1 \mathrm{~km}$ from the releaso, and close to within $20 \%$ of the observed value at about $7 \mathrm{~km}$ from the release. The greater deviation from the observations nearer the release may have been a result of assuming a constant vertical diffusivity (average value) with down-valley 
distance. The variation of $\sigma_{w}$ with distance given in Table 11 indicated greater vertical diffusion in the upper portions of the valley.

Another process identified as important in governing the concentrations was the merging of the Brush Creek and Roan Creek valley flows. The effects of the merging on ground-level conce intrations is shown by the last point in Fig. 18 and by the diminished concentrations within the Roan Creek valley down-valley from the mouth of the Brush Creek valley $-6.00 \mathrm{ppt}$ at sampler BBO9 and $5.26 \mathrm{ppt}$ at sampler BB05 [BB09 is $\sim 4 \mathrm{~km}$ down Roan Creek valley from the mouth of the Brush Creek valley ( $14 \mathrm{~km}$ from the release), and BB05 is about an additional $13 \mathrm{~km}$ beyond $\mathrm{BBO}$ ( $\sim 27 \mathrm{~km}$ from the release)]. The enhanced dilution caused by the merging of the flows is d-monstrated more clearly by looking at the rate of decrease of concentration with distance from the release: $11 \%$ per $\mathrm{km}$ ( 1 to $4 \mathrm{~km}$ from the relasise; within the Brush Creek valley), $4 \%$ per $\mathrm{km}$ (4 to $7 \mathrm{~km}$; within Brush Creek valley), 15\% per km (7 to $14 \mathrm{~km}$; merging of Brush Creek and Roan Creek valleys), and $1 \%$ per km (14 to $27 \mathrm{~km}$; within the Roan Creek valley).

e. Daytime concentrations and ventilation rate

The concentrations of the three tracers at the ridgetop samplers are given in Fig. 17. At all ridgetop samplers the $\mathrm{PMCH}$ and $\mathrm{PDCH}$ concentrations were at background levels through the night up to $0700 \mathrm{MST}$. These concentrations are therefore shown in the figure only after $0600 \mathrm{MST}$. The PMCP concentrations are shown from 0000 through 1200 MST. The PMCP results will not be discussed further, except to emphasize that simulating these concentrations, especially before sunrise, would be very difficult. 
The behavior of the PMCH (and PDCH) concentrations at ridgetop are more easily predictable than the PMCP. In general, very little tracer is seen on Brush Mountain (upwind in above-ridgetop winds) at all times. and all the samplers along Skinner Ridge (downwind in above-ridgetop winds) see PMCH tracer after 0800 MST, with peak concentrations experienced between 0900-1100 MST. The time variation of the average of the Skinner Ridge PMCH concentrations between the valley release location and Arc 1 (samplers AA6-9 and BB25-26) is given in Fig. 19. The PMCH peak value $(0.76 \mathrm{ppt})$ occurs during the hour average sample centered about 0930 MST. The peak value on Brush Mountain is slightly above background ( -0.01), roughly a factor of 100 below the Skinner Ridge values. These results simply confirm that the westerly winds above the ridgetop carry the tracer ventilated from the Brush Creek valley in an easterly direction across Skinner Ridge. The early morning upslope flows on the west sidewall initially carry the fracer up that sidewall only to be swept away in the above-ridgetop winds, never reaching the tops of Brush Mountain (the west ridge).

The hour average cross-valley isopleths of the PMCH tracer at Arc 2 and Arc 1 are given in Fig. 20, for 4 times $(0730,0830,0930$ and 1030 MST midpoint times) during the morning transition period. The tracer generally behaves as described by Whiteman (1989). Upon initial heating of the sunlit west sidewall, the tracer plume migrates toward that sidewall, is diluted in the growing convective boundary layer, and is subsequently carried up the sidewall in upslope flows. Local sunrise proceeds across the valley from the west si Jewall, to the valley floor and then up the east sidewall. The CBL grows off the respective surfaces, developing up-valley and upslope flows which continue the ventilation of the tracer from the vailey. 




Figure 19. The time variation in the average (spatial) of the Skinner Ridge PMCH concentrations ( $\square$ ) measured by the six samplers between the valley release location and $\operatorname{Arc} 1$ on $9 / 26 / 84$. Also given is the time variation of the ventilation rate of $P M C H$ per length of valley, $Q_{v},(\bullet)$ from the Brush Creek valley an $9 / 26 / 84$. $Q_{v}$ is defined later.

The reversal of the along-valley winds from down-valley to up-valley and the subsequent transport of air from the Roan Crelak valley into the Brush Creek valley has a significant effect on the tracer concentrations in the Brush Creek valley. If the up-valley wind speed is assumed to behave with time as shown in Fig. $10(A=2.5 \mathrm{~m} / \mathrm{s}-\mathrm{h})$, the approximate distance $X[\mathrm{~km}]$ an air parcel would travel in some time $t[h]$ after flow reversal is

$$
X=\int_{0}^{t} U_{T}\left(t^{\prime}\right) d t^{\prime}=\int_{0}^{t} A t^{\prime} d t^{\prime}=\frac{A}{2} t^{2}=4.5 t^{2}
$$


where $U_{T}[\mathrm{~m} / \mathrm{s}]$ is the transport wind speed $\left(U_{T}\right.$ is equal to $A$ times $\left.t\right)$. The time $t$ [h] a parcel would take to travel a distance $X[\mathrm{~km}]$ is

$$
t=0.471 \sqrt{x}
$$

Eqn (32) says that air in the Roan Creek valley, at the mouth of the Brush Creek valley, would reach Arc $1(X=2.5 \mathrm{~km})$ by roughly $0930(0.75 \mathrm{~h}$ after flow reversal), and would reach Arc $2(X=5.8 \mathrm{~km})$ by roughly $1000(1.25 \mathrm{~h}$ after flow reversal). This is confirmed by the tracer measurements, which show less total tracer mass (about $1 / 2$ as much) flowing past Arc 1 than is flowing past Arc 2 during the last two time periods (0900-1000 and 1000-1100 MST) in Table 12.

Another point to note is the tracer behavior at the Kimball Mountain sampler (Fig. 17) above the Roan Creek valley. Tracer is seen at this ridge-top sampler at the same time and in the same concentrations as at the Skinner Ridge samplers. This indicates that the process of ventilation is occurring in the Roan Creek valley, and probably all along the valley system (Roan-Brush-Carr-Clear). This supports Allwine and Whiteman's (1988) hypothesis that a system of valleys can be considered as a "line source" in regional-scale models, with material being vented from the valley system beginning shortly after sunrise. Orgill (1989) discusses the ventilation of tracer from the Brush Creek valley during a 1982 experiment. The timing of his ventilation, as observed by aircraft, is very similar to that shown in 1984.

The along-valley isopleths of PMCH conceltration are given in Fig. 21 for the same four time periods as shown in Fig. 20. The concentrations plotted in the higher elevations (above $2300 \mathrm{~m} \mathrm{MSL}$ ) of the valley in Fig. 21 are the concentrations nearer Skinner Ridge inan Brush Mountain. Fig. 21 shows the general decrease in concentrations with time throughout the valley atmosphere. 


\section{4}

Concentrations greater than background $(0.01 \mathrm{ppt})$ are seen above the ridgetops after $0730 \mathrm{MST}$. An estimate of the valley tracer ventilation rate (tracer mass transfer through the $2200 \mathrm{~m} \mathrm{MSL}$ top of the control volume) is determined by solving Eqn (6) for the last term on the RHS. Denoting this term as V (ventilation raie), and ignoring the longitudinal turbulent diffusion terms gives Eqn (6) as

$$
\mathbf{V}=\frac{\partial}{\partial t}\left[\int_{C V} \bar{C} d V\right]-\int_{A r c 1}[\bar{U} \bar{C}] d A-\int_{A r C 2}[\bar{U} \bar{C}] d A
$$

The advection terms on the RHS (last two terms) of Eqn (33) are evaluated from the measurements of tracer concentrations and winds in the same way as was done for the nighttime calculations. The storage term (1st term on RHS) was estimated from the the tracer measurements as

$$
\frac{\partial}{\partial t}\left[\int_{C V} \bar{C} d V\right]=\frac{\partial}{\partial t}\left[\frac{L}{2}\left(\int_{A r C 1} \bar{C} d A+\int_{A r C 2} \bar{C} d A\right)\right]
$$

where $L$ is the distance between Arc 1 and Arc $2(3.3 \mathrm{~km})$. The argument of the time derivative on the RHS of Eqn (34) was evaluated at each time $(0730,0830$, 0930 and 1030), and the results regressed versus time (Fig. 22) yieldins the following empirical relation with a 0.99 correlation coefficient

$$
\left[\frac{L}{2}\left(\int_{\text {ArC1 }} \bar{C} d A+\int_{\text {Arc2 }} \bar{C} d A\right)\right]=5.77 \times 10^{4} e^{-0.684 t_{D}} \quad[\mathrm{~g}]
$$

where $t_{D}$ is the time of day (MST). Differentiating Eqn (35) with respect to time and evaluating the resulting relationship at the desired times, gives the value of the storage term at each time. 

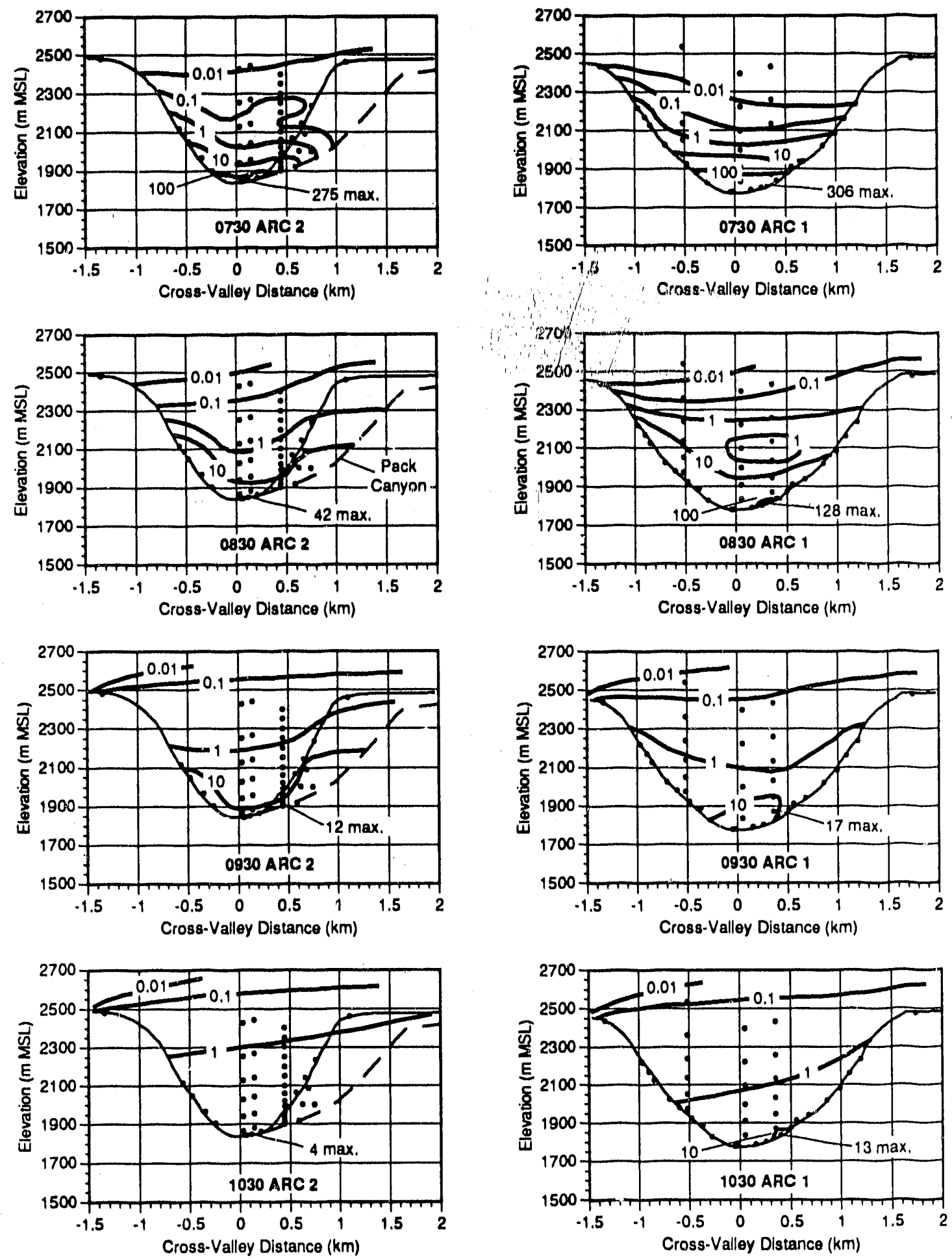

Figure 20. Hour-average cross-valley isopleths of $\mathrm{PMCH}$ concentrations at four times (midpoint) through the morning transition period for $9 / 26 / 84$ in Brush Creek valley. The locations of all of the samplers ( $\bullet$ ) used to contour the concentrations are shown along with the profile of the Brush Creek valley floor (fine solid line). The dashed line in the Arc 2 plots represents the Pack Canyon fall line. 

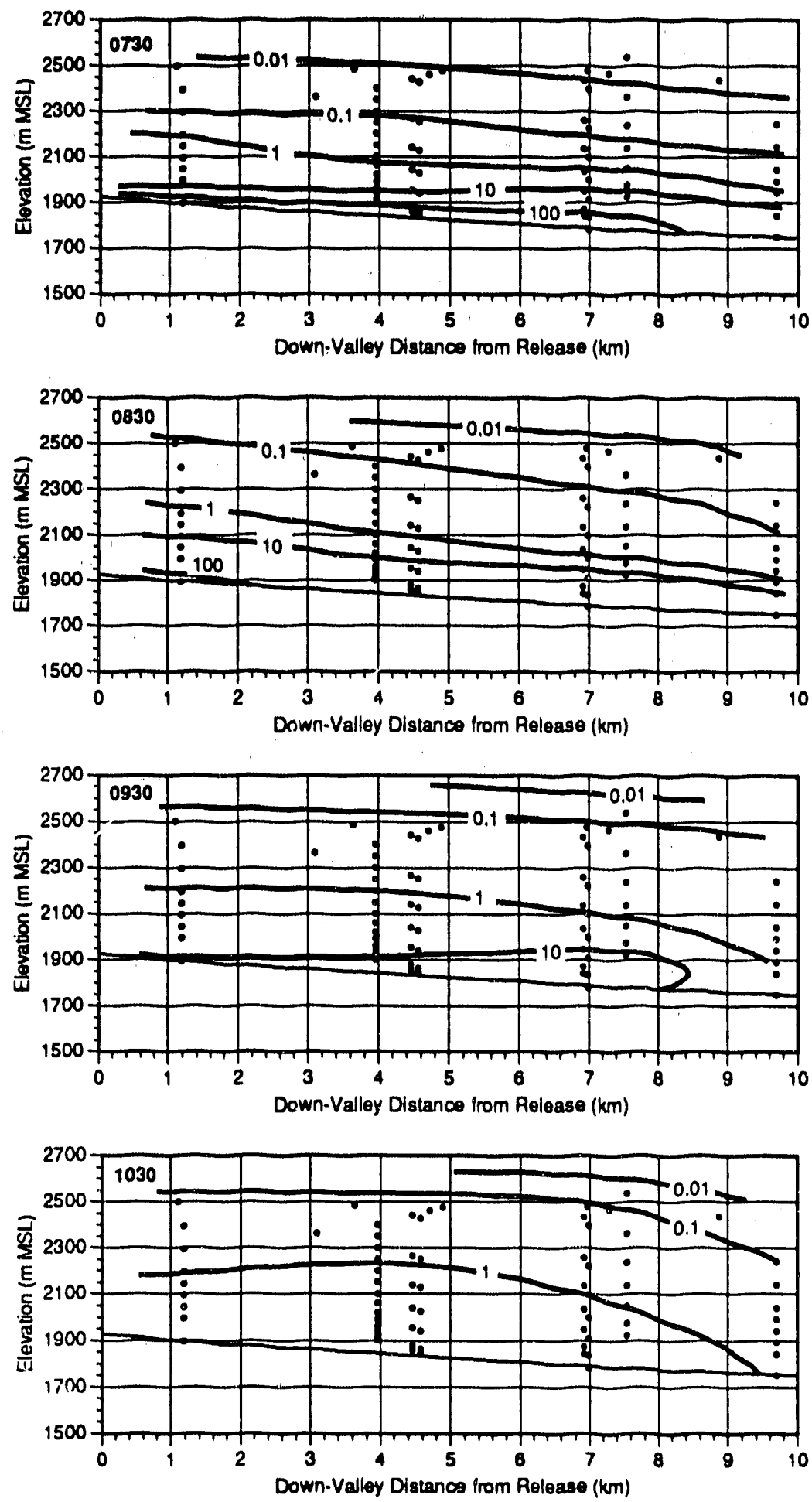

Figure 21. Hour-average along-valley isopleths of PMCH concentrations at four times (midpoint) through the morning transition period for 9/26/84 in Brush Creek valley. The locatisns of all of the vertical samplers $(\bullet)$ used to contour the concentrations are shown along with the profiie of the Brush Creek valley floor (fine solid line). 


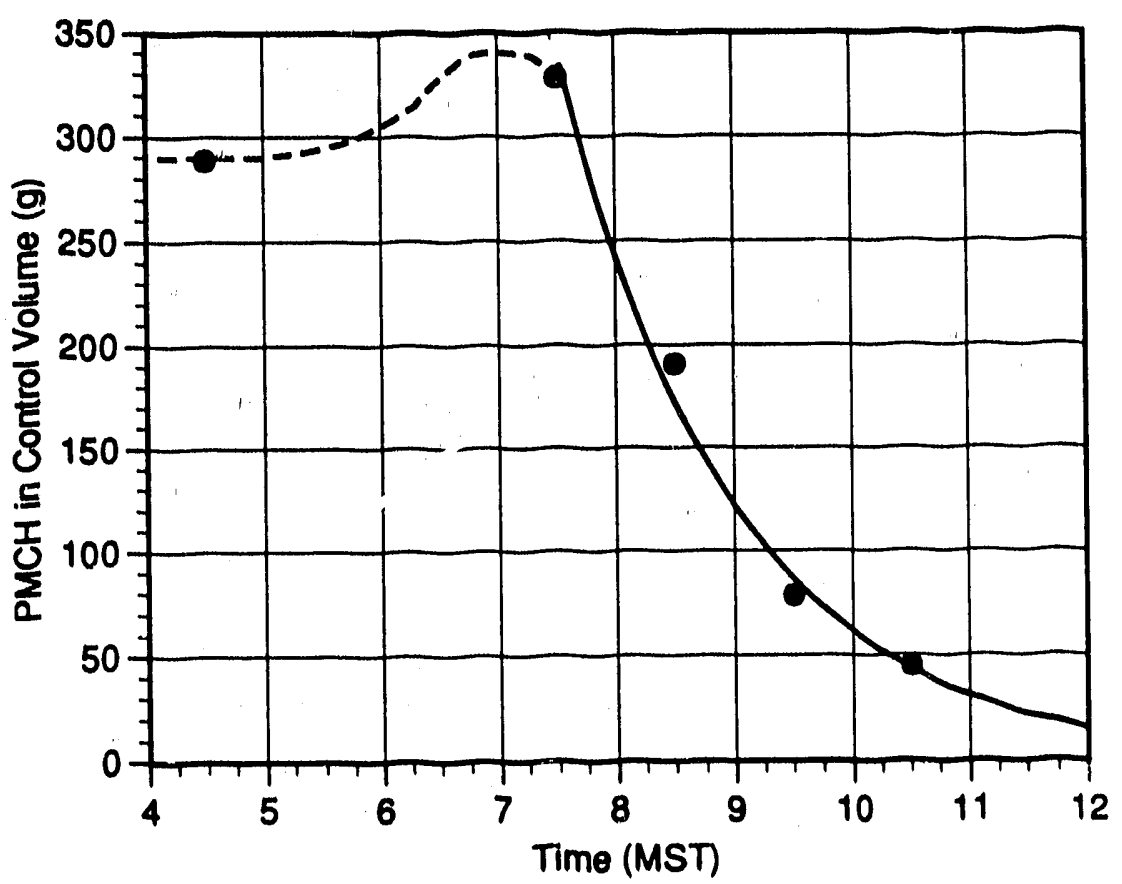

Figure 22. Estimate of the time variation of PMCH mass in the control volume (between Arc 1 and Arc 2, and below $2200 \mathrm{~m} \mathrm{MSL}$ ) on 9/26/84. The solid line represents a least-squares fit of an exponential function to the last four data points. The dashed line is a free-hand representation of the transition from the near-constant nighttime mass levels to the aftersunrise levels.

Each term of the PMCH tracer mass budget [Eqn (33)] is given in Table 12. The LLNL tethersonde winds were used to calculate the tracer advection at Arc 2 , and the PNL-1 tethersonde winds were used at Arc 1. The absolute uncertainty in the ventilation ratio given in Table 12 was not estimated, and would be very difficult to do. A rough measure of the uncertainty was estimated as

$$
\delta V=\sqrt{\left(\delta S_{t}\right)^{2}+\left(\delta A_{1}\right)^{2}+\left(\delta A_{2}\right)^{2}}
$$

where $S_{1}$ denotes the storage term, $A_{1}$ the Arc 1 advection term, and $A_{2}$ the Arc 2 advection term. The uncertainty in each of the Arc 1 and Arc 2 advection terms is determined from the nighttime results to be about $10 \%$. This was based on the assumption that the storage term and ventilation term should have been near 
zero at night. Then the difference between the advection terms $(75 \mathrm{~g} / \mathrm{h}$ in Table $12)$ is a conservative measure of the relative uncertainty $(75 / 820)$ in each of these terms.

The uncertainty in the storage term in Eqn (33) is more difficult to estimate than the advection terms; especially after reversal of the winds brings Roan Creek valley air into the control volume, in which case the spatial distribution of tracer mass along the control volume is not well known. Thus, the average of the tracer mass determined at each end of the CV times the length of the CV will be less reliable as a measure of the total mass of tracer in the CV. The uncertainty in the storage term is assumed to be roughly $10 \%$ at $0730,15 \%$ at $0830,35 \%$ at 0930 and $65 \%$ at 1030 . Since the winds shift at about 0845 MST, the last two times will have larger uncertainties than the first two. The large uncertainty for the 1030 time is based on the premise that no tracer mass should be coming into the CV through the lid, as is indicated by the positive ventilation number in Table 12. This level of uncertainty still does not account for the discrepancy that tracer mass is flowing into the CV at 1030 . This discrepancy appears to reflect the overall limits of the analysis.

TABLE 12. PMCH Mass Budget for the Control Volume on 9/26/84.

\begin{tabular}{ccccc}
\hline $\begin{array}{c}\text { Time } \\
(\mathrm{MST})\end{array}$ & $\begin{array}{c}\text { Storage } \\
(\mathrm{g} / \mathrm{h})\end{array}$ & $\begin{array}{c}\text { Arc } 1 \\
(\mathrm{~g} / \mathrm{h})\end{array}$ & $\begin{array}{c}\text { Arc } \\
(\mathrm{g} / \mathrm{h})\end{array}$ & $\begin{array}{c}\mathrm{V} \\
(\mathrm{g} / \mathrm{h})\end{array}$ \\
\hline $0200-0700$ & 0 & $-785 \pm 80$ & $860 \pm 85$ & 0 \\
$0700-0800$ & $-230 \pm 25$ & $-500 \pm 50$ & $475 \pm 50$ & $-205 \pm 75$ \\
$0800-0900$ & $-120 \pm 20$ & $-55 \pm 5$ & $30 \pm 5$ & $-95 \pm 20$ \\
$0900-1000$ & $-60 \pm 20$ & $40 \pm 5$ & $-95 \pm 10$ & $-5 \pm 25$ \\
$1000-1100$ & $-30 \pm 20$ & $55 \pm 5$ & $-115 \pm 10$ & $30 \pm 25$ \\
\hline
\end{tabular}

The ventilation rate per unit length of valley $(\mathrm{V} / \mathrm{L}), Q_{V}$, is plotted in Fig. 19 along with the average ridgetop concentrations. This clearly shows the correlation between the ventilation rate and the ridgetop concentrations. The 
ridgetop concentrations begin to decrease when the ventllation rate becomes zero. A rough check on the consistency between the magnitude of the ventilation rate and the magnitude of the ridgetop concentrations was made considering a simple box model

$$
\chi=\frac{V}{L U_{a} D_{a}}
$$

where $U_{a}$ is the above-ridgetop wind speed and $D_{a}$ is the mixing depth above the valley. Considering the maximum average $\mathrm{PMCH}$ concentration on Skinner Ridge of $0.7 \mathrm{ppt}$, the average 0700 to 0900 ventilation rate of $100 \mathrm{~g} / \mathrm{h}$, the length of the CV of $3.3 \mathrm{~km}$, and the above ridgetop wind speed (see Fig 12) of $3.5 \mathrm{~m} / \mathrm{s}$, gives a mixing depth of roughly $300 \mathrm{~m}$. This is consistent with the depth of the valley atmosphere from the top of the CV (2200 m MSL) to the ridgetops ( 2500 m MSL).

A more general representation of the ventilation rate is to express it in terms of a dimensionless grouping. A reasonable candidate is

$$
\frac{Q_{V} \tau}{Q_{s} / U_{T}}
$$

where $U_{T}$ is the mean down-valley wind speed, $Q_{S}$ is the source release rate, and $\tau$ is the duration after sunrise to the temperature inversion breakup in the valley. Eqn (38) is plotted versus time in Fig. 23 using a $U_{T}$ of $2.5 \mathrm{~m} / \mathrm{s}$ and a $\tau$ of $4 \mathrm{~h}$. The following empirical relation is plotted against the data.

$$
\frac{Q_{v} \tau}{Q_{S} / U_{T}}=6.91 e^{-3.89 \frac{t}{\tau}} \sin \left(\pi \frac{t}{\tau}\right)
$$


80

Eqn (39) may be generally applicable for representing the ventilation of material from ground-level releases during the morning transition perlod. However, verifying this will require far more work than is given here.

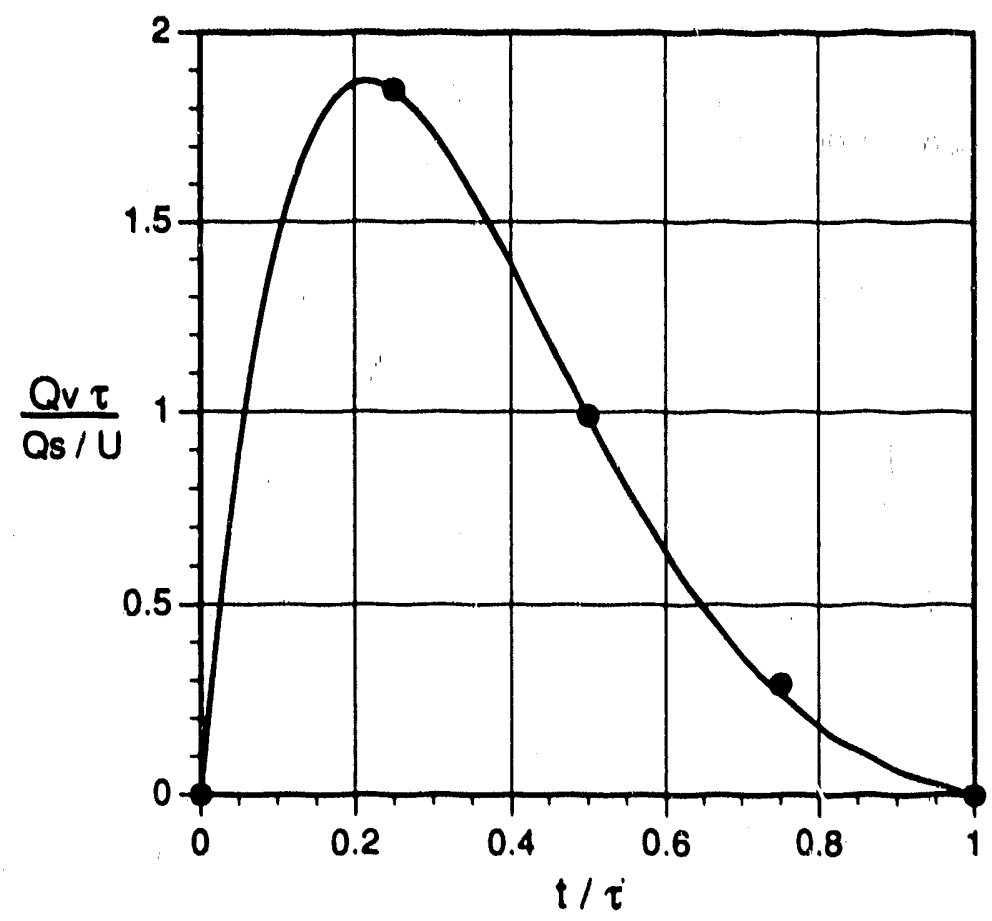

Figure 23. Dimensionless ventilation rate from the Brush Creek valley beginning at sunrise $(t / \tau=0)$ and continuing until the valley temperature inversion is destroyed $(t / \tau=1)$ on $9 / 26 / 84$.

\section{Summary and conclusions}

In September and October of 1934, a large meteorologicai and tracer field study was conducted in Colorado's Brush Creek valley. The major objective of the tracer experiments was to evaluate the behavior of inert gases entrained in nocturnal valley flows and the subsequent ventilation of the gases into aboveridgetop flows during the morning transition period. Tré ;er and meteorological data were collected in and around the Brush Creek valley during five experimental periods (typically midnight to noon). The experiment $(9 / 26 / 84)$ 
analyzed in this paper was characteristic of clear sky fall meteorology under weak synoptic influence.

The experimental results showed the ground-level releases of tracer to be completely confined within the Brush Creok valley during the nighttime in downvalley flows, with no tracer detected by the ridgetop tracer samplers. The tracer plume was neariy uniformly mixed in the closs-valley direction within $8 \mathrm{~km}$ downvalley from the release. The diffusion in the vertical direction $\left(\sigma_{z}\right.$ at $8 \mathrm{~km}$ from the release was about $20 \%$ of the half-height of the valley) was much less than that in the cross-valley direction $\left(\sigma_{y}\right.$ at $8 \mathrm{~km}$ was greater than the half-width of the valley). The nighttime valley centerline ground-level concentrations from a continuous release at the valley floor were well represented (within 20\%) out to 8 $\mathrm{km}$ by a Gaussian plume equation solved in a segmented fashion. This agreement was attained by accounting for plume reflections from the valley sidewalls, initial plume dispersion due to wake effects from a forest stand, and along-valley variations in turbulence characteristics. The concentrations downstreain from the confluence of the Brush Creek and Roan Creek valleys were considerably lower than upstream in the Brush Creek valley because of the dilution caused by the mixing of the two air streams.

In general, for nighttime valley dispersion estimates, the height of the interaction between down-vailey flows and above ridgetop flows needs to be identified for the proper treatment of dispersion. Material released below this height will travel in down-valley flows and be contained within the valley throughout the night. Material released above the inieraction height, but near the sidewalls where it can be entrained in downslope flows, can be transported to the lower portion of the valley in the downslope flows. If material is released above 
the interaction height, but not near the sidewalls, this material can be carried from the valley in above ridgetop flows, or be mixed downward below the interface height by turbulent transport, or both.

After sunrise in the valley, with the onset of convective boundary layer growth and the initiation of upslope flows in the valley, the tracer within the valley was carried into the upper reaches of the valley atmosphere and ventilated from the valley. This was confirmed by the ridgetop tracer samplers, and by a tracer mass budget applied to a valley atmosphere control volume. A ventilation rate, defined as the rate of transfer of material from the valley atmosphere to above ridgetop flows through an upper boundary of the valley atmosphere (e.g., the Interface height discussed previously), was determined by solving the tracer mass conservation equation for a valley atmosphere control volume. Tracer began leaving the valley shortly after sunrise with the maximum ventilation rate occurring within 1 to $11 / 2 \mathrm{~h}$ following astronomical sunrise. The ventilation rate decayed exponentially to relatively low values within $4 \mathrm{~h}$ after sunrise. The ridgetop concentrations began increasing from background levels within $1 \mathrm{~h}$ after sunrise, peaked within $4 \mathrm{~h}$ after sunrise, and then began to decrease.

A general form of a dimensionless ventilation rate is proposed. This dimensionless ventilation rate may be useful in regional air pollution models to represent the transport of pollutants between valley flows and regional flows, and to represent the vertical transport of heat, moisture and trace gases.

The vertical profiling of tracer added considerably to the success of the tracer mass budget analysis. This was especially true in using the tracer mass budget approach to determine the nighttime down-valley air volume flow rate in the Brush Creek valley. The best measure of the nighttime down-valley air 
volume flow (0.33-0.77 million $\mathrm{m}^{3} / \mathrm{s}$ ) was determined from tethersonde observations of the down-valley winds and a parabolic cross-valley structure determined from lidar observations of the down-valley winds. The calculation of tracer mass flow rates at two down-valley distances from the release recovered (within $5 \%$ ) the reported release rates of two tracers, confirming the calculated air volume flow rate, and air volume flow divergence $\left(65 \mathrm{~m}^{3} / \mathrm{s}-\mathrm{m}\right)$.

Acknowledgments. This research was supported by the U.S. Department of Energy under Contract DE-AC06-76RLO 1830 with Pacific Northwest Laboratory. Pacific Northwest Laboratory is operated by Battelle Memorial Institute for the U.S. Department of Energy.

\section{REFERENCES}

Allwine, K. J., and C. D. Whiteman, 1988: Ventilation of pollutants trapped in valleys: A simple parameterization for regional-scale dispersion models. Atmes Environ, 22, 1839-1845.

Allwine, K. J., and C. D. Whiteman, 1985: MEL.SAR: A mesoscale air quality model for complex terrain. Volume 1 - Overview, technical description and user's guide. Final Report. PNL-5460, Vol. 1. Pacific Northwest Laboratory, Richland, Washington, $142 \mathrm{pp}$.

Bader, D. C., and C. D. Whiteman, 1989: Numerical simulation of cross-valley plume dispersion during the morning transition period. $\mathcal{L}$. Appl. Meteor., 28 (7), 652-664.

Bader, D. C., and T. B. McKee, 1985: Effects of shear, stability and valley characteristics on the destruction of temperature inversions. $J$ Climate Appl. Meteor, 24 (8) 822-832.

Barr, S., and M. M. Orgill, 1989: Influence of external meteorology on nocturnal valley drainage winds. J. Appl. Meteor., 28 (6), 497-517.

Bell, R. C., and R. O. R. Y. Thompson, 1980: Valley ventilation by cross winds. $\mathcal{L}$ Eluid Mech, 96, 757-767.

Clements, W. E., J. A. Archuleta and P. H. Gudiksen, 1989: Experimental design of the 1984 ASCOT field study. L. Appl. Meteor, 28 (6), 405-413. 
Coulter, R. L., M. Orgill and W. Porch, 1989: Tributary fluxes into Brush Creek valley. J. Appl. Meteor, 28 (7), 555-568.

Dabbert, W. F., and R. N. Dietz, 1986: "Gaseous tracer technology and applications." In Probing the Atmospheric Boundary Layer, (D. H. Lenschow, Ed.), American Meteorological Society, Boston, Massachusetts, 103-128.

Dobosy, R. J., K. S. Rao, J. W. Przybylowicz, R. M. Eckman and R. P. Hosker, Jr., 1989: Mass and momentum balance in the Brush Creek drainage flow determined from single-profile data. L_Appl_Meteor., 28 (6), 467-476.

Doran, J. C., i991: The effects of ambient winds on valley drainage flows. Bound.-Layer Meteor, 55, 177-189.

Doran, J. C., T. W. Horst and C. D. Whiteman, 1990: The Development and structure of nocturnal slope winds in a simple valley. Bound.Laver Meteor. 52(1-2), 41-68.

Doran, J. C., M. L. Wesely, R. T. McMillen and W. D. Neff, 1989: Measurements of turbulent heat and momentum fluxes in a mountain valley. $\downarrow$. Appl. Meteor., 28 (6), 438-444.

Egan, B. A., and F. A. Schiermeier, 1986: Dispersion in complex terrain: A summary of the AMS workshop held in Keystone, Colorado, 17-20 May 1983. Am. Meteor Soc., 67(10), 1240-1247.

Gryning, S.-E., and E. Lyck, 1983: A tracer investigation of the atmospheric dispersion in the Drynaes valley, Greenland. RISO-R-481. RISO National Laboratory, DK-4000 Roskilde, Denmark, 67 pp.

Gudiksen, P. H., G. J. Ferber, M. M. Fowler, W. L. Eberhard, M. A. Fosberg, and W. R. Knuth, 1984: Field studies of transport and dispersion of atmospheric tracers in nocturnal drainage flows. Atmos. Environ., 18 (4), 713-732.

Hanna, S. R., G. A. Briggs, J. Deardorf, B. A. Egan, F. A. Gifford, and F. Pasquill, 1977: AMS workshop on stability classification schemes and sigma curves-Summary of recommendations. Bull. Amer. Meteor. Sec., 58(12), 130.51309.

Hennemuth, B., and H. Schmidt, 1985: Wind phenomena in the Dischma valley durir,g DISKUS. Arch. Meteor. Geophys, Bioclim, Ser. 8 . 35, 361-387.

Irwin, J. S., 1983: Estimating plume dispersion--A comparison of several sigma schemes. J. Climale Appl. Meteor., 22, 92-114.

Kimura, F., and P. Manins, 1988: Blocking in periodic valleys. Bound-Layer Meteor, 44(1-2), 137-170. 
McNider, R. T., 1981: Investigation of the impact of topographic circulations on the transport and dispersion of air pollutants, Ph.D. Thesis. Department of Environmental Science, University of Virginia, Available from University Microfilms, Ann Arbor, Michigan.

Neff, W. D., 1990: "Remote sensing of atmospheric processes over complex terrain." Chapter 8 in Atmospheric processes over complex terrain, (W. Blumen, Ed.), Meteorological Monegraphs, 23(45), American Meteorological Society, Boston, Massachusetts, 173-22.8.

Orgill, M. M., 1989: Early morning ventilation of a gaseous tracer from a mountain valley. L.Apol. Meteor, 28 (7), 636-651.

Porch. W. M., R. B. Fritz, R. L. Coulter and P. H. Gudiksen, 1989: Tributary, valley and sidewall air flow interactions in a deep valley. $\downarrow$. Appl. Meteor., 28 (7), 578-589.

Segal, M., C. H. Yu, R. W. Arritt, and R. A. Pielke, 1988: On the impact of valley/ridge thermally induced circulations on regional pollutant transport. Atmos. Environ, 22 (3), 471-486.

Start, G. E., C. R. Dicksion and L. L. Wendell, 1975: Diffusion in a canyon within rough mountainous terrain. L.Appl. Meteor. 14, 333-346.

Turner, D. B., 1970: Workbook.of atmospheric dispersion estimates. U. S. EPA, Office of Air Programs Publication No. AP-26, pp84.

Vergeiner, I., E. Dreiseitl and C. D. Whiteman, 1987: Dynamics of katabatic winds in Colorado's Brush Creek valley. L.Atmos. Sci., 44, 148-157.

Whiteman, C. D., K. J. Allwine, L. J. Fritschen, M. M. Orgill and J. R. Simpson, 1989: Deep valley radiation and surface energy budget microclimates. Part II: Energy budget. J. Appl. Meteor., 28 (6), 427-437.

Whiteman, C. D., 1989: Morning transition tracer experiments in a deep narrow valley. J. Appl. Meteor., 28 (7), 626-635.

Whiteman, C. D., R. Lambeth and K. J. Allwine, 1987: Major vegetation types, climatologica! jata, and solar radiation calculations for Colorado's Brush Creek valley. PNL-6209/ASCOT-87-1. April 1987. Pacific Northwest Laboratory, Richland, Washington.

Whiteman, C. D., and S. Barr, 1986: Atmospheric mass transport by along-valley wind systems in a deep Colorado valley. J. Climate Appl. Meteor., 25, 12051212.

Willson, R., F. Shair, B. Reynolds and W. Greene, 1983: Characterization of the transport and diffusion of pollutants in a narrow mountain valley region by means of an atmospheric tracer. Atmos. Environ, 17 (9), 1633-i647. 


\title{
Chapter 4
}

\section{WINTER-TIME DISPERSION IN A MOUNTAINOUS BASIN AT ROANOKE, VIRGINIA: TRACER STUDY}

\author{
Allwine, K. J., B. K. Lamb, and R. Eskridge
}

to be submitted to J. Appl. Meteor. 


\title{
Winter-Time Dispersion in a Mountainous Basin at Roanoke, Virginia: Tracer Study
}

\author{
K. Jerry Allwinet and Brian K. Lamb \\ Washington State University, Pullman, Washington \\ Robert Eskridge§ \\ U. S. EPA, Research Triangle Park, North Carolina
}

\begin{abstract}
During January 1989, five nighttime $\mathrm{SF}_{6}$ tracer experiments were conducted in Roanoke, Virginia. The experiments were designed to help identify and understand the dispersion characteristics of a basin atmosphere during winter stagnation conditions. The basin studied was the Roanoke basin located on the eastern slopes of the Appalachian Mountains. This paper documents this tracer study and gives results from the experiment conducted on the night of January 16-17, 1989. A cold air pool formed in the basin beginn'ing after the evening transition period and tilling to near the elevation of the lowest mountain barrier. A simple model of the ascent rate of the top of this cold air pool is proposed. A sharp potential temperature jump was present at the top of this fully developed cold air pool. Vertical measurements of tracer showed the initial ground-level plume to become elevated and ride over the top of the cold air pool. Horizontal plume spread was enhanced over that expected from turbulent diffusion alone, by vertical wind direction shear. The tracer concentrations within the cold air pool increased slowly with time, even after the release was terminated. After sunrise, ine elevated plume appeared to fumigate to the ground.
\end{abstract}

\section{Introduction}

During January 1989, five righttime sulfur hexafluoride $\left(S_{6}\right)$ tracer experiments were conducted in Roanoke, Virginia, in conjunction with the U.S. Environmental Protection Agency's Integrated Air Cancer Project (IACP). One of the primary goals of the IACP is to improve the capability of estimating human

† Permanent aifiliation: Pacific Northwest Laboratory, Richland, WA 99352

$\S$ Present affiliation: National Climatic Data Center, Ashville, NC 28801-2696 
exposure to airborne carcinogens (Cupitt, 1988). The Roanoke study was intended to look at airborne pollutants in an area with high heating oil usage. The tracer experiments were designed to identify the transport and diffusion characteristics of the Roanoke basin atmosphere during winter-time stagnation conditions (when the ground-level concentrations from ground-level sources are expected to be the highest and most persistent). The five experiments were performed during the nights of January 10-11, 13-14, 15-16, 16-17, and 19-20, respectively.

For the five experiments a near ground-level continuous release of $S_{6}$ was started at typically 1800 local standard time (LST) and finished 2 to 10 hours later. Hourly integrated samples were collected at 41 points up to $12 \mathrm{~km}$ from the release site, and two fast-response continuous $\mathrm{SF}_{6}$ analyzers were operated in mobile vans which traversed the Roanoke area. In addition, vertical profiles of tracer were made at one location using a balloon-borne sampler. Meteorological data were collected at 10 locations within Roanoke. The data included: surface winds and temperature; winds and temperature profiles up to about $150 \mathrm{~m}$ above-ground-level (AGL) using a balloon-borne system; and winds, temperature and turbulence characteristics on a 40-m tower at four levels.

This paper describes the 1989 Roanoke tracer experiments, and gives an assessment of the dispersive characteristics of the Roanoke basin atmosphere from analysis of the tracer data and certain of the meteorological measurements. Section 2 gives a brief review of the current understanding of dispersion in basins. A description of the site, equipment, tracer release and sampling network, and meteorological measurements, is given in Section 3 . The results 
and discussion are presented in Section 4, and Section 5 gives the summary and conclusions.

\section{Background}

Basins (closed valleys) were identified in an AMS workshop on dispersion in complex terrain (Egan and Schiermeier, 1986) as a valley configuration of importance to adverse dispersion situations and air pollution problems. Basins exhibit weak to nonexistent outflow during drainage flow (primarily nightitime, weak synoptic influence) conditions, primarily because of flow blockage. Relatively little research has been conducted on the dynamical behavior of basin atmospheres and dispersion in basin atmospheres. The bulk of basin research has been conducted within the last decade (e.g., Petkovsek, 1978; Banta and Cotton, 1981; Wanner and Hertig, 1984; Gassmann and Burki, 1987; Beniston, 1987; Maki and Hárimaya, 1988; Neff and King, 1989; Kondo and Okusa, 1990; Toritani, 1990; and Eskridge et al., 1990).

Some of the important physical characteristics and processes observed in basin atmospheres are cold air pooling, slope flows, flow blocking and channeling, external forcing, flow oscillations, thermal winds, surface roughness, urban heat island, wakes, stability, flow layering, wind direction shear, convective boundary layer growth, weather events, and turbulence. The extent to which any of these physical processes dominates the dispersion within a particular basin is dependent on the time-of-year, time-of-day, synoptic meteorology and basin physical characteristics (e.g., geometry and surface cover). 
Several research programs concerned with climate and air pollution in cities of Switzeriand have been conducted in the past decade (Wanner and Hertig, 1984; Gassmann and Burki, 1987; Beniston, 1987; Wanner et al., 1986; and Filliger and Wanner, 1986). Numerous air pollution episodes have been observed in Swiss cities when they are under the influence of anticyclonic weather situations. During the summer anticyclonic situations, high photochemical smog episodes are experienced, and during the winter the Swiss prealpine basins suffer from the effects of strong inversions, fog and relatively high amounts of air pollution. Thick cold air pools spread out over the whole surface of prealpine basins (Wanner and Hertig, 1984). These cold air pools significantly affect the dispersion characteristics of the basins.

Gudiksen et al. (1984) discuss results of tracer experiments conducted in nocturnal drainage flows in a complex terrain region of northern California. Tracers were released within slope drainage flows, immediately above the drainage flows, and at elevated heights within the Anderson Creek valley. This valley has the characteristics of a basin with pooling occurring in the lower elevations of the basin. They found that the drainage flows from about mid-slope elevations and below were generally not influenced by the regional scale flows. This was based on the observation that the surface concentration patterns of the tracer released within the slope flow did not vary appreciably over a wide range of regional flow conditions. This research underscores the importance of external forcing on basin flows.

Toritani (1990) summarized results from several studies concerning the periodical nature of wind speed and temerature in cold air drainages. The observed periodicities ranged from 25 to 90 minutes, with the average being 
roughly 60 minutes. Oscillating flows are commonly observed in nighttime basin atmospheres, but the effects of this periodic motion on dispersion are not well understood.

The main period of focus in this paper is the nighttime with some results given for the evening and morning transition periods. Cold air pooling was identified as the dominant process affecting dispersion. The effects of slope flows, wind oscillations, wind direction shear and synoptic forcing on dispersion are discussed.

\section{Experimental design}

a. Site description

Roanoke, a city of about 100,000 people, is located on the eastern slopes of the Appalachian Range in the Blue Ridge Mountains of Virginia. It has a moist climate with $109 \mathrm{~cm}$ (43 in.) annual precipitation and 70\% annual mean relative humidity. The Roanoke basin is drained by the Roanoke River and its tributaries. The basin is roughly $25 \mathrm{~km}$ in diameter with a 15-km-wide floor. Fig. 1, plotted from a USGS digital terrain file with $60-\mathrm{m}$ horizontal resolution, presents elevation contours of the Roanoke basin. The basin floor has a gradual 0.5degree slope falling to the SE. The lowest elevation of the basin floor is roughly $270 \mathrm{~m}$ above mean-sea-level (MSL) with mountains rising up to 500 to $650 \mathrm{~m}$ above that. The southeastern edge of the basin, however, is a low barrier of inountains, approximately $75 \mathrm{~m}$ above the floor and $6 \mathrm{~km}$ long that blocks the basin from opening to the SE. The Roanoke River cuts through this low barrier through a narrow gorge. 


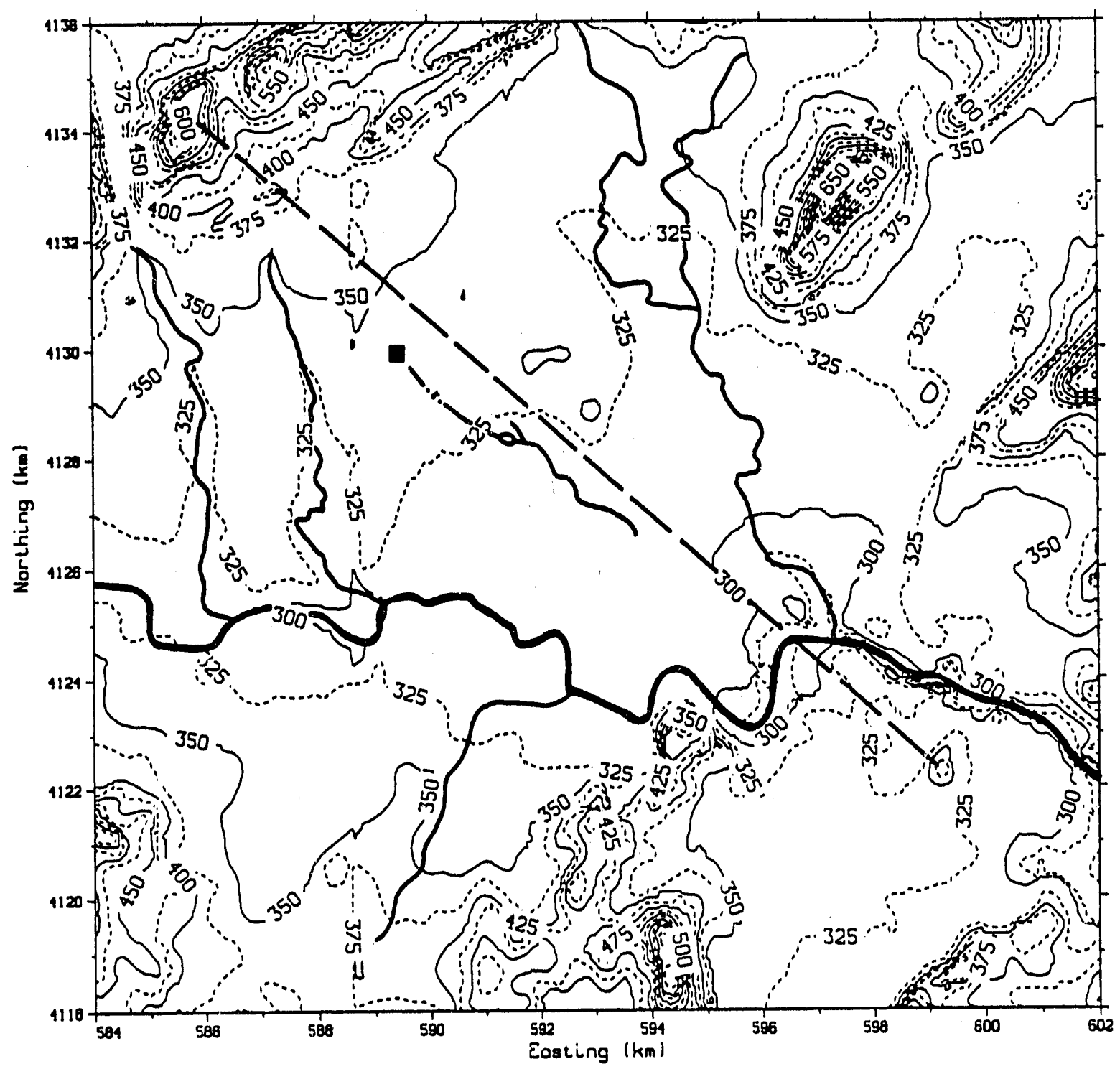

Figure 1. Terrain elevations of the Roanoke, Virginia, area. The black box is the release location at the head of Lick Run, and the havyy solid line indicates the Roanoke River and its tributaries. Note that Lick Run is shown to terminate at an earthen barrier, after which it proceeds to the Roanoke River via culverts. Tha heavy dashed line gives the location of the cross-section in Fig. 3. Coordinates are Universal Transverse Mercator (UTM), grid zone 17. 
Fig. 2 is a map of the Roanoke vicinity showing some major roads and the Roanoke River and its tributaries. The Blue Ridge Parkway shown in Fig. 2 roughly follows the crest of the low barrier of mountains blocking the basin to the SE. To the $\mathrm{N}$ and $\mathrm{W}$ of the map mountains rise to elevations above $900 \mathrm{~m} \mathrm{MSL}$. The downtown is roughly a 9-square-km area with buildings up to about $30 \mathrm{~m}$ high. It is appruximately centered at map coordinates $(594,4125)$.

The floor of the Roanoke basin is cut by several small tributaries to the Roanoke River. These are at most $30 \mathrm{~m}$ deep and $1 \mathrm{~km}$ wide flowing primarily to the SE. The tracer was released in one such shallow tributary valley, Lick Run. Lick Run valley is approximately $6 \mathrm{~km}$ long by $30 \mathrm{~m}$ deep by $500 \mathrm{~m}$ wide. An earthen barrier extends across the valley through a depth of approximately $15 \mathrm{~m}$ at about $5 \mathrm{~km}$ down-valley from the release site. This earthen barrier is at Lick Run and Orange Avenue in Fig. 2. The Roanoke basin has considerable coverage of brush and trees. The mean canopy height is roughly $8 \mathrm{~m}$ (higher than the mean residence height).

Fig. 3 shows a NW-SE cross section (Fig. 1 shows location of cross section) through the Roanoke basin. This cross section gives an appioximate representation of the basin, starting at Brushy Mountain to the $\mathrm{N}$ and ending at the low mountain barrier at the southeastern edge of the basin. The depth and extent of Lick Run is represented by the narrow line in Fig. 3. Figure 4 shows a cross section approximately perpendicular to that given in Fig. 3. This section was scaled from a USGS Roanoke 7 1/2-minite quadrangle map (20-foot contour intervals) to show more detail of the basin relief in the vicinity of the tracer release site. This cross section follows Hershberger road (Arc O1 in Fig. 2) from $W$ to $E$. 


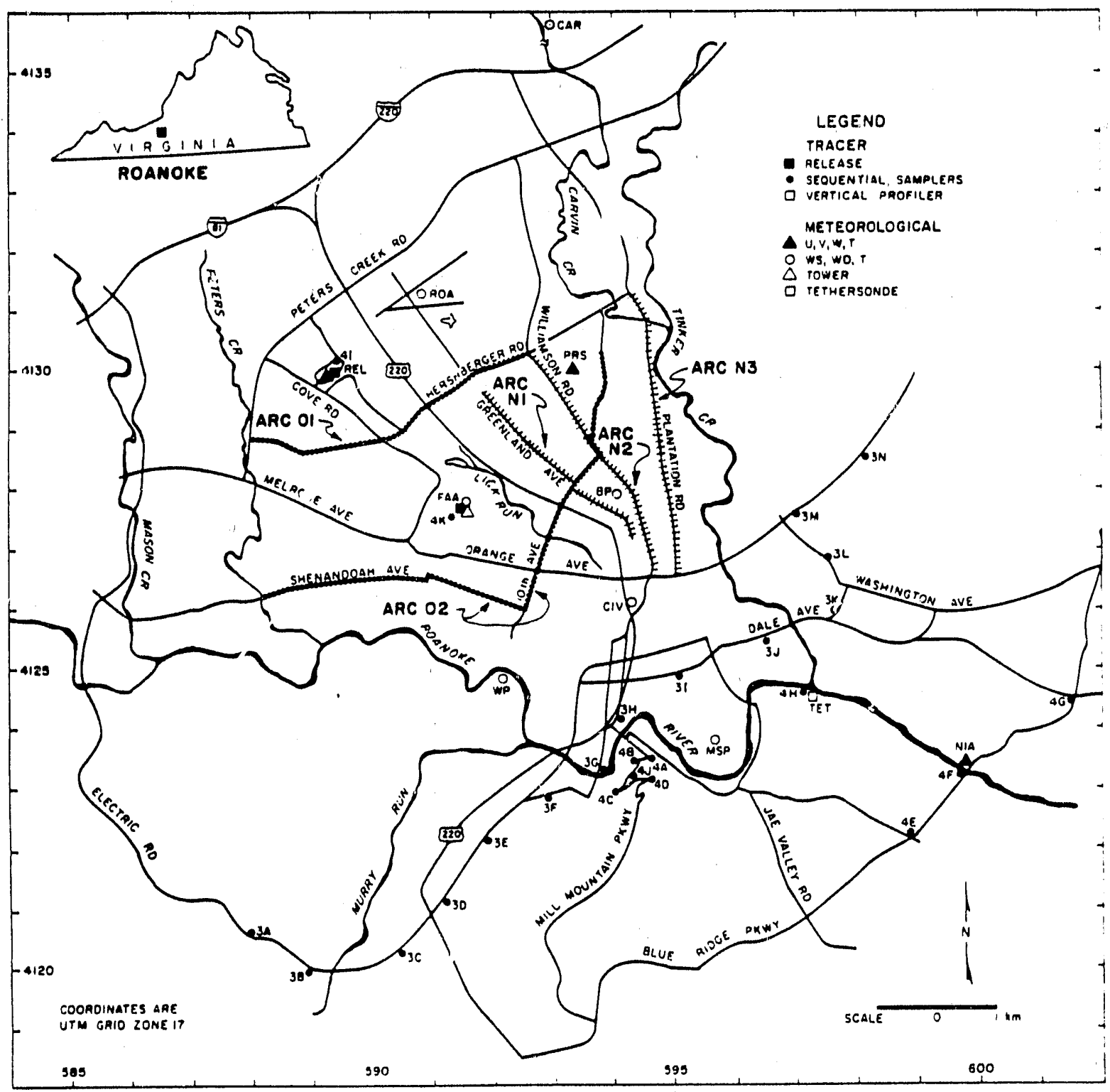

Figure 2. Roanoke, Virginia, vicinity map and measurement site locations. 


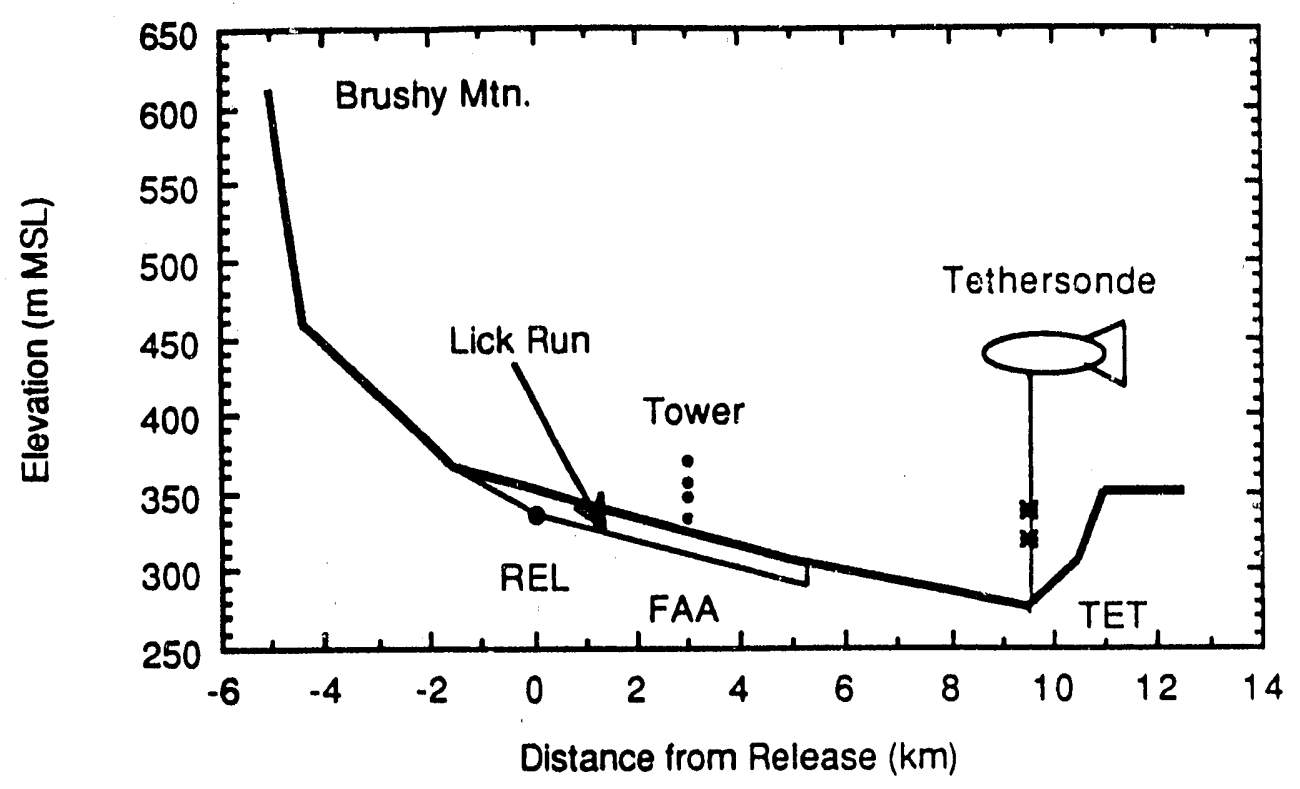

Figure 3. Northwest-southeast cross section through the Roanoke basin showing certain key measurement sites and topographic features.

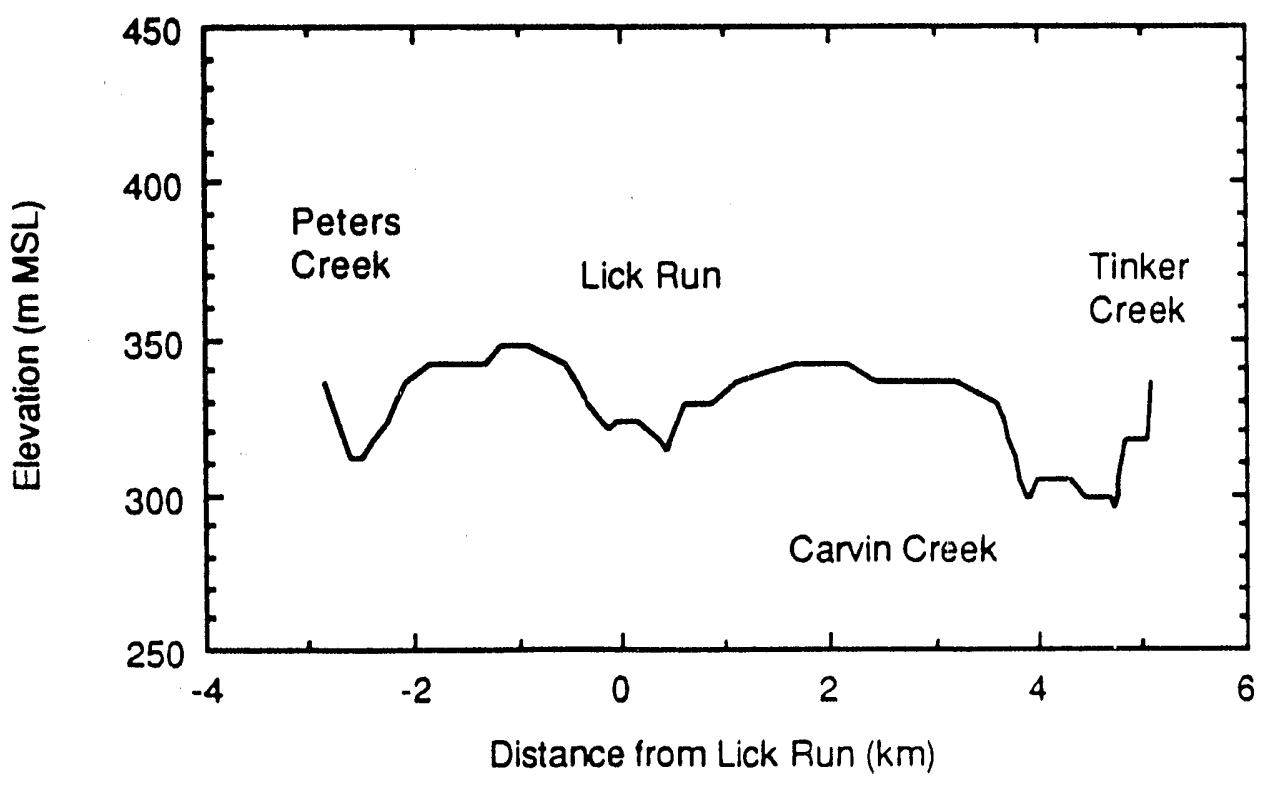

Figure 4. Southwest-northeast cross section along Hershberger road. 
b. Tracer release

Sulfur hexáfluoride was released from one of two different locations duririg the five experimental periods. The release locations are at the sites labeled REL (335 $\mathrm{m} \mathrm{MSL}$ ) and FAA (331 $\mathrm{m} \mathrm{MSL}$ ) in Fig. 2. The release site was at the bottom of Lick Run valley (REL site) for the first foul experiments, and was near ridgetop (FAA site) for the final experiment. The release rate was nearly constant (variability of $1-12 \%$ ) and the release height was $1.2 \mathrm{~m} \mathrm{AGL}$ during each experiment. A summary of the releases is given in Table 1. The release rate given in Table 1 for each experiment is the average of the 30-minute values. Also reported with the release rate is the standard deviation of the observations from the mean. The standard deviation for Exp 1 is approximately $12 \%$ because of problems experienced during this release.

Table 1. SF 6 Release Information.

\begin{tabular}{cccccccc}
\hline $\begin{array}{c}\text { EXP. } \\
\text { NO. }\end{array}$ & $\begin{array}{c}\text { DATE } \\
(89)\end{array}$ & $\begin{array}{c}\text { START } \\
(\text { LST) }\end{array}$ & $\begin{array}{c}\text { STOP } \\
(\text { LST }\end{array}$ & $\begin{array}{c}\text { DURATION } \\
(\mathrm{h})\end{array}$ & $\begin{array}{c}\text { TOTAL } \\
(\mathrm{kg})\end{array}$ & $\begin{array}{c}\text { RATE } \\
(\mathrm{g} / \mathrm{s})\end{array}$ & $\begin{array}{l}\text { RELEASE } \\
\text { LOCATION }\end{array}$ \\
\hline$\vdots$ & $1 / 10$ & 2000 & 0300 & 7.00 & 38.05 & $1.48 \pm 0.18$ & REL Site \\
2 & $1 / 13$ & 1800 & 0400 & 10.0 & 33.58 & $0.93 \pm 0.01$ & REL Site \\
3 & $1 / 15$ & 1857 & 2117 & 2.33 & 6.36 & $0.77 \pm 0.02$ & REL Site \\
4 & $1 / 16$ & 2000 & 0400 & 8.00 & 26.06 & $0.91 \pm 0.04$ & REL Site \\
5 & $1 / 19$ & 1815 & 2330 & 5.25 & 14.01 & $0.74 \pm 0.03$ & FAA Site \\
\hline
\end{tabular}

c. Gro'nd-level sequential tracer sampling

Time integrated samples of $\mathrm{SF}_{6}$ were collected at ground-level using 41 sequential syringe samplers, as described by Krasnec et al. (1984). Each sampler held nine syringes, and integration times were primarily $1 \mathrm{~h}$ with a few samplers operating at 30 minutes and 15 minutes. The locations of sampling Arcs $\mathrm{O} 1, \mathrm{O} 2, \mathrm{~N} 1, \mathrm{~N} 2$ and $\mathrm{N} 3$ are shown in Fig. 2, and individual sampler locations on these arcs are identified in Fig. 5. Arc $\mathrm{O} 3$ individual sampler locations are labeled $3 A$ to $3 \mathrm{~N}$ in Fig. 2. The individual sampler locations labeled $4 \mathrm{~A}$ through 
4K, shown in Fig. 2, are referred to in the text as Arc O4 jor convenience, even though they are spread throughout the study area.

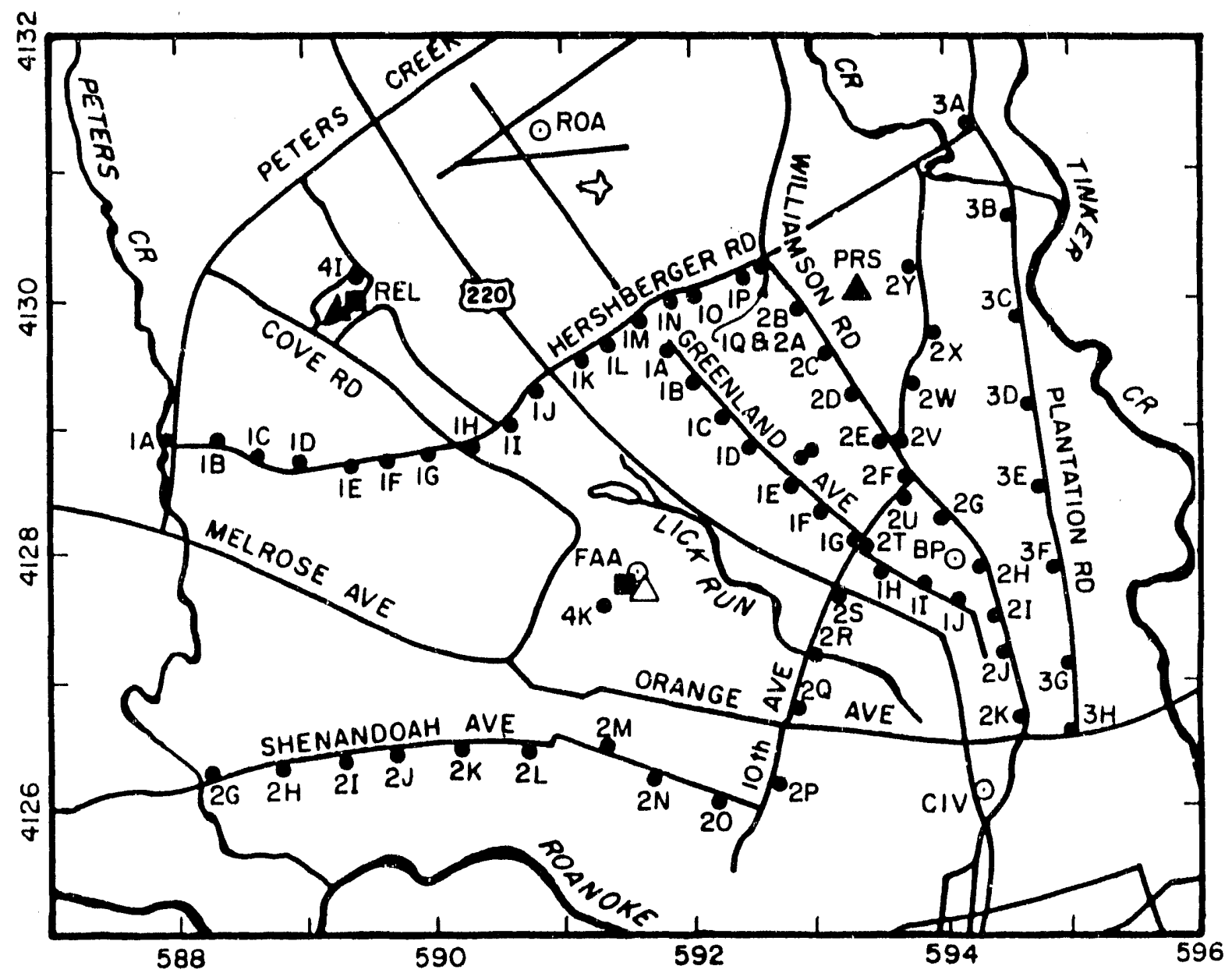

Figure 5. Locations of integrated tracer samplers in Roanoke.

Operating specifications for the samplers are given in Table 2. No integrated samples were collected during Exp 3. During Exps 1, 2 and 4, 11 samplers were located on each of Arcs 01,02 , and 03 , and 8 samplers were located on Arc 04. During Exp 5, 11 samplers were located on Arc N1, 13 on N2, 
100

9 on N3, 1 on 01,6 on 02 , and 1 on 04 . Overall, the sample recovery was about $95 \%$.

Table 2. Operation of Integrated Tracer Samplers.

\begin{tabular}{ccccccc}
$\begin{array}{c}\text { EXP. } \\
\text { NO. }\end{array}$ & $\begin{array}{c}\text { DATE } \\
(89)\end{array}$ & $\begin{array}{c}\text { START } \\
\text { (LST) }\end{array}$ & $\begin{array}{c}\text { STOP } \\
\text { (LST) }\end{array}$ & $\begin{array}{c}\text { DUR. } \\
\text { (min) }\end{array}$ & $\begin{array}{c}\text { NUMBER } \\
\text { UNITS }\end{array}$ & $\begin{array}{c}\text { SAMPLER LOCATIONS } \\
\text { (refer to Figs. 2 and 5) }\end{array}$ \\
\hline 1 & $1 / 10$ & 1800 & 0300 & 60 & 41 & O1A-L, O2G-S, O3A-K, O4A-H \\
2 & $1 / 13$ & 1900 & 0400 & 60 & 22 & O1A-M, O2G-S \\
& & 2000 & 0500 & 60 & 11 & O3A-K \\
4 & $1 / 16$ & 2100 & 0600 & 60 & 8 & O4A-1 \\
5 & $1 / 19$ & 1900 & 0800 & 60 & 41 & O1A-Q, O21-Y, O3D-N, O4A-J \\
& & 2330 & 30 & 37 & N1A-J, N2A-K, N3A-H, O4K, O1I, \\
& & 1900 & 2115 & 15 & 2 & O2Q-U \\
& & 2115 & 2330 & 15 & 2 & N2E, O2R \\
& $1 / 20$ & 0130 & 0600 & 30 & 3 & O2Q, O2R \\
\hline
\end{tabular}

d. Chemical analysis of the syringe samiples

In past SF 6 tracer studies (see, for example, Lamb et al., 1990, Guenther et al., 1990, Eskridge et al., 1990) syringe or bag samples collected during an experiment were analyzed using electron capture gas chromatographs (GC). In such studies, the analysis rate per GC was typically one sample every 4 minutes, or 50 samples per hour with a system of four GOs (one operator required). The detection limit with such systems was typically less than 5 ppt.

For the present study the syringe samples were analyzed after each experiment using a new analysis system based on a fast-response continuous SF 6 analyzer (Benner and Lamb, 1985). With this approach, a gas chromatography sampling valve (Valco, Inc.) fitted with a 5-cc sampling loop is used with the analyzer. Ambient air is pumped through the valve and past the analyzer inlet through a tee at a steady controlled rate using an external pump and flowmeter. The flow rate is in slight excess of the analyzer inlet flow. The analyzer continuously samples this air stream from one side of the tee and establishes a baseline. 
When a sample is injected from the valve into the air stream, the analyzer immediately responds to any $S_{6}$ present and a single peak results. The analyzer's electronic output is connected to an HP3390 electronic integrator and the peak height for each sample is measured. Standards (Scott-Marin, Inc., $\pm 5 \%$ certified accuracy) are analyzed in the same manner using the sampling valve and a response curve is determined. This response curve is then used to convert the peak height information into concentration. Because of the continuous response inherent in the instrument there is no wait between samples. Approximately 100 samples can be analyzed per hour with one instrument. This is twice as fast as the old system operating four gas chromatographs (Lamb et al., 1990). The detection limit is less than $10 \mathrm{ppt}$, and the reproducibility is approximately $\pm 10 \%$.

An EPA calibration audit (Shores, 1989) was performed on the fastresponse analyzers and the gas chromatographs. The average difference between the analyzer/chromatograph results and the $\mathrm{SF}_{6}$ standards was $-2.1 \% \pm$ $5.5 \%$ (average percent difference \pm standard deviation).

e. Ground-level continuous tracer sampling

Each of two mobile vans was equipped with a fast-response continuous SF6 analyzer. These vans traveled the roads around Roanoke during the experiments measuring $\mathrm{SF}_{6}$ concentrations at one $\mathrm{Hz}$. The sample air was drawn through an inlet located near the top of the van. This sampling rate translates to a roughly $10 \mathrm{~m}$ spatial resolution for a van traveling at $50 \mathrm{~km} / \mathrm{h}$. According to Benner and Lamb (1985), the analyzer has a response time constant of $0.36 \mathrm{~s}$. This means $94 \%$ of any response change is measured per $1-\mathrm{s}$ sample. The instrument response in conjunction with manually entered location 
102

information was logged in the memory of a personal-computer-based data acquisition system. After a traverse the data were transferred to diskettes. A summary of the traverses is given in Table 3.

Table 3. Operation of Mobile Tracer Vans.

\begin{tabular}{ccccccc}
$\begin{array}{c}\text { EXP. } \\
\text { NO. }\end{array}$ & $\begin{array}{c}\text { DATE } \\
(89)\end{array}$ & $\begin{array}{c}\text { VAN } \\
\text { NO. }\end{array}$ & $\begin{array}{c}\text { START } \\
\text { (LST) }\end{array}$ & $\begin{array}{c}\text { STOP } \\
\text { (LST) }\end{array}$ & $\begin{array}{c}\text { NO. OF } \\
\text { TRAV. }\end{array}$ & TRAVERSE LOCATIONS \\
\hline 1 & $1 / 10$ & 1 & $21: 43$ & $04: 31$ & 20 & Various parts of Roanoke \\
& & 2 & $21: 06$ & $02: 36$ & 11 & Primarily Arcs O1 and O2 \\
2 & $1 / 11$ & 1 & $19: 42$ & $20: 06$ & 2 & Around ITT facility \\
& $1 / 13$ & 1 & $18: 16$ & $05: 28$ & 37 & Various parts of Roanoke \\
3 & & 2 & $19: 06$ & $03: 47$ & 25 & Primarily Arcs O1 and O2 \\
& $1 / 15$ & 1 & $19: 24$ & $23: 07$ & 9 & Various parts of Roanoke \\
4 & & 2 & $19: 12$ & $22: 42$ & 15 & Primarily Arcs O1 and O2 \\
& $1 / 16$ & 1 & $20: 48$ & $04: 52$ & 20 & Various parts of Fioanoke \\
5 & & 2 & $21: 44$ & $04: 02$ & 20 & Primarily Arcs O1 and O2 \\
& $1 / 19$ & 1 & $19: 15$ & $02: 11$ & 16 & Various parts of Roanoke \\
& & 2 & $19: 12$ & $23: 25$ & 21 & Primarily Arcs O2, N1 and N2 \\
\hline
\end{tabular}

- Special sampling around ITT iacility.

The delay time for the sample to travel through the tubing to the detector was determined to be $5 \mathrm{~s}$ and $8 \mathrm{~s}$ for the two vans, respectively. This information in conjunction with the entered location information was used in the data processing to determine the concentration as a function of location. The location information was entered by the operator through the keyboard at the time a landmark was passed. The coordinates of these landmarks were scaled from a map for subsequent use in the data processing. Based on uncertainties in some landmark locations, location codes entered late or early, and map resolution, the actual location is roughly within $30 \mathrm{~m}$ of that computed.

Before and after each experiment the analyzers were calibrated at five points over a range of about $50 \mathrm{ppt}$ to $5000 \mathrm{ppt}$. Periodically throughout each experiment span checks were made. During any given experiment the analyzers' responses remained essentially constant. An uncertainty analysis revealed the data to be accurate to better than approximately $\pm 15 \%$ for values 
greater than roughly $400 \mathrm{ppt}$, and decreasing in accuracy to $\pm 100 \%$ at roughly the $50 \mathrm{ppt}$ noise level.

\section{f. Elevated sequential tracer sampling}

Samples of tracer were collected in the vertical at one location using a tethered balloon system. The sampling location is labeled TET in Fig. 2. A tracer sampler was attached to a tethered balloon along with a meteorological package that measured winds, temperatures, and pressure change. The elevation of the balloon was determined from this information. A 7.5-cubic-meter balloon was needed to lift both the sampler and the meteorological package. An early version of the tracer sampler was designed by Sandia National Laboratory (Gay, 1982) for use in the 1982 ASCOT study in western Colorado. This sampler was later redesigned by Sandia for use in the 1984 ASCOT study in the same region. The 1984 version of the sampler was then modified and used in the Roanoke study.

The tracer sampler held seven syringes that were sequenced by the operator using a hand-held radio-control transmitter. The syringes were initially set at a vacuum by blocking the plungers in the drawn position. Solenoidactuated valves at the inle! to each syringe were initially closed. When the balloon attained a predetermined height, it was stopped and the operator sent a signal to the sampler to open the first solenoid valve. A flash of light was sent back to the operator from a strobe in the sampler to indicate the signal had been received. The sample flow into the syringe was regulated by a glass capillary tube at its inlet, sized to give a flow rate of about $10 \mathrm{cc} / \mathrm{min}$. After two minutes of sampling a signal was sent to close the first solenoid valve and open the second. Simultaneously the balloon began its ascent to the next predetermined height. The ascent rate was such that the iravel from the first position to the second took 
two minutes. Upon reaching the second position, the balloon was stopped and a signal was sent to switch to the next syringe. Sampling proceeded for two minutes at this height, and the same procedure continued until the seven syringes were filled. This sampling procedure resulted in every other syringe containing a vertically averaged sample.

Six vertical profiles of $\mathrm{SF}_{6}$ were made during this study, one in Exp 1, four in Exp 2, and one in Exp 4. The constant height samples were collected primarily at $25 \mathrm{~m}, 50 \mathrm{~m}, 75 \mathrm{~m}$ and $100 \mathrm{~m}$ AGL. The vertically integrated samples were collected at 25-50, 50-75, and 75-100 m AGL. The sampling time for all profiles was 14 minutes (two minutes per sample).

g. Meteorological observations

Several meteorological observation systems were operated during this study. As part of the overall Integrated Air Cancer Project, wind speed, wind direction, temperature and relative humidity were continuously measured by PEI Associates Inc. at several locations in the Roanoke vicinity for a few months during the winter in 1989. At six locations (CAR, BP, WP, MSP, FAA, and CIV in Fig. 2.) data were collected continuously during the January tracer experiments. The winds were measured at $10 \mathrm{~m}$ and the temperature and relative humidity were measured at $2 \mathrm{~m}$ AGL. Hourly average values were recorded. R.M. Young propeller and vane anemometers and temperature sensors were used.

Two Gill uvw propeller anemometers (R.M. Young) were operated at two locations during each experimental period. Temperature was also continuously measured at each location using Type $T$ thermocouples (No. SA1-T, Omega Engineering Inc.) connected to Calex Model 470 thermocouple amplifiers. The 
data was collected every four s, and five-minute-average data were recorded. The standard deviations of $u, v, w$, and temperature were calculated and recorded. One system (uvw1) was operated at the tracer release sites (locations REL and FAA in Fig. 2) and the other system (Uvw2) was operated on the Niagara Dam (location NIA in Fig. 2) except for Exp 5 where it was located at the Preston School (location PRS in Fig. 2). The height of the wind and temperature measurements at the Niagara Dam site were $3.2 \mathrm{~m}$ and $1.0 \mathrm{~m}$ above the riverlevel, respectively. At the Preston School site and the release sites, the winds were measured at $2.1 \mathrm{~m} \mathrm{AGL}$ and the temperature at $0.7 \mathrm{~m} \mathrm{AGL}$.

A tethered instrumented balloon (Morris et al., 1975) was operated during Exps 1,2 and 4 at the location TET in Fig. 2. Ascents were made to a maximum of $150 \mathrm{~m} \mathrm{AGL}$ at various times throughout each experimental period. Wind speed and direction, temperature, wet-bulb temperature and pressure change were measured and recorded. Ascents were limited to $150 \mathrm{~m}$ because of the proximity to the airport.

A Campbell Scientific, Inc Model CR21X data logger was used to collect net radiation, air temperature, and soil temperature profile data continuously throughout the study period at the FAA site (Fig. 2). Five-minute-averaged data were recorded for the period 0955 LST on 1/9/89 through 1255 LST on 1/20/89. A Micromet net radiometer measured net radiation at $0.8 \mathrm{~m} \mathrm{AGL}$, and Type $T$ thermocouples were used to measure air temperature at $1.5 \mathrm{~m} \mathrm{AGL}$, and soil temperature at $0.6,1.6,4.0,10.0,24.0$, and $58.9 \mathrm{~cm}$ below ground level.

A tower at the FAA site (Fig. 2) was instrumented with two three-axis sonic anemometers (model no. BH-478 C/3 Applied Technology, Inc.) at 11.4 and 29.6 m AGL, two Gill propeller and vane anemometers (R. M. Young) at 19.8 and 33.7 
m AGL, two delta-temperature systems (R. M. Young) operating between 1.5 to 16.2 $\mathrm{m} \mathrm{AGL}$, and 25.4 to $39.5 \mathrm{~m} \mathrm{AGL}$, and two dew point sensors at 1.5 and 25.4 m AGL. The data were collected with a personal computer based data acquisition system. Solar radiation data were also collected using an Eppley pyranometer located at the same site at $1.7 \mathrm{~m} \mathrm{AGL}$. A similar tower configuration was operated during an earlier Integrated Air Cancer Project study in Boise, Idaho, in December 1986. Eskridge et al. (1990) give a more detailed description of the sensors and the data acquisition system. The R.M. Young data were collected at one $\mathrm{Hz}$ and averaged to $10 \mathrm{~s}$ for data storage. The sonic data were collected at $10 \mathrm{~Hz}$ and averaged to one s for data storage.

Temperature was measured : vith one mobile van using a 0.010-in.-dia. Type $T$ thermocouple (No. SA1-T, Omega Engineering Inc.) mounted near the top of the van. This thermocouple has a response time of better than $0.3 \mathrm{~s}$. It was attached to a Calex Model 470 thermocouple amplifier, and the amplifier output signal was recorded at one $\mathrm{Hz}$ by the data acquisition system in the van. The thermocouple amplifier has a low pass filter set to eliminate noise higher than about $1.5 \mathrm{~Hz}$. This means a response change will be mostly realized within $0.7 \mathrm{~s}$ (assuming minimal filter roll-off). This is about the same as the sampling frequency of the data acquisition system. Thus the spatial resolution is limited by the sampling frequency which translates to about $10 \mathrm{~m}$ at a van speed of $50 \mathrm{~km} / \mathrm{h}$. Any temperature changes over distances less than this will not be resolved completely.

This temperature sensor, the temperature sensors with the uvw systems, and the temperature sensors with the CR21x system were all compared over a 
range of $-10^{\circ} \mathrm{C}$ to $20^{\circ} \mathrm{C}$ in the laboratory after the study. Corrections were applied to the data so that these data compared to within $0.1^{\circ} \mathrm{C}$ of each other.

Hourly surface weather observations were acquired from the National Climatic Data Center for the Roanoke airport observation station (ROA site in Fig. 2). The nearest National Weather Service (NWS) twice-daily upper-air observations of winds and temperature were made at Greensboro, North Carolina. Greensboro is iocated $140 \mathrm{~km} \mathrm{~S}$ of Roanoke on the eastern side of the Appalachian Mountains. The nearest upper-air station on the western side of the Appalachian Mountains is at Huntington, West Virginia. Huntington is located $245 \mathrm{~km} \mathrm{W-NW}$ of Roanoke.

\section{Results and discussion}

a. General meteorology during the study period

Figure 6 shows the variation of the temperature, net radiation, winds, humidity and precipitation at the FAA site through the study period. This site is representative of the general behavior of the basin-wide flow. Exp 2 and $\operatorname{Exp} 4$ both exhibit the greatest net long-wave radiation loss $\left(\sim 50 \mathrm{~W} / \mathrm{m}^{2}\right)$ at the surface at night. They also register the coldest nighttime near surface air temperatures ( $6^{\circ} \mathrm{C}$ ), weakest nighttime wind speeds and greatest drop in wind speed from the afternoon maximum winds.

Exp 4 was conducted during a wintertime night with the weakest synoptic influence of the five nights studied. This experiment provides the best opportunity for understanding and characterizing the dispersion during stagnating conditions. The remainder of this paper will focus on Exp 4. 


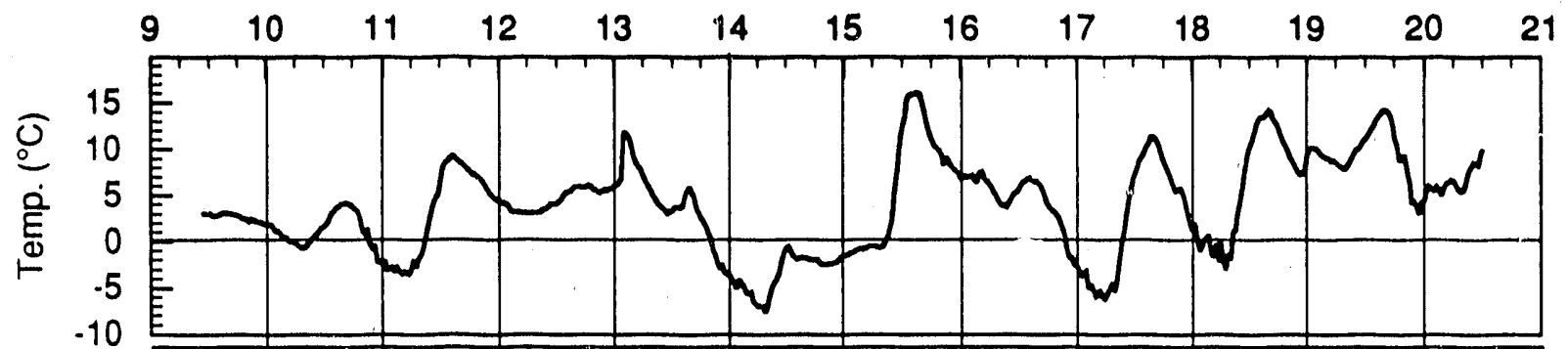

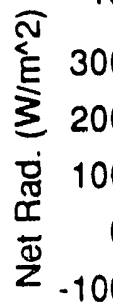

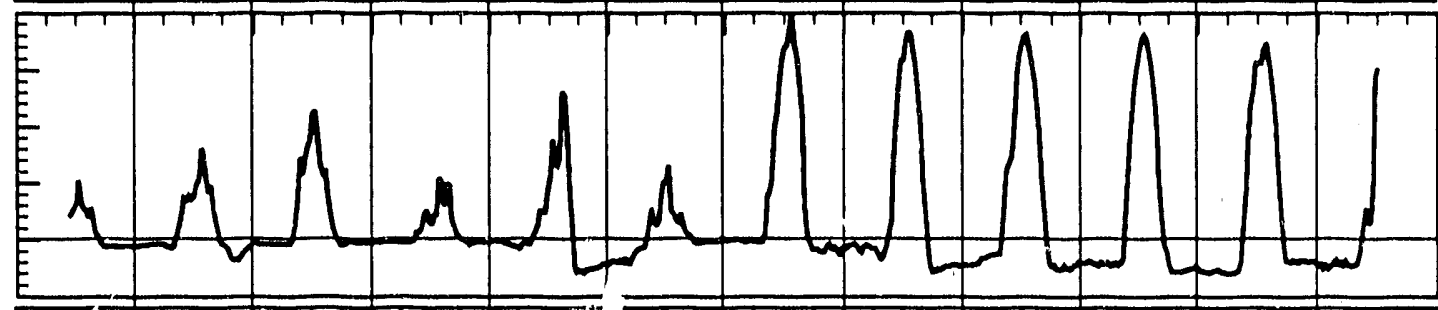

送

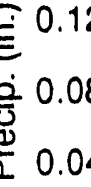

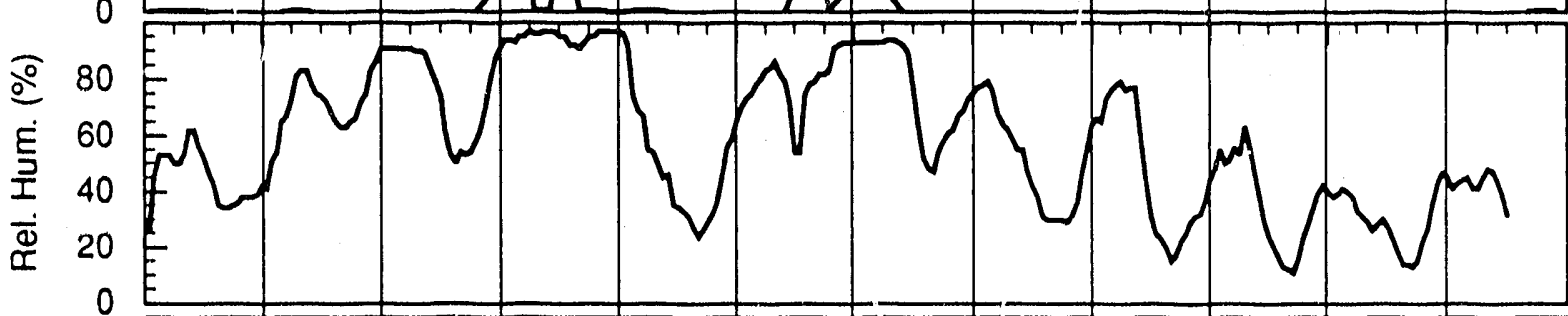

है 6

के 4 -

ह

$\sum_{\mathfrak{s}} 270$

180

妾 90

0

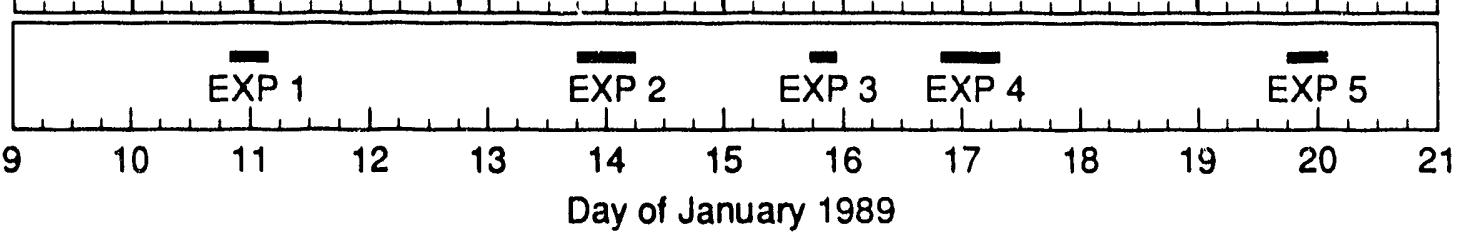

Figure 6. Temperature, net radiation, wind direction, wind speed, and relative humidity for the entire study period measured at the tower site. The precipitation amounts are from Roanoke NWS observations. 
b. Meteorological conditions

During Exp 4 the sky was clear, the surface winds were generally weak, and the ground was not snow-covered. Inspection of the NWS upper air observations from Greensboro, North Carolina and Huntington, West Virginia show that the winds aloft (above the Appalachian Mountains) were generally from the WNW at 5 to $10 \mathrm{~m} / \mathrm{s}$. The time of astronomical sunset for January 16 and astronomical sunrise for January 17, computed from sun-earth relationships, are 1722 and 0737 LST, respectively. These computed values are consistent with the measurements of solar radiation.

From inspection of the winds that were continuously measured at six locations (CAR, BP, MSP, FAA, and CIV in Fig. 2), the afternoon surface winds throughout the basin were persistent from the NW at approximately $6 \mathrm{~m} / \mathrm{s}$. During the evening transition period (roughly 1700-2100 LST) the wind speed decreased to around $1 \mathrm{~m} / \mathrm{s}$ and the wind direction became primarily locally dependent. That is, the winds appeared to be dictated by local topographic features. This behavior of the winds is evident in Fig. 7 for the winds measured at the WP site. After 2100 LST the winds were from the $S$ (down-slope) at approximately $1 \mathrm{~m} / \mathrm{s}$.

The winds at $34 \mathrm{~m} \mathrm{AGL}$ at the tower (FAA in Fig. 2) are given in Fig. 8. During the release period (2000-0400 LST) the winds were primarily from $290^{\circ}$ at roughly $1.8 \mathrm{~m} / \mathrm{s}$. The tower is on a ridge bounding the $W$ side of Lick Run. It's at an elevation of $331 \mathrm{~m} \mathrm{MSL}$ (Figs. 2 and 3). The predominant wind direction observed at the upper level on the tower is consistent with the winds aloft and the general "down-basin" orientation of the Roanoke basin (Fig. 1). For the same period at the release site, the winds at $2 \mathrm{~m} \mathrm{AGL} \mathrm{(Fig.} \mathrm{8)} \mathrm{were} \mathrm{generally}$ 


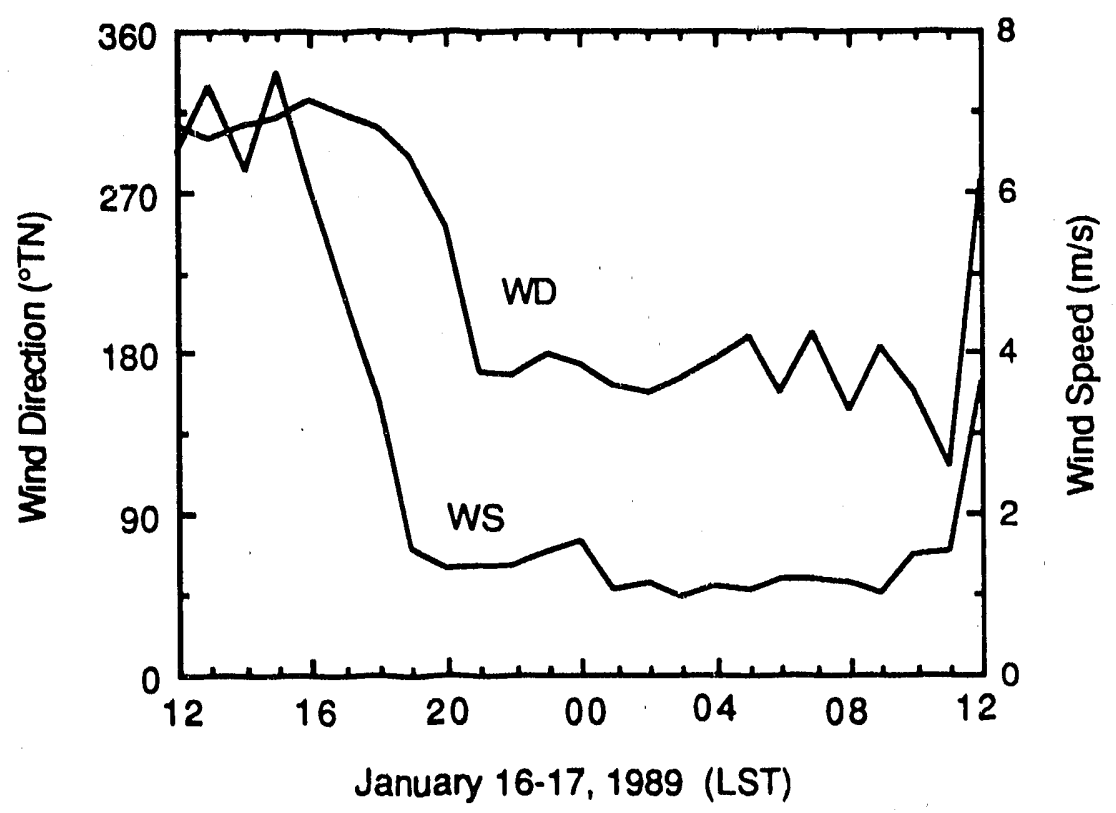

Figure 7. Hourly average winds at $10 \mathrm{~m} \mathrm{AGL}$ at the WP site.

from $350^{\circ}$ at approximately $0.6 \mathrm{~m} / \mathrm{s}$. This is along the local axis of Lick Run. The release site is at an elevation of $335 \mathrm{~m} \mathrm{MSL} \mathrm{(Fig.} \mathrm{3),} \mathrm{however,} \mathrm{it's} \mathrm{located} \mathrm{roughly}$ $20 \mathrm{~m}$ below the ridgeline.

On four occasions (identified in Fig. 8) during the tracer release period the winds at the release site briefly reversed (southerly winds) and went up Lick Run. These reversal times correspond to a shift from NNE to SSW-to-S winds at the upper level on the tower, indicating the strong effect of the winds above Lick Run on the winds within Lick Run at the release location. The temperature at $\sim 1 \mathrm{~m}$ AGL at the release site increased approximately $1^{\circ}$ to $3^{\circ} \mathrm{C}$ during these episodes of southerly winds. This indicates an increase in the vertical mixing (downward transport of heat) in Lick Run during these episodes.

The cause of this periodic shift in the winds at the tower (period of roughly 70 min.) is unclear. When the winds were from the SW quadrant, they were generally weaker $(\sim 1 / \mathrm{ms})$ than the winds from the WNW $(\sim 2.5 \mathrm{~m} / \mathrm{s})$. Inspection of 


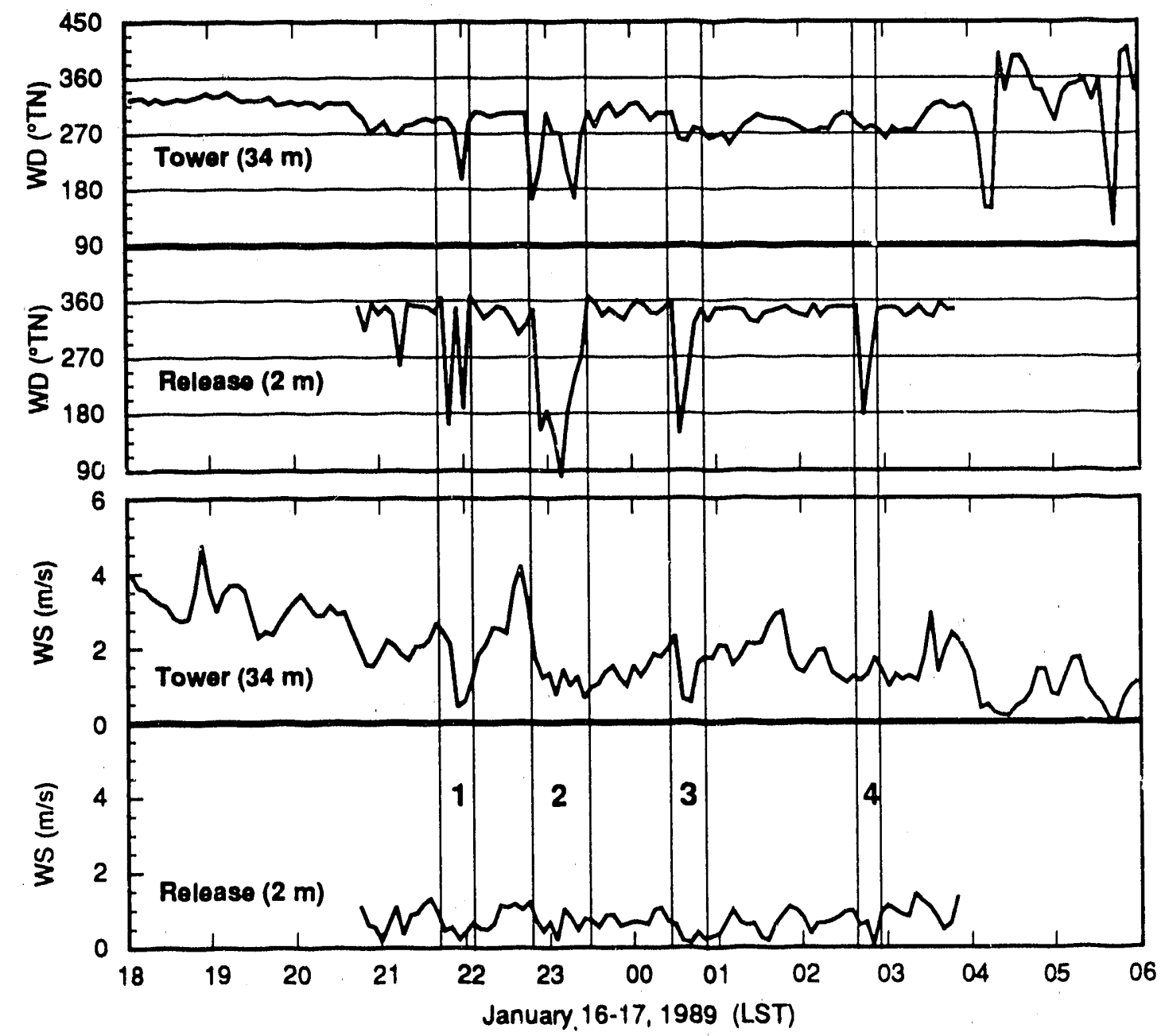

Figure 8. Five minute average winds at $2.1 \mathrm{~m} \mathrm{AGL}$ at the release site and at $34 \mathrm{~m}$ $A G L$ at the tower site.

a topographic map of the region shows high mountains ( $1000 \mathrm{~m} \mathrm{MSL}$; the foothills of these mountains can be seen in Fig. 1) roughly 15 to $20 \mathrm{~km} \mathrm{SW}$ of the tower site, and to the NW of the tower site. This is in contrast to the $350 \mathrm{~m} \mathrm{MSL}$ elevation of the Roanoke River Valley at the same distance to the $W$ of the tower site. One explanation of this periodic shift in the winds at the tower is the changing balance between the downslope flows from the various slopes of the basin. Occasionally, the downslope flows from the SW portion of the basin will be "felt" more at the tower site than the other flows. Another explanation is the balance between the synoptic forcing and the various basin flows. The actual 
112

forcing is probably a combination of these conditions. Dynamic modeling of the basin atmosphere would be the next step toward unraveling the dominant causes. Whatever the cause, it is quite clear that flow in Lick Run at the release location is strongly influenced by these changes, and hence the dispersion is strongly affected, as will 'oe discussed later.

The surface air temperature (approx. $2 \mathrm{~m} \mathrm{AGL}$ ) behaved in a similar manner throughout the basin. Prior to sunset the temperature was at a maximum of roughly $6^{\circ} \mathrm{C}$, and subsequently cooled to a minimum of $-6^{\circ} \mathrm{C}$ at about $0600 \mathrm{LST}$. This is a cooling rate of about $0.8^{\circ} \mathrm{C} / \mathrm{h}$. Figure 9 gives the temperature measured at the WP site and at three levels $(1.5,16$ and $40 \mathrm{~m} \mathrm{AGL})$ on the tower. Temperature differences vere measured on the tower through two layers, 1.5-16 and 25-40 $\mathrm{m} \mathrm{AGL}$. The temperature gradient between 1.5-16 $\mathrm{m}$ during the release period is strongly stable at about $0.15^{\circ} \mathrm{C} / \mathrm{m}$. Between $25-40 \mathrm{~m}$ the temperature gradient is $0.02^{\circ} \mathrm{C} / \mathrm{m}$, which is cioser to the adiabatic temperature gradient of $-0.01^{\circ} \mathrm{C} / \mathrm{m}$.

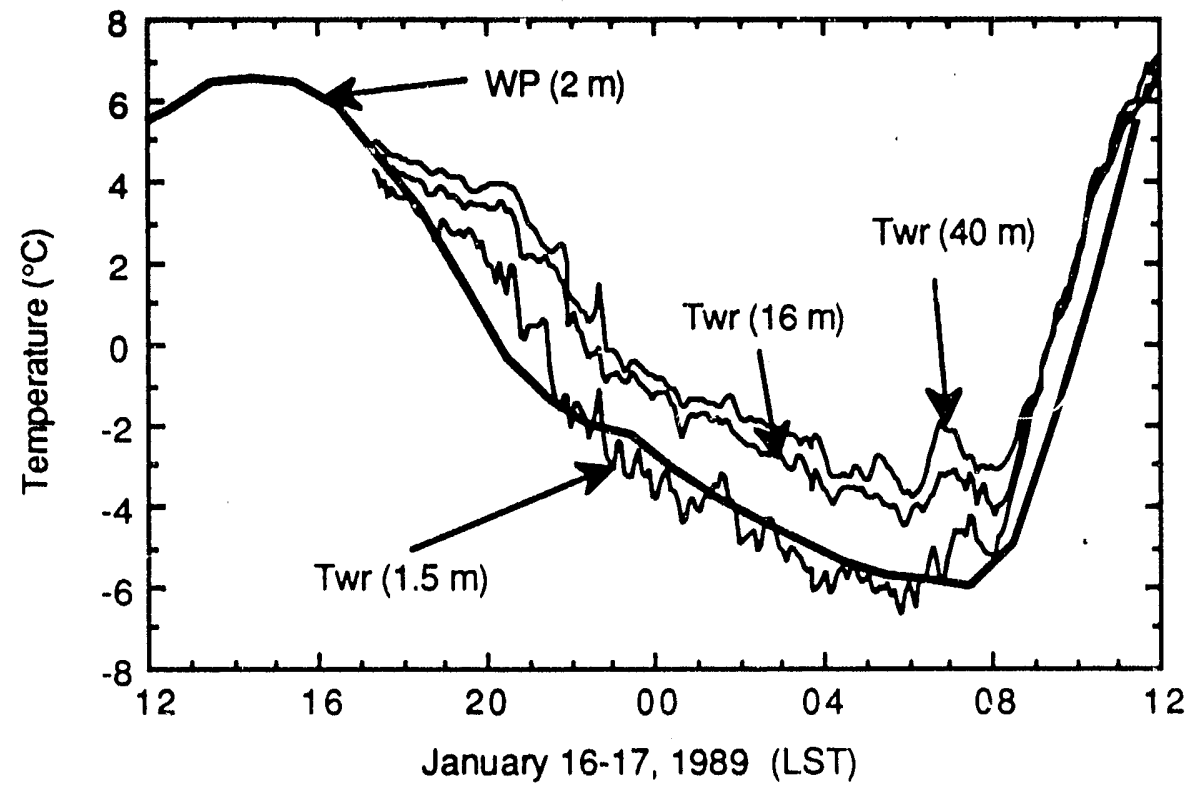

Figure 9. Five-minute average temperatures at the tower and hour-average temperatures at the WP site. 


\section{c. Transport winds}

The character of the horizontal transport winds is exhibited in Fig. 10. Each panel gives estimated centerline locations in the study domain of an averaged continuous "plume" for various times after the release start at 2000 LST. These "plume" locations were determined from the Lagrangian description of fluid particle motion using the measured velocities $u(t)$, and $v(t)$, where

$$
\begin{aligned}
& x_{i}=x_{i-1}+\int_{t_{i-1}}^{t_{1}} u(t) d t=x_{i-1}+u_{i} \Delta t \\
& y_{i}=y_{i-1}+\int_{t_{i-1}}^{t_{1}} v(t) d t=y_{i-1}+v_{i} \Delta t
\end{aligned}
$$

and

$t_{i}=t_{i-1}+\Delta t$

$\left(x_{i}, y_{i}\right)$ is the location of the particle at time $i_{i}$,

$\left(x_{i-1}, y_{i-1}\right)$ is the location of the particle at tirne $t_{i-1}$,

$u_{i}$, is the $x$-component of winds averaged over time interval $t_{i-1}$ to $t_{i}$,

$v_{i}$, is the $y$-component of winds averaged over time interval $t_{i-1}$ to $t_{j}$.

The initial location $\left(x_{0}, y_{0}\right)$ is the wind station coordinates, and the time interval $\Delta t$ is either $1 / 2 \mathrm{~h}$ or $1 \mathrm{~h}$, depending on the wind station averaging interval.

The 1/2-h to 1-h averaging times are reasonable for the scales of turbulence (integral time scales of minutes to severai minutes) expected in these flows. In principle, the "average" continuous plume at any distance from the release site will not vary with averaging time greater that $t_{p}$, where $t_{p}$ is the averaging time required to account for the effects on diffusion of the dominant scales of turbulent 
114
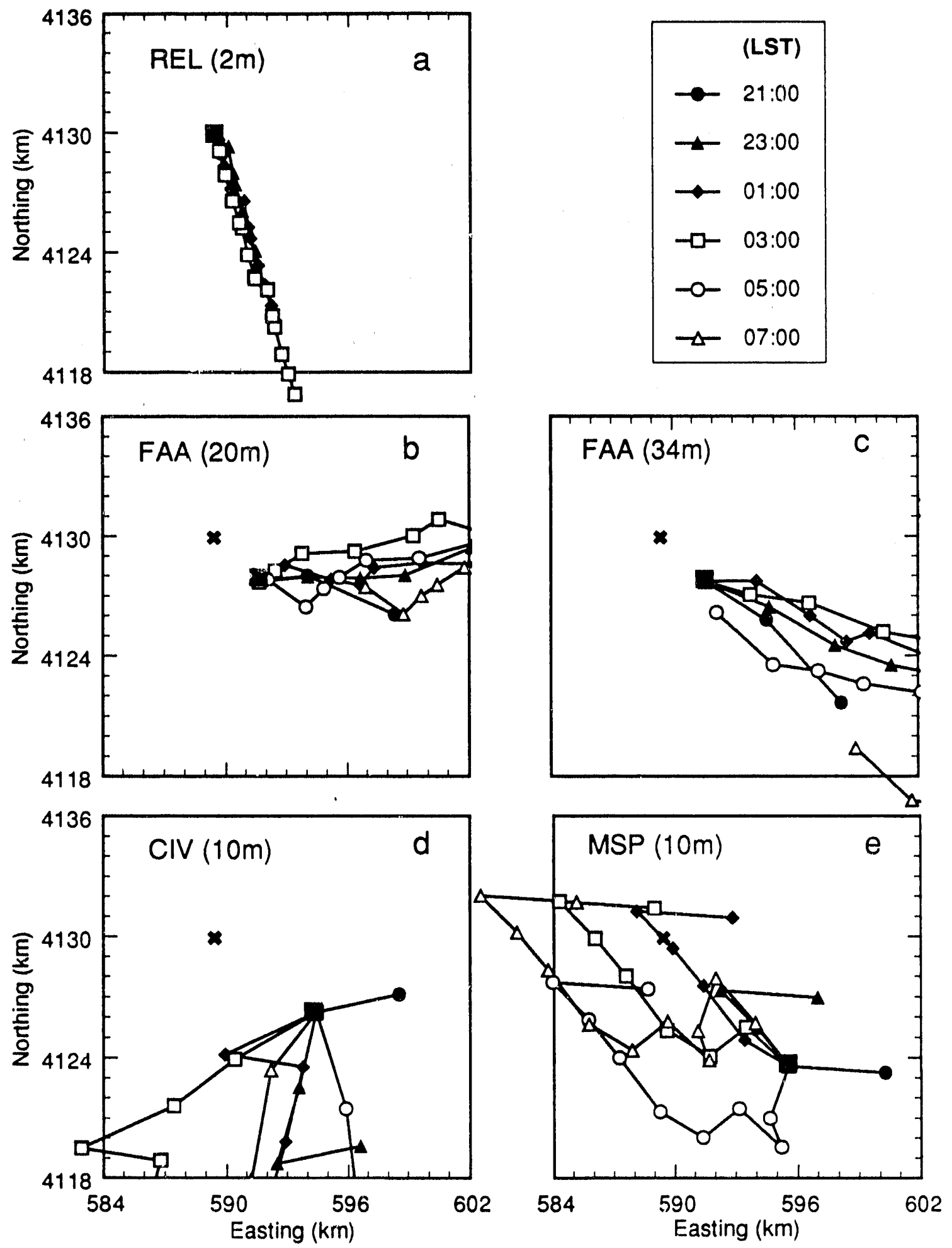

Figure 10. Estimated "plume" centerline locations at six times computed using measured winds. Panels $A, B$, and $C$ use $1 / 2 h$ average winds and panels $D$ and $E$ use $1 \mathrm{~h}$ average winds. The " $X$ " is the tracer release location, and the darkened square is the wind data site. 
motion. In practice, the average continuous plume will likely vary with averaging times greater than $t_{p}$ beceuse of changes in wind direction due to other timevarying forces. These can be, for example, flow oscillations, rotors, waves, blocking and channeling. The range in variations of the averaged plume location is demonstrated in the various panels in Fig. 10. Panel $A$ shows a narrowly confined plume, whereas panel $B$, for example, shows more variation in plume location with time, even though both use 30-min.-average wind data.

The "plume" centerline location in panel $A$ is within Lick Run at the release location. The winds above Lick Run, as represented by the wind profile at the FAA site (panels $B$ and $C$ ), indicate greater "plume" meander ( $40^{n}$ sector) than within Lick Run ( $\sim 4^{\circ}$ sector). The transport direction is to the $E$ through $S E$ above Lick Run versus to the SSE in Lick Run. This is a $30^{\circ}-70^{\circ}$ wirid direction shear, which would enhance horizontal plume dispersion (discussed later) as the plume moves from the release location. The distance between symbols on any plume path in panels A-C, represents the distance the plume traveled in 1/2-h intervals. The winds were much lighter at the release location in Lick Run (panel A) than above the ridge along Lick Run (panels $B$ and $C$ ).

Panels $D$ and $E$ in Fig. 10 reveal the transport character of the winds at other locations in the Roanoke Basin. Hourly winds at locations CIV and MSP are represented. The CIV site (290 m MSL) is located near the Roanoke city center in the lower portions of the Roanoke basin. The transport direction is southerly over a large sector of influence ( $80^{\circ}$ sector). This direction is consistent with the local slope of the basin floor being in a southerly direction. The transport directions at the MSP site (panel E) are in nearly the opposite direction from those of the tower and release site transport directions. The winds at the MSP 
site are dominated by the downslope winds off the NW facing slopes at the outflow boundary of the Roanoke basin.

d. Pool formation

A tethersonde was operated at the lowest point in the basin (Fig. 3) with ascents to about $150 \mathrm{~m} \mathrm{AGL}$ (424 m MSL). Potential temperature profiles from four ascents are given in Fig. 11. These profiles reveal a slightly stable region that grows from the basin floor up to a maximum height of $50 \mathrm{~m} \mathrm{AGL} \mathrm{(324} \mathrm{m} \mathrm{MSL)}$ by about 0250 LST. The top of this slightly stable region is considered to be the top of the cold air pool and is marked by black dots on each successive sounding in Fig. 11. Thrs ascent rate of the top of the pool is calculated to be about $9 \mathrm{~m} / \mathrm{h}$. At this ascent rate the entire fill time is about $5.6 \mathrm{~h}$. This gives a fill start time of arcund 2115 , which is consistent with the end of the evening transition period.

Also shown in Fig. 11, with the heavy dark lines, are the temperature measurements from four levels on the tower. These measurements are shown at the same MSL height as the tethersonde observations. (The base elevation of the tower is $331 \mathrm{~m} \mathrm{MSL}$ and the tethersonde is $274 \mathrm{~m} \mathrm{MSL}$.) After the pool has formed, an elevated temperature inversion, with virtually the same strength and location as the surface temperature inversion at the tower site, is present over the tethersonde site. The evolution of this elevated inversion over the tethersonde site is consistent with cold air filling the basin behind the barrier. During the early stages of the pool formation, the cold air, moving down the slopes, falls to the lower portions of the basin seeking a level with the same potential temperature. As the basin fills the cold air travels at succassively higher levels until the basin is full. 

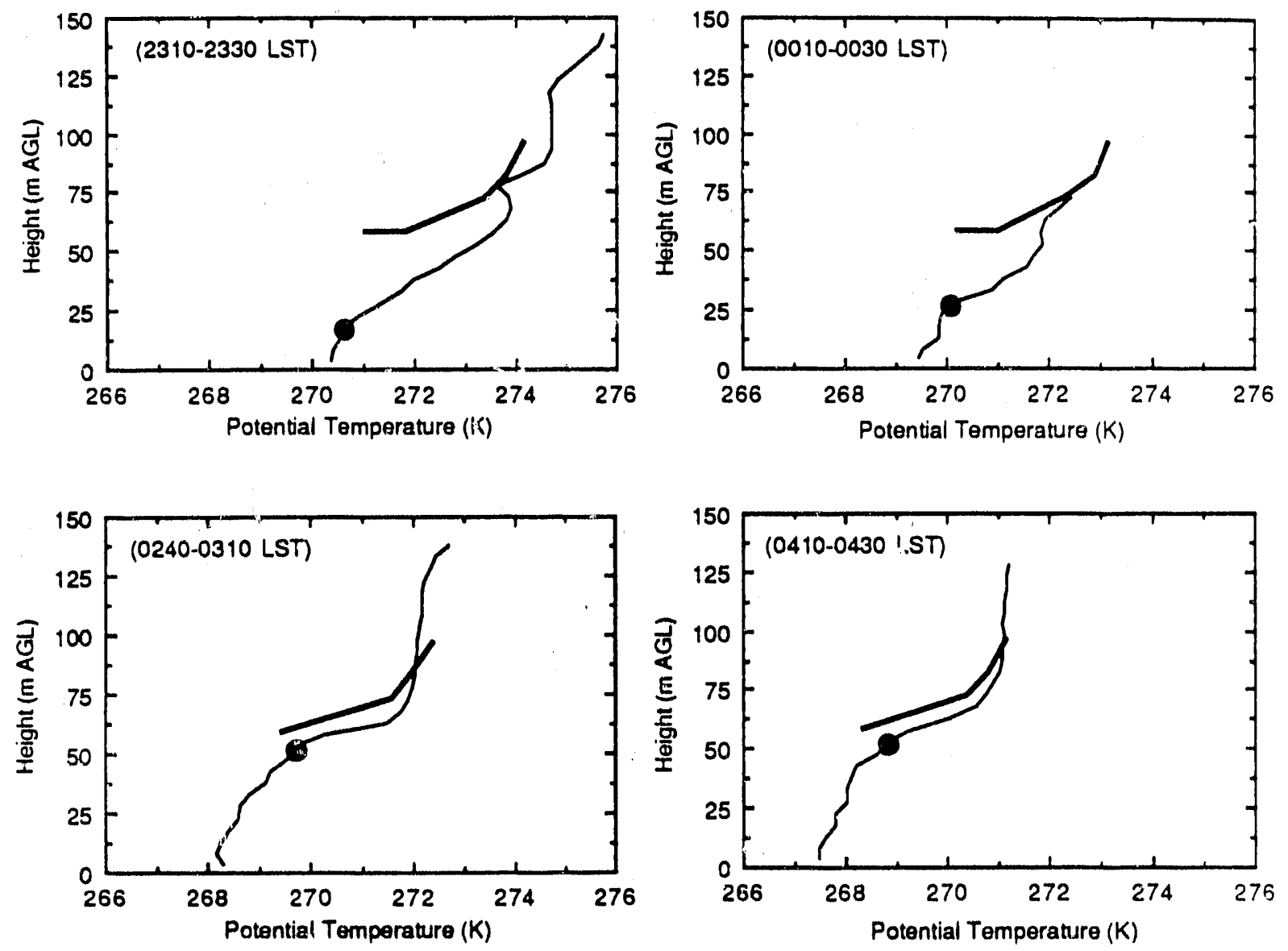

Figure 11. Potential temperature profiles at the tower and tethersonde during Exp 4. The thick line represents 5-minute-average values on the tower at the same time as the corresponding instantaneous tethersonde observations. The solid dots represent the top of the cold air pool.

The elevated temperature inversion, after about 0300 LST, has its base at $324 \mathrm{~m} \mathrm{MSL}$ and its top at $342 \mathrm{~m} \mathrm{MSL}$. These are marked with asterisks on the tethersonde line in Fig. 3. It is apparent from this that the top of the inversion is about the same height as the barrier. This further supports the conclusion that the elevated stable layer is produced by pooling behind the barrier. Also, as evidenced by the tower observations (and the configuration in Fig. 3), the pool extends horizontally to roughly the vicinity of the tower. 
Figures 12 and 13 give profiles of wind speed and wind direction from the tethersonde for the soundings given in Fig. 11. These show the winds to be weak and variable below the inversion top (about $70 \mathrm{~m} \mathrm{AGL}$ ), and stronger and more steady above the inversion top. These observations also help define the limits of the pool that has formed.

A simple model is proposed for determining the pool filling rate based on continuity. Knowing the volume flow rate of the slope winds feeding the basin, and the volume of the basin, the height of the top of the cold air pool, $\mathrm{H}_{\mathrm{ca}}(\mathrm{t})$, can be calculated from

$$
\int_{0}^{H_{c a}} A_{b}(z) d z=\int_{0}^{t_{c a}} \dot{V}_{s}(t) d t
$$

where

$A_{b}(z)$ is the horizontal area of the basin as a function of height $\left[\mathrm{m}^{2}\right]$,

$Z$ is the vertical coordinate with its origin at the lowest point in the basin, $\dot{V}_{s}(t)$ is the volume flow rate of air accumulating in the basin $\left[\mathrm{m}^{3} / \mathrm{s}\right]$, and $t_{c a}$ is elapsed time [s], with the basin beginning to fill at $t_{c a}=0$.

Initially, $\mathrm{H}_{\text {ca }}$ is zero when $\mathrm{t}_{\mathrm{ca}}$ is zero. The maximum value of $\mathrm{H}_{\mathrm{ca}}$ is constrained to be less than or equal to the height of the lowest outflow barrier in the basin. The maximum value of $\mathrm{H}_{\mathrm{ca}}$ is expected to depend on atmospheric stability and wind strength above the cold air pool. The volume flow rate of air accumulating in the basin can be determined from observations of slope flow strengths and depths, or from slope flow models (e.g., Hanna et al.,1982). The horizontal area of the basin as a function of height can be determined from topographic maps or digital terrain models. Based on results from this study, filling should start at the end of the evening transition period. 


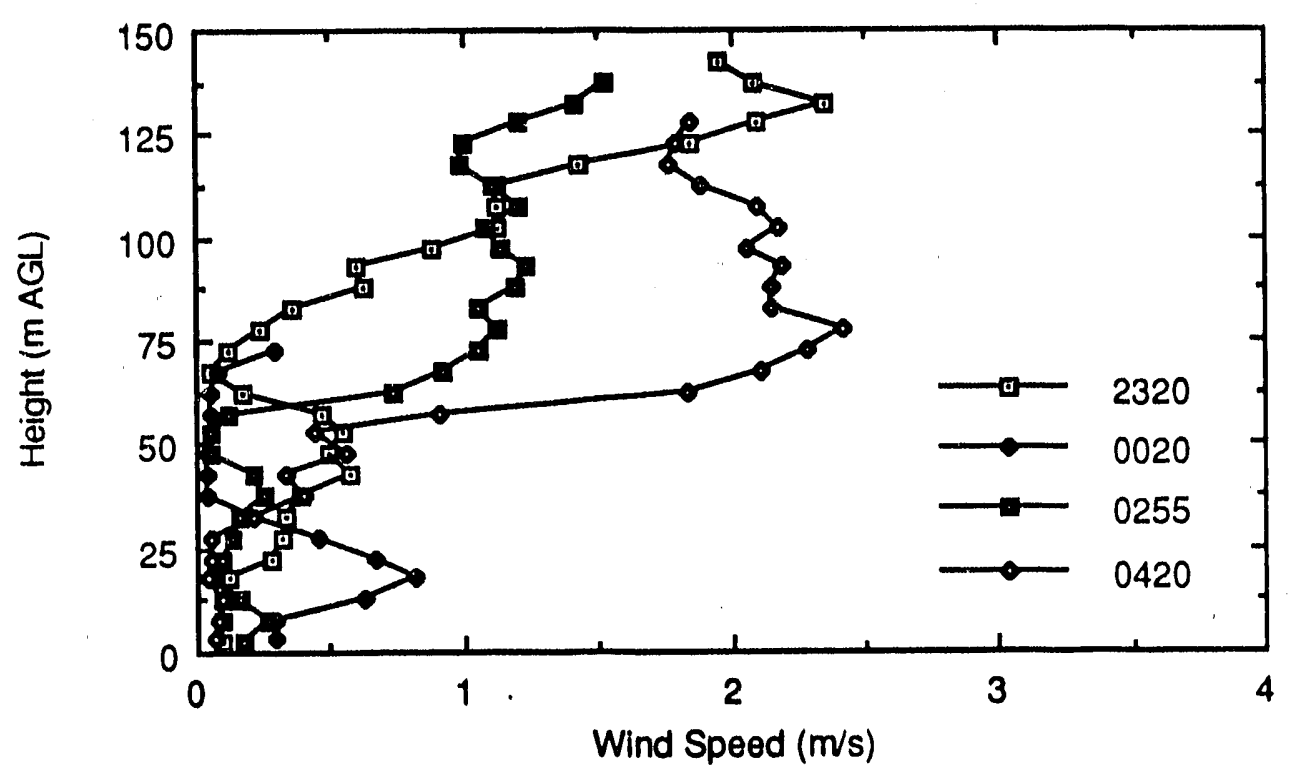

Figure 12. Wind speed profiles from the tethersonde during Exp 4.

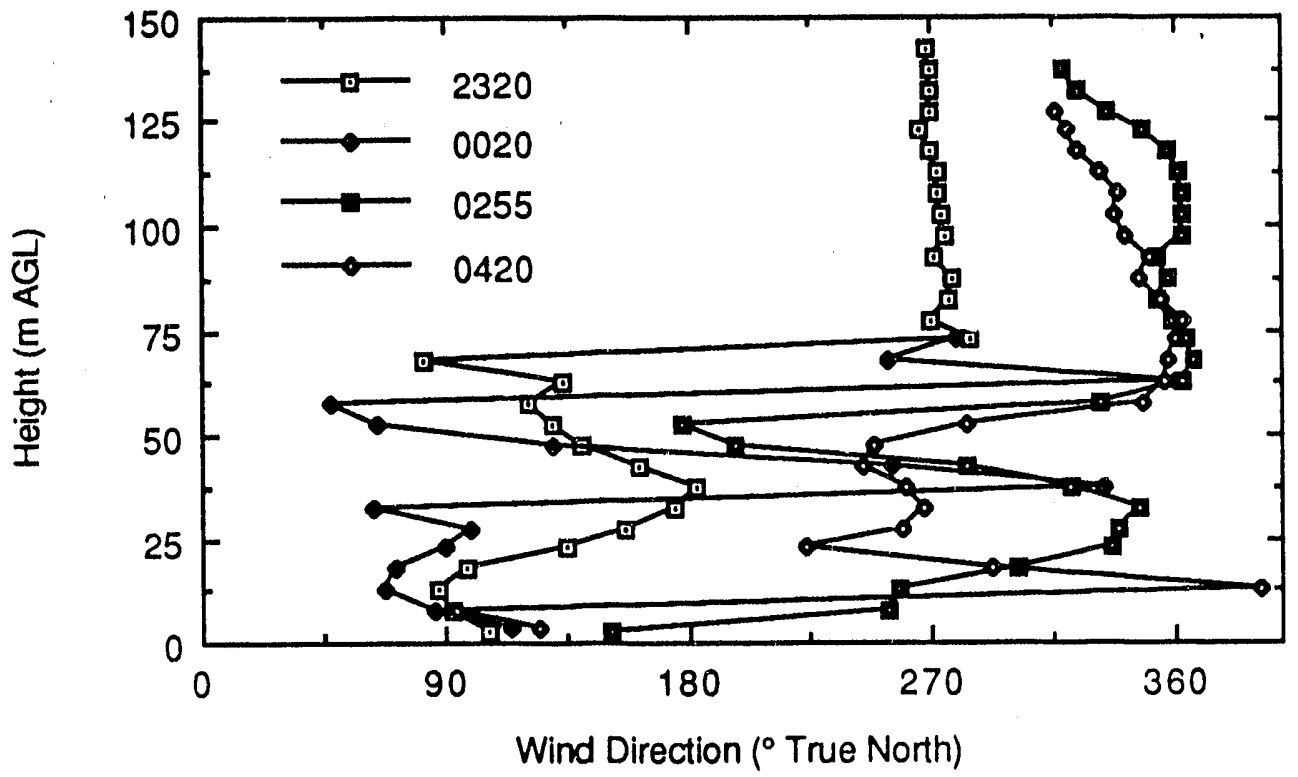

Figure 13. Wind direction profiles from the tethersonde during Exp 4. 
Consider the 2-D representation of the Roanoke basin given in Fig. 3. Eqn (4) for the Roanoke basin can then be approximated as

$$
H_{c a}=\sqrt{2 \dot{V}_{s} t_{c a} \tan \theta}
$$

where

$\theta$ is the elevation angle of the basin floor, and

$\dot{V}_{s}(t)$ is the volume flow rate per unit width of the basin $\left[\mathrm{m}^{2} / \mathrm{s}\right]$.

The basin fill time, $T_{c a}$, can be calculated from Eqn (5) as

$$
T_{c a}=\frac{H_{c a}^{2}\left(T_{c a}\right)}{2 \dot{V}_{s} \tan \theta}
$$

where $H_{c a}$ is approximately $50 \mathrm{~m}, \theta$ is $0.5^{\circ}$ and $\dot{V}_{s}$ is estimated from the tower measurements as $8 \mathrm{~m}^{2} / \mathrm{s}(0.8 \mathrm{~m} / \mathrm{s}$ through a depth of $10 \mathrm{~m})$. The $10-\mathrm{m}$ depth corresponds roughly to the depth of the strongest portion of the surface-based temperature inversion observed at the tower. The resulting fill time for the Roanoke basin determined from Eqn (6) is approximately $5 \mathrm{~h}$. This is comparable with fill time estimated from Fig. 11.

e. Tracer concentrations and diffusion rates

A vertical profile of $\mathrm{SF}_{6}$ was measured at $0340-0400$ LST. The results are given in Fig. 14 plotted with the temperature as a reference. An elevated plume is present above the inversion top. This is consistent with the results given previously, that air from near the elevation of the tower site (and the release site; Fig. 3) traveled at the elevation of the top of the cold air pool.

Ground-level concentrations are given in Fig. 15 for selected hours during Exp 4. The temporal variation in the pattern does not chinge significantly 
through the study period other than the downwind movement of the trailing edge of the tracer plume after the release stops at 0400 . The tracer plume also covers a significant portion of the basin, especially within a few $\mathrm{km}$ of the release site. The ground-level concentration diminishes rapidly with distance from the release point, especially downwind from Arc O2. Figure 16 shows this more clearly, where the maximum concentration measured on each arc is plotted versus distance from the release site. The decrease in concentration with distance is much greater than normally expected for a ground-level continuous plume in a slightly stable atmosphere, even in complex terrain situations.

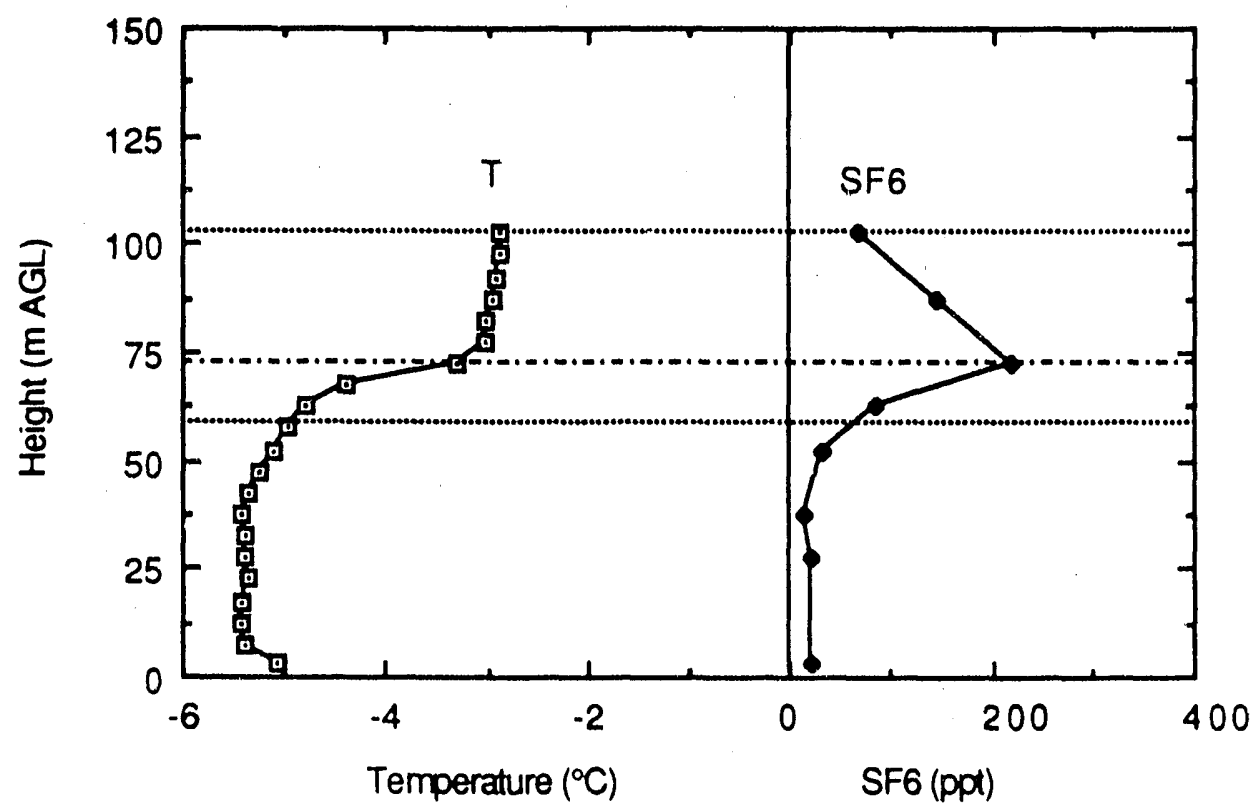

Figure 14. Tracer and temperature profiles at 0340-0400 LST from the tethersonde during Exp 4.

The cold air pool described previously plays a significant role in the dispersion of the tracer, as is demonstrated in Fig. 14. The pool behavior dictates the height of the plume above the ground, which has a distinct effect on groundlevel concentrations. Inspection of Fig. 14 indicates that the vertical diffusion rate 

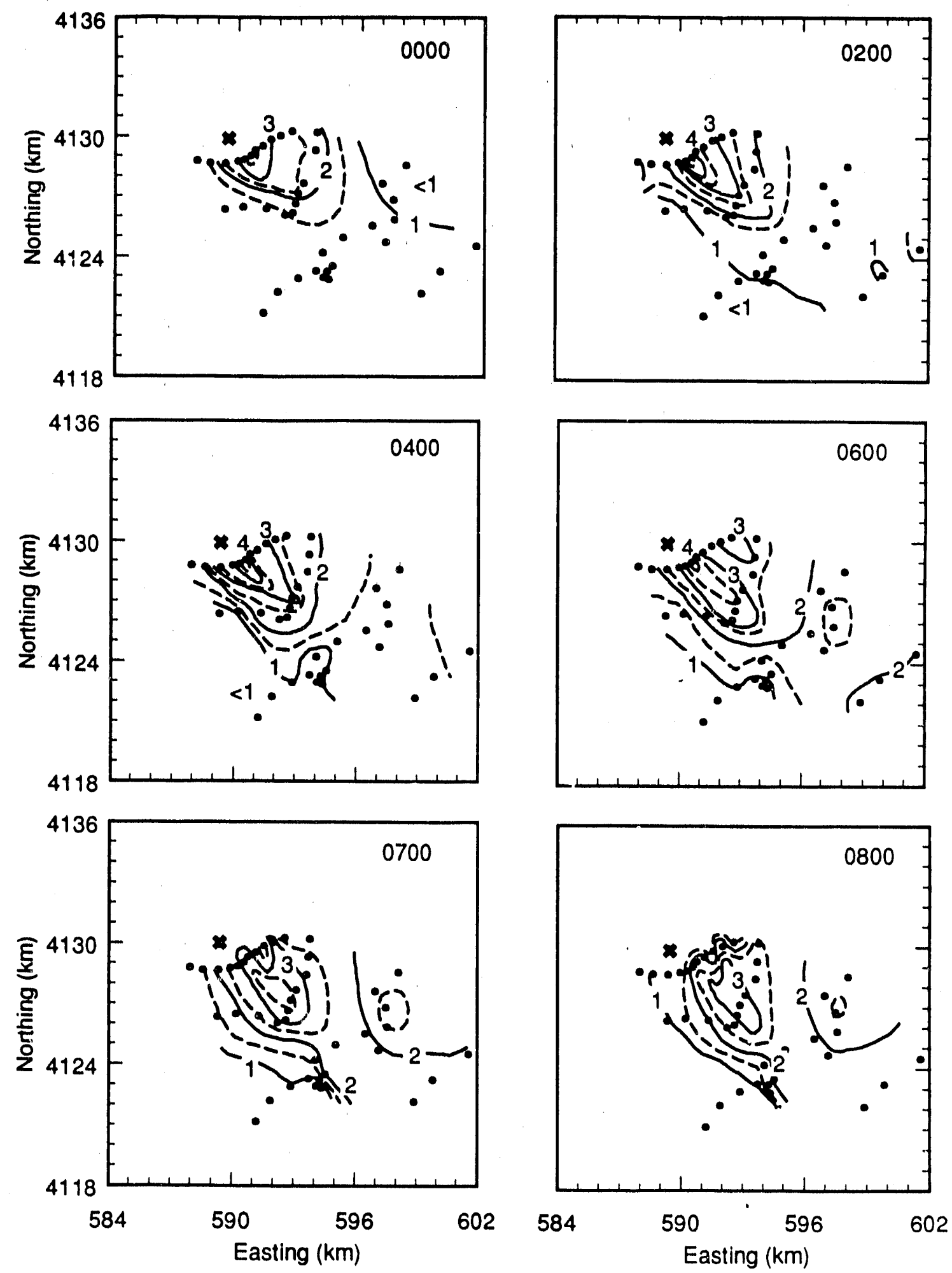

Figure 15. One-hour-average ground-level tracer concentrations measured over the study domain at six selected times. The " $x$ " denotes the release location and the numbers are the exponents of 10 representing the tracer concentration in ppt. 
may be affected considerably by the vertical temperature structure of the pool. The magnitude of the concentration gradient below the concentration peak ( $\sim 75$ $m$ AGL) is twice the magnitude of the gradient above the peak, indicating weaker diffusion downward (toward the surface). This may be due to ir. hibited exchange across the temperature inversion.

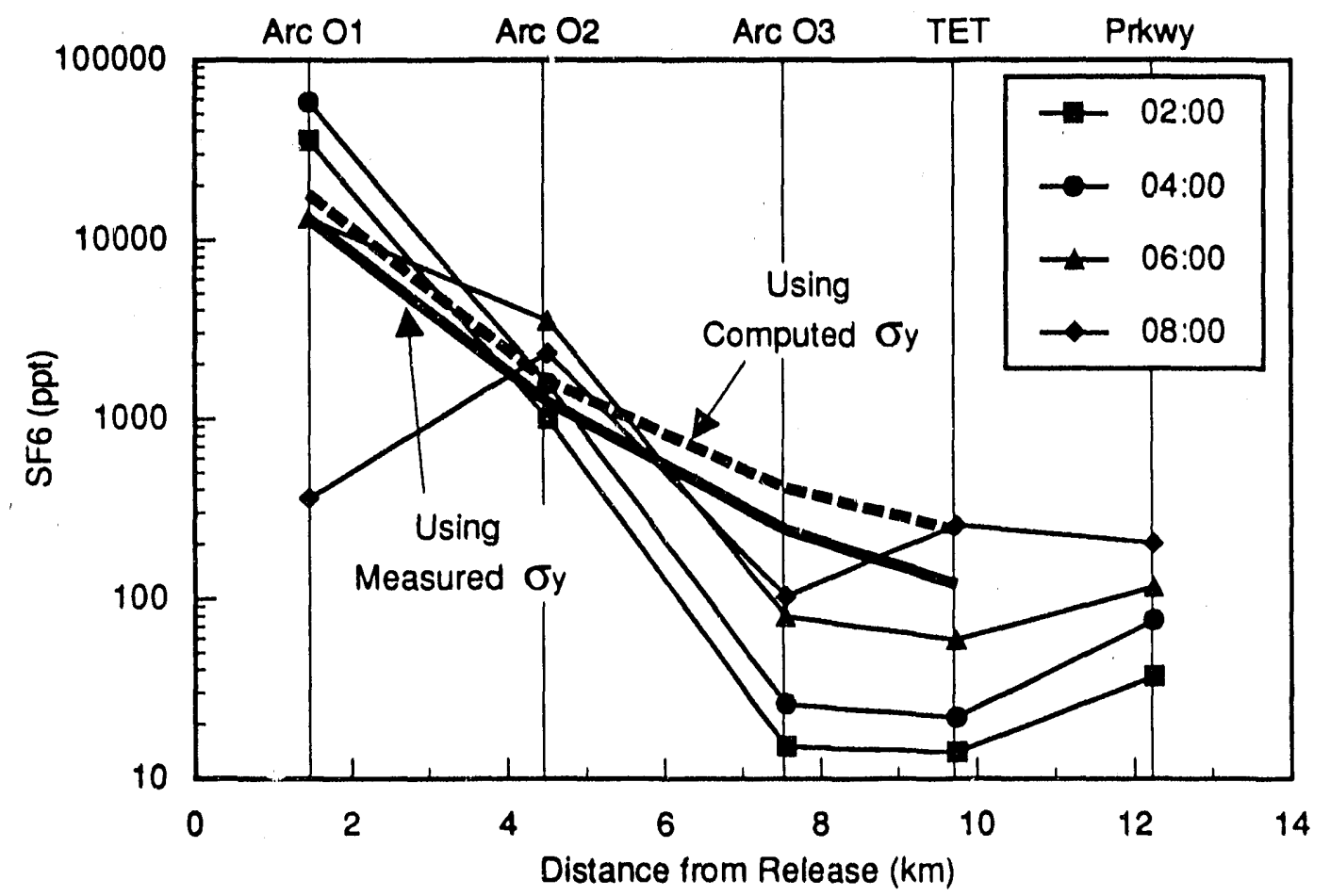

Figure 16. Maximum 1-hour-average ground-level tracer concentration measured on each sampling arc versus distance from the release site. The heavy solid and dashed lines give results using the Gaussian plume equation with measured and computed horizontal plume spread, respectively. The plume spread values are from Table 4.

The effects of the pool formation on the plume character at Arc O1, and to a lesser extent Arc 02, is not as clearly demonstrated. As discussed in the previous section, the MSL elevation of the top of the fully developed pool approached the elevation of the release site. The elevation differences between 
the release site and the lowest point in Arcs 01, 02, 03 and the tethersonde site are $10,35,55$, and $60 \mathrm{~m}$, respectively. These elevation differences indicate that the tracer plume may still be at ground-level at Arc 01, but probably elevated at Arc 02 , and certainly at Arc $\mathrm{O} 3$.

As discussed in the section on transport winds, the wind direction shear between winds in Lick Run and winds above Lick Run may enhance the horizontal plume spread over the spread due to pure turbulent diffusion. The effects of this wind direction shear on horizontal plume spread are investigated next. An estimate of the plume spread, $\bar{Y}$, from measurements of the groundlevel concentrations can be determined by

$$
\bar{Y}^{2}=\frac{1}{A} \int_{-\infty}^{\infty}\left(Y-Y_{0}\right)^{2} C d y
$$

where

$$
Y_{0}=\frac{1}{A} \int_{-\infty}^{\infty} Y C d y
$$

$$
A=\int_{-\infty}^{\infty} C d y
$$

$Y$ is the cross-plume coordinate [m], and

$C$ is the concentration as a function of cross-plume distance [ppt].

A useful exercise is to compare these "measured" plume widths with estimated values from commonly used relationships. This provides a link with a large body of previous work. on the dispersion of a continuous time-averaged plume in the near-surface boundary layer. This comparison of plume widths is not meant to imply similarity between the atmospheric conditions during this 
experiment and the atmospheric conditions in the previous studies, but is meant to provide guidance in the interpretation of the experimental results. The relationship used here is an approximation presented by Pasquill (1976) and discussed by Irwin (1979) where the total plume width $\sigma_{y}$ is computed as

$$
\sigma_{y}^{2}=\sigma_{t}^{2}+\sigma_{s}^{2}
$$

where

$\sigma_{t}^{2}$ is the horizontal plume spread from atmospheric turbulence, and $\sigma_{s}^{2}$ is the horizontal plume spread from wind direction shear.

A rough estimate of $\sigma_{\mathrm{S}}$ suggested by Pasquill (1976) is

$$
\sigma_{s}^{2}=0.03 \phi^{2} x^{2}
$$

where

$X$ is the downwind distance [m], and

$\phi$ is the turning of wind direction through the plume depth [radians].

The plume spread due to turbulence is of the form recommended by Hanna et al. (1977)

$$
\sigma_{t}=\sigma_{v} t t_{y}
$$

where

$\sigma_{v}$ is the standard deviation of the cross-plume winds [m/s],

$t$ is the travel time [s], and

$f_{y}$ is a nondimensional function of travel time.

The function $f_{y}$ used is that recommended by Irwin (1983)

$$
f_{y}=[1+0.9 \sqrt{t / 1000}]^{-1}
$$


and the travel time $t$ can be estimated by $t=X / U$, where $U$ is the average transport wind speed.

The "measured" $\bar{Y}$ 's determined using Eqn (7) are given in Table 4. The computed plume widths are also given in Table 4 , using $\sigma_{v}$ equal to $0.2 \mathrm{~m} / \mathrm{s}, \phi$ equal to 1.22 radians $\left(70^{\circ}\right)$, and $U$ equal to $0.6 \mathrm{~m} / \mathrm{s}$. To be consistent with the one $h$ averaging time of the measurements of plume spread, the above values reflect one $h$ averages. The $\sigma_{v}$ and $U$ were from measurements at the release site, and $\phi$ was estimated from Fig. 10. This value of $\dot{\phi}$ is an extreme value taken as the difference between the plume path in panel a and the middle of the paths in panal $b$, and is an estimate of the maximum wind direction shear between the winds in Lick Run and the winds above Lick Run.

Table 4. Horizontal Plume Spread.

\begin{tabular}{ccccccc}
\hline ARC & $X$ & $\bar{Y}$ & $\sigma_{y}$ & $\sigma_{t}$ & $\sigma_{y} / \bar{Y}$ & $\sigma_{t} / \bar{Y}$ \\
& $(\mathrm{~m})$ & $(\mathrm{m})$ & $(\mathrm{m})$ & $(\mathrm{m})$ & \\
\hline 01 & 1450 & 550 & 400 & 200 & .73 & .36 \\
O2 & 4500 & 1350 & 1050 & 450 & .78 & .33 \\
03 & 7550 & 2900 & 1700 & 600 & .59 & .21 \\
\hline
\end{tabular}

The resuits in Table 4 show that the estimate of plume spread due to turbulent diffusion is about $1 / 3$ of the measured plume spread for Arcs 01 and O2. Including the effects of wind direction shear on total (turbulence plus shear) , llume spread improves the ratio to $3 / 4$. This indicates that other processes are probably contributing to the horizontal plume spread besides turbulence and wind direction shear. Also, Eqns (11) and (12) probably give conservative (bigger) estimates of turbulence- and shear-generated plume spread for the meteorological conditions experienced during Exp 4. The complex nature of the terrain around the release site and Arcs 01 and 02 is probably the dominant reason for the large plume spread experienced at these travel distances. The 
plume cari follow various paths down gullies and around or over small terrain features. Even slight changes in the winds can cause path changes.

The decrease of the maximum ground-level concentration with distance from the release site is discussed next. As mentioned previously, the concentration decreased, after Arc 01, at a greater rate than expected for a ground-level plume, given the meteorological conditions observed during Exp 4. Figure 16 shows the maximum hour-average ground-level concentrations at five sampling distances for four times. The times reported are ending times of the hour-integrated samples. Considering an average transport wind speed of 0.6 $\mathrm{m} / \mathrm{s}$, the three sampling arcs and the tethersonde site should be "seeing" the plume before the time of the earliest (0200 LST) results given in Fig. 16.

The vertical profile of tracer measured at the tethersonde site (Fig. 14) showed the preserice of an elevated tracer plume. The results concerning the spatial extent of the cold air pool (Fig. 11) indicate that the plume was probably elevated beyond Arc 01 . This plume elevation by itself will result in a greater decrease in concentration with distance than for a ground-level plume.

Simple plume calculations are made next to provide guidance for investigating the effect of an elevated plume on ground-level concentrations. The tracer plume is assumed to travel at ground-level to Arc 01, then travel horizontally at $324 \mathrm{~m} \mathrm{MSL}$. This makes the plume centerline $24 \mathrm{~m}$ above Arc O2, $42 \mathrm{~m}$ above Arc $\mathrm{O} 3$, and $50 \mathrm{~m}$ above the tethersonde site. The plume equation used assumes Gaussian shaped probability density functions of the horizontal and vertical concentration distributions, and does not consider reflections from the ground or elevated layers. The plume equation is 
128

$$
\chi=\left(155 \times 10^{6}\right) \frac{Q}{\pi \cup \sigma_{y} \sigma_{z}} e^{-\frac{1}{2}\left(\frac{z}{\sigma_{z}}\right)^{2}}
$$

where

$\chi$ is the ground-level centerline concentration [ppt],

$Q$ is the tracer release rate $[\mathrm{g} / \mathrm{s}]$, and

$z$ is the plume height above ground-level [m].

and the numerical coefficient coverts the concentration to ppt. The vertical diffusion coefficient $\sigma_{z}$ is determined using the same general form as used to estimate $\sigma_{t}$ in Eqn (12)

$$
\sigma_{z}=\sigma_{w} t f_{z}
$$

where

$\sigma_{w}$ is the standard deviation of the vertical winds $[\mathrm{m} / \mathrm{s}]$,

$t$ is the travel time [s], and

$f_{z}$ is a nondimensional function of travel time.

The function $f_{z}$ used is that recommended by Irwin (1983) for stable conditions

$$
f_{z}=[1+0.9 \sqrt{t / 50}]^{-1}
$$

and the travel time $t$ is estimated in the same way as in the calculation of $\sigma_{t}$. Eqn (15) is evaluated using a value of $U$ equal to $0.6 \mathrm{~m} / \mathrm{s}$ and a value of $\sigma_{w}$ equal to $0.03 \mathrm{~m} / \mathrm{s}$. These are hour average values measured at the release site.

The ground-level concentration is calculated from Eqn (14) with $Q$ equal to $0.87 \mathrm{~g} / \mathrm{s}$, the $\sigma_{y}$ values from Table 4 , and the $\sigma_{z}$ values from Eqn (15). The results are plotted in Fig. 16 along with the observed values of ground-level concentrations. Also given in Fig. 16 is a curve of computed ground-level 
concentrations using the measured values of plume width, $\bar{Y}$, from Table 4. Both of these curves of computed concentrations are roughly a factor of 10 to 20 higher than the concentrations observed cluring the early morning hours at Arc $\mathrm{O} 3$ and the tethersonde site. These differences are large enough to support the notion that wind direction shear and an elevated plume (formation of a cold air pool) are not the only processes significantly affecting dispersion in the Roanoke basin during wintertime stagnation conditions.

Using a wind speed of $0.6 \mathrm{~m} / \mathrm{s}$, and a release stop time of 0400 LST, the trailing edge of the tracer plume is expected to move downwind of Arcs 01,02 and 03 by 0440,0605 and 0730 LST, respectively. Figure 16 shows that the concentration has decreased at Arc 01 after the 0400 observation, and slightly decreased at Arc $\mathrm{O} 2$ after the 0600 observation. This is consistent with the times the trailing edge of the plume is expected to move beyond the arcs. However, the concentrations should decrease more rapidly, especially on Arc 02. This may indicate that the plume is traveling slower than indicated by the measured winds at the release site $(0.6 \mathrm{~m} / \mathrm{s})$. This is possible because of the heavy cover of trees in the lower portions of Lick Run and the earthen barrier blocking Lick Run about $5 \mathrm{~km}$ down-valley from the release site.

The concentrations on Arc 03 , and at the tethersonde site, increased throughout the night with the 0800 sample registering the highest concentration at these two locations. The gradual increase in concentration throughout the night may have been due to accumulation of tracer in the cold air pool. The maximum concentrations registered at 0800 were probably caused by the fumigation of an elevated plume to the ground after sunrise (0740). 
The character of the "instantaneous" plume is revealed in Figs. 17 and 18. The first figure shows the instantaneous plume measured on Arcs $\mathrm{O} 1$ and $\mathrm{O2}$. At these travel distances, $1.45 \mathrm{~km}$ and $4.50 \mathrm{~km}$, respectively (travel times of roughly $1 / 2$ to $2 \mathrm{~h}$ ), the instantaneous plume characteristics should begin to approach those of the "averaged" plume. That is, the plumes in Fig. 17 should be similar to the results from the integrated samplers, which they are. This is the case because the dominant scales of turbulent motion have had sufficient time to enter into the diffusion of the tracer plume by the time it reaches Arc 01 .

Two striking observations from Fig. 17 are the variations in the plume shape and concentrations with time, and the considerable difference between Arc 01 and Arc $\mathrm{O} 2$ levels. The flat portions of the traces for Arc $\mathrm{O} 1$ indicate detector saturation. The actual concentrations are higher. The low concentrations on Arc 01 at times near 2300 correspond to a period of wind direction reversal in Lick Run (refer to Fig 8). After this period we see a wider plume and higher concentrations on Arc 01. Figure 18 shows some instantaneous plume traces made throughout the study region. The tracer was observed in significant concentrations along Highway 220 to the $E$ and SE of the release site. These higher concentrations were observed in a portion of Lick Run that Highway 220 follows for a few $\mathrm{km}$. As the road climbs from Lick Run the concentrations diminish.

A local source of $\mathrm{SF}_{6}$ (coordinates 593, 4134 in Fig. 2), labeled "ITT" in Figs. 17 and 18, was observed in the study area. The influence of this source was isolated from the controlled release and did not complicate the interpretation of the results. 

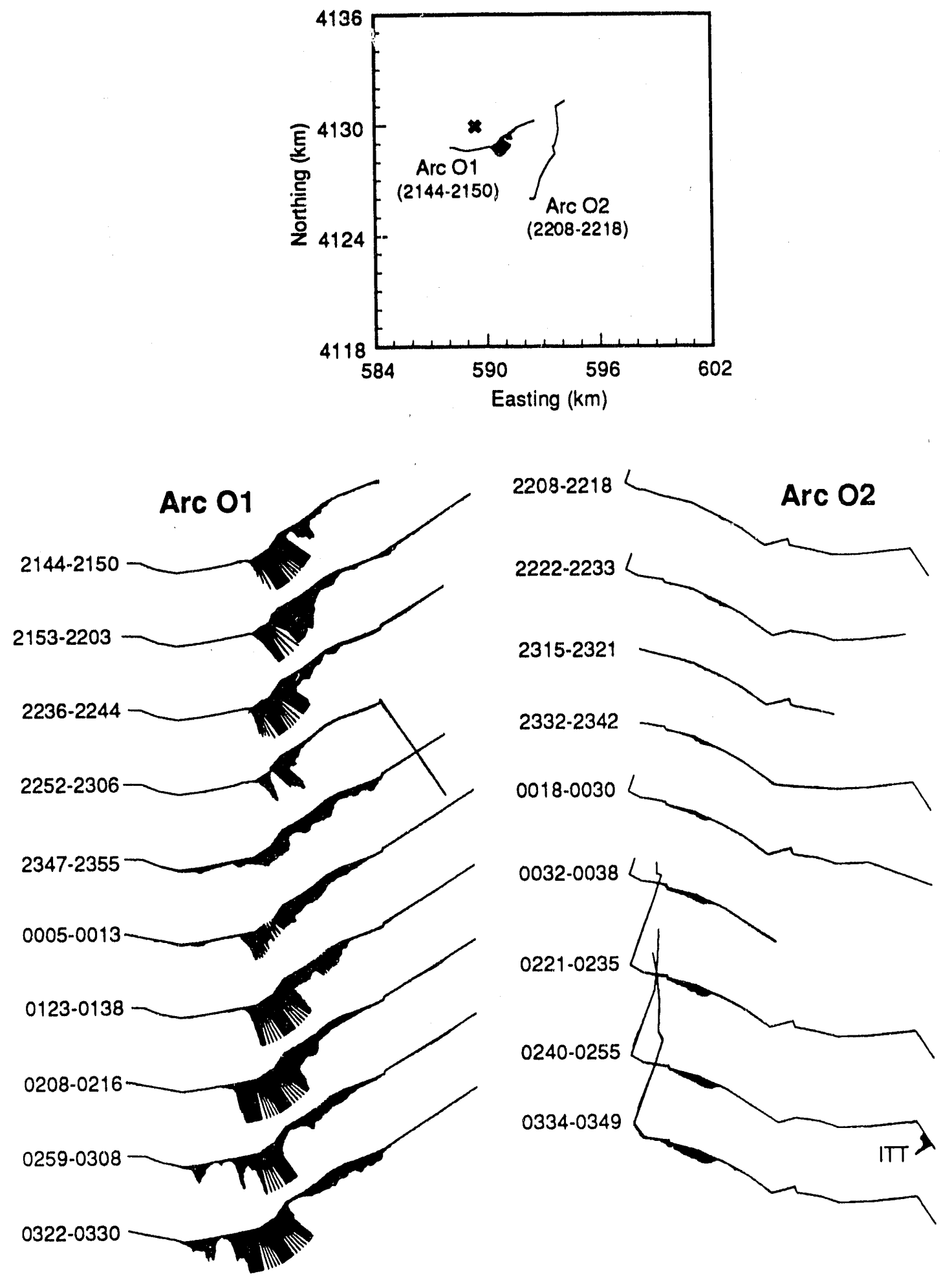

Figure 17. Sampling path showing instantaneous ground-level tracer concentrations on Arcs $\mathrm{O} 1$ and $\mathrm{O} 2$ measured at various times with the mobile van. The concentrations are represented by the dark area along the sampling path. The scale is $1 \mathrm{~km}=10,000 \mathrm{ppt}$. 

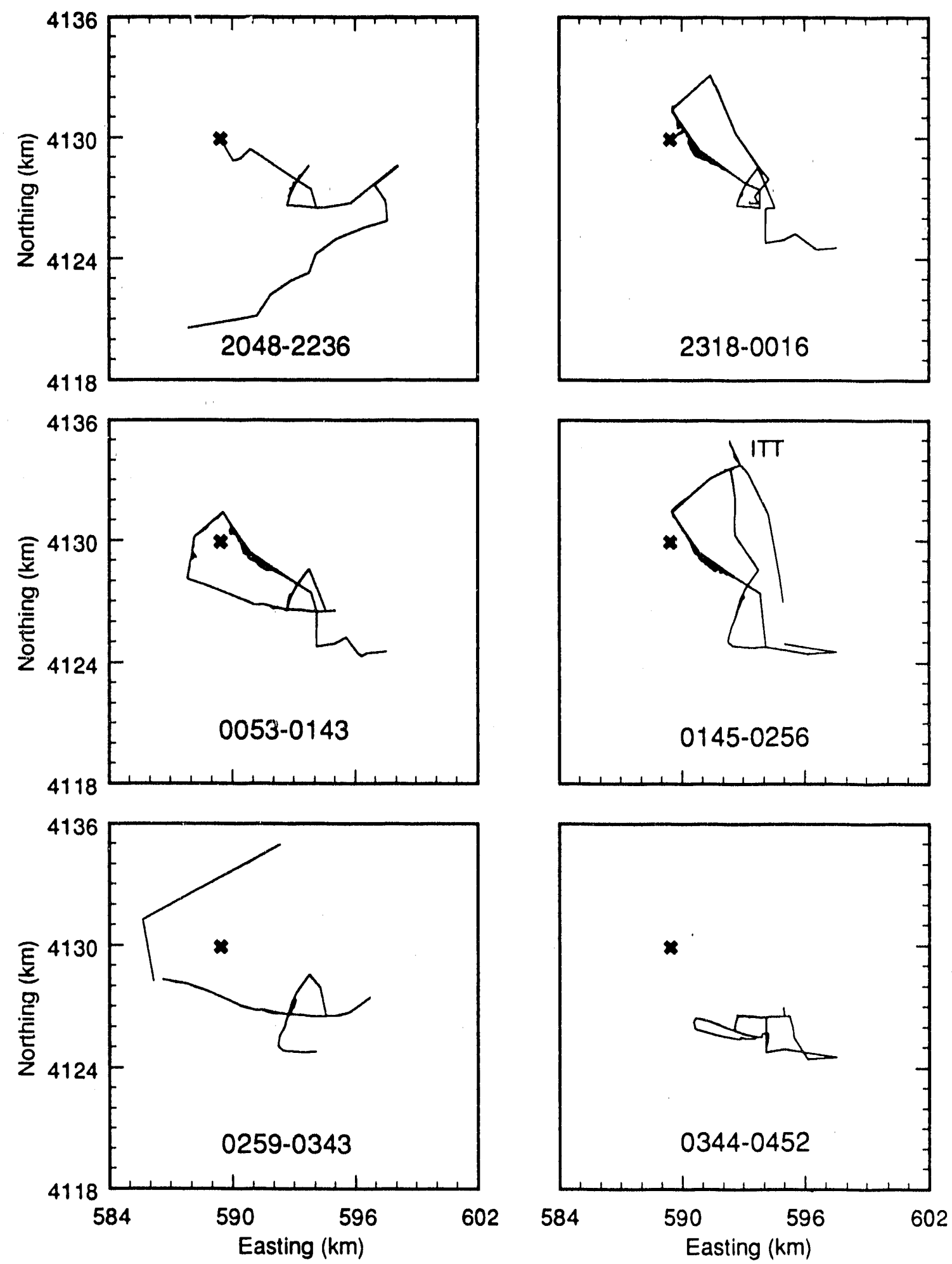

Figure 18. Sampling path showing instantaneous ground-level tracer concentrations around the study domain measured at various times with the mobile van. The concentrations are represented by the dark area along the sampling path. The scale is $1 \mathrm{~km}=10,000 \mathrm{ppt}$. 


\section{Summary and conclusions}

An SF $_{6}$ tracer study conducted in Roanoke, Virginia, during January 1989 has been described. The study was designed to identify the transport and diffusion characteristics of the Roanoke basin atmosphere during winter-time stagnation conditions. The Roanoke basin is located on the eastern slopes of the Appalachian Range in the Blue Ridge Mountains. Results were given for the experiment on the night of January 16-17, 1989, one of the five nighttime tracer experiments conducted during the study period. In general, this research identified cold-air pool formation as a dominant meteorological process governing nighttime dispersion in basins. Modeling of basin dispersion must treat the formation of cold-air pools in order to adequately predict concentrations.

The surface winds throughout the Roanoke basin on the afternoon of January 16, 1989 (Exp 4) were from the NW at $6 \mathrm{~m} / \mathrm{s}$. During the evening transition period $(1700-2100$ LST) the winds weakened to less than $1 \mathrm{~m} / \mathrm{s}$ with wind directions becoming very locally dependent. The winds at the release site were down a local drainage, Lick Run, at about $0.6 \mathrm{~m} / \mathrm{s}$ throughout the duration of the release from 2000 to 0400 LST. The surface temperature behaved similarly throughout the basin with the afternoon temperature reaching about $6^{\circ} \mathrm{C}$ and then cooling to a minimum of roughly $-6^{\circ} \mathrm{C}$ by about 0600 LST. A strong surfaced-based temperature inversion of $0.15^{\circ} \mathrm{C} / \mathrm{m}$ formed in the lowest $20 \mathrm{~m}$ at the tower site after the evening transition period, and persisted through the night.

Tethersonde observations, made at the lowest point in the basin, showed the formation of a cold air pool behind the low barrier of mountains (about $75 \mathrm{~m}$ above the elevation of the tethersonde site) blocking the basin to the SE. The pool depth grew at the rate of about $9 \mathrm{~m} / \mathrm{h}$ until reaching a height of $50 \mathrm{~m}$ above 
the tethersonde site by about 0300 LST. At the top of the cold air pool a $20-\mathrm{m}$ deep, $3^{\circ} \mathrm{C}$ temperature inversion had formed. This elevated inversion above the tethersonde site was at the same elevation and of the same strength as the surface-based inversion at the tower site. The pool top extended from the SE barrier of the basin to nearly the tower site, a distance of about $8 \mathrm{~km}$ to the NW.

From the observations of the formation of the cold air pool, a simple model based on mass continuity was proposed to describe the ascent rate of the top of the pool. Given the strength and depth of the slope flows feeding the basin and the geometry of the basin, the ascent rate can be determined.

The surface wind observations at the release site showed a low frequency (roughly 70 -min. period) and low amplitude (roughly $0.4 \mathrm{~m} / \mathrm{s}$ ) oscillation to these winds throughout the night. Shifts in the wind direction measured at the tower site occurred at roughly the same rate. Based on these observations, it was speculated that the wind oscillations were caused by surges in competing drainage flows from various parts of the basin.

Vertical tracer profile measurements in the early morning hours (about 0330 LST) indicated an elevated plume riding along the top of the cold air pool. The behavior of the cold air pool dictates the height of the plume above the ground, which has a significant effect on the magnitude of concentrations observed at ground-level. In addition the temperature inversion at the top of the pool appeared to inhibit the downward transport of tracer.

The horizontal plume widths within $5 \mathrm{~km}$ of the release site, determined from the hourly integrated tracer concentrations, were found to be about a factor of three larger than plume widths estimated from common relationships for turbulent 
diffusion. Adding a component to the turbulent diffusion estimates to account for enhanced horizontal plume spread due to wind direction shear, brought the agreement between measured and estimated to within a factor of 1.3. The remaining difference was thought to be due to the complex nature of the terrain between the release site and the first two sampling arcs.

The decrease in ground-level concentration with distance from the release site was observed to be much greater than normally expected for a ground-level continuous plume in a slightly stable atmosphere. The concentrations observed in the lower portions of the basin were much less than expected. This greater decrease in ground-level concentrations with distance from the release site was attributed to plume elevation, enhanced horizontal plume spread caused by wind direction shear, and inhibition of downward diffusion caused by the presence of an elevated stable layer at the top of the pool.

The ground-level concentrations at measurement sites in the lower portions of the basin increased throughout the night, with highest concentrations at 0800 LST. The gradual increase in concentration throughout the night may have been caused by the accumulation of tracer in the cold air pool resulting from the downward diffusion of the elevated plume. The peak hourly-average concentrations registered at 0800 were probably caused by the fumigation of an elevated plume to the ground after sunrise. The temperatures measured on the tower indicated the growth of a CBL beginning shortly after sunrise ( 0740 LST).

Acknowledgments. This research was supported in part by the U.S. Environmental Protection Agency (EPA) (CR 815352010). The contents of this paper do not necessarily reflect the views and policies of the EPA, nor does 
mention of trade names or commercial products constitute endorsement or recommendation for use. The preparation of this paper was supported by the U.S. Department of Energy under Contract DEAC06-76RLO 1830 with Pacific Northwest Laboratory. Pacific Northwest Laboratory is operated by Battelle Memorial Institute for the U.S. Department of Energy.

\section{REFERENCES}

Banta, R., and W. R. Cotton, 1981: An analysis of the structure of local wind systems in a broad mountain vasin. L.Appl. Meteor, 20, 1255-1266.

Beniston, M., 1987: A numerical study of atmospheric pollution over complex terrain in Switzerland. Bound.-Layer Meteor., 41(1-4), 75-96.

Benner, R L., and B. Lamb, 1985: A fast response continuous analyzer for halogenated atmospheric tracers. L of Atmos, and Oceanic Tech, 2(4), 582 589.

Cupitt, L. T., 1988: The Integrated Air Cancer project: overview and Boise survey results. Proceedings of the 1988 EPA APCA International Symposium. EPA Report 600/9-88-015, 799-803.

Egan, B. A., and F. A. Schiermeier, 1986: Dispersion in complex terrain: A summary of the AMS Workshop held in Keystone, Colorado, 17-20 May 1983. Am. Meteor Sec, 67(10), 1240-1247.

Eskridge, R. E., B. Lamb, and E. Allwine, 1990: Velocity oscillations and plume dispersion in a residential neighborhood during wintertime nights. Atmos. Environ, 24A (7), 1781-1796.

Filliger, P., and H. Wanner, 1986: Transport and dispersion of air pollutants in a slope wind area. Fifth Conference on Applications of Air Pollution Meteorology, 18-21 November 1986, Chapel Hill, North Carolina. American Meteorological Society, Boston, Massachusetts.

Gassmann, F., and D. Burki, 1987: Experimental investigation of atmospheric dispersion over the Swiss Plain - Experiment 'Siesta'. Bound-Layer Meteor., 41(1-4), 295-308.

Gay, G.T., 1982: Vertical sampling flights in support of the 1981 ASCOT cooling tower experiments: Field effort and data. Sandia National Laboratories, SAND82-0172. 
Gudiksen, P. H., G. J. Ferber, M. M. Fowler, W. L. Eberhard, M. A. Fosberg, and W. R. Knuth, 1984: Field studies of transport and dispersion of atmospheric tracers in nocturnal drainage flows. Atmos. Environ., 18 (4), 713-732.

Guenther, A., B. Lamb, and E. Allwine, 1990: Building wake dispersion at an arctic industrial site: Field tracer observations and plume model evaluations. Atmos. Environ, 24A (9), 2329-2348.

Hanna, S. R., G. A. Briggs, and R. P. Hosker, 1982: Handbook on atmospheric diffusion. Technical Information Center, DOE/TIC-11223 (DE82002045), 102 pp.

Hanna, S. R., G. A. Briggs, J. Deardorf, B. A. Egan, F. A. Gifford, and F. Pasquill, 1977: AMS Workshop on stability classification schemes and sigma curves-Summary of recommendations. Bull. Amer. Meteor. Soc., 58(12), 13051309.

Irwin, J. S., 1979: Estimating plume dispersion -- A recommended generalized scheme. Proceedings: Eourth Symoesium on Turbulence. Diffusion and Air Pollution, Reno, Nevada, American Meteorological Society.

Irwin, J. S., 1983: Estimating plume dispersion--A comparison of several sigma schemes. LL Climate Appl. Meteor, 22, 92-114.

Kondo, J., and N. Okusa, 1990: A simple numerical prediction model of nocturnal cooling in a basin with various topographic parameters. J.Appl. Meteor., 29 (7), 604-619.

Krasnec, J. P., D. E. Demaray, B. Lamb, and R. Benner, 1984: An automated sequential syringe sampler for atmospheric tracer studies. $L$ of Atmos, and eceanic Tech, 1(4), 372-378.

Lamb, B., X. F. Zhang, R. E. Eskridge, R. Benner, H. Westberg, J. Mitchell, Z. Xiacheng, and L. Jun, 1990: Elevated plume transport and dispersion 20 to $150 \mathrm{~km}$ downwind of Bejing, PRC. Atmos. Enviren, 24A(4), 859-870.

Maki, M., and T. Harimaya, 1988: The effect of advection and accumulation of downslope cold air on nocturnal cooling in basins. J. Meteor. Soc. Japan, 66 (4), 581-597.

Morris, A. L., D. B. Call and R. B. McBeth, 1975: A small tethered balloon sounding system. Bull. Amer. Meteor. Sec., 56, 964-969.

Neff, W. D., and C. W. King, 1989: The accumulation and pooling of drainage flows in a large basin. J.Appl. Meteor., 28 (6), 518-529. 
Pasquill, F., 1976: Atmospheric dispersion parameters in Gaussian plume modeling. Part II. Possible requirernents for change in the Turner Workbook Values. EPA-600/4-76-030b Environmental Monitoring Series, June 1976, $44 \mathrm{pp}$.

Petkovsek, Z., 1978: Relief meteorologically relevant characteristics of basins. Z Meteor, 28, 333-340.

Shores, R. C., 1989: Second performance and systems audit of the IACP air monitoring network in Roanoke, Virginia. Research Triangle Institute Report No. RTI/4399/09-01F.

Toritani, H., 1990: A local climatological study on the mechanics of nocturnal cooling in plains and basins. Environmental Research Center, The University of Tsukuba, 13, 62 pp.

Wanner, H., and J. Hertig, 1984: Studies of urban climates and air pollution in Switzerland. J. Climate Appl. Meteor, 23 (12), 1614-1625.

Wanner, H., K. Ammann, P. Berlincourt, P. Filliger, R. Herzig, L. Liebendörfer, R. Rickli, and M. Urech, 1986: Urban meteorology and air pollution in BielBienne (Switzerland). International Symposium on Climatology, 20-21 February 1986, Freiburg im Breisgau, FRG. 


\section{Chapter 5}

\section{DISPERSION MODELING IN VALLEYS AND BASINS}

\section{GENERALDISCUSSION}

Assessing the short-term (hours to days) air pollution impacts in complex meteorological and topographical situations such as the Roanoke Basin (see Chapter 4 ) is a difficult undertaking. The difficulty arises in both prescribing the mean wind conditions ( $u, v$ and $w$ ) for transport and the turbulence characteristics for diffusion. The wind and turbulence characteristics can be highly space and time dependent. Especially during nighttime stable conditions, the mean wind direction and speed can vary considerably, especially in the lowest few hundred meters (depending on the local relief). Near step changes can occur at the tops of cold air pools and at ridgetops of local drainages. Gravity waves can be present giving low frequency (15 to $90 \mathrm{~min}$. periods) oscillations to the winds. Also turbulence characteristics can vary considerably in the vertical, such as near step changes at the tops of cold air pools and other potential shear layers.

The starting point in assessing air pollution impacts is identifying the source configuration (e.g. ground-level, elevated, intermittent or continuous, single or multiple), exposure times (e.g. hours, days, seasons), transport distances (e.g. few $\mathrm{km}$, hundreds km, global) and impact areas (e.g. urban centers, sensitive ecological regions) of interest. The time and space scales specified in the air pollution analysis dictate the physical processes that are probably dominant in governing the levels of concentrations expected. 
For example, an elevated continuous plume located in a valley may give highest hourly growid-level concentrations on the valley sidewalls as it diffuses laterally while traveling down-valley in stable nighttime flows, or it may encounter and impact a terrain feature. The dominant physical process governing the pollutant behavior are surface sensible heat flux leading to drainage winds from the slopes anc tributaries, along-valley winds due to along-valley pressure gradients, turbulence levels from surface roughness, low-level jets and other shear regions, gravity waves, ridgetop winds, and vertical stability.

Normally air pollution assessments are made using computer models where the winds are specified and the concentrations are determined using analytical functions (e.g. Gaussian plume or puff), by solving the conservation of species equation numerically using specified eddy diffusivities, or by using some particlein-cell or Monte Carlo techniques. Very seldom are conservation equations for momentum and energy solved to determine the winds.

Often the mass conservation equation is used to help specify the wind field in many complex terrain air pollution models. Given an initial guess at the winds, based primarily on observations of the horizontal winds and constraints on the vertical winds, the initial field is adjusted to become divergence free (i.e., satisfy continuity). In some complex terrain models, a simple interpolation scheme (e.g. $1 / r^{2}$ weighting) is used instead of continuity to estimate the spatial variation in winds from observations. A major shortcoming to the kinematic approaches mentioned above is usually that the meteorological measurements are not of sufficient spatial coverage to accurately reflect the dynamics of the region of interest. 
Determining the dynamical behavior of the atmosphere specific to any air pollution situation can be very challenging. Probably the most effective tool is to make numerous field observations covering the meteorological conditions leading to worst-case air pollution situations. The sum of many field efforts can lead to an identification and understanding of the dominant physical processes governing the dynamics. However, the cost of intensive field experiments can be prohibitive.

At this time, it is still not practical to use full physics models for routine air pollution applications. In many applications different scales of motion are present dictating the need for nested solutions. Usually there is no doc!mentation available for the models, they are difficult and time consuming to operate, and there is still no assurance that the results will be any more accurate than simpler approachs. The user needs to know the limitations of the numerical techniques used, the turbulence closure and the surface parameterizations. Also specifying the initial and boundary conditions can be challenging.

One approach for incorporating atmospheric dynamics into air pollution models is to parameterize the dominant physical processes in terms of measured or computed quantities using empirical, semi-empirical or theoretical relationships. An example is Allwine and Whiteman's (1988) parameterization of the coupling of valley flows with regional flows (refer to Chapter 2). They calculate a time-varying transfer coefficient for the transfer of pollutant mass from a valley atmosph. गre to the flow above ridgetops (regional flows) during the morning transition period. Their parameterization is based on the bulk thermodynamic behavior of the valley atmosphere as the valley is being heated by the sun. 
This approach of parameterizing the dominant processes is the basis of the following proposed phenomenological model for dispersion in valleys.

\section{EORMULATION OF A VALLEY DISPERSION MODEL}

The proposed valley dispersion model uses a very simple approach for treating dispersion in valleys. It is designed to operate through at least one diurnal cycle for a single valley. The key processes being incorporated in a simplified fashion are 1) nonsteady and nonhomogeneous along-valley winds and lateral and vertical diffusivities, 2) convective boundary layer growth and inversion descent, 3) cross-valley circulations and subsideince, 4) interactions with above-ridgetop winds, and 5) time- and spatially-varying emissions.

The inputs needed for the valley dispersion model are the domain boundaries, the computational grid, the valley physical characteristics, the alongvalley wind speed and depth of the flow for at least one valley cross section, temperature inversion characteristics, sensible heat flux as a function of time following sunrise, lateral and vertical diffusivities, the strengths and paths of closed and open lateral circulations, and an emissions inventory. The inputs can be a function of time and space, if available. The outputs include concentrations of species mass as a function of along-valley and cross-valley location and time, and ground-level deposition as a function of along-valley distance and time.

Accounting for the effects of the key processes on dispersion is accomplished by solving the 1-D (along-valley) species conservation equation for each of a number of "flowtubes" aligned with the valley. Species mass can 
"advect" and "diffuse" among the flowtubes. The equation solved for each flowtube, ij, is

$$
\frac{\partial\left[A_{i j}(S) C_{i j}(S, t)\right]}{\partial t}+\frac{\partial\left[\dot{V}_{i j}(S, t) C_{i j}(S, t)\right]}{\partial S}+\Gamma_{i j}^{C}(S, t)=0
$$

where

$C_{i j}$ is the concentration along flowtube ij $\left[\mu \mathrm{g} / \mathrm{m}^{3}\right]$,

$A_{i j} \quad$ is the cross sectional area of flowtube ij $\left[\mathrm{m}^{2}\right]$,

$\dot{\mathrm{V}}_{\mathrm{ij}} \quad$ is the air volume flow rate through flowtube $\mathrm{ij}\left[\mathrm{m}^{3} / \mathrm{s}\right]$, and

$$
\begin{aligned}
\Gamma_{i j}^{c}= & {\left[\Gamma_{i j}^{c s}+\Gamma_{i j}^{c p}+\Gamma_{i j}^{c c}\right]+\left[\Gamma_{i j}^{c a}\right]+\left[\Gamma_{i j}^{c d}\right] } \\
& {\left[\begin{array}{l}
\text { CONVENTIONAL } \\
\text { SOURCE/SINKS }
\end{array}\right]+\left[\begin{array}{c}
\text { ADVECTIVE } \\
\text { EFFECTS }
\end{array}\right]+\left[\begin{array}{c}
\text { TURBULENT } \\
\text { DIFFUSION }
\end{array}\right] }
\end{aligned}
$$

are the source/sirik terms for flowtube ij $[\mu \mathrm{g} / \mathrm{s}-\mathrm{m}]$. The first term in Eqn (1) is the rate of change of storage of species mass in the control volume $\left(A_{i j} \mathrm{dS}\right)$, and the second term is the along-valley advection of species mass. The various source/sink terms in Eqn (2) are of three general types. The first three are the more conventional "source/sink" terms representing emissions, deposition, and chemical or physical transformations. The next term accounts for lateral advective effects from, for exan,ple, slope flows, cross-valley circulations, subsidence, regional flow intrusions, and tributary flows. The last term accounts for the effects of both lateral and vertical turbulent diffusion. An example flowtube configuration used to compute down-valley drift from aerial spray operations is illustrated in Fig. 1. 


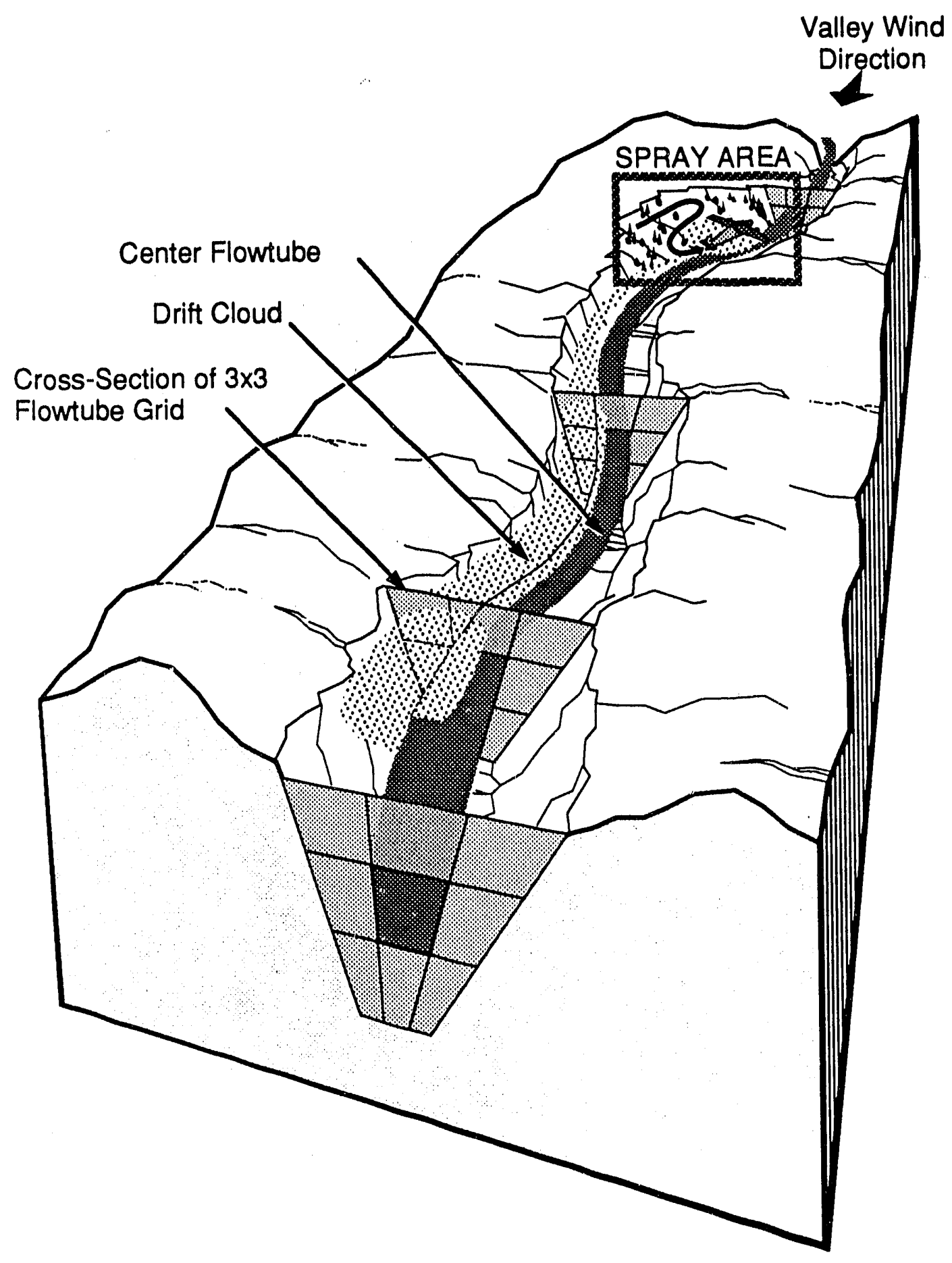

Figure 1. Example of the flowtube approach used in the valley dispersion model. A potential application of the model, predicting the extent of downvalley drift from aerial spraying operations, is shown. 
Air mass is conserved using the continuity equation considering only the along-valley flow explicitly. Nonrecirculating lateral flows are treated as source/sink terms in the equation. Possible sources/sinks of air mass are from subsidence, regional flow intrusions, and tributary flows. Assuming the flow to be incompressible, the air mass (volume) in the valley is conserved as

$$
\frac{\partial \dot{V}(S, t)}{\partial S}+\Gamma^{a}(S, t)=0
$$

where

$\dot{v} \quad$ is the total along-valley volume flow rate $\left[\mathrm{m}^{3} / \mathrm{s}\right]$, and

$\Gamma^{a} \quad$ is the air mass source/sink term $\left[\mathrm{m}^{3} / \mathrm{s}-\mathrm{m}\right]$.

The approach given allows the governing processes to be treated in a simple modeling framework. The flow in a valley can be considered predominantly one-dimensional and confined, which allows this simplified approach to be taken. The dominant processes yoverning dispersion are alongvalley flow, and convective boundary layer (CBL) and inversion top behavior. Along-valley flow dictates the flowtube configuration aligned with the valley, and CBL-inversion behavior dictates the flowtube grid to be conformal to the valley and horizontal in the cross-valley direction. Secondary processes important to dispersion are cross-valley circulations (thermally and mechanically induced), tributary flows, subsidence, turbulence, and interactions with winds aloft. The effects of these secondary processes on dispersion are incorporated through the source/sink terms in Eqns (1) and (2).

The dynamics of the important physical processes are described parametrically. Some thoughts on the parametric description of each process is given next. The discussion is structured about the various meteorological 
regimes encountered during a diurnal cycle, to show the temporal relationships of the various processes. As discussed in Chapter 2 and further investigated in Chapter 3, the daily behavior of the valley atmosphere from thermal effects can be divided into four time regimes, morning transition, daytime, evening transition, and nighttime.

During the nighttime period, the winds throughout the valley will typically be down-valley with down-slope flow near the sidewalls. Tributary flows can also penetrate the valley, adding to the down-valley flow. The vertical temperature structure will typically be sub-adiabatic with a surface-based inversion. Wind direction shifts can be present within the surface-based inversion, and the flow in the valley can be decoupled from the flow above the ridgetops. The horizontal and vertical diffusivities may vary significantly with height because of the complicated vertical structure of the valley atmosphere.

One approach to characterizing the cross-valley and vertical structure of the down-valley winds is using empirical relationships and measurements. For example, Clements et al. (1989) developed a semi-empirical relationship, they called a Prandlt-parabolic wind field, for mean nighttime drainage flow in a deep valley. The down-valley winds at a valley cross section can be fully specified knowing the maximum wind speed in the valley as a function of time, and the depth of the down-valley flow as a function of time. Cross-valley circulations can be parameterized in terms of approach flow Froude number and ridge separations, or differential heating. The down-valley flow can be parameterized in terms of synoptic meteorology and topographic-amplification factors.

The daytime period will be characterized by a developed CBL over the valley floor, sidewalls and ridgetops with the valley flow coupled to the above- 
ridgetop flow. The winds in the valley will be up-valley with up-slope flows near the valley sidewalls. The cross-valley and vertical structure of the daytime winds will not be developed here. An initial approach could be the same form as the nighttime winds, a Prandtl profile in the vertical and parabolic on the cross-valley direction.

The characteristics of the morning transition period are discussed in Chapters 2 and 3 . The dominant processes working during the morning transition period are the growth of a convective boundary layer (CBL) and the descent of an elevated stable core. These play a major role in the behavior of material in the valley atmosphere. The approach for treating the morning transition period in the model is based on the CBL growth-inversion descent formulation in Whiteman and Allwine's (1985) VALMET model. Flowiubes below the CBL have up-valley winds and the species mass is uniformly mixed in these flowtubes. Above the $\mathrm{CBL}$ and below the elevated inversion, the flow continues down-valley in the flowtubes in the stable core. Above the inversion, the flow is in the direction of the above-ridgetop winds. The interaction of the CBL growth/inversion descent and flowtubes is demonstrated in Fig. 2.

The characteristics of the evening transition period are the least studied and understood. After sunset, surface heating ceases, shutting off convective mixing near the surface. Radiative cooling of the surface then leads to cooling of the air near the surface and down-slope flows begin. Convective mixing above the surface may persist and decay off throughout the evening. An initial approach for specifying the winds during the evening transition period is to use the same form as the nighttime winds. 


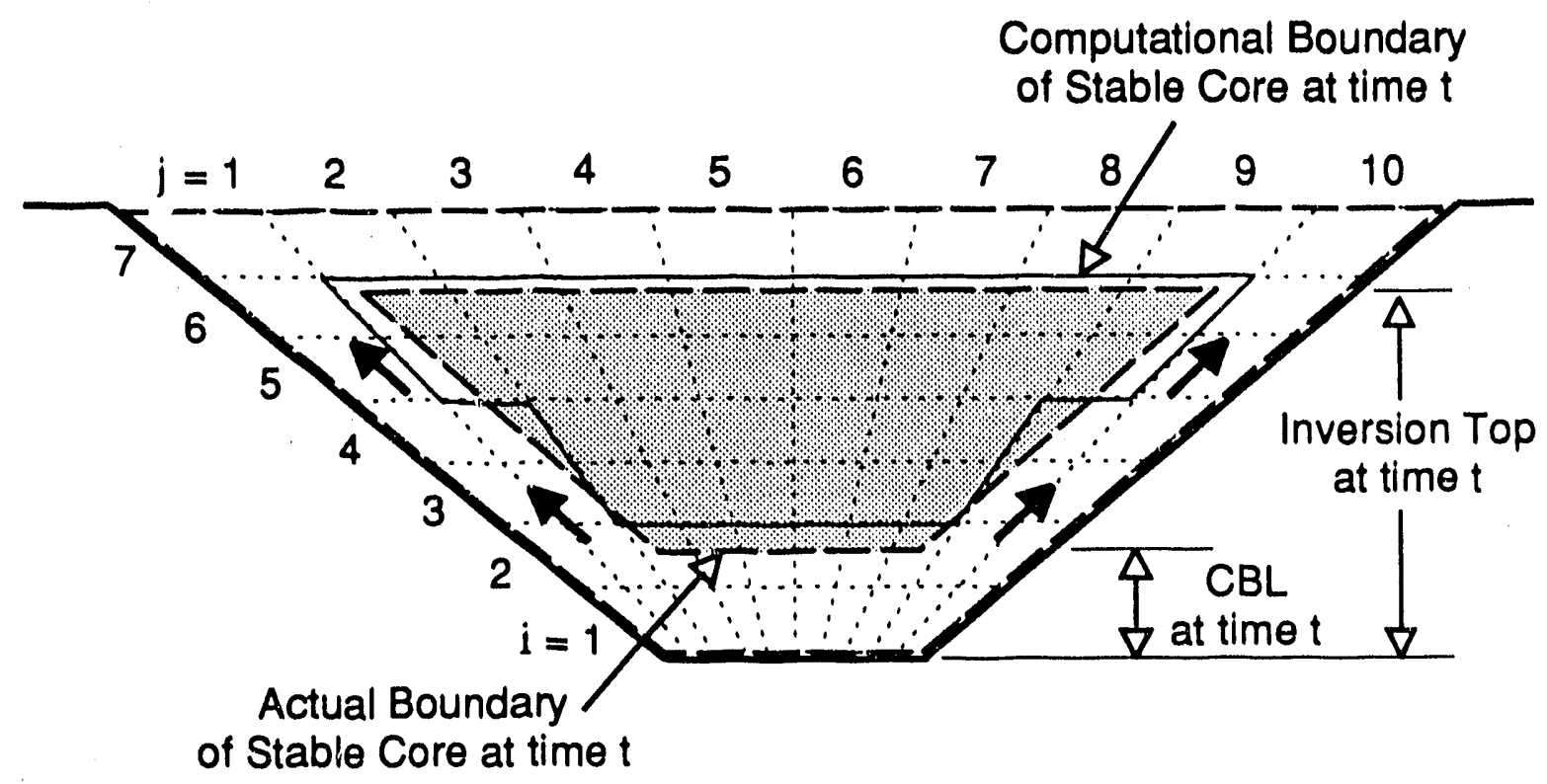

Figure 2. Illustration of the computational domain on a valley cross section at time $t$ after sunrise. The stable core, CBL, and inversion top are shown within $\mathrm{a}$ by 10 array of valley flowtubes.

Diffusion can be characterized in terms of mean flow characteristics and surface roughness. The effects of winds aloft on dispersion in the valley can be represented by approach flow Froude numbers.

Details of the proposed valley dispersion model are given in the Appendix. The domain, coordinate system, computational grid, governing equations, solution method, and meteorological regimes are described there.

\section{THOUGHTS ON A BASIN DISPERSION MODEL}

Extending the valley dispersion model, outlined above, to application in basins is briefly discussed. The primary difference between its use in basins and in valleys is the need to solve the species mass conservation equations in two- 
dimensions for basins. The flow in a basin is not necessarily predominantly onedimensional as is the case for narrow valleys. The winds in the basin under the influence of weak synoptic conditions will be light or stagnant with the formation of a cold-air pool filling the basin after the evening transition period. Circulations of various scales can be imbedded in this cold air pool. These circulations may result from local topographical features (e.g., water bodies, hills, gullies), interactions with flows aloft and urban heat island effects.

The dominant processes identified in Chapter 4 that affect dispersion in basins are the formation of a cold air pool, wind direction shear, interactions at the top of the cold air pool, accumulation of material within the pool, and fumigation during CBL growth. The predominant effect of the formation of the cold air pool on ground-level concentrations is the directing of plumes to follow nearly constant MSL surfaces, rather than following the terrain surface. This results in plumes released at ground-level in the upper reaches of the basin (above the cold air pool) to become elevated over the lower portions of the basin. The behavior of plumes released within the cold air pool can be very complicated and the behavior is not very well understood.

In any modeling approach for treating dispersion in basins, knowing the behavior of the top of the cold air pool will be essential. A very simple method for predicting the height of the top of the pool as a function of time is given in Chapter 4. 


\section{Chapter 6}

\section{SUMMARY AND RECOMMENDATIONS}

The primary goal of this research was to further characterize and understand dispersion in valley and basin atmospheres. A secondary, and related, goal was to identify and understand the dominant physical processes governing dispersion in valley and basin atmospheres. These research goals were accomplished through a review of the literature (Chapter 2), and through analyses of recently collected data from two tracer experiments (Chapters 3 and 4). From this added understanding, a phenomenological modeling approach, applicable to dispersion in valleys was proposed (Chapter 5).

In September and October of 1984, a large meteorological and tracer field study was conducted in Colorado's Brush Creek valley by the U.S. Department of Energy's Atmospheric Studies in Complex Terrain (ASCOT) program (see Chapter 3$)$. This valley has a semiarid, continental climate with low precipitation (40 cm annually), low relative humidity, large temperature variations, and high evaporation. Strong down-valley winds develop in this valley during the night. Tracer and meteorological data were collected in and around the Brush Creek valley during five experimental periods (typically midnight to noon). The single experimental period analyzed (Sept. 26,1984 ) was characteristic of clear sky fall meteorology under weak synoptic influence. The major objectives of the tracer experiments were to evaluate the behavior of inert gases entrained in nocturnal 
valley flows and the subsequent ventilation of the gases into above-ridgetop flows during the morning transition period.

Ground-level releases of tracer were completely confined within the Brush Creek valley during the nighttime in down-valley flows, with no tracer detected by the ridgetop tracer samplers. The tracer plume was nearly uniformly mixed in the cross-valley direction within $8 \mathrm{~km}$ down-valley from the release. The diffusion in the vertical direction $\left(\sigma_{z}\right.$ at $8 \mathrm{~km}$ from the release was about $20 \%$ of the halfheight of the valley) was much less than in the cross-valley direction ( $\sigma_{y}$ at $8 \mathrm{~km}$ was greater than the half-width of the valley). The nighttime valley centerline ground-level concentrations from a continuous release at the valley floor were well represented (within 20\%) out to $8 \mathrm{~km}$ by a Gaussian plume equation solved in a segmented fashion. This agreement was attained by accounting for plume reflections from the valley sidewalls, initial plume dispersion due to wake effects from a forest stand, and along-valley variations in turbulence characteristics. The concentrations downstream from the confluence of the Brush Creek and Roan Creek valleys were conșiderably lower than upstream in the Brush Creek valley because of the dilution caused by the mixing of the two air streams.

In general, for nighttime valley dispersion estimates, the height of the interaction between down-valley flows and above ridgetop flows needs to be identified for the proper treatment of dispersion. Material released below this height will travel in down-valley flows and be contained within the valley throughout the night. Material released above the interaction height, but near the sidewalls where it can be entrained in downslope flows, can be transported to the lower portion of the valley in the downslope flows. If material is released above the interaction height, but not near the sidewalls, this material can be carried from 
the valley in above ridgetop flows, or be mixed downward below the interface height by turbulent transport, or both.

After sunrise in the valley, with the onset of convective boundary layer growth and the initiation of upslope flows in the valley, the tracer within the valley was carried into the upper reaches of the valley atmosphere and ventilated from the valley. This was confirmed by the ridgetop tracer samplers, and by a tracer mass budget applied to a valley atmosphere control volume. A ventilation rate, defined as the rate of transfer of material from the valley atmosphere to above ridgetop flows through an upper boundary of the valley atmosphere (e.g., the interface height discussed previous(y), was determined by solving the tracer mass conservation equation for a valley atmosphere control volume. Tracer began leaving the valley shortly after sunrise with the maximum ventilation rate occurring within 1 to $11 / 2 \mathrm{~h}$ following astronomical sunrise. The ventilation rate decayed exponentially to relatively low values within $4 \mathrm{~h}$ after sunrise. The ridgetop concentrations began increasing from background levels within $1 \mathrm{~h}$ following sunrise, peaked within $4 \mathrm{~h}$ following sunrise, and then began to decrease. The tracer mass budget results were consistent with the magnitude and timing of concentrations measured by the ridgetop samplers. A dimensionless ventilation rate, $\Theta_{v}$, for a ground-level source in a valley was defined as

$$
\Theta_{v}=\frac{Q_{v} \tau}{Q_{s} / U_{T}}
$$

where $Q_{V}$ is the ventilation rate per unit length of valley, $U_{T}$ is the mean downvalley wind speed, $Q_{S}$ is the source release rate, and $\tau$ is the time interval between astronomical sunrise and the time of the temperature inversion breakup 
In the valley. For the Brush Creek valley, $\Theta_{v}$ was a maximum of 1.9 at a nondimensional time following astronomical sunrise of $t / \tau \approx 0.2$.

The vertical profiling of tracer added considerably to the success of the tracer mass budget analysis. This was especially true in using the tracer mass budget approach to determine the nighttime down-valley air volume flow rate in the Brush Creek valley. The best measure of the nighttime down-valley air volume flow (0.33-0.77 million cubic meters per second) was determined from tethersonde observations of the down-valley winds and a parabolic cross-valley structure determined from lidar observations of the down-valley winds. The calculation of tracer mass flow rates at two down-valley distances from the release recovered (within 5\%) the reported release rates of two tracers, confirming the calculated air volume flow rate, and air volume flow divergence (65 cubic meters per second per meter).

During January of 1989 an $\mathrm{SF}_{6}$ tracer study was conducted in a broad basin at Roanoke, Virginia, as part of the U.S. Environmental Protection Agency's Integrated Air Cancer Project (see Chapter 4). The Roanoke basin is located on the eastern slopes of the Appalachian Range in the Blue Ridge Mountains. This basin has a moist, continental climate with moderate precipitation $(110 \mathrm{~cm}$ annually), high relative humidity, moderate temperature variations, and low evaporation. During relatively undisturbed and cloud-free nights, calm to very light winds develop in this basin. Tracer and meteorological data were collected in the Roanoke vicinity during five experimental periods (typically 2000 to 0800 LST). The single experimental period analyzed (January 16 to 17, 1989) was representative of clear sky winter conditions. The study was designed to identify 
and understand the transport and diffusion characteristics of the Roanoke basin atmosphere during winter-time stagnation conditions.

A cold air pool formed in the Roanoke basin, filling the basin to the depth of the lowest outflow barrier to the basin. A simple model, based on mass continuity, was formulated to describe the ascent rate of the top of the cold air pool. The pool began to fill after the evening transition period ( 2100 LST) and was filled by the early morning ( 0300 LST). A steep temperature inversion ( 0.15 ${ }^{\circ} \mathrm{C} / \mathrm{m}$ ) marked the top of the fully developed cold air pool. Flow oscillations with a period of roughly 70 minutes were observed. These may have been caused by surges in competing slope flows from various parts of the basin.

A ground-level tracer plume became elevated in the basin, riding over the top of the cold air pool. Horizontal plume spread was enhanced by wind direction shear, and the downward diffusion of the elevated plume was inhibited by the elevated temperature inversion at the top of the cold air pool. The decrease in ground-level concentration with downwind distance was greater than expected, even when accounting for the plume elevation and enhanced horizontal diffusion. The tracer concentration within the cold air pool increased slowly with time throughout the night and early morning. The peak concentrations in the lowest portions of the basin were observed in the last sample (0800 LST). This could have been caused by the fumigation of the elevated plume to the surface in a growing CBL.

In general, this research identified cold-air pool formation as a dominant meteorological process governing nighttime dispersion in basins. Modeling of basin dispersion must treat the formation of cold-air pools in order to adequately predict concentrations. 
The nighttime average ground-level concentrations, multiplied by the wind speed and divided by the release rate, at $8 \mathrm{~km}$ from the release point in the Brush Creek valley were roughly a factor of 300 greater than those measured in the Roanoke basin. The primary reasons for these large differences in the groundlevel concentrations for these two similar (ground-level, continuous) releases were: 1) The tracer plume was narrowly confined by the sidewalls in the freeflowing Brush Creek valley with the plume becoming nearly uniformly mixed in the cross-valley direction. 2) The plume followed along the ground as it moved down-valley in Brush Creek valley. 3) The plume became elevated in the Roanoke basin as it travelled over the top of a cold air pool forming in the Roanoke basin throughout the evening. The top of this pool stabilized at the height of terrain blockages at the down-valley edge of the basin. 4) Lateral dispersion of the plume in the Roanoke basin was enhanced by wind direction shear in the vertical.

A valley dispersion model (see Chapter 5 and the Appendix) is proposed. It is designed to operate through at least one diurnal cycle for a single valley. The key processes being incorporated in a simplified fashion are 1) nonsteady and nonhomogeneous along-valley winds and lateral and vertical diffusivities, 2) convective boundary layer growth and inversion descent, 3) cross-valley circulations and subsidence, 4) interactions with above-ridgetop winds, and 5) time- and spatiall.j-varying emissions. Accounting for the effects of these key processes on cispersion is accomplished by solving the 1-D (along-valley) species conservation equation for each of a number of "flowtubes" aligned with the valley. Species mass can "advect" and "diffuse" among the flowtubes via source/sink terms in the species conservation equation. 
The inputs needed for the valley dispersion model are the domain boundaries, the computational grid, the valley physical characteristics, the alongvalley wind speed and depth of the flow for at least one valley cross section, temperature inversion characteristics, sensible heat flux as a function of time following sunrise, lateral and vertical diffusivities, the strengths and paths of closed and open lateral circulations, and an emissions inventory. The inputs can be a function of time and space, if available. The outputs include concentrations of species mass as a function of along-valley and cross-valley location and time, and ground-level deposition as a function of along-valley distance and time.

The following recommendations and research questions result from this work.

1) The experimental results should be compared in more detail with the conservation of mass, momentum and energy equations (both differential and integral forms) to investigate further the characteristics of the ventilation process in the Brush Creek valley and the pool formation process in the Roanoke basin. The most fruitful ar,proach may be from a bulk (integral) standpoint, which could lead to simplified models. A model of the ascent rate of the top of the cold air pool forming in the basin could be formulated based on bulk thermodynamic considerations. Sensitivity studies can be performed to identify the key factors influencing ventilation and pooling.

2) Diffusion through the top of the cold air pool needs to be investigated further. How important a role do wave motion and turbulent bursts play in the vertical transport in and through the cold air pool? 
3) Oscillations in the flow (periods about one-quarter to one hour) appeared in botil the Brush Creek valley and Roanoke basin flows. What are the effects of these oscillations on dispersion?

4) The results from this research and dynamic model investigations can be used to formulate and test parameterizations of the processes of ventilation and pooling. These parameterizations can add to improving regional air pollution modeling and global climate modeling. 


\section{REFERENCES}

Allwine, K. J., and C. D. Whiteman, 1985: MELSAR. A mesoscale air quality model for complex terrain. Volume 1 - Overview, technical description and user's guide. Final Report. PNL-5460, Vol. 1. Pacific Northwest Laboratory, Richland, Washington, $142 \mathrm{pp}$.

Allwine, K. J., and C. D. Whiteman, 1988: Ventilation of pollutants trapped in valleys: A simple parameterization for regional-scale dispersion models. Atmos. Environ, 22, 1839-1845.

Arya, S. P., 1988: Introduction to Micrometeorolegy. Academic Press, San Diego, California.

Bader, D. C. and C. D. Whiteman, 1989: Numerical simulation of cross-valley plume dispersion during the morning transition period. $\downarrow$ L. Appl. Meteor, 28 (7), 652-664.

Bader, D. C., and T. B. McKee, 1985: Effects of shear, stability and valley characteristics on the destruction of temperature inversions. $\downarrow$ L Climate Appl. Meteor, 24 (8) 822-832.

Banta, R., and W. R. Cotton, 1981: An analysis of the structure of local wind systems in a broad mountain basin. J.Appl. Meteor., 20, 1255-1266.

Barr, S., and M. M. Orgill, 1989: Influence of external meteorology on nocturnal valley drainage winds. L.Appl. Meteor, 28 (6), 497-517.

Bell, R.C., and R.O.R.Y. Thompson, 1980: Valley ventilation by cross winds. L Fluid Mech, 96, 757-767.

Beniston, M., 1987: A numerical study of atmospheric pollution over complex terrain in Switzerland. Bound.Layer Meteor, 41(1-4), 75-96.

Blumen, W., 1990: Atmospheric processes over complex terrain. Meteorological Monographs, 23(45), American Meteorological Society, Boston, Massachusetts, $323 \mathrm{pp}$.

Brehm, M., 1986: Experimentelle und numerische untersuchungen der hangwindschicht und ihrer rolle bei der erwärmung von välern. [Experimental and numerical investigations of the slope wind layer and its role in the warming of valleys]. Wiss. Mitt. $\mathrm{Nr}$. 54, dissertation, Universität München - Meteorologisches Institut, München, FRG. 
Clements, W. E., J. A. Archuleta and P. H. Gudiksen, 1989: Experimental design of the 1984 ASCOT field study. J. Appl. Meteor, 28 (6), 405-413.

Cooper, J. A., 1980: Environmental impact of residential wood combustion emissions and its implications. L. Air Poll. Control Assoc, 30 (8), 855-861.

Cotton, W. R., and R. A. Anthes, 1989: Storm and Cloud Dynamics. Academic Press.

Csanady, G. T., 1973: Turbulent Diffusion in the Environment. D. Reidel Publishing Co., Dordrecht, Holland.

Doran, J. C., T. W. Horst and C. D. Whiteman, 1990: The development and structure of nocturnal slope winds in a simple valley. Bound.-Layer Meteor. 52(1-2), 41-68.

Dutton, J. A., 1986: The Ceaseless Wind. Dover, New York.

Egan, B. A., and F. A. Schiermeier, 1986: Dispersion in complex terrain: A summary of the AMS workshop held in Keystone, Colorado, 17-20 May 1983. Am. Meteor Soc, 67(10), 1240-1247.

Egger, J., 1990: "Thermally forced flows: Theory." Chapter 3 in Atmospheric Processes Over Complex Terrain, (W. Blumen, Ed.), Meteorological Monographs, 23(45). American Meteorological Society, Boston, Massachusetts, 43-58.

Eskridge, R. E., B. Lamb, and E. Allwine, 1990: Velocity oscillations and plume dispersion in a residential neighborhood during wintertime nights. Atmos. Environ, 24A (7), 1781-1796.

Filliger, P., and H. Wanner, 1986: Transport and dispersion of air pollutants in a slope wind area. Fifth Conference on Applications of Air Pollution Meteorology, 18-21 November 1986, Chapel Hill, North Carolina. American Meteorological Society, Boston, Massachusetts.

Gassmann, F., and D. Burki, 1987: Experimental investigation of atmospheric dispersion over the Swiss plain - Experiment 'Siesta'. Bound-Layer Meteor. 41(1-4), 295-308.

Gryning, S.-E., and E. Lyck, 1983: A tracer investigation of the atmospheric dispersion in the Drynaes valley, Greenland. RISO-R-481. RISO National Laboratory, DK-4000 Roskilde, Denmark, $67 \mathrm{pp}$.

Gudiksen, P. H., G. J. Ferber, M. M. Fowler, W. L. Eberhard, M. A. Fosberg, and W. R. Knuth, 1984: Field studies of transport and dispersion of atmospheric tracers in nocturnal drainage flows. Atmos. Environ., 18 (4), 713-732. 
Haugen, D. A., ed., 1973: Workshop on Micrometeorology. American Meteorological Society.

Hennemuth, B., 1986: Thermal asymmetry and cross-valley circulation in a small alpine valley. Bound-Layer Meteor, 36(4), 371-394.

Hewson, E. W., and G. C. Gill, 1944: Meteorological investigations in Columbia River valley near Trail, B.C. Bur. Mines Bull., U.S. Department of Interior, 453, 23-228.

Holzworth, G.C., 1971: Meteorological potential for urban air pollution in the contiguous United States. Proceedings from the Second International Clean Air Congress, Academic Press, New York, pp. 1076-1080.

Kimura, F., and P. Manins, 1988: Blocking in periodic valleys. Bound.-Layer Meteor, 44(1-2), 137-170.

Kondo, J., and N. Okusa, 1990: A simple numerical prediction model of nocturnal cooling in a basin with various topographic parameters. J.Appl. Meteor, 29 (7) 604-619.

Liu, C.Y., and W.R. Goodin, 1976: A two-dimensional model for the transport of pollutants in an urban basin. Atmos. Enviren, 10, 513-526.

Maki, M., and T. Harimaya, 1988: The effect of advection and accumulation of downslope cold air on nocturnal cooling in basins. J. Meteor. Sec. Japan, 66 (4), 581-597.

McNider, R.T., 1981: Investigation of the impact of topographic circulations on the transport and dispersion of air pollutants, Ph.D. Thesis. Department of Environmental Science, University of Virginia, Available from University Microfilms, Ann Arbor, Michigan.

Nappo, C. J., K. S. Rao and J. A. Herwehe, 1989: Pollutant transport and diffusion in katabatic flows. L Appl_ Meteor, 28 (7), 617-625.

Neff, W. D., and C. W. King, 1989: The accumulation and pooling of drainage flows in a large basin. J.Appl. Meteor., 28 (6), 518-529.

Olsson, L. E., M. P. McCormick, W. P. Elliot, and S. H. Melfi, 1974: An observational study of the mixing layer in western Oregon. Atmos. Environ, 8, 241-252.

Orgill, M. M., 1989: Early morning ventilation of a gaseous tracer from a mountain valley. J. Appl. Meteor., 28 (7), 636-651. 
Orgill, M.M., 1981: Atmospheric Studies in Complex Terrain: A planning guide for future studies. PNL-3656/ASCOT-80-4. February 1981. Pacific Northwest Laboratory, Richland, Washington.

Orlanski, I., 1975: A rational subdivision of scales for atmospheric processes. Bull.Amer. Meteor. Soc., 56, 527-530.

Pasquill, F., and F. B. Smith, 1983: Atmospheric Diffusion. Ellis Horwood Limited, Chichester, England.

Petkovsek, Z., 1978: Relief meteorologically relevant characteristics of basins. $Z$ Meteor, 28, 333-340.

Pielke, R. A., 1984: Mesoscale Meteorological Modeling. Academic Press.

Randerson, D., ed., 1984: Atmospheric Science and Power Production. Technical Information Center, U.S. Department of Energy, Oak Ridgo, Tennessee.

Segal, M., C. H. Yu, R. W. Arritt, and R. A. Pielke, 1988: On the impact of valley/ridge thermally induced circulations on regional pollutant transport. Atmos. Environ., 22 (3), 471-486.

Seinfield, J. H., 1986: Atmospheric Chemistry and Physics of Air Pollution. Wiley Interscience.

Sexton, K., J. D. Spengler, R. D. Treitman, and W. A. Turner, 1984: Winter air quality in a wood-burning community: A case study in Waterbury, Vermont. Atmos. Environ, 18 (7), 1357-1370.

Slade, D. H., ed., 1968: Meteorology and Atemic Energy. National Technical Information Service, Springfield, Virginia.

Sorbjan, Z., 1989: Structure of the Atmospheric Boundary Layer. Prentice Hall, Englewood Cliffs, New Jersey.

Start, G.E., C.R. Dickson, and L.L. Wendell, 1975: Diffusion in a canyon within rough mountainous terrain. L.Appl. Meteor, 14, 333-346.

Stephens, E. R., 1975: Chemistry and meteorology in an air pollution episode. لـ Air Poll. Control Assoc., 25 (5), 521-524.

Stull, R. B., 1988: An Introduction to Boundary Layer Meteorolegy. Kluwer Academic Publishers, Dordrecht, The Netherlands.

Tapp, R. G., 1985: Indications of topographically-induced eddies in stratified flow during a severe air pollution event. Bound-Layer Meteor., 33(3), 283-302. 
Toritani, H., 1990: A local climatological study on the mechanics of nocturnal cooling in plains and basins. Environmental Research Center, The University of Tsukuba $1362 \mathrm{pp}$.

Tyson, P.D., 1969: Air pollution fumigation conditions associated with the dissipation of the mountain wind and onset of the valley wind over Pietermaritzburg. S. Afr. Geogr. $\mathrm{J}, 51$, 99-105.

Venkatram, A., and J. C. Wyngaard, ed., 1988: Lectures on Air Pollution Modelling. American Meteorological Society, Boston, MA.

Vergeiner, I., E. Dreiseitl, and C. D. Whiteman, 1987: Dynamics of katabatic winds in Colorado's Brush Creek valley. L.Atmos. Scl, 44, 148-157.

Wanner, H., and J. Hertig. 1984: Studies of urban climates and air pollution in Switzerland. L. Climate Appl. Meteor., 23 (12) 1614-1625.

Wanner, H., K. Ammann, P. Berlincourt, P. Filliger, R. Herzig, L. Liebendörfer, R. Rickli, and M. Urech, 1986: Urban meteorology and air pollution in BielBienne (Switzerland). International Symposium on Climatology, 20-21 February 1986, Freiburg im Breisgau, FRG.

Whiteman, C. D., 1982: Breakup of temperature inversions in deep mountain valleys: Part I. Observations. L.Appl. Meteor, 21, 270-289.

Whiteman, C. D., 1989: Morning transition tracer experiments in a deep narrow valley. J. Appl. Meteor., 28 (7), 626-635.

Whiteman, C. D., 1990: "Observations of thermally developed wind systems in mountainous terrain." Chapter 2 in Atmospheric Processes Over Complex Terrain, (W. Blumen, Ed.), Meteorological Monographs, 23(45), American Meteorological Society, Boston, Massachusetts, 5-42.

Whiteman, C. D., and K. J. Allwine, 1985: VALMET - A valley air pollution model. Final Report. PNL-4728, Rev. 1. [Available from NTIS as PB86-104106/AS]. Pacific Northwest Laboratory, Richland, Washington, 176 pp.

Whiteman, C. D., and T. B. Mckee, 1982: Breakup of temperature inversions in deep mountain valleys: Part II. Thermodynamic model. J_Appl. Meteor. 21, 290-302.

Whiteman, C. D., K. J. Allwine, and J. M. Hubbe, 1991: Winter meteorology of the Grand Canyon region. Report prepared by Battelle, Pacific Northwest Laboratories under contract No. 16660 to the Salt River Project, Phoenix, Arizona, $176 \mathrm{pp}$.

Willson, R., F. Shair, B. Reynolds, and W. Greene, 1983: Characterization of the transport and diffusion of pollutants in a narrow mountain valley region by means of an atmospheric tracer. Atmos. Environ, 17 (9), 1633-1647. 
Appendix

VALLEY DISPERSION MODEL

\section{GENERALDESCRIPTION}

The proposed valley dispersion model, designed to operate through at least one diurnal cycle for a single valley, uses a very simple conceptual approach for treating dispersion in valleys. The key processes being incorporated in a simplified fashion are 1) nonsteady and nonhomogeneous along-valley winds and diffusivities, 2) convective boundary layer growth and inversion descent, 3) cross-valley circulations and subsidence, 4) interactions with above-ridgetop winds, and 5) time- and spatially-varying emissions.

Accounting for the effects of the key processes on dispersion is accomplished by solving the 1-D (along-valley) species conservation equation for each of a number of "flowtubes" aligned with the valley. The air mass conservation equation is satisfied for the along-valley flow in each flowtube, and for the entire valley. An example flowtube configuration used to compute downvalley drift from aerial spray operations is illustrated in Fig. 1 in Chapter 5. Interactions among flowtubes can occur and are handled through source/sink terms in each conservation equation. The interactions treated in a highly simplified fashion are turbulent diffusion and lateral advection. The advection can result from subsidence, cross-valley circulations, or interactions from aloft. 
The inputs needed are the domain boundarles, computational grid, the valley physical characteristics, the along-valley wind speed for at least one valley

cross section, temperature inversion characteristics, sensible heat flux as a function of time following sunrise, lateral and vertical diffusivities, the strengths and paths of closed and open lateral circulations, and an emissions inventory. The inputs can be a function of time and space, if available. The outputs include concentrations of species mass as a function of along-valley distance and time for each of the flowtubes, and ground-level deposition as a function of alongvalley distance and time.

The domain, coordinate system, computational grid, governing equations, solution method, and meteorological regimes are described.

\section{DOMAIN AND COORDINATE SYSTEM}

The computational domain should extend far enough down-valley and upvalley from the source area to handle transport distances commensurate with the simulation period. This could be up to $100-200 \mathrm{~km}$ up-valley and down-valley (provided the valley is this long) for one diurnal cycle. Another consideration is that the domain extend enough beyond the receptor area of concern that edge effects are minimized. That is, material advected off the grid is lost, and consequently, cannot contribute in the event of flow reversal. The cross-valley extent of the domain should be from ridgetop to ridgetop.

Two coordinate systems are used. One is Cartesian $(x, y, z)$ and, if possible, is based in a convenient geographic coordinate system (e.g., UTM). The second coordinate system $(S, Y, Z)$ is nonorthogonal and the $S$-axis follows the valley floor 
centerline. The origin is at the up-valley edge of the domain, at the center of the valley cross section, and at the level of the valley floor. The positive S-axis follows down-valley at the valley center; the positive $\mathrm{Y}$-axis extends horizontally to the right (looking up-valley) locally perpendicular to the S-axis; and the positive Z-axis is the same orientation as the z-axis in the Cartesian grid. The transformation of an equation from the first coordinate system Into the second would introduce "streching factors" into the transformed equations. However, these streching factors will not be treated in the 1-D equations developed here.

Once the computational domain and coordinate systems have been determined, certain terrain characteristics need to be specified. These can be determined from contour maps and/or computer-based digital elevation data sets. The terrain characteristics required are

$S(x, y)=$ the down-valley distance following the valley floor [m],

$\mathrm{Y} L(\mathrm{~S}, \mathrm{z})=\mathrm{Y}$-coordinate of left sidewall (negative) [m], and

$\mathrm{Y}^{\mathrm{R}}(\mathrm{S}, \mathrm{z})=\mathrm{Y}$-coordinate of right sidewall (positive) $[\mathrm{m}]$.

$Z^{\prime}(S)=$ elevation of the valley floor [m MSL],

$z^{r}(S)=$ elevation of the ridgetops (if different, then use lower) [m MSL],

The vertical axis transforms as

$$
z=z(S)-z^{\dagger}(S)
$$

where $\mathrm{Z}$ is in meters above the valley floor at the down-valley distance $\mathrm{S}$. 


\section{COMPUTATIONAL GRID - FLOWTUBES}

The number of flowtubes must be specified in the vertical and cross-valley directions in order to generate the computational grid. The number of flowtubes is identified as

$$
\begin{aligned}
& N^{Z}=\text { number of "rows" (layers) in valley, and } \\
& N Y=\text { number of "columns" across valley. " }
\end{aligned}
$$

The computational grid can then be generated as follows.

First a valley cross section is initialized from which the complete grid is generated. This cross section shouid be "typical" and roughly the median in area. The i-index denotes the "row", and the j-index the "column." The "rows" (layers) are evenly spaced in $\mathrm{Z}$, and the "columns" are evenly spaced in $\mathrm{Y}$ at each $\mathrm{Z}$. The cross-sectional areas of the flowtubes, $A_{i j}$, at section $S_{0}$ are

$$
A_{i j}\left(S_{0}\right)=\frac{A_{1}\left(S_{0}\right)}{N^{Y}} ; j=1, N^{Y}
$$

where,

$$
\begin{aligned}
& A_{i}\left(S_{0}\right)=\int_{Z_{1-1}\left(S_{0}\right)}^{Z_{1}\left(S_{0}\right)}\left[Y^{R}\left(S_{0}, Z\right)-Y^{L}\left(S_{0}, Z\right)\right] d Z \\
& Z_{i}\left(S_{0}\right)=Z_{i-1}\left(S_{0}\right)+\Delta Z_{i}\left(S_{0}\right) ; \quad i=1, N^{Z} ; Z_{0}=0 \\
& \Delta Z_{i}\left(S_{0}\right)=\frac{Z^{r}\left(S_{0}\right)-Z^{\prime}\left(S_{0}\right)}{N^{Z}}
\end{aligned}
$$

The computational grid (flowtubes) can then be generated at all $S$, using the following two relationships

$$
A_{i}(S)=\frac{A_{i}\left(S_{0}\right)}{A\left(S_{0}\right)} A(S)
$$




$$
A_{1 j}(S)=\frac{A_{1}(S)}{N^{Y}} ; j=1, N^{Y}
$$

where the total cross-sectional area of the valley, $A$, at any location, $S$, can be determined by

$$
A(S)=\sum_{i=1}^{N^{Z}} A_{i}(S)
$$

or,

$$
A(S)=\int_{0}^{Z_{N Z}(S)}\left[Y^{R}(S, Z)-Y^{L}(S, Z)\right] d Z
$$

The vertical spacing of the flowtubes on any along-valley cross section is not generally the same as at $S_{0}$ [Eqn (5) does not necessarily hold at any arbitrary cross section, S]. Rather, the layer heights at $S$ are determined by finding the $Z_{j}^{\prime}$ 's where

$$
\int_{Z_{1-1}(S)}^{Z_{1}(S)}\left[Y^{R}(S, Z)-Y^{L}(S, Z)\right] d Z=A_{i}(S)
$$

Eqns (6), (7) and (10) maintain the conditions 1) that the area of each flowtube remains in the same proportion to the total cross-sectional area for all $S$; and, 2) that the layers are always horizontal in the valley cross section. These conditions impose a configuration of the flowtubes that is consistent with the general flow characteristics. Fig. 1 shows a section of valley divided into 9 flowtubes. The flowtube in the center of the valley is outlined to show it's conformity with the shape of the valley. 


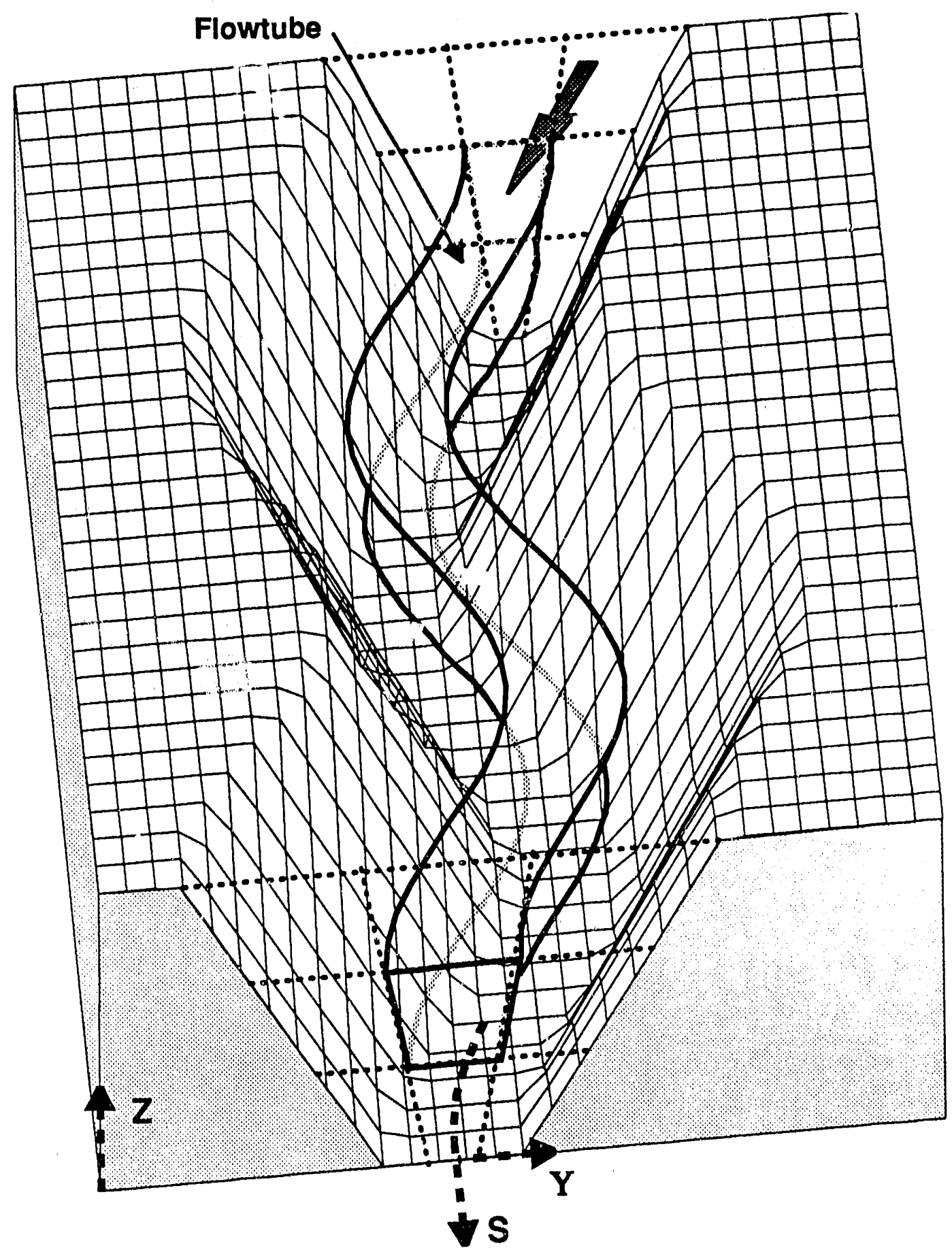

Figure 1. Conforming of the center flowtube to the shape of the valley. 
Idealized Valley Cross Section

Consider the valley cross section to be approximated as shown in Fig. 2. The computational grid can then be generated from analytical expressions determined from the integration of

$$
\begin{aligned}
\int_{Z,(S)}^{Z_{2}(S)}\left[Y^{R}(S, Z)-Y^{L}(S, Z)\right] d Z & =\int_{Z,(S)}^{Z_{2}(S)}\left[\left(\frac{l}{2}+\frac{Z}{\tan \alpha^{R}}\right)-\left(-\frac{\ell}{2}-\frac{Z}{\tan \alpha^{L}}\right)\right] d Z(1) \\
& =\ell\left(Z_{2}-Z_{1}\right)+\frac{\theta}{2}\left(Z_{2}{ }^{2}-Z_{1}^{2}\right)
\end{aligned}
$$

where

$$
\begin{aligned}
\Theta & =\frac{1}{\tan \alpha^{L}}+\frac{1}{\tan \alpha^{R}} \\
\ell & =\text { width of valley floor }[\mathrm{m}], \\
\alpha^{L} & =\text { elevation angle of left sidewall, and } \\
\alpha^{R} & =\text { elevation angle of right sidewall. }
\end{aligned}
$$

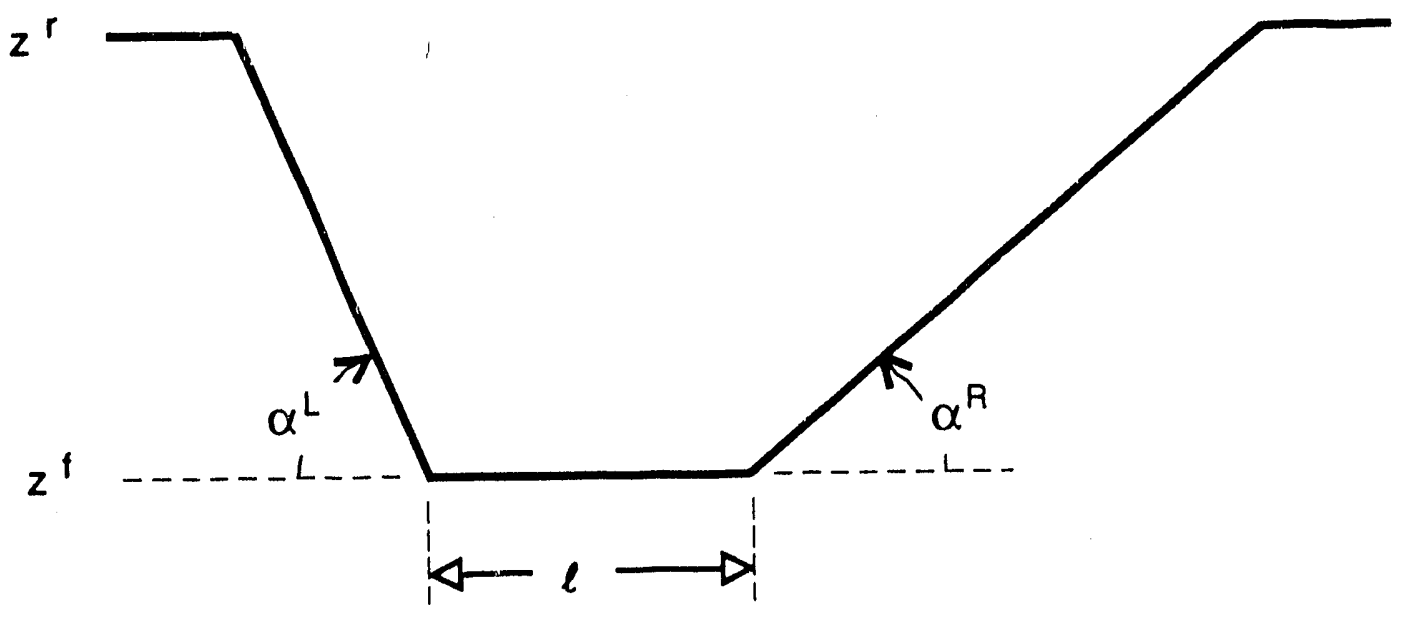

Figure 2. Simplified valley cross section showing required parameters. 
The following relations can be determined from Eqn (12)

$$
\begin{aligned}
& A\left(S_{0}\right)=Z_{N^{z}}\left(S_{0}\right)\left(\ell\left(S_{0}\right)+\frac{\Theta\left(S_{0}\right)}{2} Z_{N^{z}}\left(S_{0}\right)\right) \\
& A_{i}\left(S_{0}\right)=\Delta Z_{i}\left(S_{0}\right)\left[\ell\left(S_{0}\right)+\Theta\left(S_{0}\right)\left(i-\frac{1}{2}\right) \Delta Z_{i}\left(S_{0}\right)\right]
\end{aligned}
$$

The total cross-sectional area at location $S$ is

$$
A(S)=Z_{N^{2}}(S)\left(\ell(S)+\frac{\Theta(S)}{2} Z_{N^{2}}(S)\right)
$$

The $A_{i}$ 's at location $S$ can be calculated from Eqn (6), using the results from Eqns (14), (15) and (16). The area of each flowtube at cross section $S$ can then be calculated using Eqn (7). The heights of the flowtube levels can be calculated as

$$
Z_{i}(S)=\frac{1}{\Theta(S)}\left[\sqrt{\ell(S)^{2}+2 \Theta(S) \hat{A}_{i}(S)}-\ell(S)\right]
$$

where

$$
\hat{A}_{i}(S)=\hat{A}_{i-1}(S)+A_{i}(S) ; \quad \hat{A}_{0}(S)=0
$$

The cross-valley locations of the flowtube faces can be determined as

$$
Y_{i, j}(S)=Y_{i, j-1}(S)+\Delta Y_{i}(S) ; \quad Y_{i, 0}(S)=Y_{i}^{L}(S)
$$

where

$$
\begin{aligned}
& \Delta Y_{i}(S)=\frac{1}{N^{Y}}\left[\ell(S)+\Theta(S) Z_{i}(S)\right] \\
& Y_{i}^{L}(S)=-\frac{\ell(S)}{2}-\frac{Z_{i}(S)}{\tan \alpha^{L}(S)}
\end{aligned}
$$


$A_{i}=\Delta Z_{i}\left[\ell+\Theta \bar{Z}_{i}\right]$

$\Delta \mathrm{Z}_{\mathrm{i}}=\mathrm{Z}_{\mathrm{i}}-\mathrm{Z}_{\mathrm{i}-1}$

$\bar{Z}_{i}=\frac{1}{2}\left(Z_{i}+Z_{i-1}\right)$

$A_{i j}=\Delta Z_{i} \overline{\Delta Y_{i}}$

$\overline{\Delta Y_{i}}=\frac{1}{2}\left(\Delta Y_{i}+\Delta Y_{i-1}\right)=\frac{1}{N^{Y}}\left(\ell+\Theta \bar{Z}_{i}\right)$

$Y_{i j}=\left(\frac{j}{N^{Y}}-\frac{1}{2}\right) l+\left(\frac{j}{N^{Y}} \Theta-\frac{1}{\tan \alpha^{L}}\right) Z_{i}$

$A_{i j}=\int_{Z_{i-1}}^{z_{i}}\left[Y_{i, j}-Y_{i, j-1}\right] d z$

\section{CONSERVATION OF AIR MASS}

Air mass is conserved using the continuity equation considering only the along-valley flow explicitly. Nonrecirculating lateral flows are treated as source/sink terms in the equation. Possible sources/sinks of air mass are from subsidence, regional flow intrusions, and tributary flows. Assuming the flow to be incompressible, the air mass (volume) in the valley is conserved as

$$
\frac{\partial \dot{V}(S, t)}{\partial S}+\Gamma^{a}(S, t)=0
$$

where

$\dot{V}$ is the total along-valley volume flow rate $\left[\mathrm{m}^{3} / \mathrm{s}\right]$, and

$\Gamma^{a}$ is the air mass source/sink term $\left[\mathrm{m}^{3} / \mathrm{s}-\mathrm{m}\right]$. 
The air mass is also conserved for each flowtube, ij, as

$$
\frac{\partial \dot{V}_{i j}(S, t)}{\partial S}+\Gamma_{i j}^{a}(S, t)=0
$$

where

$\dot{V}_{i j}$ is the along-valley volume flow rate in flowtube ij [ $\left.\mathrm{m}^{3} / \mathrm{s}\right]$, and

$\Gamma_{i j}^{a}$ is the air mass source/sink term in flowtube ij $\left[\mathrm{m}^{3} / \mathrm{s}-\mathrm{m}\right]$.

The following two relationships between the flowtubes and the entire valley hold,

$$
\dot{V}(S, t)=\sum_{i=1}^{N^{Z}} \sum_{j=1}^{N^{Y}} \dot{V}_{i j}(S, t) \quad \text { and } \quad \Gamma^{a}(S, t)=\sum_{i=1}^{N^{Z}} \sum_{j=1}^{N^{Y}} \Gamma_{i j}^{a}(S, t)
$$

Integrating Eqn (30) between a starting cross section, $S_{0}$, and some arbitrary cross section, S, gives

$$
\dot{V}_{i j}(S, t)=\dot{V}_{i j}\left(S_{0}, t\right)-\int_{S_{0}}^{s} \Gamma_{i j}^{a}\left(S^{\prime}, t\right) d S^{\prime}
$$

Given the volume flow rate at $S_{0}$ and the source/sink terms for all $S$, the volume flow rate for each flowtube at time $t$ can be determined for all $S$ from Eqn (32). The along-valley wind speed, $u_{i j}$, averaged over the area $A_{i j}$ can then be calculated as

$$
u_{i j}(S, t)=\frac{\dot{V}_{i j}(S, t)}{A_{i j}(S)}
$$




\section{Along-Valley Volume Flow Rate}

Next consider the coordinate system $(S, \beta, \gamma)$ which transforms from the $(S, Y, Z)$ coordinate system using the equations

$$
\beta=\frac{Y-Y^{L}}{Y^{R}-Y^{L}}-\frac{1}{2} \quad\left(-\frac{1}{2} \leq \beta \leq \frac{1}{2}\right)
$$

and,

$$
\gamma=\frac{z-z^{\dagger}}{z^{r}-z^{1}} \quad(0 \leq \gamma \leq 1)
$$

Given the along-valley winds $u(S, \beta, \gamma, t)$ at one valley cross section $\left(S_{0}\right)$, the volume flow rate for each flowtube at $S_{0}$ is determined as

$$
\dot{V}_{i j}\left(S_{0}, t\right)=\left\{z^{r}\left(S_{0}\right)-z^{\dagger}\left(S_{0}\right)\right\} \int_{\gamma_{i-1}}^{\gamma_{i}}\left[\left\{Y^{R}\left(S_{0}, \gamma\right)-Y^{L}\left(S_{0}, \gamma\right)\right\} \int_{\beta_{j-1}}^{\beta_{j}} u\left(S_{0}, \beta, \gamma, t\right) d \beta\right] d \gamma
$$

where,

$$
\begin{aligned}
& \beta_{j}=\frac{j}{N^{Y}}-\frac{i}{2} ; \quad j=1, N^{Y} ; \quad \beta_{0}=-\frac{1}{2} \\
& \gamma_{i}\left(S_{0}\right)=\frac{i}{N^{Z}} ; \quad i=1, N^{Z} ; \quad \gamma_{0}=0
\end{aligned}
$$

If the along-valley winds are known at more than one location (e.g., two locations, $S_{0}$ and $S_{1}$ ), the flow field is made to conform to the measurements by incorporating a source/sink term in Eqn ( 30 ) calculated as

$$
\Gamma_{i j}^{a}\left(S:\left\{S_{0} \rightarrow S_{1}\right\}, t\right)=\frac{\dot{V}_{i j}\left(S_{0}, t\right)-\dot{V}_{i j}\left(S_{1}, t\right)}{S_{1}-S_{0}}
$$

The along-valley winds need to be known over an entire valley cross section in order to calculate the volume flow rate for each flowiube using Eqn (36). These wind fields can be developed using various methods, including 
176

measurements, primitive equation models, parameterizations of pertinent physics, and empirical relationships. In most cases, winds are not measured over an entire cross section, but rather point measurements or, at best, vertical profiles of winds are available as a function of time. Empirical relations can be used to interpolate and/or extrapolate the measurements to cover the entire valley cross section.

\section{CONSERVATION OF SPECIES}

The basis of the approach is the solution of the 1-D species conservation equation for each flowtube. Species mass can "advect" and "diffuse" among the flowtubes. The equation solved for each flowtube, $i j$, is

$$
\frac{\partial\left[A_{i j}(S) C_{i j}(S, t)\right]}{\partial t}+\frac{\partial\left[\dot{V}_{i j}(S, t) C_{i j}(S, t)\right]}{\partial S}+\Gamma_{i j}^{c}(S, t)=0
$$

where

$C_{i j}$ is the concentration along flowtube ij $\left[\mu \mathrm{g} / \mathrm{m}^{3}\right]$,

$A_{i j}$ is the cross-sectional area of flowtube ij [m²],

$\dot{V}_{i j}$ is the air volume flow rate through flowtube ij $\left[\mathrm{m}^{3} / \mathrm{s}\right]$, and

$$
\begin{aligned}
\Gamma_{i j}^{c}= & {\left[\Gamma_{i j}^{c s}+\Gamma_{i j}^{c p}+\Gamma_{i j}^{c c}\right]+\left[\Gamma_{i j}^{c a}\right]+\left[\left[\Gamma_{i j}^{c d}\right]\right.} \\
& {\left[\begin{array}{l}
\text { CONVENTIONAL } \\
\text { SOURCE/SINKS }
\end{array}\right]+\left[\begin{array}{c}
\text { ADVECTIVE } \\
\text { EFFECTS }
\end{array}\right]+\left[\begin{array}{c}
\text { TURBULENT } \\
\text { DIFFUSION }
\end{array}\right] }
\end{aligned}
$$

are the source/sink terms for flowtube ij $[\mu \mathrm{g} / \mathrm{s}-\mathrm{n}]$. Various terms of Eqns (40) and (41) are shown graphically in Fig. 3. The first term in Eqn (40) is the rate of change of storage of speciers mass in the control volume $A_{i j} d S$, and the second term is the along-valley advection of species mass. The various source/sink terms in Eqn (41) are of three genoral types. The first three are the more 
conventional "source/sink" terms representing emissions, deposition, and chemical or physical transformations. The next term account for lateral advective effects from, for example, slope flows, cross-valley circulations, subsidence, regional flow intrusions, and tributary flows. The last term accounts for the effects of both lateral and vertical turbulent diffusion. The source/sink terms are described next. (The deposition and transformations source/sink terms are not developed here.)

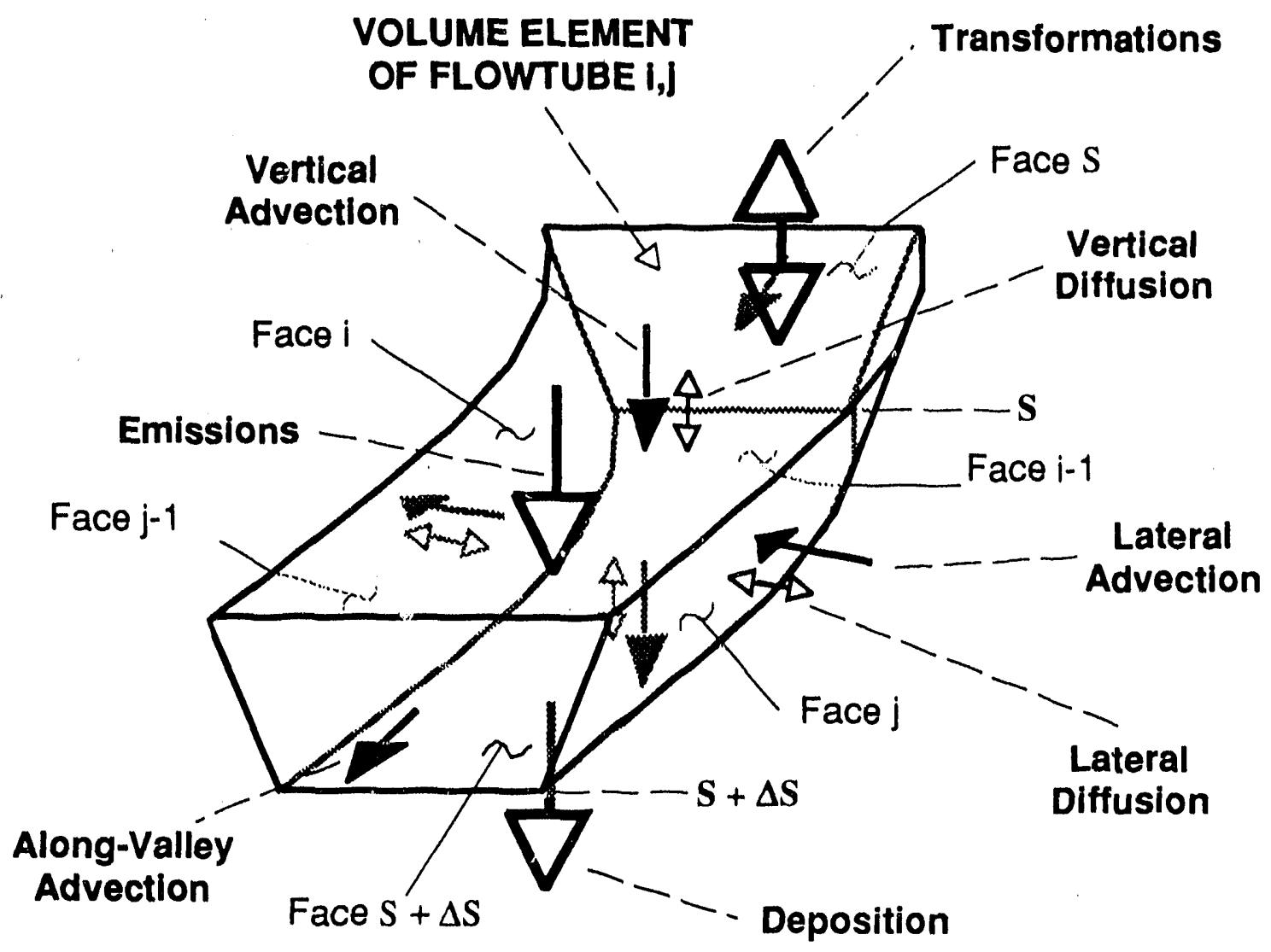

Figure 3. Sources/sinks, flow and flux of species mass through a flowtube volume element. 


\section{Emissions Source/Sink Term}

Each flowtube can have an emission inventory associated with it. The inventory for each flowtube can be a function of along-valley distance and time. The emissions are accounted for as the source term, $\Gamma_{\|}^{\text {cs }}$, in Eqn (41).

\section{Iurbulent Diffusion Source/Sink Term}

Material can move among flowtubes by turbulent diffusion. The K-theory approach is used where horizontal (lateral) and vertical diffusivities can be specified for each flowtube. Assuming the lateral and vertical diffusivities to be only a function of $Z$, the source/sink term representing diffusion in Eqn (41) is given as

$$
\Gamma_{i j}^{c d}=\Gamma_{i j}^{c d^{Y}}+\Gamma_{i j}^{c d^{Z}}
$$

where the lateral and vertical turbulent diffusion terms are represented as,

$$
\begin{aligned}
& \Gamma_{i j}^{c d^{Y}}=\left[\overline{\dot{V}^{Y} \cdot C^{\prime}}\right]_{F a c \theta j}-\left[\overline{\dot{V}^{Y} \cdot C^{\prime}}\right]_{F a c \theta j-1} \\
& \Gamma_{i j}^{c d^{Z}}=\left[\overline{\dot{V}^{Z} \cdot C^{\prime}}\right]_{F a c \theta i}-\left[\overline{\bar{V}^{Z} \cdot C^{\prime}}\right]_{F a c \theta i-1}
\end{aligned}
$$

and the overbar terms represent the time-averaged turbulent fluxes of $C$ in the $Y$ and $\mathrm{Z}$-directions as denoted. The turbulent volume flow terms $\left(\dot{\mathrm{V}}^{\mathrm{Y}_{1}}\right.$ and $\left.\dot{\mathrm{V}}^{\mathrm{Z}_{1}}\right)$ are flow in the $\mathrm{Y}$ - and Z-directions per unit length in tha S-direction $\left[\mathrm{m}^{3} / \mathrm{s} \cdot \mathrm{m}\right]$. Eqns (43) and (44) can be approximated using K-theory as

$$
\Gamma_{i j}^{c d^{Y}}=\Delta Z_{i} K_{i}^{Y}\left[\frac{\partial C}{\partial Y}\right]_{\text {Facej }}-\Delta Z_{i} K_{i}^{Y}\left[\frac{\partial C}{\partial Y}\right]_{\text {Face } j-1}
$$


$\mathrm{r}_{i j}^{\mathrm{cd}^{\mathrm{Z}}}=\Delta \mathrm{Y}_{i} \mathrm{~K}_{i}^{\mathrm{Z}}\left[\frac{\partial \mathrm{C}}{\partial \mathrm{Z}}\right]_{\mathrm{Facei}}-\Delta \mathrm{Y}_{\mathrm{I}-1} \mathrm{~K}_{i-1}^{\mathrm{Z}}\left[\frac{\partial \mathrm{C}}{\partial \mathrm{Z}}\right]_{\mathrm{Facei}-1}$

Writing the derivatives in difference form and regrouping gives

$$
\begin{aligned}
& \Gamma_{i j}^{c d^{Y}}=\frac{\Delta Z_{i} K_{j}^{Y}}{\overline{\Delta Y_{i}}}\left(C_{i, j-1}-2 C_{i, j}+C_{i, j+1}\right) \\
& \Gamma_{i j}^{c d^{Z}}=\frac{\Delta Y_{i} K_{i}^{Z}}{\Delta Z_{i+1}}\left(C_{i+1, j}-C_{i, j}\right)-\frac{\Delta Y_{i-1} K_{i-1}^{Z}}{\overline{\Delta Z_{i}}}\left(C_{i, j}-C_{i-1, j}\right)
\end{aligned}
$$

where

$$
\overline{\Delta \bar{Z}_{i}}=\frac{1}{2}\left(\Delta \mathrm{Z}_{i}+\Delta \mathrm{Z}_{\mathrm{i}-1}\right)
$$

and $K^{Y}$ is the lateral diffusivity and $K^{Z}$ is the vertical diffusivity. The index convention is shown in Fig. 4. The lengths $\Delta \mathrm{Y}$ and $\Delta \mathrm{Z}$ are functions only of $\mathrm{Z}$ on each cross section, and are determined from Eqns (20) and (23).

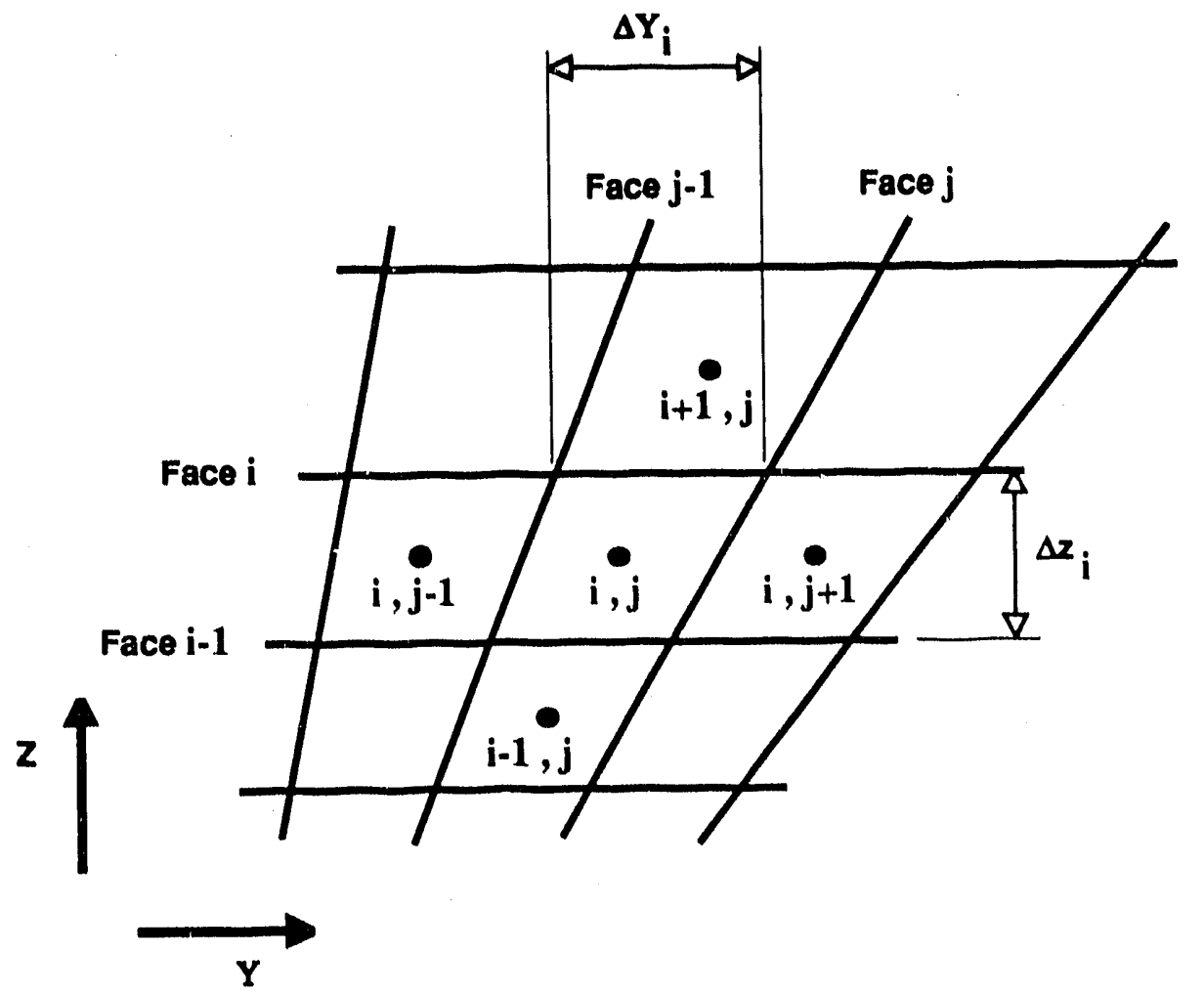

Figure 4. Index notation associated with the flowtubes on a valley cross section. 


\section{Advective Effects Source/Sink Term}

The lateral advective processes (e.g. subsidence, lateral circulations, intrusions from aloft, tributary flows) affect the concentration in a flowtube element by moving air mass (and consequently species mass) among the flowtubes. The advective effects source/sink term is calculated as

$$
\Gamma_{i j}^{c a}=\dot{V}_{i, j}^{Y} C_{i, j}-\dot{V}_{i, j-1}^{Y} C_{i, j-1}+\dot{V}_{i, j}^{Z} C_{i, j}-\dot{V}_{i-1, j}^{Z} C_{i-1, j}
$$

The terms, $\dot{V}^{Y}$ and $\dot{V}^{Z}$, are volume flow rates in the $Y$ - and $Z$-directions per unit length in the S-direction $\left[\mathrm{m}^{3} / \mathrm{s}-\mathrm{m}\right]$. If the flow is in the opposite direction (negative values) through a particular face or faces of the flowtube, then the source/sink term is calculated as

$$
\Gamma_{i j}^{c a}=\dot{V}_{i, j}^{Y} C_{i, j+1}-\dot{V}_{i, j-1}^{Y} C_{i, j}+\dot{V}_{i, j}^{Z} C_{i+1, j}-\dot{V}_{i-1, j}^{Z} C_{i, j}
$$

The method of incorporating lateral advective effects is to describe the physical process creating this motion in terms of two basic flow elements: "closed" and "open" valley circulations. The air mass in these circulations must be conserved on each valley cross section.

The closed valley circulation has the properties that 1) no air mass can be added or removed; and 2) the circulation must begin and end at the same flowtube, or begin anywhire on the boundary and end anywhere on the boundary. The effects of the closed circulation are not felt in the air mass conservation equation, but enter into the conservation of species mass Eqn (40). Examples of closed circulation are slope flows and cross-valley circulations. 
The open valley circulation has the properties that air mass is added or removed from the valley atmosphere at the cross section of interest, the circulation must begin or end on the boundary, and the path of the circulation does not intersect or eross itself. The effects of the open circulation are felt in both the air and species mass conservation equations. Examples of open circulations are subsidence, penetrations from aloft, and tributary flows.

Determining the lateral volume flow rates through all flowtube faces resulting from closed and open circulations is discussed next. The source/sink term in the air mass conservation equation resulting from open circulations is also discussed. It should be noted that no "branching" of a circulation path is permitted. That is, lateral inflow to a flowtube element is through one face and lateral outflow can only occur at one other face.

Cross-valley circulations are treated numerically using the concept of a "circulation vector." Once the location of an open or closed circulation of initial magnitude, $\Omega_{0, p}$, has been prescribed, the $\mathrm{i}$ (Z-direction) and $\mathrm{j}$ (Y-direction) indicies of the $N_{p}$ number of flowtubes that the "pth" circulation passes through are specified in vectors $Z_{p}(k)$ and $Y_{p}(k)$, where $k=1,2, \ldots, N_{p}$. The order of the indicies specifies the order of the sirculation. The vector locations $Z_{p}(0)$ and $\mathbf{Y}_{\mathrm{p}}(0)$ are used as a means of closing the circulation path of a closed circulation, where $Z_{p}(0)$ is set to $Z_{p}\left(N_{p}\right)$, and $Y_{p}(0)$ is set to $Y_{p}\left(N_{p}\right)$. In the case where the circulation begins on a boundary, $Z_{p}(0)$ and $Y_{p}(0)$ are set to the boundary index. The volume flow rates through the faces of each flowtube element in the circulation are

$$
\Omega_{k, p}(S)=\Omega_{k-1, p}(S)-k, p(S) \Omega_{0, p}(S) ; k=1,2, \ldots, N_{p}(S)
$$

where 
$\Omega_{k, p}$ is the volume flow rate of alr through the $k^{\text {th }}$ flowtube in the pth circulation $\left[\mathrm{m}^{3} / \mathrm{s}-\mathrm{m}\right]$, and

$f_{k, p}$ is the fraction of the initial air volume flow converted to along-valley flow in the kth flowtube.

For a closed circulation, all of the $f_{k, p}$ values are zero, and for an open circulation, the following continuity condition must be satisfied

$$
\sum_{k=1}^{N} k_{k, p}=1
$$

The air source term, included in the air conservation Eqn (30), for the ijth flowtube is

$$
\Gamma_{\| j}^{a}(S)=\sum_{p} k_{, p}(S) \Omega_{0, p}(S)
$$

where $k$ and $i j$ are related by the circulation vectors $Z_{p}$ and $Y_{p}$.

The lateral flow imposes a constraint on the size of the modeling time step

$$
\Delta t<\frac{\min \left\{A_{i j}\right\}}{\left|\Omega_{0, p}\right|}
$$

This constraint ensures that the volume flow of air through control volume elements during $\Delta t$ does not exceed the volume of any of the elements. The constraint in Eqn (55) is not the most restrictive. It assumes that not more than one of the $p$ circulations passes through any flowtube, wlich may not necessarily be true.

The laterail volume flow rates needed in the advective effects source/sink terms are determined as follows. First the volume flow rates for a valley crisss section are all initialized to zero. Then the flow rates associated with each circulation are summed to the appropriate flowtube face as mapped with the 
circulation vectors. The result is an array of flow rates for all the faces for a given time step.

\section{Boundary Conditions}

An infinite reservoir of air is assumed to surround the lateral boundaries (includes top and bottom boundaries) of the computational domain. That is, air can be removed from or added to the reservoir without changing any properties of the reservoir. The background species concentration can be specified on the lateral boundaries as a function of time and space. The longitudinal boundary conditions of species concentration can vary in time and space.

\section{Solution Methed}

Rewrite Eqn (40) as

$$
\frac{\partial C_{i j}(S, t)}{\partial t}+\frac{1}{A_{i j}(S)} \frac{\partial\left[\dot{V}_{i j}(S, t) C_{i j}(S, t)\right]}{\partial S}+\frac{\Gamma_{i j}^{C}(S, t)}{A_{i j}(S)}=0
$$

Eqns (56) can be solved for $C_{i j}$ given $\dot{V}_{i j}$ from Eqn (30), and the initial and boundary conditions for $\mathrm{C}_{\mathrm{ij}}$.

The finite difference form of the advection term in Eqn (56), using upwind differencing at the advanced time step (implicit form), is

$$
\frac{1}{A_{i j}} \frac{\partial\left[\dot{V}_{i j} C_{i j}\right]}{\partial S}=\frac{1}{A_{i j}^{m}} \frac{\dot{V}_{i j}^{m, n+1} C_{i j}^{m, n+1}-\dot{V}_{i j}^{m-1, n+1} C_{i j}^{m-1, n+1}}{\Delta S}
$$


The $m$ index refers to steps in the space dimension, $S$, and the $n$ index refers to steps in time. The grid spacing is $\Delta S$, and the time step is $\Delta t$. The continuity equation [Eqn (30)], in finite difference form, gives

$$
\dot{V}_{i j}^{m-1, n+1}=\dot{V}_{i j}^{m, n+1}+\Delta S\left(\Gamma_{i j}^{a}\right)^{m, n+1}
$$

Substituting this into Eqn (32), using Eqn (17), and regrouping gives the advection term as

$$
\frac{1}{A_{i j}} \frac{\partial\left[\dot{V}_{i j} C_{i j}\right]}{\partial S}=\frac{u_{i j}^{m, n+1}}{\Delta S} C_{i j}^{m, n+1}-\left[\frac{u_{i j}^{m, n+1}}{\Delta S}+\frac{\left(\Gamma_{i j}^{a}\right)^{m, n+1}}{A_{i j}^{m}}\right] C_{i j}^{m-1, n+1}
$$

Writing the storage term of Eqn (56) in finite difference form (using forward differencing), and regrouping, gives the implicit finite difference representation of Eqn (56) as

$$
C_{i j}^{m, n+1}=\left[C_{i j}^{m, n}+(r+E) C_{i j}^{m-1, n+1}+F\right] /[1+r]
$$

where

$$
\begin{aligned}
& r=u_{i j}^{m, n+1} \frac{\Delta t}{\Delta S} \\
& E=\frac{\left(\Gamma_{i j}^{a}\right)^{m, n+1}}{A_{i j}^{m}} \Delta t \\
& F=-\frac{\left(\Gamma_{i j}^{c}\right)^{m, n+1}}{A_{i j}^{m}} \Delta t
\end{aligned}
$$

The concentration along each flowtube at the advanced time step $(n+1)$, can be determined using Eqn (60), by marchin! downstream from the specified boundary condition, and given the values from the previous time step $(n)$. The 
wind speed required in Eqn (61) is determined from measurements and Eqn (20). The source/sink term resulting from air mass convergence is determined using Eqn (39), and the source/sink terms required in Eqn (63), are specified or calculated depending on the particular term [refer to Eqn (41)]. These finite difference equations developed above are for flow in the down-valley direction. The upwind differencing criteria for the advection terms will result in different equations for up-valley flows. These equations are not given here, but follow the same development.

Note from Eqn (60) that the concentration can be calculated explicitly at the advanced time step if the "old" source/sink terms in Eqn (63) are used. This approach is adopted to simplify the calculations. Consequently, Eqn (63) becomes

$$
F=-\frac{\left(\Gamma_{i j}^{c s}+\Gamma_{i j}^{c p}+\Gamma_{i j}^{c c}\right)^{m, n+1}+\left(\Gamma_{i j}^{c d}+\Gamma_{i j}^{c a}\right)^{m-1, n+1}}{A_{i j}^{m}} \Delta t
$$

\section{IREATMENT OF VARIOUS METEOROLOGICAL REGIMES}

As discussed in Chapter 2, the daily behavior of the valley atmosphere from thermal effects can be divided into four time regimes, morning transition, daytime, evening transition, and nighttime.

During the nighitime period, the winds throughout the valley will typically be down-valley with down-slope flow near the sidewalls. Tributary flows can also penetrate the valley, adding to the down-valley flow. The vertical temperature structure will typically be sub-adiabatic with a surface-based inversion. Wind 
direction shifts can be present in the surface-based inversion, and the flow in the valley may be decoupled from the flow above the ridgetops. The horizontal and vertical diffusivities may vary significantly with height because of the complicated vertical structure of the valley atmosphere. One approach to specifying the crossvalley and vertical structure of the along-valley winds is given below.

The daytime period will be characterized by a developed CBL over the valley floor, sidewalls, and ridgetops with the valley flow coupled to the aboveridgetop flow. The winds in the valley will be up-valley with up-slope flows near the valley sidewalls. The cross-valley and vertical structure of the daytime winds will not be developed here. An initial approach for describing the daytime winds is to use the same form of the equation that describes the nighttime along-valley winds.

The morning transition period proceeds from nighttime profiles to daytime profiles. The characteristics of the morning transition period are discussed in Chapters 2 and 3 . The dominant processes working during the morning transition period are the growth of a convective boundary layer (CBL) and the descent of the stable core of the valley. These play a major role in the behavior of material in the valley atmosphere. The approach for treating the morning transition period in the model is based on the CBL growth-inversion descent formulation in Whiteman and Allwine's (1985) VALMET model. Flowtubes below the CBL have up-valley winds and the species mass is uniformly mixed in these flowtubes. Above the CBL and below the elevated inversion, the flow continues down-valley in the flowtubes in the stable core. Above the inversion, the flow is in the direction of the above-ridgetop winds. The interaction of the CBL growth/inversion descent and flowtubes is demonstrated in Fig. 2 in Chapter 5. 
The characteristics of the evening transition period are the least studied and understood. After sunset, surface heating ceases, shutting off convective mixing near the surface. Radiative cooling of the surface then leads to cooling of the air near the surface and down-slope flows begin. Convective mixing above the surface may persist and decay off throughout the evening. An initial approach for specifying the winds during the evening transition period is to use the same form as the nighttime winds.

\section{Niahttime along-valley winds}

Clements, et al. (1989) gave the following semi-empirical relationship, called a "Prandlt parabolic wind field," for mean nighttime drainage flow in a deep valley in western Colorado

$$
u(Y, z)=U f(Y) g(z)
$$

where,

$$
\begin{aligned}
& f(Y)=0.95-0.85\left(\frac{Y}{H(z)}\right)^{2} \\
& g(z)=3.2 e^{-\left[3.3 \frac{z-z^{\dagger}}{D-z^{\dagger}}\right]} \sin \left(\pi \frac{z-z^{\dagger}}{D-z^{\dagger}}\right) \\
& U=\text { the maximum wind speed [m/s], } \\
& H=\text { the valley half width [m], and } \\
& D=\text { the depth of the drainage flow (height at which wind speed goes to } \\
& \text { zero), [m MSL]. }
\end{aligned}
$$

Eqns (66) and (67), expressed in the computational coordinates, and assuming the depth of the drainage extends to the ridgetop level (i.e., $D=z^{r}$ ), are 


$$
\begin{aligned}
& f(\beta)=0.95-3.4 \beta^{2} \\
& g(\gamma)=3.2 e^{-3.3 \gamma} \sin (\pi \gamma)
\end{aligned}
$$

Then from Eqn (36), the along-valley volume flow rate can be determined as

$$
\dot{V}_{i j}\left(S_{0}, t\right)=U\left(S_{0}, t\right)\left\{z^{r}\left(S_{0}\right)-z^{i}\left(S_{0}\right)\right\} \int_{\beta_{J-1}}^{\beta_{1}} f(\beta) d \beta \int_{\gamma_{1-1}}^{\gamma_{l}}\left\{Y^{R}\left(S_{0}, \gamma\right)-Y^{L}\left(S_{0}, \gamma\right)\right\} g(\gamma) d \gamma(70)
$$

or, after integrating over $\beta$,

$\dot{V}_{i j}\left(S_{0}, t\right)=U\left(S_{0}, t\right)\left\{z^{r}\left(S_{0}\right)-z^{\prime}\left(S_{0}\right)\right\}\left\{\frac{0.95}{N^{\beta}}-1.13\left(\beta_{j}^{3}-\beta_{j-1}^{3}\right)\right\} \int_{\gamma_{i-1}}^{\gamma_{i}}\left\{Y^{R}\left(S_{0}, \gamma\right)-Y^{L}\left(S_{0}, \gamma\right)\right\} g(\gamma) d \gamma(71)$

Eqn (71) can be used to generate the along-valley volume flow rate for each flowtube, at time $t$, given the maximum wind speed as a function of time.

\section{IMPROVEMENTS AND ADDITIONS}

Wet and dry deposition can be incorporated in a straight-forward manner in the model. Deposition would be treated as an additional sink term in Eqn (41). The treatment of chemistry would require a conservation equation for each species of interest. The treatment of chemical transformations would be handled through the source/sink term in each conservation equation.

It would be desirable to have the flowtube areas be functions of time as well as $\mathrm{S}$, as this would allow for moving boundaries. For example, the atmosphere in the lower portions of the valley may become stagnant and become decoupled from the flow above. In such cases, it would be desirable to define the valley "floor" as the top of the pool. This would cause the valley cross-sectional area to change with time. This time dependency can be incorporated into Eqn (40). 


\section{DISTRIBUTION}

No. of

Copies

\section{OFFSITE}

12 DOE/Office of Scientific and Technical Information

Dr. Ray W. Arritt

Dept. of Physics \& Astronomy

University of Kansas

Lawrence, KS 66045-2141

Dr. Robert Banta

NOAAVERLWPL

R/ENP2

325 Broadway

Boulder, CO 80302

Dr. Sumner Barr

Los Alamos National Laboratory

Mail Stop F665

Los Alamos, NM 87545

Dr. J. G. Bartzis

NCSR Demokritos

15310 Aghia Paraskevi

GR-Athens

Greece

Mr. Hugh Church

Division 6321

Sandia National Laboratories

Albuquerque, NM 87185-5800

Dr. William E. Clements

Los Alamos National Laboratory

Mail Stop D466

Los Alamos, NM 87545
No. of

Copies
Dr. Richard L. Coulter

Atmospheric Physics Section, ER/Building 203

Argonne National Laboratory

Argonne, IL 60439

Dr. Clayton Crowe

Dept. of Mechanical and

Materials Engineering

Washington State University

Pullman, WA 99164-2920

Mr. Robert Ekblad

814 Whitaker Drive

Missoula, MT 59803

Dr. Peter Finkelstein

Atmospheric Sciences Research Laboratory

U.S. Environmental Protection

Agency

Research Triangle Park, NC 27711

Dr. Paul H. Gudiksen

Lawrence Livermore National Laboratory

P.O. Box 808, L-262

Livermore, CA 94550

Dr. Jim Hadfield

U.S. Forest Service

Forest Pest Management

P.O. Box 3623

Portland, OR 97208 
No. of

Copies

Dr. Tom Horst

National Center for Atmospheric

Research

P.O. Box 3000

Boulder, CO 80307

Dr. Brian Lamb

Laboratory for Atmospheric

Research

Dept. of Civil and Environmental

Engineering

Washington State University

Pullman, WA 99164-2730

Dr. Rolf Lange

Lawrence Livermore National Laboratory

P.O. Box 808, L-262

Livermore, CA 94550

Prof. Thomas McKee

Department of Atmospheric

Sciences

Colcrado State University

Fort Collins, Co 80523

Dr. Carmen Nappo

Atmospheric Turbulence and

Diffusion Division

National Oceanic and Atmospheric

Administration

P.O. Box 2456

Oak Ridge, TN 37831

Dr. William D. Neff

NOAAVERLWPL

R/ENP1

325 Broadway

Boulder, CO 80303
No. of

Copies

Dr. Montie M. Orgill

904 Lenox

Las Cruces, NM 88005

Dr. William Porch

Los Alamos National Laboratory

Mail Stop D466

Los Alamos, NM 8.7545

Dr. K. Shankar Rao

Atmospheric Turbulence and

Diffusion Division

National Oceanic and Atmospheric Administration

P.O. Box 2456

Oak Ridge, TN 37831

Mr. Mike R. Riches

Program Manager

Environmental Sciences Division

OHER/ER-76

Office of Energy Research

U.S. Department of Energy

Washington, DC 20585

Mr. Donald L. Shearer

Certified Consulting Meteorologist

7175 South Forest Lane

Littleton, CO 80122

Mr. Gene Start

Air Resources Laboratory

National Oceanic and Atmospheric

Administration

550 Second Street

Idaho Falls, ID 83401 
No. of

Cepies

Dr. Dave Stock

Dept. of Mechanical and

Materials Engineering

Washington State University

Pullman, WA 99164-2920

Mr. Richard Thuillier

Pacific Gas and Electric Company

245 Market Street

San Francisco, CA 94106

Dr. Marvin Wesely

Environmental Sciences Section

BEM/CER, Bldg. 203

Argonne National Laboratory

9700 South Cass Avenue

Argonne, IL 60439

Mr. Robert Wilson

U.S. Environmental Protection

Agency

1200 6th Avenue

Seattle, WA 98101
No. of

Copies

22 Pacific Northwest Laboratory

K. J. Allwine (10)

K6-11

D. C. Bader

$\mathrm{K} 6-11$

J. C. Doran

$\mathrm{K} 6-11$

C. E. Elderkin

$\mathrm{K} 6-03$

J. M. Hubbe

$\mathrm{K} 6-11$

C. D. Whiteman

$\mathrm{K} 6-11$

Technical Report Files (5)

\section{Bouting}

R. M. Ecker

J. W. Falco

M. J. Graham

R. L. Skaggs

P. C. Hays (last)

\section{QNSITE}

DOE Richland Field Office

P. W. Kruger 

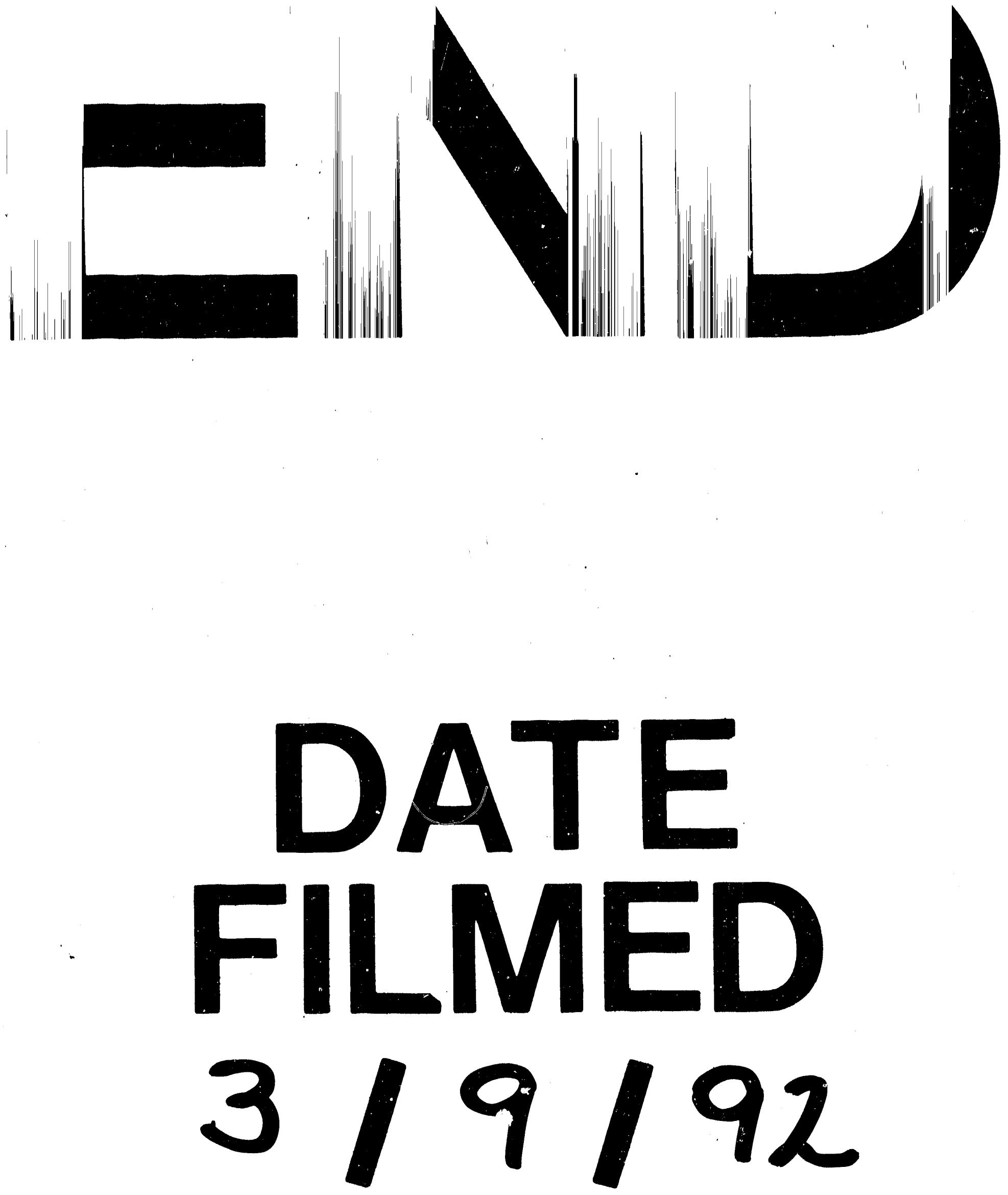
